\title{
UMA FERRAMENTA PARA PLANEJAMENTO DA MOBILIDADE SUSTENTÁVEL COM BASE EM MODELO DE USO DO SOLO E TRANSPORTES
}

Tese de Doutorado apresentada à Escola de Engenharia de São Carlos da Universidade de São Paulo, como parte dos requisitos para a obtenção do título de Doutor em Ciências, Programa de Pós-graduação em Engenharia de Transportes.

Área de Concentração: Planejamento e Operação de Sistemas de Transporte.

Orientador: Prof. Dr. Antônio Nélson Rodrigues da Silva 


\begin{abstract}
AUTORIZO A REPRODUC̄̃O E DIVULGACÃO TOTAL OU PARCIAL DESTE TRABALHO, POR QUALQUER MEIO CONVENCIONAL OU ELETRÔNICO, PARA FINS DE ESTUDO E PESQUISA, DESDE QUE CITADA A FONTE.
\end{abstract}

Ficha catalográfica preparada pela Seção de Tratamento da Informação do Serviço de Biblioteca - EESC/USP

Uma ferramenta para planejamento da mobilidade sustentável com base em modelo de uso do solo e transportes / Simone Becker Lopes ; orientador Antônio Nélson Rodrigues da Silva. -- São Carlos, 2010.

Tese (Doutorado-Programa de Pós-Graduação em Engenharia de Transportes e Área de Concentração em Planejamento e Operação de Sistemas de Transportes -Escola de Engenharia de São Carlos da Universidade de São Paulo, 2010 .

1. Planejamento de transportes. 2. Uso do solo.

3. Sistemas dinâmicos. 4. Geoestatística.

5. Acessibilidade ao meio físico. I. Título. 
Ao Léo, meu marido, à Julia e à Bruna, minhas filhas, com amor, admiração e gratidão por sua compreensão, carinho e por serem minhas eternas fontes de estímulo e inspiração. 


\section{AGRADECIMENTOS}

Ao Prof. Antônio Nélson Rodrigues da Silva, pela orientação, apoio e estímulo durante todo o período de pós-graduação, desde o mestrado, e por aceitar mais este desafio.

Ao Prof. Paul Pfaffenbichler, da Universidade Tecnológica de Viena, meu supervisor no doutorado sanduiche, não só pelo grande apoio, carinho e amizade com que, juntamente com sua esposa Gerti, me recebeu durante seis meses em Viena, mas por emprestar seu conhecimento e confiar a mim o modelo MARS para aplicação no Brasil.

Ao Prof. Eiji Kawamoto, da Escola de Engenharia de São Carlos, por participar com importantes contribuições e sugestões quando da defesa do Projeto de Tese.

Ao Prof. Archimedes Raia Junior, da Universidade Federal de São Carlos, pelas contribuições e sugestões quando das defesas do Projeto de Tese e do Exame de Qualificação.

À Prof ${ }^{a}$ Helena Beatriz Bettella Cybis, da Universidade Federal do Rio Grande do Sul, não só pelas importantes sugestões quando do Exame de Qualificação, mas por ter contribuído para a minha formação desde os primeiros dias do meu ingresso como profissional na área de transportes e por despertar meu interesse pela área acadêmica.

A todos os ex-colegas, mas eternamente amigos, da EPTC - Empresa Pública de Transportes e Circulação, com quem convivi durante 10 anos de trabalho e que compartilharam e contribuíram para o meu aprendizado e qualificação profissional na área de transportes. Em especial aos que, durante o meu doutorado, se empenharam para que todas as necessidades pudessem ser atendidas: Carla Meinecke, Fabiane da Cruz Moscarelli, Fábio Porcher, Gilmar Cardoso, Isabel Chaifuch, Lucia Maciel, Luciana Guadalupe Ferronatto, Márcio Saueressig, Nire Lima, Régulo Franquine Ferrari, Ricardo Leiria Rodrigues.

À Diretoria da EPTC, que viabilizou o afastamento para o doutorado sanduíche: Luiz Affonso dos Santos Senna (Diretor Presidente), Fernando Dutra Michel (Diretor de Transportes), Lucia Helena Zuchovski (Diretora Administrativo Financeira) e Carmen Penerai (Gerente de Recursos Humanos).

Ao Eng. Davi Araujo, por seu auxilio técnico em muitas etapas do trabalho.

Aos amigos e ex-colegas Eng. Pedro Silber e Eng. Alexandre Moretto, que abriram caminho junto ao SINDUSCON-RS para obtenção de dados imobiliários. 
À Arq. Sandra Axelrud Saffer, a quem ainda não tive a honra de conhecer pessoalmente, por simplesmente acreditar no projeto da tese, entender a importância e suas necessidades e dele ser uma das grandes incentivadoras, com palavras de estímulo e abertura de valiosos caminhos que me levaram a pessoas que contribuíram diretamente, com atenção e competência: Economista Marco Túlio (SINDUSCON), Moacir Schucster (Presidente do SECOVI), Hermes Consiglio (SPM - Secretaria de Planejamento Municipal) e Arq. Jairo Batista (SMOV - Secretaria Municipal de Obras Viárias - Porto Alegre).

À Advogada Andrea Teichmann Vizzotto, Procuradora do município de Porto Alegre, amiga, ex-colega de pós-graduação no PROPUR-FAU-UFRGS, que abriu caminhos para muitos contatos que permitiram a obtenção de dados utilizados nesta pesquisa.

A todos os profissionais de diversos órgãos da Prefeitura Municipal de Porto Alegre que contribuíram com fornecimento de dados, em especial a Arq. Maria Tereza Fortini Albano e Arq. Glenio Vianna Bohrer, da SPM, Claudio Lopes Almeida, Lauro Marino Wollmann (Chefe da Unidade de Tributação Imobiliária), Maria Alice, Rodrigo Sartori Fantinel, Maria Gorete da Costa Castro e Christiane Silva Salomoni, da SMF, e Eng. Flávio Nestor Ferreira Dau, da SMOV. E, também, aos profissionais Eng. Nelson Monteiro Oliveira (Assessoria de Estatística - DETRAN-RS) e Ademir Barbosa Koucher (IBGE/UE-RS/SDI).

Aos amigos da TUW - Universidade Tecnológica de Viena, Prof. Knoflacher, Prof. Schopf, Prof. Maccoun, Angelika, Anna, Alberto, Axel, Harald, Igor, Luis, Robert, Tadej e Takeru, pelo carinho e atenção durante os 6 meses de estadia em Viena, e em especial àqueles que compartilharam suas experiências com o MARS e auxiliaram em muitas etapas do desenvolvimento do trabalho: Prof. Guenter Emberger, Reinhard, Giovanni e, particularmente, ao Prof. Simon Shepherd da ITS-LEEDS, por seu envolvimento, auxílio e valiosas sugestões, e ao Eng. Matthew Hardy, da AASHTO, por compartilhar suas experiências no ajuste do MARS para Washington, DC.

Aos professores do Departamento de Transportes da EESC-USP, que muito contribuíram para a minha formação acadêmica.

Aos Professores Luís Antonio Lindau, Christine Tessele Nodari (LASTRAN-UFRGS) e Orlando Strambi (Poli-USP), pelo incentivo e apoio no início da minha carreira acadêmica, Romulo Krafta, Simone Leão e Douglas Aguiar (PROPUR-FAU-UFRGS), por valiosos ensinamentos em planejamento urbano, técnicas e ferramentas aplicadas, durante o período em que fui aluna especial. 
A todos os funcionários do Departamento de Transportes da EESC-USP, em especial a Heloisa Bello, Elizabeth Ortega, Sueli Chinaglia, Antônia Magali, Alexandre Reis, Antônio Carlos Mariano e Vicente Rafael Daló.

À Prof ${ }^{a}$ Nair Cristina Brondino, da UNESP de Bauru, por ter participado de muitas etapas de análise no decorrer deste trabalho e por ter compartilhado seu conhecimento de estatística, sempre com paciência e dedicação.

A todos os colegas da Pós-Graduação do Departamento de Transportes da EESC-USP, em especial a Marcela, Fabíola, Michael, Renata, Mário, Gustavo, Hellen, Victor, Marcelo, Sérgio, Jesner, Vivian, Luís Miguel, Cira, Dinato, Mateus, Pablo, Bruno, André e Elievan.

À CAPES, pelas bolsas de estudo concedidas.

À minha família, em especial aos meus pais Miguel e Loiva (in memorian), meus irmãos Cristina e Luciano, meus sogros Léo e Olga e meu genro André. 


\section{RESUMO}

A meta deste estudo era obter uma ferramenta de apoio à decisão adequada à nova visão de planejamento da mobilidade, enfatizada inclusive pelo Ministério das Cidades, no Brasil. Isso é justificado pela importância da consideração de efeitos espaciais, de forma explícita, e pelas relações de transportes e uso do solo, de forma dinâmica e integrada, no estudo da mobilidade urbana. Além destes pontos, este trabalho procurou analisar a viabilidade de ajuste e de aplicação desta ferramenta para uma cidade brasileira de grande porte. $O$ método aplicado foi dividido em duas etapas concomitantes e uma terceira etapa final: i. análise de técnicas para a consideração dos efeitos espaciais no processo de modelagem urbana; ii. análise de modelos que considerassem a uso do solo e transportes de forma dinâmica e integrada e iii. análise da viabilidade de ajuste e de aplicação da ferramenta, através de um estudo de caso. Para a consideração da dinâmica do desenvolvimento urbano, o modelo MARS (Metropolitan Activity Relocation Simulator) foi o selecionado dentre mais de vinte avaliados. Trata-se de um modelo estratégico, dinâmico e integrado de uso do solo e transportes, desenvolvido na Áustria, que foi aplicado em 16 cidades da Europa e da Ásia e está em desenvolvimento em Washington, D.C., nos EUA. A primeira aplicação do MARS na América do Sul foi viabilizada através deste trabalho. $O$ ajuste do MARS para Porto Alegre compreendeu as etapas de levantamento, tratamento e análise dos dados necessários, o processo de calibração e o processo de validação. Os modelos de transporte foram calibrados com dados da pesquisa origem-destino de 2003. Para a validação do modelo MARS Porto Alegre, aplicou-se a técnica de meta-análise. Oito diferentes cenários de planejamento urbano, considerando diferentes políticas energéticas, foram simulados em um horizonte de 30 anos. Quando comparados com as projeções de cenários similares de seis modelos aplicados na Europa, os resultados de Porto Alegre confirmaram a viabilidade do ajuste e de aplicação na cidade brasileira. Entre outras vantagens, a flexibilidade do MARS permite que sejam introduzidas variáveis espaciais nos procedimentos de modelagem, o que pode contribuir para aprimorar os resultados da simulação. A exemplo das aplicações nas cidades da Europa e da Ásia, o modelo ajustado (inclusive com os dados do Censo 2010, que devem ser divulgados nos próximos meses) pode vir a constituir uma importante contribuição para estudos de planejamento da mobilidade não apenas em Porto Alegre, mas também em outras cidades do Brasil.

Palavras-chave: Planejamento de transportes, Uso do solo, Sistemas dinâmicos, Análise espacial, Acessibilidade 
The goal of this study was to get a decision support tool able to cope with the new mobility planning paradigm that is currently emphasized even by the Ministry of the Cities, in Brazil. This is justified by the need of explicitly considering spatial urban attributes, and the dynamic and integrated land use and transport relationships, in the study of urban mobility. In addition to those points, this work tried to analyze the feasibility of the setting up and the application of such a tool in a large Brazilian city. The method involved two concurrent steps and a final application, as follows: i. analysis of the available techniques for introducing spatial characteristics in the urban modeling process; ii. analysis of the models able to consider the land use-transport relationships in a dynamic and integrated way; and iii. analysis of the feasibility in setting up the model and apply in a case study. Among more than twenty alternatives considered, the Metropolitan Activity Relocation Simulator (MARS) was the model selected to replicate the dynamics of the urban development. This strategic, dynamic and integrated transportation-land use model, which was originally developed in Austria, was applied in sixteen European and Asian cities and it is currently being applied in Washington, D.C., USA. This study is the first application of MARS in South America. The adjustments of the model for Porto Alegre involved the phases of data collection, treatment and analyses, and calibration and validation procedures. The transport models were successfully calibrated with data of an origin-destination survey conducted in 2003. The validation of the Porto Alegre MARS was done through a meta-analysis process. Eight different urban planning scenarios, related to different energy policies, were simulated for a time horizon of thirty years. When compared with the results found in similar scenarios built in six applications of land use-transport models in Europe, the results of the Porto Alegre projections confirmed the validity of the adjustment procedures and of the application in the Brazilian case. Among other advantages, the flexibility of MARS allows the introduction of spatial variables in the modeling procedures, what can eventually improve the simulation results. Following what was observed in Europe and in Asia, the adjusted model (that soon will also be able to rely on the 2010 Census data) can become an important contribution to mobility planning studies not only in Porto Alegre but also in other Brazilian cities.

Keywords: Transport planning, Land use, Dynamic systems, Spatial analysis, Accessibility 


\section{SUMÁRIO}

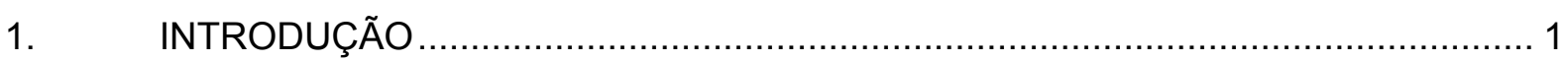

1.1. Caracterização do Problema...................................................................... 1

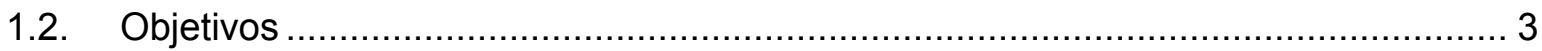

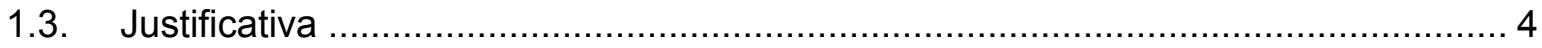

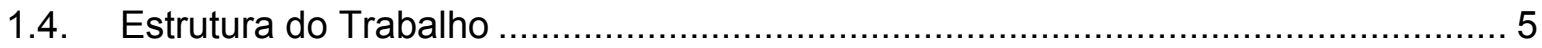

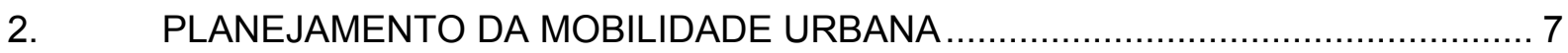

2.1. Características Espaciais das Cidades e a Modelagem de Transportes................. 7

2.2. Os Principais Problemas do Modelo Tradicional de Quatro Etapas ....................... 8

2.3. Modelos que Consideram Efeitos Espaciais .................................................. 10

2.4. Uso do Solo e Transportes - Sistema Dinâmico e Integrado ................................ 14

2.5. Projetos Relacionados à Dinâmica do Desenvolvimento Urbano e Integração de Uso do Solo e Transportes ............................................................................. 15

2.6. Modelos Integrados de Uso do Solo e Transportes............................................ 16

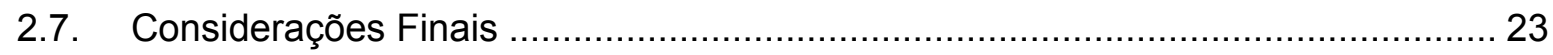

3. O MODELO MARS - METROPOLITAN ACTIVITY RELOCATION SIMULATOR .. 25

3.1. Módulo de Entrada de Dados - Configuração de Cenários ................................... 26

3.2. Módulo de Entrada e Configuração de Políticas................................................. 26

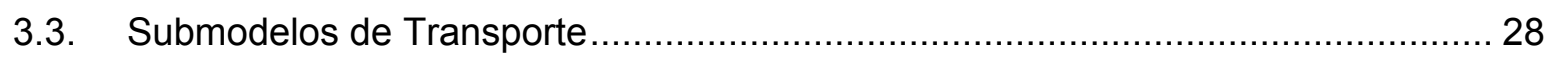

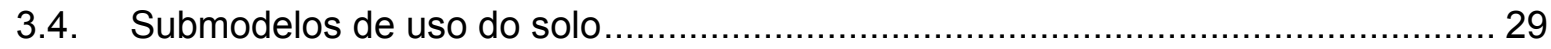

3.4.1. Submodelos de criação e localização de unidades habitacionais .................... 30

3.4.2. Submodelo de localização de postos de trabalho........................................... 32

3.5. Módulo de Composição da Frota e Emissão de Poluentes ................................... 32

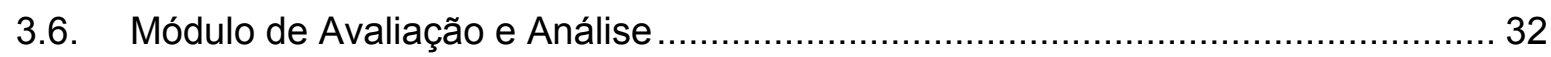

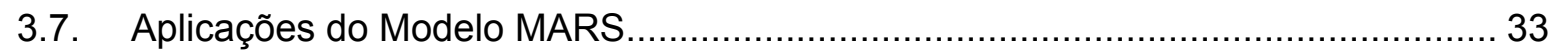

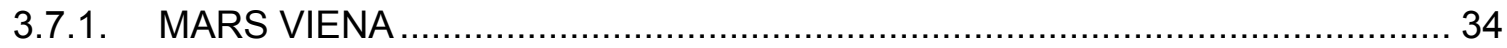

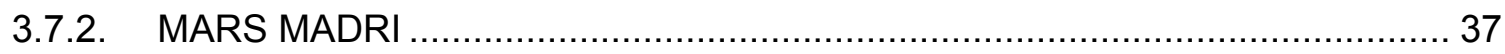




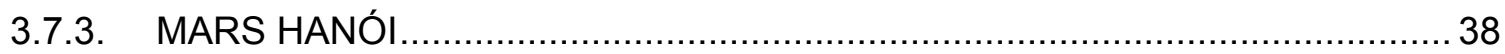

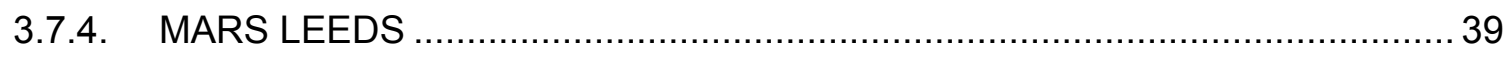

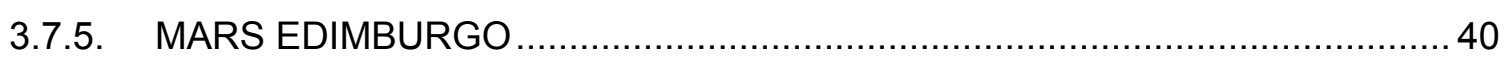

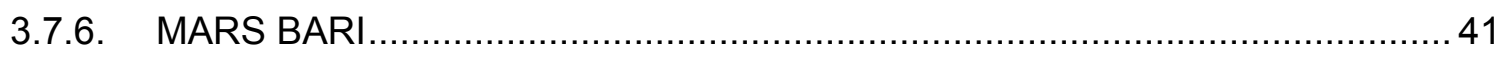

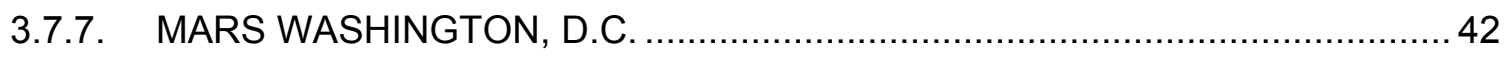

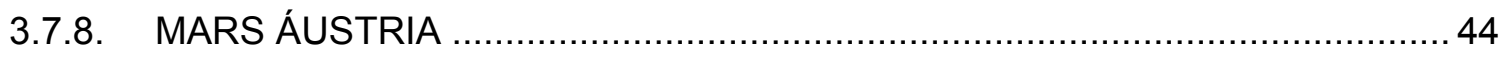

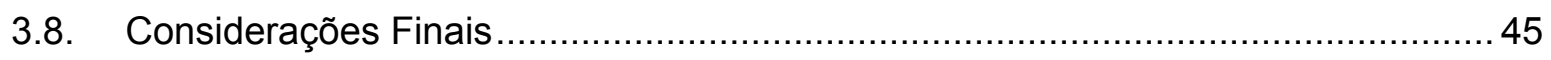

4. ESTATÍSTICA ESPACIAL EM ANÁLISES URBANAS E DE TRANSPORTES ...... 47

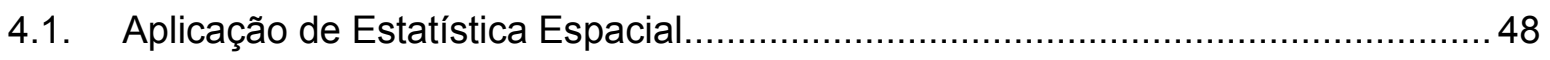

4.2. Ferramentas de Estatística Espacial............................................................. 49

4.2.1. Ferramentas da ESDA - Exploratory Spatial Data Analysis .............................49

4.2.2. Ferramentas da CSDA - Confirmatory Spatial Data Analysis ..........................5 51

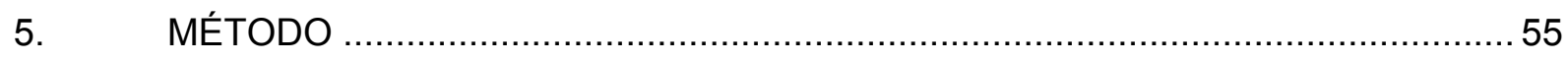

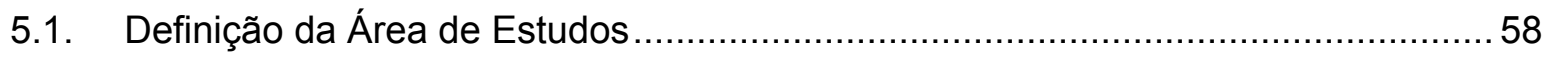

5.2. Bloco 1 - Obtenção de Modelos Espaciais....................................................... 58

5.2.1. Verificação dos efeitos espaciais a serem considerados ...................................58

5.2.2. Obtenção de modelos espaciais mais adequados ........................................... 58

5.3. Bloco 2 - Ajuste de um Modelo LUTI Dinâmico..................................................... 60

5.3.1. Seleção de um Modelo LUTI Dinâmico............................................................. 61

5.3.2. Avaliação da viabilidade de ajuste do Modelo LUTI Dinâmico............................ 61

5.4. Bloco 3 - Obtenção e Ajuste de um Modelo LUTI Dinâmico e Espacial .................. 63

5.5. Bloco 4 - Avaliação do Modelo LUTI Dinâmico e Espacial ........................................ 63

5.6. Bloco 5 - Verificação da viabilidade de aplicação do modelo como ferramenta de apoio à decisão na análise de políticas de mobilidade urbana sustentável.............64

5.6.1. Definição de cenários - políticas de mobilidade urbana sustentável.................64

5.6.2. Configuração, simulação e análise dos impactos dos cenários ..........................65

5.6.3. Análise da consistência das projeções - Meta-análise.....................................65

6. APLICAÇÃO DO MÉTODO E ANÁLISES DOS RESULTADOS ...........................67 


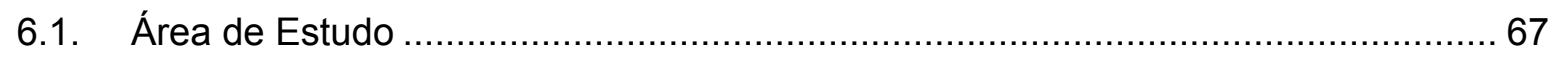

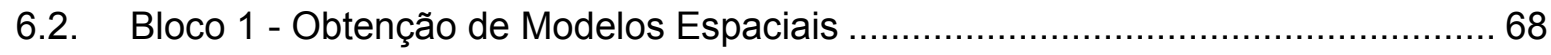

6.2.1. Verificação dos efeitos espaciais a serem considerados.............................69

6.2.2. Obtenção de modelos espaciais mais adequados.................................... 74

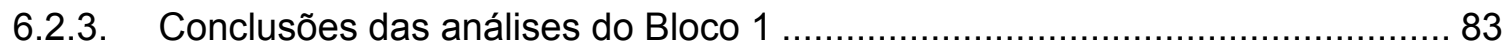

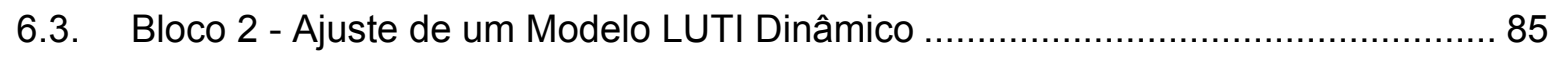

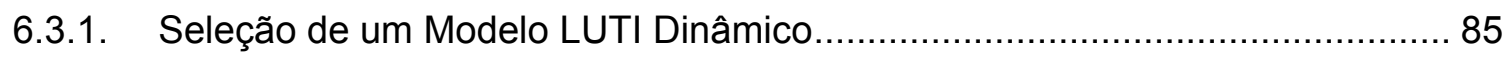

6.3.2. Avaliação da viabilidade de ajuste do modelo MARS à cidade de Porto Alegre .

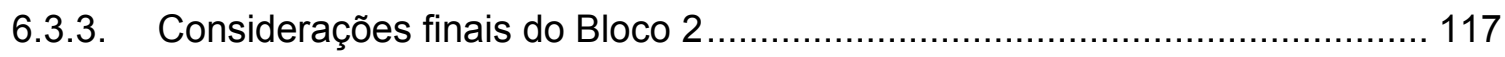

6.4. Bloco 3 - Obtenção e ajuste de um Modelo LUTI Dinâmico e Espacial - MARS POA

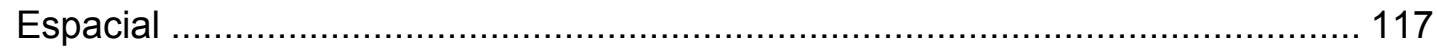

6.4.1. Formas para inserção de variáveis espaciais no MARS ............................... 118

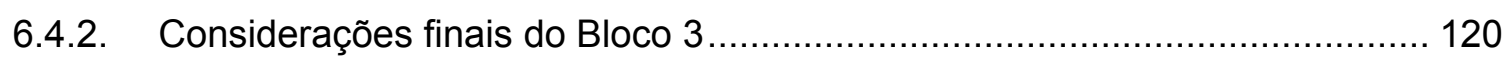

6.5. Bloco 4 - Avaliação do MARS POA Espacial .............................................. 121

6.5.1. Definição dos indicadores de dependência espacial .................................. 122

6.5.2. Análise da inserção de variáveis espaciais............................................... 127

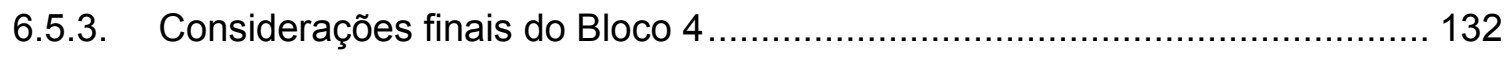

6.6. Bloco 5 - Viabilidade de aplicação do MARS POA para avaliar políticas de mobilidade urbana sustentável ................................................................... 133

6.6.1. Definição dos cenários a serem simulados no MARS POA ........................... 134

6.6.2. Configuração, simulação e análise dos impactos dos cenários para Porto

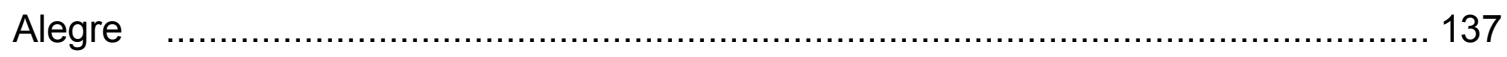

6.6.3. Análise da consistência das projeções - Meta-análise ................................. 148

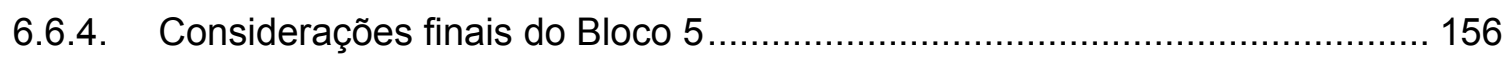

7. CONCLUSÕES E SUGESTÕES PARA TRABALHOS FUTUROS ..................... 159

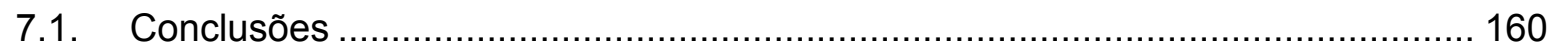

7.1.1. Conclusões do Bloco 1- Obtenção de modelos espaciais ............................ 160 
7.1.2. Conclusões do Bloco 2 - Ajuste de um Modelo LUTI Dinâmico para Porto

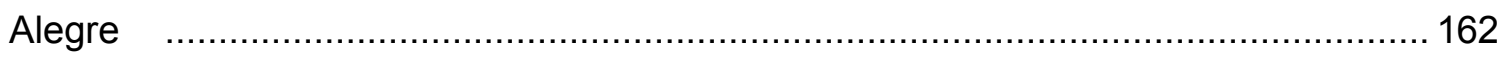

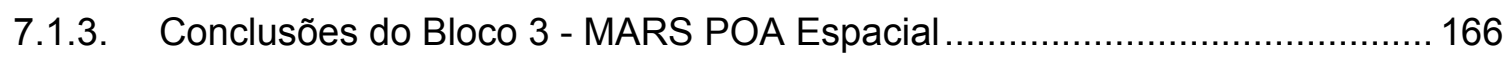

7.1.4. Conclusões do Bloco 4 - Avaliação do Modelo LUTI Dinâmico e espacial .... 166

7.1.5. Conclusões do Bloco 5 - Viabilidade de aplicação do MARS POA para avaliar políticas de mobilidade sustentável ............................................................................ 167

7.2. Sugestões para Trabalhos Futuros …................................................................. 168 


\section{INTRODUÇÃO}

Este capítulo aborda alguns aspectos relacionados à nova visão de planejamento da mobilidade, preconizada mundialmente, em busca do desenvolvimento urbano sustentável. Destaca-se a necessidade de instrumentos de apoio à decisão, capazes de avaliar políticas urbanas de mobilidade sustentável em cidades brasileiras, o que constitui o foco desta pesquisa. São apresentados, ainda, os objetivos e as justificativas para este trabalho. Ao final é apresentada a estrutura deste documento.

\subsection{Caracterização do Problema}

Entende-se mobilidade como algo que vai além do número de viagens por pessoa por dia, mas algo que também está relacionado com saúde (física e psicológica), sociedade, economia e ambiente. Embora não seja possível encontrar uma definição única para mobilidade sustentável, porém, entendendo a busca da sustentabilidade como um esforço para proteger os sistemas ecológicos e os recursos naturais, visando minimizar o consumo de ar, água e solo, ela pode se caracterizada por conceitos gerais. Ou seja, mobilidade sustentável pode ser entendida como aquela que minimiza os efeitos negativos do transporte relacionados à poluição do meio ambiente, aos acidentes de trânsito, aos tempos perdidos em congestionamentos, à exclusão social, aos altos custos de viagens, ao consumo de energia não renovável, ao consumo do solo urbano.

A busca da mobilidade urbana sustentável constitui, atualmente, um dos principais interesses dos órgãos públicos, pois os sistemas de transportes e uso do solo, nas cidades de todo o mundo, dão sinais inequívocos de insustentabilidade, tais como, espalhamento urbano, poluição, consumo de recursos não renováveis, congestionamentos e acidentes, 
entre outros. Como consequência, o planejamento urbano tem se tornado cada vez mais complexo, salientando a importância dos instrumentos de apoio à decisão para que os objetivos globais de sustentabilidade sejam atingidos.

O transporte tem um papel fundamental no desenvolvimento urbano, podendo ser um relevante e eficaz instrumento de reestruturação urbana e vetor de expansão controlada ou direcionada, mas para tanto deve estar inserido no planejamento integrado das cidades, incorporando os princípios da sustentabilidade plena e tendo o seu planejamento e controle submetido aos interesses da maioria da população, conforme tem sido enfatizado pelo Ministério das Cidades, no Brasil.

O conceito de planejamento da mobilidade preconizado para os municípios brasileiros se contrapõe aos planos de transportes tradicionais. Representa uma reformulação de conteúdo, pois a mobilidade é um atributo das cidades, relativo ao deslocamento de pessoas e bens, utilizando veículos, vias e toda a infraestrutura urbana. É bem mais abrangente do que a forma tradicional de tratar os elementos da circulação, não os considerando de forma segmentada e administrando a circulação de pessoas e não de veículos.

No planejamento de transporte tradicional, os modelos de demanda têm sido amplamente utilizados com a finalidade de prever mudanças nas viagens e na utilização do sistema de transportes, em função do desenvolvimento de regiões, de alterações demográficas e de mudanças na oferta. Muitos são os fatores intervenientes, tais como renda, posse de veículos, localização e características dos domicílios, dos empregos e das instituições de ensino. A partir dos anos 1980, avanços tecnológicos intensificaram e aprimoraram as técnicas de modelagem. No entanto, ainda cabem muitas críticas aos modelos tradicionais, como o modelo de quatro etapas.

Entre outras limitações, os modelos tradicionais em geral não incorporam características espaciais na estrutura dos dados. Além disso, parte das deficiências se deve também ao seu caráter estático, o que prejudica projeções em longo prazo, e por não serem consideradas mudanças urbanas relativas ao uso do solo. Isso que reforça a necessidade de projeções baseadas no estudo da dinâmica do desenvolvimento urbano, como será, neste trabalho, abordado.

O que se propõe nesta pesquisa é, portanto, implementar um instrumento de apoio à decisão capaz de avaliar planos de transporte voltados à nova visão de planejamento da mobilidade e sua busca por um desenvolvimento urbano sustentável. Deve-se destacar que se trata de uma continuidade de estudos já desenvolvidos por Lopes (2005), em que foram avaliadas as deficiências e implementadas algumas melhorias nos modelos tradicionais de 
transporte, particularmente a incorporação de características espaciais nos modelos de demanda por transportes, resultando em modelos com melhor qualidade de ajuste. Concluiu-se então que, para estimativas futuras, não bastava apenas considerar as variáveis espaciais. Era preciso incorporar a dinâmica do desenvolvimento urbano nos modelos. O objetivo deste estudo, portanto, tem base nos resultados obtidos com os modelos espaciais analisados por Lopes (2005) e na hipótese de que a incorporação, na modelagem, da dinâmica existente na relação entre uso do solo e transportes pode produzir resultados melhores.

Modelos LUTI (Land Use and Transport Interaction Models) consideram a interação existente entre uso do solo e transportes. Parte-se da hipótese básica que um Modelo LUTI Dinâmico, ou seja, que modele o uso do solo e transportes de forma dinâmica e integrada constitui uma ferramenta adequada para servir de apoio à decisão no planejamento da mobilidade sustentável. Adicionalmente, acredita-se que, se os efeitos de dependência existente entre os dados forem considerados no modelo inicial, a ferramenta deve produzir resultados melhores para as estimativas de demanda por transportes.

\subsection{Objetivos}

O presente trabalho tem com objetivo geral contribuir para o planejamento da mobilidade no Brasil, visando à implementação de uma ferramenta de apoio a decisão às políticas urbanas de desenvolvimento sustentável em uma cidade brasileira de grande porte.

Com base no objetivo geral e nas hipóteses básicas, e considerando a definição de uma cidade brasileira de grande porte como objeto de estudo, têm-se como objetivos específicos:

1) Avaliar técnicas que considerem efeitos decorrentes da distribuição espacial das atividades urbanas de forma a amenizar a dependência espacial dos resíduos das estimativas de modelos de demanda por transporte (Modelo Espacial);

2) Avaliar a viabilidade de se ajustar um modelo LUTI Dinâmico à cidade brasileira;

3) Avaliar a viabilidade de se considerar, no modelo LUTI Dinâmico, os efeitos de dependência espacial decorrentes da distribuição espacial das atividades urbanas (Modelo LUTI Dinâmico e Espacial);

4) Verificar a hipótese que a consideração desses efeitos espaciais na modelagem de transportes resultará em melhorias para o modelo inicial (Modelo LUTI Dinâmico $x$ Modelo LUTI Dinâmico e Espacial); 
5) Avaliar a viabilidade de aplicação do modelo LUTI Dinâmico ou do modelo LUTI Dinâmico e Espacial como uma ferramenta de apoio à decisão na análise de políticas de mobilidade urbana sustentável.

\subsection{Justificativa}

Embora o conceito de mobilidade sustentável seja um assunto já bastante debatido em outros países, ainda é um tema que carece de investigação e aplicação no Brasil, onde exemplos de uso de algum tipo de ferramenta de apoio à decisão aos planos de transporte se valem, usualmente, do modelo de quatro etapas, na sua forma tradicional e com suas limitações.

O Governo Federal do Brasil, através do Ministério das Cidades, mais especificamente da SEMOB (Secretaria Nacional de Transporte e da Mobilidade Urbana), está reunindo esforços em busca de um plano de gestão integrada da mobilidade urbana, dentro da Política Nacional de Mobilidade Urbana Sustentável (PNMUS) (Brasil, 2004, 2006, 2007).

Dessa forma, a noção de sustentabilidade ambiental, econômica e social foi recentemente incorporada ao processo de planejamento das cidades brasileiras, especialmente no que se refere ao planejamento de seus sistemas de mobilidade. No entanto, as tentativas atuais de integrar os diferentes níveis de planejamento das cidades, que envolvem mais diretamente as questões de mobilidade, têm ocorrido de forma tímida. Ocorrem mais no sentido de discussões conjuntas entre técnicos das secretarias municipais responsáveis pelo planejamento urbano $\mathrm{e}$ as secretarias ou empresas públicas responsáveis pelo planejamento de transportes e de circulação, sem considerar de forma dinâmica e integrada todos os elementos que interferem na mobilidade.

Espera-se, do ponto de vista prático, obter resultados melhores que os obtidos com modelos tradicionais em estudos de mobilidade urbana e, assim, contribuir com uma ferramenta mais eficiente de apoio à decisão para estudos de desenvolvimento e mobilidade urbana sustentável em cidades brasileiras.

Do ponto de vista teórico, espera-se contribuir com um instrumento de exploração de novas técnicas e métodos na análise de mobilidade urbana e que sirva, também, de estímulo a outros pesquisadores no avanço da pesquisa para o desenvolvimento e aplicação, no Brasil, de modelos espaciais, dinâmicos e integrados de uso do solo e transportes. 


\subsection{Estrutura do Trabalho}

No sentido de melhor contextualizar os temas abordados nesta pesquisa é apresentada, no Capítulo 2, revisão bibliográfica abordando os principais tópicos que constituem o referencial teórico para elaboração deste estudo. Inclui um levantamento de estudos com aplicações de ferramentas de estatística espacial para análises de mobilidade e de modelos de uso do solo e transportes já desenvolvidos e aplicados em vários lugares do mundo.

No Capítulo 3 é apresentado o Modelo MARS (Metroplolitan Activity Relocation Simulator), que foi o modelo dinâmico e integrado de uso do solo e transportes selecionado para aplicação nesta pesquisa, abordando suas características gerais, estrutura e algumas das suas aplicações em diversos lugares da Europa, Ásia e América do Norte.

O Capitulo 4 apresenta as ferramentas de Estatística Espacial, com foco na ESDA (Exploratory Spatial Data Analysis) e CSDA (Confirmatory Spatial Data Analysis), que são as de interesse neste estudo.

O método para desenvolvimento do trabalho é apresentado no Capitulo 5. Uma aplicação do método, com os resultados e análises, é discutida no Capítulo 6. As conclusões do estudo e sugestões para trabalhos futuros são apresentadas no Capítulo 7, seguidas das referências bibliográficas. 


\section{PLANEJAMENTO DA MOBILIDADE URBANA}

Neste capítulo são discutidas algumas questões relacionadas às características fundamentais das cidades e como estas interferem nas análises de transportes, destacandose os principais problemas dos modelos tradicionais de demanda para o estudo da mobilidade sustentável. A revisão bibliográfica inclui, também, exemplos de políticas, projetos e diretrizes atuais para estudo da mobilidade visando um desenvolvimento urbano sustentável. Finalmente, faz-se um levantamento de técnicas já desenvolvidas para resolver os problemas relacionados aos modelos tradicionais, procurando destacar modelos e ferramentas que sejam adequadas aos objetivos propostos por este estudo.

\subsection{Características Espaciais das Cidades e a Modelagem de Transportes}

Echenique (1975) define cidade como um sistema em que os elementos do espaço são inter-relacionados e qualquer alteração em um deles pode acarretar alterações nos demais. Krafta (1995), complementarmente, define um sistema configuracional urbano como sendo um sistema cujos componentes são porções de espaço definidos por muitos objetos arquitetônicos, relacionados entre si por posições ocupadas no solo e por adjacências. $O$ sistema configuracional urbano constitui, assim, um grande conjunto de espaços interligados que contém todas as atividades e todos os fluxos derivados da vida urbana.

Para Câmara et al. (2002), um conceito importante para a compreensão e análise dos fenômenos espaciais é a dependência espacial. Tal afirmação se baseia na citação de Tobler (1970), referindo-se à Primeira Lei da Geografia, de que todos os objetos no espaço estão relacionados, porém objetos mais próximos no espaço estão mais relacionados. Isso 
significa que as características dos diferentes espaços das cidades, seja qual for a forma de agregação que se analise (quadras, setores censitários, zonas de tráfego, bairros etc.), guardam alguma relação com as características dos espaços vizinhos e, consequentemente, o mesmo ocorre com as atividades e fluxos derivados da vida urbana.

Para Páez e Scott (2004) a expressão "análise de sistemas urbanos" pode ser aplicada ao estudo de uma cidade individual, conceituada como uma coleção de vários componentes interligados. Normalmente, estes componentes incluem um subsistema de atividades, o qual determina a configuração do uso do solo, um subsistema de transportes e as interações entre esses componentes. Os autores destacam ainda que, em função da crescente preocupação com as questões ambientais, têm sido considerados, nas análises de sistemas urbanos, os efeitos causados no meio-ambiente pelas configurações do uso do solo e consequentes atividades de transporte das cidades. Sendo assim, os processos de interesse nas análises urbanas incluem diferentes tipos de construção (residencial, infraestrutura industrial, transporte), alterações econômicas e demográficas, mobilidade (viagens, escolha residencial e transporte de mercadorias) e processos ambientais relacionados, como consumo de energia, emissões e ruído.

Uma questão metodológica na análise urbana é a definição de unidades de análise, que podem ser agregadas (zonas de tráfego - ZTs) ou desagregadas (indivíduos ou famílias). Outra característica dos processos urbanos é que estes são intrinsecamente espaciais e, além disso, espaço-dependentes (o que ocorre em um local afeta eventos em outros locais).

Tais conceitos e definições chamam a atenção para características fundamentais das cidades: a inter-relação entre seus componentes, a dinâmica resultante dessa inter-relação e a natureza eminentemente espacial dos componentes. Em outras palavras, a modelagem da demanda de transportes deveria considerar todos os fatores responsáveis pela dinâmica do desenvolvimento das cidades e, também, que a localização no espaço de cada componente não é aleatória, ou seja, os efeitos da localização não devem ser ignorados.

\subsection{Os Principais Problemas do Modelo Tradicional de Quatro Etapas}

O tradicional modelo de Quatro Etapas ainda é largamente utilizado na prática. Um dos fatores que facilita o uso dessa ferramenta é que, atualmente, está incluída em pacotes de Sistemas de Informações Geográficas para transportes (SIG-T). Se, por um lado, essa combinação significa um grande avanço para a modelagem tradicional de demanda por transportes, pois, entre outras vantagens, facilita a manipulação dos dados e a visualização 
dos resultados, por outro lado é alvo de muitas críticas, que dizem respeito, principalmente, à falta de consideração do impacto que alterações no sistema de transportes provocam no uso do solo e vice-versa.

Conforme colocado por Lopes (2003), alterações como a inclusão ou melhorias da infraestrutura existente aumentam a acessibilidade de algumas zonas, tornando-as mais atrativas para residências e empresas e o consequente aumento da população ou de atividades nas zonas vai implicar na necessidade de infraestrutura adicional. Tais fatos não são considerados no modelo tradicional de transportes.

Outro problema é a "estabilidade temporal" implícita no modelo. O desenvolvimento urbano tem caráter dinâmico, ocorrendo mudanças significativas nas relações entre as diferentes variáveis do modelo em um longo período de tempo. Dessa forma, projeções em longo prazo podem gerar grandes erros nas estimativas (LOPES; BRONDINO; SILVA, 2006). Saraiva (2000) salienta que o problema é ainda maior em países em desenvolvimento, como é o caso do Brasil. Isto ocorre porque, enquanto nos países desenvolvidos ocorrem situações em que prevalecem populações e áreas urbanas relativamente estáveis, as análises de demanda em cidades brasileiras incluem até mesmo áreas desocupadas.

Raia Jr. (2000) salienta que os modelos tradicionalmente utilizados são geralmente elaborados em países desenvolvidos, onde a acessibilidade ao sistema de transporte sofre poucas restrições e os aspectos de mobilidade, especialmente os relacionados às questões socioeconômicas, não apresentam obstáculo ao deslocamento urbano, o que difere da situação em países emergentes como o Brasil. $O$ autor salienta que não basta apenas prover a população de acessibilidade física, mas é preciso propiciar a ela meios que possam garantir melhores índices de mobilidade.

Hoover e Altshuler (1977) apud Vasconcellos (1996) criticam os modelos de demanda tradicionais por terem uma visão limitada do processo de desenvolvimento urbano, com um enfoque orientado prioritariamente à definição de projetos e para facilitar a projeção futura das tendências existentes, quando deveriam tratá-las como políticas a serem analisadas pelo processo de planejamento. Comentam, também, sobre a falta de interdisciplinaridade dos enfoques.

Outra questão relevante e já mencionada anteriormente é a dependência espacial e os efeitos que causam em modelo de previsão de demanda por transportes. Ela está entre as principais questões analítico-espaciais que deveriam ser consideradas na análise de transportes. No entanto, a modelagem tradicional ignora seus efeitos (MILLER, 1999; CÂMARA et al., 2002; LOPES; BRONDINO; SILVA, 2006, 2007). 
Tais constatações tornam evidente a necessidade de se dar mais atenção a três assuntos relevantes no planejamento da mobilidade:

1) Consideração de políticas, planos e uso de modelos que integrem o uso do solo e os transportes;

2) Uso de modelos e técnicas que consigam captar a dinâmica do desenvolvimento urbano para projeções em longo prazo;

3) Uso de técnicas que consigam captar os efeitos espaciais e os considerarem na modelagem.

\subsection{Modelos que Consideram Efeitos Espaciais}

Através da análise de dados de diversas características relacionadas a uma determinada cidade ou região é que planejadores e engenheiros de transporte adquirem os conhecimentos utilizados para diagnosticar o estado atual dos sistemas de transporte e para prognosticar o seu estado futuro (com ou sem intervenções).

Existem diversas técnicas e métodos estatísticos utilizados na análise e avaliação de sistemas de transportes que servem como ferramentas de suporte à decisão sobre a tomada de medidas preventivas ou corretivas, porém a maioria assume que as observações são independentes. No entanto, a condição de independência entre variáveis é raramente encontrada quando são analisados dados espaciais.

Nas análises dos sistemas de transportes, a maioria dos métodos está relacionada a variáveis que se caracterizam como dados espaciais. Ou seja, são dados cuja informação da sua localização no espaço é relevante para a análise, podendo estar agregados em áreas ou até desagregados em dados pontuais, como os acidentes de trânsito, por exemplo, utilizados nas análises de segurança viária. $\mathrm{Na}$ análise de demanda por transportes, em particular, os dados relevantes, que dizem respeito a características demográficas, socioeconômicas e de uso do solo, são geralmente agregados em áreas que podem ser em diferentes níveis, como municípios, bairros, setores censitários, zonas de tráfego ou outras formas de zoneamento definidas pelos planos diretores municipais.

Dentre os métodos estatísticos para análise de transportes, os modelos de regressão são muito utilizados na fase de geração de viagens do Modelo de Quatro Etapas. No processo de previsão de demanda, no entanto, é comum a existência de um fenômeno denominado "dependência espacial", que quebra o pressuposto de independência entre as variáveis e que pode resultar em problemas nas análises (MILLER, 1999). 
O que se observa é que os resíduos dos modelos não apresentam uma distribuição espacial aleatória, como seria o esperado. Esse fenômeno, também conhecido como "autocorrelação espacial", está relacionado com a similaridade de características de um determinado local com as dos vizinhos, ou seja, há correlação entre valores de uma mesma variável no entorno próximo e é por esse motivo que a validade dos métodos estatísticos tradicionais é afetada.

Para abordar corretamente o problema e incorporar o efeito espacial, existem dois tipos básicos de modelagem: a regressão espacial Global e a regressão espacial Local (ANSELIN, 2002; CÂMARA et al., 2002; FOTHERINGHAM et al., 2000). Os modelos de forma Global capturam a estrutura espacial através de um único parâmetro, que é adicionado ao modelo de regressão tradicional (CÂMARA et al., 2002). Os modelos mais simples de regressão espacial, formalmente apresentados por Anselin (2002), são o modelo espacial auto-regressivo misto (Spatial Auto Regressive = SAR ou Spatial Lag Model) e o modelo do erro espacial (Conditional Auto Regressive = CAR ou Spatial Error Model).

Miller (1999) salienta que a questão ainda não é bem reconhecida na literatura de modelagem de transportes, apesar de constituir um problema potencial. Isso foi confirmado por Lopes (2005), cujas análises com dados de duas pesquisas origem e destino da cidade de Porto Alegre (1974 e 1986) mostraram a existência de altos índices de dependência espacial entre as variáveis explicativas do modelo de demanda, efeitos que também se manifestavam nos resíduos dos modelos.

Outra forma de considerar a dependência espacial nos modelos de regressão foi proposta por Lopes (2005), através de um método que consiste na introdução de indicadores de autocorrelação espacial (Globais e Locais) como variáveis explicativas, somados às variáveis tradicionais, no modelo de regressão múltipla (LOPES; SILVA, 2004; LOPES, 2005; LOPES; SILVA, 2005; LOPES; BRONDINO; SILVA, 2005, 2006). Para esse modelo são definidas variáveis espaciais globais e locais, obtidas da análise espacial das variáveis socioeconômicas através do uso de ferramentas de ESDA (Exploratory Spatial Data Analysis) e de software de estatística espacial.

As variáveis espaciais globais são variáveis binárias (dummy), associadas aos quadrantes do diagrama de Moran (indicador global). Para uma determinada variável independente "X" são definidas três variáveis (X_Q1, X_Q2 e X_Q3), que representam o regime espacial de cada ZT. Para a definição das variáveis espaciais locais são considerados os indicadores LISA (LISA_X). O estudo inicial (LOPES, 2005) e pesquisas posteriores (LOPES; BRONDINO; SILVA, 2006, 2007) verificaram uma melhoria significativa nos resultados das previsões através da consideração dos efeitos espaciais nos modelos de demanda. 
No entanto, apesar de ter-se observado melhores resultados nas previsões para um horizonte de doze anos (de 1974 a 1986), apenas com a introdução de variáveis espaciais nos modelos de geração de viagens, uma constatação adicional foi que, para estimativas de longo prazo (de 1974 a 2003), outras melhorias deveriam ser implementadas. Concluiu-se que a análise mais detalhada da dinâmica do desenvolvimento urbano poderia, em conjunto com a análise de estatística espacial, resultar em modelos de demanda por transportes ainda melhores.

A dependência espacial e seus efeitos sobre os modelos de demanda por transporte estão, sem dúvida, entre as questões relativas à análise espacial que ainda não foram totalmente exploradas no planejamento de transportes. Em vinte e seis estudos identificados nas duas últimas décadas para esta pesquisa, vinte e quatro trabalham com foco na associação espacial (ou seja, dependência espacial ou autocorrelação espacial), mas apenas oito estão relacionados à análise de demanda por transporte (Tabela 1).

Na Tabela 1 são sintetizados vários exemplos de aplicação de ferramentas de estatística espacial nas análises de transportes realizadas nas duas últimas décadas, destacando-se os efeitos espaciais analisados e os campos e subcampos de aplicação do estudo. Dentre as muitas conclusões de todas essas aplicações, uma é a mesma para a grande maioria dos estudos: a consideração dos efeitos espaciais melhora os resultados da análise.

Considerando os aspectos discutidos acima, a regressão espacial, ou seja, a análise de regressão que incorpora a dependência espacial é capaz de melhorar o poder preditivo dos modelos de regressão. Bolduc et al. (1989), Bolduc et al. (1992), Bolduc et al. (1995), Haider e Miller (2000), Wang (2001), Czado e Prokopenko (2008), Kawamura e Mahajan (2005), Vichiensan et al. (2006), Zhou e Kockelman (2008), Ribeiro e Antunes (2009), Chalermpong (2007), Hackney et al. (2007a), Hackney et al. (2007b), Novak et al. (2008) apresentam exemplos de aplicação de regressão espacial, em que diversos campos da análise urbana e de transporte, como os fluxos de viagens, a escolha do modo, o tempo e a distância dos deslocamentos pendulares, os valores de propriedade, a acessibilidade, as velocidades de tráfego e a demanda por mercadorias, são avaliados. Em geral, um modelo espacial resulta em melhor ajuste para os dados em relação a um modelo não-espacial.

Considerando-se apenas a aplicação de modelos de regressão espacial para a análise de demanda por transportes, a melhoria da capacidade de previsão dos modelos já foi observada por Bolduc et al. (1992), Bolduc et al. (1995), Czado e Prokopenko (2008), Eom et al. (2006) Wang e Kockelman (2009), Bhat e Zhao (2002), Novak et al. (2008). O mesmo foi observado em estudos realizados por Lopes e Silva (2004), Lopes (2005), Lopes e Silva (2005) e Lopes, Brondino e Silva (2005). 
Tabela 1 - Aplicações de ferramentas de estatística espacial em análise da mobilidade urbana: efeitos espaciais analisados e campo e subcampo de aplicação do estudo.

\begin{tabular}{|c|c|c|c|c|c|c|c|c|c|c|c|c|c|c|c|c|c|c|c|c|c|c|}
\hline \multirow[b]{2}{*}{$\begin{array}{l}\text { Características } \\
\text { dos estudos }\end{array}$} & \multicolumn{3}{|c|}{$\begin{array}{c}\text { EFEITO } \\
\text { ESPACIAL } \\
\text { EM } \\
\text { ANÁLISE } \\
\end{array}$} & \multicolumn{6}{|c|}{$\begin{array}{c}\text { DEMANDA } \\
\text { DE } \\
\text { VIAGENS } \\
\end{array}$} & \multicolumn{3}{|c|}{\begin{tabular}{|c|} 
COMPORT. \\
DE \\
VIAGENS \\
\end{tabular}} & \multicolumn{9}{|c|}{$\begin{array}{c}\text { USO DO SOLO E TRANSPORTES } \\
\text { MODELAGEM E ESTIMATIVA DE } \\
\text { DADOS } \\
\end{array}$} & \multirow[b]{2}{*}{ 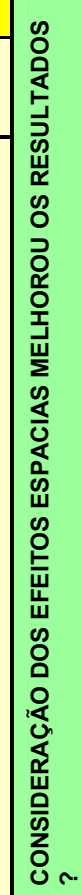 } \\
\hline & 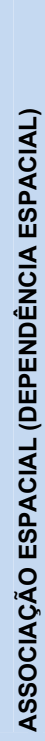 & 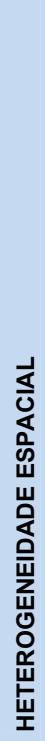 & 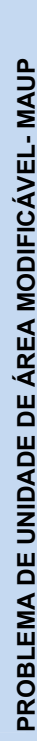 & 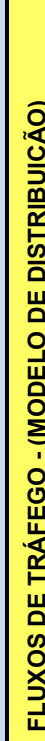 & 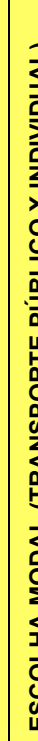 & & & 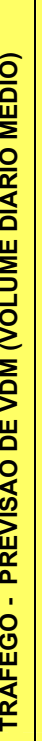 & 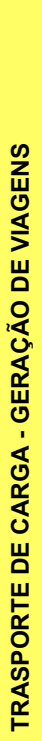 & 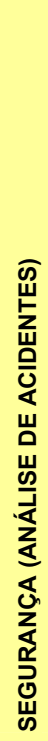 & 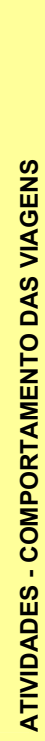 & 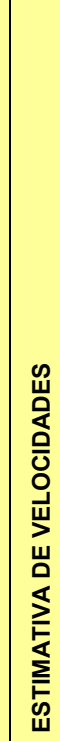 & 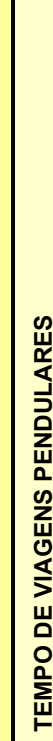 & 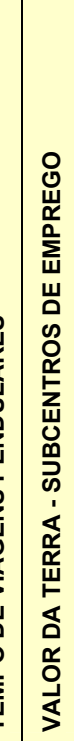 & 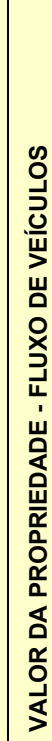 & 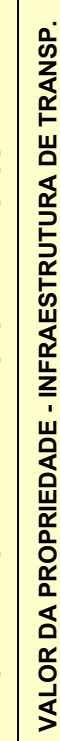 & 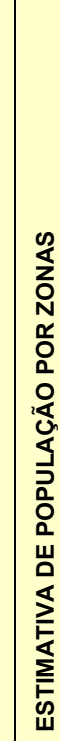 & 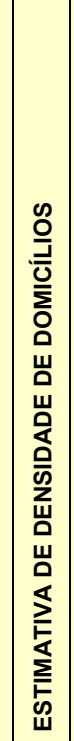 & 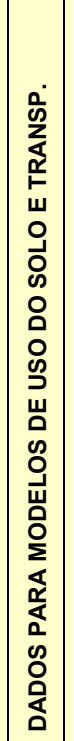 & 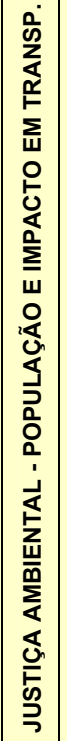 & & \\
\hline Bender e Hwang (1985) & & $\mathbf{x}$ & & & & & & & & & & & & $\mathbf{x}$ & & & & & & & & SIM \\
\hline Bolduc et al. (1989) & $\mathrm{x}$ & & & $\bar{x}$ & & & & & & & & & & & & & & & & & & SIM \\
\hline Bolduc et al. (1992) & $\mathrm{x}$ & $\mathrm{x}$ & & $\mathrm{x}$ & & & & & & & & & & & & & & & & & & SIM \\
\hline Bolduc et al. (1995) & $x$ & $x$ & & $\bar{x}$ & & & & & & & & & & & & & & & & & & SIM \\
\hline Kwan (2000) & $x$ & & & & & & & & & & $x$ & & & & & & & & & & & SIM \\
\hline Haider e Miller (2000) & $\mathrm{x}$ & & & & & & & & & & & & & & & $\mathbf{x}$ & & & & & & SIM \\
\hline Wang (2001) & $x$ & & & & & & & & & & & & $x$ & & & & & & & & & SIM \\
\hline Horner e Murray (2002) & & & $\mathrm{x}$ & & & & & & & & & & $x$ & & & & & & & & & SIM \\
\hline Bhat e Zhao (2002) & $x$ & $x$ & & & & 2 & & & & & & & & & & & & & & & & $\operatorname{sim}$ \\
\hline Steenberghen et al. (2004) & $x$ & & & & & & & & & $x$ & & & & & & & & & & & & NÃO \\
\hline $\begin{array}{l}\text { Kawamura e Mahajan } \\
\text { (2005) }\end{array}$ & $x$ & & & & & & & & & & & & & & $x$ & & & & & & & SIM \\
\hline Vichiensan et al. (2006) & $x$ & $x$ & & & & & & & & & & & & & & & $x$ & $x$ & & & & $\operatorname{siM}$ \\
\hline Victoria et al. (2006) & $x$ & & & & & & & & & & & & & & & & & & & $\mathbf{x}$ & & SIM \\
\hline Eom et al. (2006) & $\mathrm{x}$ & & & & & & & $\mathrm{x}$ & & & & & & & & & & & & & & SIM \\
\hline Li e Zhang (2007) & $x$ & & & & & & & & & $x$ & & & & & & & & & & & & $\operatorname{siM}$ \\
\hline Chalermpong (2007) & $x$ & & & & & & & & & & & & & & & $x$ & & & & & & SIM \\
\hline Hackney et al. (2007a) & $x$ & & & & & & & & & & & $x$ & & & & & & & & & & SIM \\
\hline Hackney et al. (2007b) & $x$ & & & & & & & & & & & $x$ & & & & & & & & & & SIM \\
\hline Czado e Prokopenko (2008) & $\mathrm{x}$ & $\mathrm{x}$ & & & $\lambda$ & & & & & & & & & & & & & & & & & SIM \\
\hline Zhou e Kockelman (2008) & $x$ & & & & & & & & & & & & & & & $x$ & $x$ & & & & & SIM \\
\hline Gundogdu et al. (2008) & $x$ & & & & & & & & & $\mathrm{x}$ & & & & & & & & & & & & SIM \\
\hline Novak et al. (2008) & $x$ & & & & & & & & $x$ & & & & & & & & & & & & & $\operatorname{siM}$ \\
\hline Ribeiro e Antunes (2009) & $x$ & $x$ & & & & & & & & & & & & & & & & & & & $\mathrm{x}$ & SIM \\
\hline Khan et al. (2009) & $\mathrm{x}$ & & & & & & & & & $\mathbf{x}$ & & & & & & & & & & & & SIM \\
\hline Wang e Kockelman (2009) & $x$ & & & & & & & $x$ & & & & & & & & & & & & & & $\operatorname{siM}$ \\
\hline Guo et al. (2009) & $\mathrm{X}$ & & & & & & & & & $\mathrm{x}$ & & & & & & & & & & & & SIM \\
\hline TOTAIS DE ESTUDOS & 24 & 7 & 1 & 3 & 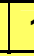 & 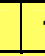 & & 2 & 1 & 5 & 1 & 2 & 2 & 1 & 1 & 3 & 2 & 1 & 0 & 1 & 1 & \\
\hline
\end{tabular}




\subsection{Uso do Solo e Transportes - Sistema Dinâmico e Integrado}

Existem evidências na literatura de que se faz necessário considerar, em estudos de mobilidade, a dinâmica que existe na relação dos transportes com o uso do solo. No entanto, a maioria dos planos de transportes das cidades se baseia em dados obtidos com modelos tradicionais, que não consideram essas questões.

A esse respeito, Pfaffenbichler (2003) afirma que a suposição de que o uso do solo é estático constitui o estado da prática na maioria dos estudos. No entanto, muitas pesquisas demonstram que transportes e uso do solo formam um sistema dinâmico intimamente integrado e que modelos integrados de uso do solo e transportes são necessários para avaliar o desempenho de políticas urbanas estratégicas visando o desenvolvimento sustentável.

Conforme Pietrantonio et al. (1996), a análise e a modelagem da interação entre uso do solo e transportes é o aspecto mais delicado da avaliação da integração entre as políticas de adensamento ou controle do uso do solo e a disponibilidade de capacidade da infraestrutura e serviços de transportes. Salientam, ainda, que foi possível identificar, na década de 90, o ressurgimento do interesse em explorar o potencial de complementaridade entre as políticas de uso do solo e transportes como forma de atenuar ou superar problemas de saturação das infraestruturas urbanas. Chamam a atenção, também, para a necessidade de um ferramental científico, pois o problema da integração entre as políticas de uso do solo e de transportes não é uma questão teórica apenas, mas uma das mais complexas questões práticas na administração das cidades, sempre presente na agenda das discussões de políticas públicas, tanto das grandes áreas urbanas quanto das cidades de porte médio.

Ramos e Silva (2002) afirmam que a retomada das pesquisas sobre o tema vem sendo, em grande medida, impulsionada por um conjunto de técnicas que, embora não sejam necessariamente novas, podem ser consideradas técnicas emergentes, dado que somente nos últimos anos do século $X X$ ganharam destaque, fruto, principalmente, do aumento de recursos computacionais disponíveis. Apresentam uma listagem de doze diferentes técnicas avançadas de uso recente que se adequam ao planejamento urbano e de transportes:

- Sistemas especialistas

- Redes Neurais Artificiais

- Lógica Fuzzy

- Técnicas não tradicionais de otimização:

- Algoritmos genéticos 
- Simulated Annealing

- Algoritmos híbridos

- Programação orientada a objetos

- Sistemas de Informação Geográfica

- Sistemas de Suporte à Decisão

- Estatística Espacial

- Microssimulação

- Modelos baseados em atividades

- Cellular Automata

- Sintaxe Espacial

Pode-se acrescentar, ainda, a Modelagem da Dinâmica de Sistemas, cujo conceito principal é o entendimento de como os elementos interagem em um sistema. Esses modelos se baseiam nos CLD (Causal Loop Diagrams), os quais representam, de forma qualitativa, como a mudança em uma variável afeta outras variáveis, que por sua vez voltam a afetar a variável inicial. Os componentes quantitativos podem ser acrescentados em forma de regras de evolução do sistema, as quais podem ser, por exemplo, iterações, equações diferenciais e fluxos estocásticos, tendo por objetivo a construção de uma teoria matemática capaz de explicar e prever a evolução de um sistema dinâmico em longo prazo. Em algumas análises torna-se importante, inclusive, a associação de duas ou mais técnicas para captar da melhor forma possível os fatores envolvidos no fenômeno em estudo.

\subsection{Projetos Relacionados à Dinâmica do Desenvolvimento Urbano e Integração de Uso do Solo e Transportes}

As questões referentes à dinâmica do desenvolvimento urbano e à necessidade de desenvolvimento de políticas e instrumentos de integração entre uso do solo e transportes são de grande relevância nas políticas públicas urbanas atuais. Tanto assim que, em diversos países, têm sido criados centros e programas para desenvolvimento de projetos específicos relacionados ao tema (TORRENS, 2000, EMBERGER; PFAFFENBICHLER; JAERSIRISAK, 2005). Mais detalhes são encontrados nas páginas virtuais dos projetos CITYMOBIL, PNMUS (BRASIL, 2004), PROSPECTS, SCATTER, SPARKLE, SprawISIM, STEPs e TMIP, apresentadas nas referências deste documento. 
Somente com base no modelo MARS (Metropolitan Activity Relocation Simulator), desenvolvido por Pfaffenbichler (2003) na Universidade Tecnológica de Viena, 16 projetos foram implementados em várias cidades da Europa e Ásia (Emberger et al., 2005), cujo foco era a mobilidade urbana sustentável (INSTITUTE FOR TRANSPORT PLANNING AND TRAFFIC ENGINEERING - VIENNA UNIVERSITY OF TECNOLOGY). Pode-se citar, como um exemplo, o CityMobil, integrado ao Sixth Framework Programme, que tem o objetivo de alcançar uma organização mais efetiva no transporte urbano, resultando em um uso mais racional do transporte motorizado e, consequentemente, menor congestionamento e poluição, maior segurança no tráfego, maior qualidade de vida e maior integração com o desenvolvimento espacial. O Projeto CityMobil visa validar e demonstrar a capacidade de novas soluções de mobilidade em diferentes cidades da Europa.

No Brasil, o Ministério das Cidades defende que os principais objetivos da Política Nacional de Mobilidade Urbana Sustentável, PNMUS (BRASIL, 2004, 2006, 2007) são: integrar o transporte ao desenvolvimento urbano, reduzir as deseconomias da circulação, ofertar um transporte público eficiente e de qualidade e contribuir para o desenvolvimento econômico. A PNMUS está fundamentada no princípio de articulação entre políticas públicas de transporte e trânsito, política nacional de mobilidade urbana sustentável e política de desenvolvimento urbano e meio ambiente (BRASIL, 2006).

\subsection{Modelos Integrados de Uso do Solo e Transportes}

Wegener (2003) salienta que, apesar da grande importância de se promover políticas integradas de uso do solo e transportes para o desenvolvimento urbano sustentável, tal interrelação é complexa e ainda pouco compreendida, o que dificulta para os planejadores perceber os impactos de políticas de transportes no uso do solo e vice-versa.

Modelos teóricos e matemáticos têm sido há tempos criados para fins de estudos urbanos, visando esclarecer processos de mudanças urbanas e regionais. Uma das mais antigas contribuições nesse sentido é a teoria de anéis concêntricos de Von Thünen, de 1826. De acordo com esse modelo, o uso mais intenso da terra será próximo ao centro e o preço do aluguel e da terra decresce na periferia. Outras abordagens, baseadas na teoria econômica, foram desenvolvidas por Weber, em 1909, que minimiza o custo de transporte de matériaprima até a indústria e do produto final até o mercado, o modelo de lugares centrais de Christaller, de 1933, e a teoria de regiões econômicas, concebida por Lösch em 1940 (PERRATON; BAXTER, 1974).

Conforme Almeida (2003), desenvolvimentos pioneiros em modelagem urbana surgiram quase que exclusivamente na América do Norte, onde a crescente propriedade de 
automóveis durante os anos 1940 e início dos anos 1950 levou à constatação de que as cidades, com sua estrutura física tradicional, não poderiam fazer frente às novas necessidades de mobilidade. Os primeiros estudos, contudo, negligenciavam questões importantes sobre o uso do solo. Porém, a crescente consciência acadêmica e profissional à época em relação ao interrelacionamento entre tráfego e uso do solo permitiu a construção de modelos de uso do solo já por volta de 1960 (BATTY, 1976). Almeida (2003) salienta que muitas são as limitações desses primeiros modelos, classificando-os como "modelos não dinâmicos de mudança do uso do solo".

Uma revisão detalhada sobre modelos integrados de uso do solo e transportes é apresentada em Wegener e Fürst (1999) e complementada por Wegener (2003). Vinte modelos são destacados dos demais, pelos autores, por vários aspectos. O primeiro ponto de destaque é que esses modelos incorporam os processos essenciais de desenvolvimento espacial em regiões urbanas, o que significa que são capazes de prever usos do solo tanto residencial como comercial e também industrial. Outra questão é que os modelos são operacionais, ou seja, foram implementados, calibrados e aplicados para análise de políticas em pelo menos uma região metropolitana. Para avaliar os vinte modelos, os autores destacam oito subsistemas urbanos a serem modelados, os quais se distinguem pela velocidade no processo de mudança. Dessa forma, os oito subsistemas são ordenados em quatro estágios, que vão de processos "muito lentos" de mudança a processos de mudança "imediata", conforme segue:

- Processo muito lento de mudança - rede viária (infraestrutura de transportes) e uso do solo (que se altera somente de forma incremental);

- Processo lento de mudança - prédios residenciais e não-residencias (industriais, de escritórios, shoppings centers, teatro, universidades, lojas);

- Processo rápido de mudança - empregos e população;

- Processo muito rápido de mudança - transporte de bens e deslocamentos. A localização espacial da atividade humana origina a demanda por interações espaciais na forma de transporte de bens e deslocamentos. A mobilidade constitui o fenômeno mais flexível do desenvolvimento urbano espacial.

A lista dos vinte modelos que foram destacados por Wegener (2003) para análise é apresentada na Tabela 2. Acrescenta-se à lista o modelo MARS, desenvolvido por Pfaffenbichler (2003), cuja conclusão foi posterior ao estudo de Wegener (2003). O modelo MARS foi incluído por ser um modelo dinâmico e integrado de uso do solo e transportes que foi testado, calibrado e aplicado para estudos de mobilidade em diversas cidades da Europa e da Ásia, com o objetivo de analisar políticas de desenvolvimento sustentável. 
Tabela 2 - Modelos Integrados de Uso do Solo e Transportes.

\begin{tabular}{|c|c|}
\hline BOYCE & $\begin{array}{l}\text { Combinação de modelos de localização e escolha de viagens. Desenvolvido por } \\
\text { Boyce (Boyce et al. 1983; Boyce 1986; Boyce et al. 1992); }\end{array}$ \\
\hline CUFM & $\begin{array}{l}\text { Califórnia Urban Futures Model, desenvolvido na Universidade da California, } \\
\text { Berkeley (Landis, 1992, 1993, 1994; Landis e Zhang, 1998a, 1998b); }\end{array}$ \\
\hline DELTA & $\begin{array}{l}\text { Pacote de modelagem econômica e de uso do solo DELTA de Davids Simmonds } \\
\text { Consultancy, Cambrige, Ingraterra, que forma um modelo integrado de uso do solo } \\
\text { e transporte quando combinado com um modelo apropriado de transporte } \\
\text { (Simmonds e Still, 1998; Simmonds, 2001); }\end{array}$ \\
\hline HUDS & Harvard Urban Development Simulation, desenvolvido por Kain e Apgar (1985); \\
\hline ILUTE & $\begin{array}{l}\text { Integrated Land Use, Transportation, Environment - Sistema de modelos integrados } \\
\text { de uso do solo, transportes e meio-ambiente que está em desenvolvimento em } \\
\text { diversas universidades canadenses (Miller e Salvini, 2001); }\end{array}$ \\
\hline IMREL & $\begin{array}{l}\text { Integrated Model of Residential and Employment Location, desenvolvido por } \\
\text { Anderstig e Mattson }(1991,1998) ;\end{array}$ \\
\hline IRPUD & $\begin{array}{l}\text { Modelo da região de Dortmund de Wegener (1982a, 1982b, 1985, 1986a, Wegener } \\
\text { et al. 1991; Wegener, 1996, 1998b); }\end{array}$ \\
\hline ITLUP & $\begin{array}{l}\text { Integrated Transportation and Land Use Package de Putman (1983, 1991, 1998), } \\
\text { que consiste num pacote com o modelo de locação residencial DRAM e com o } \\
\text { modelo de empregos EMPAL; }\end{array}$ \\
\hline KIM & $\begin{array}{l}\text { Versão não-linear do modelo de equilíbrio urbano desenvolvido por Kim (1989) e } \\
\text { Rho e Kim (1989); }\end{array}$ \\
\hline LILT & $\begin{array}{l}\text { Leeds Integrated Land-Use/Transport Model desenvolvido por Mackett (1983, } \\
\text { 1990c, 1991a, 1991b); }\end{array}$ \\
\hline MEPLAN & $\begin{array}{l}\text { Pacote de modelagem integrada desenvolvido por Marcial Echenique \& Partners } \\
\text { (Echenique et al. 1969; Echenique e Williams, 1980; Echenique, 1985; Echenique et } \\
\text { al. 1990; Hunt e Echenique, 1993; Hunt e Simmonds, 1993; Williams, 1994; Hunts, } \\
\text { 1994); }\end{array}$ \\
\hline METROSIM & $\begin{array}{l}\text { Modelo microeconômico de uso do solo e transportes desenvolvido por Anas (Anas, } \\
\text { 1992; Anas, 1994, 1998); }\end{array}$ \\
\hline MUSSA & $\begin{array}{l}\text { 5-Stage Land-Use Transport Model desenvolvido para Santiago do Chile por } \\
\text { Martinez (1991, 1992a, 1992b; Martinez e Donoso, 1995; Martinez 1996, 1997a, } \\
\text { 1997b); }\end{array}$ \\
\hline POLIS & $\begin{array}{l}\text { Projective Optimization Land Use Information System desenvolvido por Prastacos } \\
\text { para a Association of Bay Area Governments (Prastacos, 1986; Caindec e } \\
\text { Prastacos, 1995); }\end{array}$ \\
\hline RURBAN & $\begin{array}{l}\text { Random-Utility Urban - modelo desenvolvido por Miyamoto (Miyamoto et al. } 1986 \text {, } \\
\text { Miyamoto e Kitazume, 1989); }\end{array}$ \\
\hline STASA & $\begin{array}{l}\text { Master-Equation based transport and urban/regional model desenvolvido por } \\
\text { Haag (1990); }\end{array}$ \\
\hline TLUMIP & $\begin{array}{l}\text { Modelo de uso do solo e transportes do estado de Oregon, Estados Unidos, } \\
\text { desenvolvido no Oregon Transport and Land Use Model Integration Program } \\
\text { (ODOT, 2002) }\end{array}$ \\
\hline TRANUS & $\begin{array}{l}\text { Modelo integrado de transporte e uso do solo desenvolvido por de la Barra (de la } \\
\text { Barra 1982; de la Barra et al. 1984; de la Barra, 1989, 1998); }\end{array}$ \\
\hline TRESIS & $\begin{array}{l}\text { Transportation and Environment Strategy Impact Simulator desenvolvido por } \\
\text { Hensher e Ton (2001); }\end{array}$ \\
\hline URBANSIM & $\begin{array}{l}\text { Modelo de escolha de localização domiciliar e de firmas desenvolvido por Waddell } \\
\text { (1998a; 1998b, 1998c, 1998d, Waddell et al. 1998); }\end{array}$ \\
\hline MARS & $\begin{array}{l}\text { Metropolitan Activity Relocation Simulator que é um modelo estratégico, dinâmico e } \\
\text { integrado de uso do solo e transportes desenvolvido por Pfaffenbichler (2003). }\end{array}$ \\
\hline
\end{tabular}

Fontes: Wegener (2003) e Pfaffenbichler (2003)*

* Nota: Todas as referências listadas encontram-se nas duas fontes citadas ao final da tabela. 
A Tabela 3 apresenta a avaliação dos modelos, indicando os subsistemas urbanos que são modelados de acordo com a classificação de velocidade de mudança proposta por Wegener e Fürst (1999) e Wegener (2003). O modelo MARS foi acrescentando à Tabela 3 com base na análise apresentada por Pfaffenbichler (2003).

Tabela 3 - Subsistemas urbanos representados nos modelos integrados de uso do solo e transportes - adaptada de Wegener (2003).

\begin{tabular}{|c|c|c|c|c|c|c|c|c|}
\hline \multirow[b]{3}{*}{ Modelos } & \multicolumn{8}{|c|}{ Velocidade de mudança } \\
\hline & \multicolumn{2}{|c|}{ Muito lenta } & \multicolumn{2}{|c|}{ Lenta } & \multicolumn{2}{|c|}{ Rápida } & \multicolumn{2}{|c|}{ Imediata } \\
\hline & $\begin{array}{l}\text { Infraestrut. } \\
\text { viária e } \\
\text { transp. }\end{array}$ & $\begin{array}{c}\text { Uso do } \\
\text { solo }\end{array}$ & $\begin{array}{l}\text { Prédios } \\
\text { não } \\
\text { resid. }\end{array}$ & $\begin{array}{c}\text { Prédios } \\
\text { resid. }\end{array}$ & Empr. & Popul. & $\begin{array}{c}\text { Transp. } \\
\text { Bens }\end{array}$ & Desloc. \\
\hline \multicolumn{9}{|l|}{ BOYCE** $^{* *}$} \\
\hline \multicolumn{9}{|l|}{ CUFM } \\
\hline \multirow{2}{*}{\multicolumn{9}{|c|}{$\begin{array}{l}\text { DELTA }^{* * *} \\
\text { HUDS }\end{array}$}} \\
\hline & & & & & & & & \\
\hline \multicolumn{9}{|l|}{$\begin{array}{l}\text { HUDS } \\
\text { ILUTE }\end{array}$} \\
\hline \multicolumn{9}{|l|}{ IMREL ${ }^{* *}$} \\
\hline \multicolumn{9}{|l|}{ IRPUD $^{* * *}$} \\
\hline \multirow{2}{*}{\multicolumn{9}{|c|}{$\frac{\text { ITLUP }^{* *}}{\mathrm{KIM}^{* *}}$}} \\
\hline \multirow{2}{*}{\multicolumn{9}{|c|}{$\mathrm{KIM}^{* *}$}} \\
\hline \multirow{2}{*}{\multicolumn{5}{|c|}{ LILT $^{* *}$}} & & & & \\
\hline \multirow{2}{*}{\multicolumn{8}{|c|}{$\frac{\text { MEPLAN }^{* * *}}{\text { METROSIM }^{* *}}$}} & \\
\hline \multicolumn{6}{|c|}{ METROSIM** } & & & \\
\hline \multicolumn{9}{|l|}{ MUSSA** } \\
\hline \multicolumn{9}{|l|}{ POLIS ${ }^{\star *}$} \\
\hline \multicolumn{9}{|l|}{ RURBAN $^{* *}$} \\
\hline \multirow{2}{*}{\multicolumn{9}{|c|}{$\begin{array}{l}\text { STASA } \\
\text { TLUMIP }\end{array}$}} \\
\hline & & & & & & & & \\
\hline \multicolumn{9}{|l|}{ TRANUS } \\
\hline \multicolumn{9}{|l|}{ TRESIS } \\
\hline URBANSIM & & & & & & & & \\
\hline MARS $^{*}$ & & & & & & & & \\
\hline
\end{tabular}

${ }^{*}$ Modelo acrescentado à tabela por Pfaffenbichler (2003)

**Modelos também avaliados na revisão realizada por Chang (2006)

*** Modelos explicitamente descartados da análise de Chang (2006)

Fontes: Wegener (2003) e Pfaffenbichler (2003).

Outro importante instrumento para avaliação de modelos é a matriz evolutiva proposta inicialmente por Miller et al. (1998), a qual foi, posteriormente, ampliada por Wegener e Fürst (1999) (Figura 1). A matriz apresenta diferentes níveis de avanço nos modelos integrados de uso do solo e transportes, onde as linhas correspondem aos níveis de modelagem de uso do solo, variando de L1 a L6. A última linha (L6), acrescentada por Wegener e Fürst (1999), representa os modelos de uso do solo baseados em atividades. As colunas da matriz correspondem aos avanços na modelagem de transporte, variando de T1 a T4. Os modelos integrados de uso do solo e transportes mais evoluídos são os localizados na célula L6/T4 no canto inferior direito. A distribuição dos vinte modelos na matriz apresentada na Figura 1 
tem como base o estudo de Arruda (2005), enquanto a localização do modelo MARS é apresentada por Pfaffenbichler (2003).

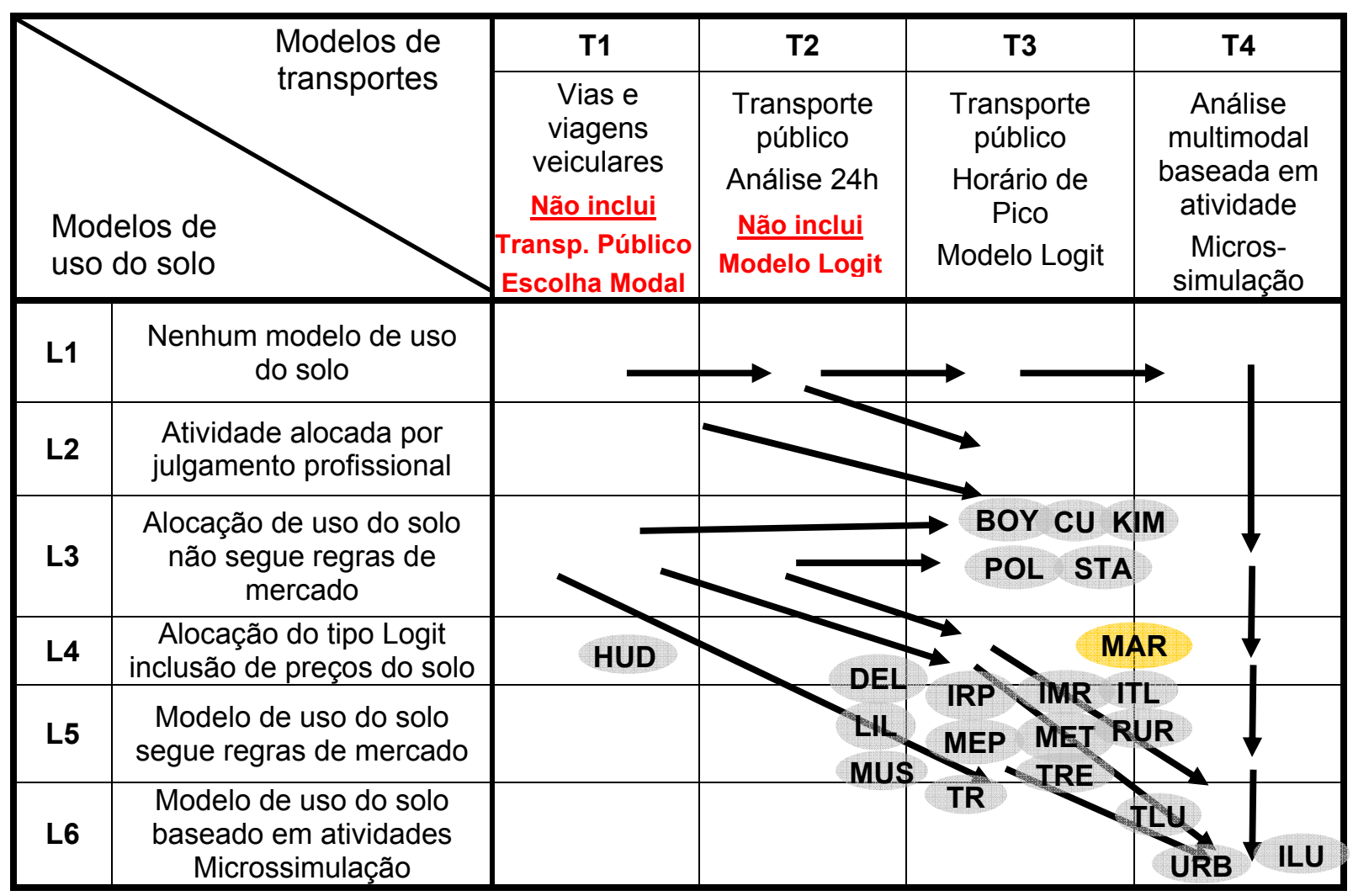

Figura 1 - Distribuição dos modelos na matriz evolutiva de Miller et al. (1998), modificada por Wegener e Fürst (1999), Pfaffenbichler (2003) e Arruda (2005).

Apesar de sugerido por Wegener e Fürst (1999), através da complementação da matriz evolutiva de Miller et al. (1998), que maiores avanços vão no sentido da simulação microscópica de uso do solo, Pfaffenbichler (2003) argumenta que para questões estratégicas, como a sustentabilidade, o comportamento macroscópico do sistema urbano é essencial e não o comportamento microscópico.

A este respeito, Pfaffenbichler (2008) destaca que existam duas formas de aumentar a complexidade na modelagem de transportes: aumentando o nível de detalhes através da desagregação espacial e aumentando o número de subsistemas envolvidos. O autor considera que mais importante que a desagregação espacial é garantir a inclusão, no modelo, de retroalimentações relevantes entre os sistemas e subsistemas envolvidos. $O$ autor destaca ainda que os problemas de transporte, como congestionamentos, acidentes, poluição, consumo de recursos não renováveis, não são problemas de comportamentos individuais e sim problemas de comportamento coletivo, podendo ser objeto de estudo da sinergética, ciência da colaboração, que lida com o comportamento coletivo. 
O MARS, adicionado por Pfaffenbichler (2003) na matriz evolutiva, entre os estágios T3 e T4 da evolução dos modelos de transporte, é multimodal e, de certa forma, baseado em atividades, embora somente dois tipos de atividades sejam considerados (escolha de localidade e escolha de transporte). O modelo de uso do solo não é totalmente baseado em regras de mercado, mas usa no mínimo uma alocação com inclusão de preços do solo urbano. O MARS, diferentemente de muitos outros modelos, considera modos não motorizados nos submodelos de transporte. Também cobre sete dos oito subsistemas destacados por Wegener (2003) (Tabela 3). Pfaffenbichler (2008) destaca, ainda, que ao contrário de outros modelos LUTI, como MEPLAN e TRANUS, por exemplo, o MARS não se baseia na modelagem transversal entre os sistemas de uso do solo e de transporte. Seu caráter dinâmico está exatamente na modelagem de mudanças anuais no uso do solo e transportes ao longo do período de análise (30 anos).

Wegener (2003) apresenta, ainda, a análise comparativa dos vinte modelos, considerando os critérios abrangência, estrutura, fundamentação teórica, técnicas de modelagem, dinamismo, dados requeridos, calibração e validação, operacionalidade e aplicabilidade. O estudo do estado da arte em modelos integrados de uso do solo e transportes iniciado por Wegener e Fürst (1999) e complementado por Wegener (2003) vem sendo a base para outras pesquisas sobre o assunto, como as de Pfaffenbichler (2003) e de Arruda (2005).

Seguindo a mesma linha do trabalho de Wegener (2003) e com a mesma relevância, podese citar, também, o estudo apresentado por Chang (2006), que realiza uma revisão crítica da literatura atual sobre os desenvolvimentos na modelagem integrada de uso do solo e transportes. Segundo o autor, a base da interação entre o uso do solo e transportes está fundamentada na relação entre os transportes e a localização das atividades. Sendo assim, o autor selecionou para seu estudo somente os modelos que tratam dessa relação de forma explícita e direta, ou seja, modelos cujo principal objetivo é representar o processo de interação entre transporte e localização das atividades. Chang (2006) analisa, em mais de trinta modelos, com base nas suas características metodológicas, teóricas e operacionais, a forma que cada um trata essa interrelação.

Devido à complexidade dos modelos, Chang (2006) definiu três características estruturais básicas para facilitar a análise, as quais dizem respeito: $i$. aos mecanismos utilizados para representar as características particulares de localização das atividades; ii. à forma de representação do processo de decisão do indivíduo; iii. à medida de representação da resposta mútua entre transporte e uso do solo. Deve-se destacar que apenas nove dos vinte modelos analisados por Wegener (2003) (Tabelas 2 e 3) se encaixaram nos objetivos da pesquisa de Chang (2006). 
Chang (2006) identifica, também, quatro grupos básicos em termos de estrutura matemática dos modelos de uso do solo e transporte, aos quais denomina de modelos: i. de Interação Espacial, ii. de Programação Matemática, iii. de Utilidade Aleatória e iv. de "Bid-Rent". O autor destaca vantagens e desvantagens para cada grupo, no entanto, salienta que nenhum dos modelos analisados aborda de forma satisfatória a relação transporte e localização de atividades. Segundo o autor, ocorreram melhorias significativas nos últimos anos nesses tipos de modelos, porém mais focadas em detalhar de forma demasiada seus componentes do que em refinar a base da inter-relação entre uso do solo e transportes. Para obtenção de melhorias efetivas é necessário concentrar-se nas três condições estruturais básicas da interação de uso do solo e localização de atividades destacadas por ele.

Além dos modelos analisados por Wegener (2003) e Chang (2006), destacam-se outros modelos recentemente desenvolvidos: RB\&SM (Random Bidding and Supply Model), apresentado por Martinez e Henríquez (2007); TIGRIS XL, que é o novo modelo de interação de uso do solo e transportes do Transport Research Center, na Holanda (ZONDAG; PIETERS, 2005); MUSSA II (MARTINEZ; JAVIER; DONOSO, 2007), que é uma evolução do modelo MUSSA (Tabelas 2 e 3); UPLAN, que é um modelo em plataforma SIG para planejamento urbano integrado, apresentado por Walker, Gao e Johnton (2007); modelo hedônico, baseado em regressão espacial, desenvolvido para Bancoc com o objetivo de analisar a relação de impactos causados no uso do solo residencial decorrente de melhorias no transporte público (CHALERMPONG, 2007).

O trabalho de Pitombo (2007) também é de grande contribuição para o tema de integração entre uso do solo e transportes. Apesar de não se tratar do desenvolvimento de um modelo e sim de um estudo exploratório e investigativo para melhor compreender os fatores que os indivíduos consideram ao escolher a sequência de atividades, os modos de viagens utilizados e os destinos durante o período de um dia, o estudo contribui para o entendimento da relação entre as diferentes variáveis envolvidas na mobilidade urbana, no contexto brasileiro. É salientado que, para se entender a relação entre uso do solo e comportamento referente a viagens, é necessário, primeiramente, investigar formas de mensurar características do meio urbano. Propõe-se, então, um conjunto de variáveis de uso do solo baseado no modelo de oportunidades intervenientes, ou seja, variáveis que consideram parcelas acumuladas de oportunidades, como, por exemplo, empregos por setor econômico ou escolas por grau de instrução, a partir dos centróides da zona de tráfego da residência do indivíduo. A conclusão é de que as características de uso do solo do local de residência estão fortemente relacionadas à escolha de destinos das viagens. 
Pitombo (2007) destaca, ainda, que a aplicação de estatística espacial nas análises pode aprimorar a compreensão do comportamento das viagens encadeadas. Sendo assim, sugere, para trabalhos de pesquisa futuros, a incorporação de análise espacial de dados, pois a dependência espacial presente nas áreas urbanas exerce efeitos em modelos de previsão de demanda por transportes.

Finalmente, cabe mencionar a relação de itens para verificação (check list) sugerida por Sterman (1991), que é fundamental na escolha da melhor ferramenta de apoio à decisão para estudos de mobilidade urbana sustentável. Destacam-se, abaixo, quatro itens, que também foram aplicados por Pfaffenbichler (2003) para avaliar a adequação do modelo MARS, tendo-se acrescentado mais uma questão (item $V$ ), de relevância particular para esta pesquisa:

I. Qual é o propósito do modelo? Ele é adequado para analisar planos estratégicos de mobilidade com o objetivo de desenvolvimento urbano sustentável?

II. Quais são os limites do modelo? As questões e variáveis importantes para o tema são tratadas de forma endógena? Quais variáveis importantes são exógenas ou excluídas? Existem variáveis importantes excluídas porque não existem dados numéricos que as quantifiquem?

III. Qual o horizonte de projeto para o problema em questão? O modelo inclui, como elementos endógenos, fatores que podem sofrer alteração significativa ao longo do período de horizonte?

IV. O nível de agregação dos dados e das análises é compatível com o propósito do estudo em questão?

V. O modelo considera, de alguma forma, efeitos causados pela dependência espacial? Se não, qual é a flexibilidade do modelo para incluir tais indicadores?

\subsection{Considerações Finais}

Procurou-se fazer uma análise de estudos, teorias, aplicações e políticas que dizem respeito ao problema atualmente encontrado no planejamento de transportes, que envolve a consideração da dinâmica do desenvolvimento urbano e a integração de uso do solo e transportes. Salienta-se que, que existem estudos e políticas que conduzem à reflexão sobre o assunto, em busca do planejamento da mobilidade urbana sustentável, e que, em termos de ferramentas, já existe algum avanço nesse sentido. Na prática, porém, o mais usual, no Brasil, ainda é a aplicação do modelo de quatro etapas, na sua forma tradicional. 
Muitas questões foram levantadas a respeito do modelo tradicional de transportes, destacando-se que se trata de um modelo estático, que pode gerar erros consideráveis para projeções de longo prazo, além de não incorporar os impactos que alterações no uso do solo podem causar na estrutura de transportes (e vice-versa) e ignorar os efeitos espaciais sobre as variáveis introduzidas.

As considerações aqui apresentadas reforçam a tese de que a utilização de uma ferramenta pertencente à nova geração de modelos, que avaliam a dinâmica existente na integração entre uso do solo e transportes e agregam indicadores que, de alguma forma, consideram os possíveis efeitos da dependência espacial existente entre os dados, pode contribuir para a obtenção de resultados melhores que os obtidos com modelos tradicionais. 


\section{O MODELO MARS - METROPOLITAN ACTIVITY RELOCATION SIMULATOR}

O modelo MARS (Metropolitan Activity Relocation Simulator), após a análise preliminar de mais de vinte alternativas, apresentadas no capitulo anterior, foi considerado a ferramenta apropriada para se atingir os objetivos deste trabalho. Trata-se de um modelo estratégico, dinâmico e integrado de uso do solo e transportes, desenvolvido por Pfaffenbichler (2003) na Universidade de Tecnologia de Viena, Áustria. É um modelo amplamente testado e vem sofrendo melhorias constantes a cada nova cidade onde é aplicado para estudos de desenvolvimento urbano sustentável. Hoje, o MARS já está sendo aplicado em 16 cidades da Europa e Ásia e está em fase de desenvolvimento nos Estados Unidos, na cidade de Washington, D.C.

O MARS é um modelo dinâmico que integra uso do solo e transportes e cuja hipótese básica é de que os assentamentos e as atividades dentro deles são sistemas autoorganizados. O MARS é baseado em princípios de dinâmica de sistemas (STERMAN, 2000) e sinergética (HAKEN, 1983), tendo seu desenvolvimento começado em 2000, em parte financiado por projetos de pesquisa da União Européia. A presente versão do MARS é implementada no Vensim $®$, um ambiente de programação de Dinâmica de Sistemas, sendo capaz de analisar combinações de políticas municipais e regionais e de avaliar os seus impactos ao longo de um período de planejamento de 30 anos em menos de um minuto. $O$ modelo MARS é constituído por elementos de transporte e de uso do solo e pode ser dividido conforme mostrado na Figura 2. 


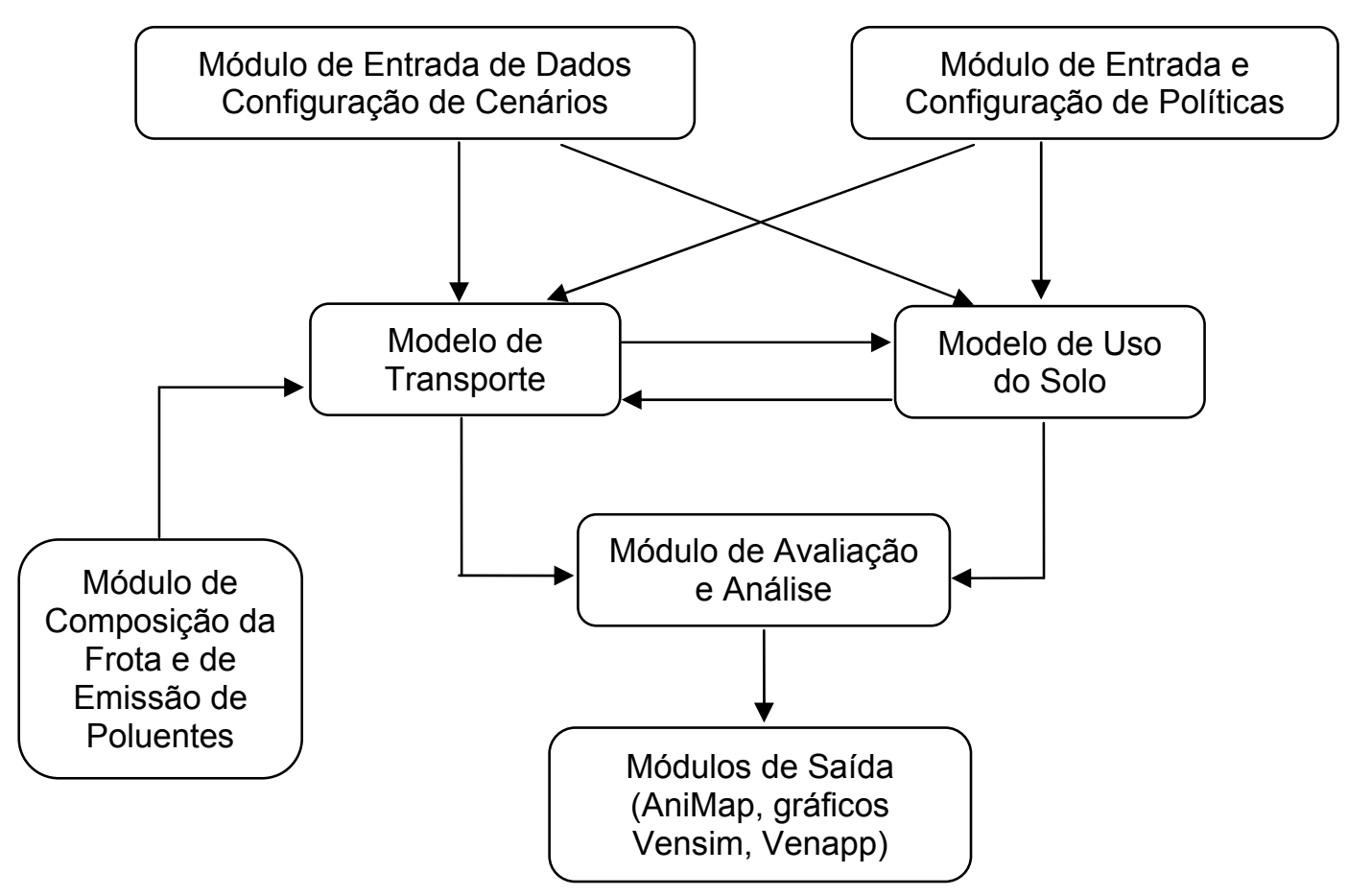

Figura 2 - Estrutura básica do Modelo MARS.

\subsection{Módulo de Entrada de Dados - Configuração de Cenários}

Módulo em que as tendências dentro da região em estudo são definidas pelo usuário, como, por exemplo, as hipóteses de crescimento da população ou as previsões de desenvolvimento econômico. É utilizado para a seleção de parâmetros globais de diferentes cenários a serem testados com o MARS.

\subsection{Módulo de Entrada e Configuração de Políticas}

Módulo que tem o propósito de organizar as diferentes políticas ao longo do tempo e que permite aos usuários especificar o ponto inicial e final, bem como o nível inicial e final de cada intervenção. Por exemplo, é possível testar o impacto de níveis crescentes de tarifas do transporte público, começando no ano 3 com um valor inicial de $+20 \%$ e aumentando linearmente até atingir $50 \%$ no ano 12 , a partir do qual o valor da tarifa fica constante até o final da simulação. Através deste módulo é possível especificar vários perfis de políticas simultaneamente. Dependendo do estudo de caso, mais de 15 diferentes instrumentos podem ser combinados em um simulador (Flight Simulator), interface gráfica que permite que o usuário controle facilmente a configuração de políticas através de botões deslizantes (sliders) e possa avaliar, em menos de um minuto, os impactos (efeitos sinergéticos) das diferentes combinações de fatores. 
Apresenta-se, apenas a título de exemplo, a análise para a cidade de Leeds, na Inglaterra, de um cenário em que as zonas Holbeck, Kirkstall, Headingley, University, Hunslet, Weetwood, Rothwell e Cookridge são afetadas pelo corredor de trólebus modelado com o MARS (Figura 3). Todos os instrumentos são definidos para serem aplicados nas zonas afetadas pelo corredor, sendo os anos de início e fim arbitrariamente fixados em 5 e 30 anos, respectivamente (PFAFFENBICHLER, EMBERGER, SHEPHERD, 2010).

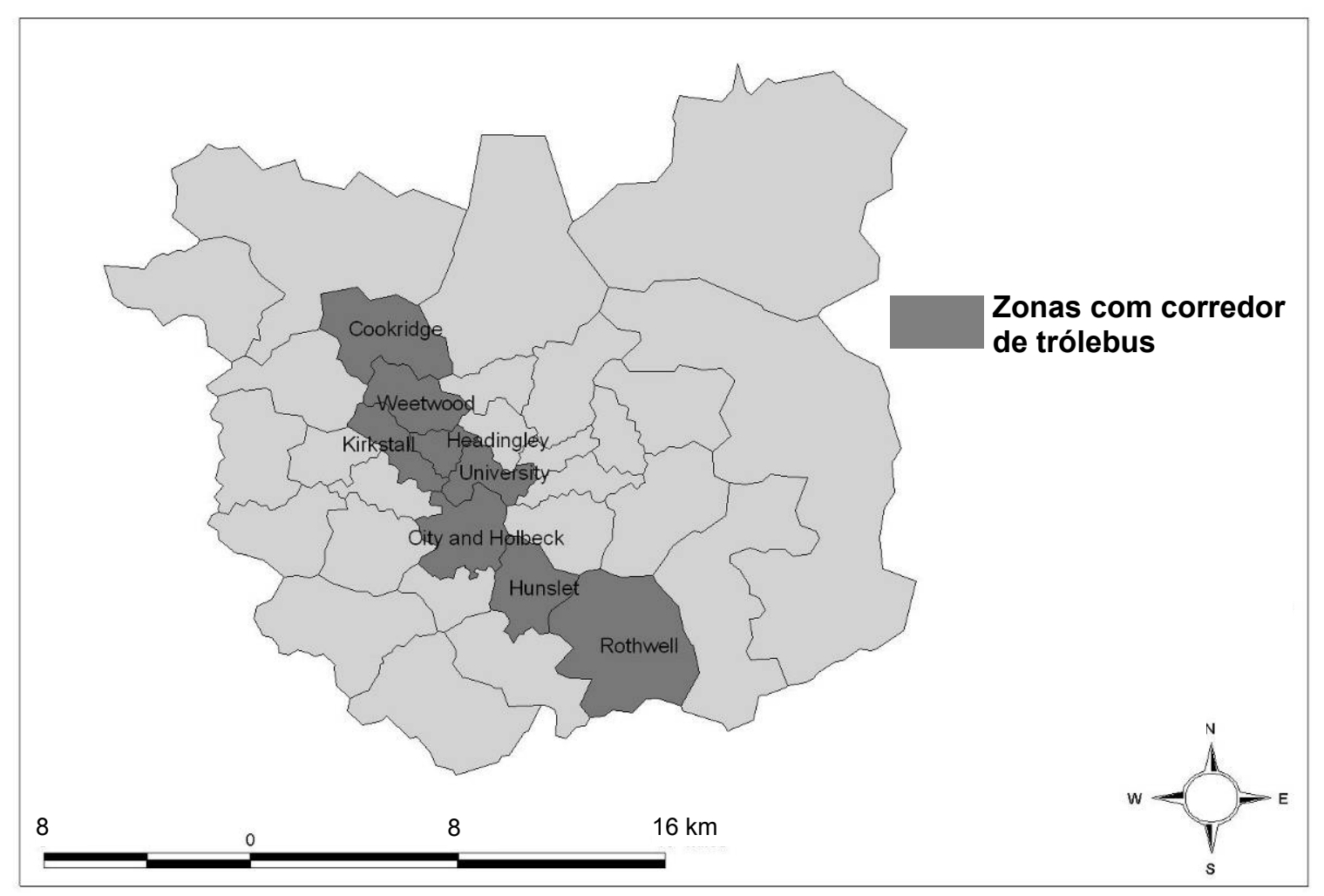

Figura 3 - Esquema do corredor de trólebus de Leeds. Fonte: Pfaffenbichler, Emberger e Shepherd (2010)

A Figura 4 mostra as definições dos instrumentos de política, que são feitas com o simulador e afetam diretamente o modo ônibus. O corredor de ônibus funciona em períodos fora de pico e pico, em que de $10 \%$ a $50 \%$ dos ônibus circulam pelo corredor. Admite-se um efeito positivo sobre a tarifa paga, com ganho de 20 centavos de Euro, tanto no pico como nos períodos fora de pico. Supõe-se que o corredor de ônibus reduz o tempo de circulação, de tal forma que é possível um aumento de $25 \%$ na frequência sem que ocorram custos operacionais adicionais. Supõe-se, também, que o corredor de ônibus reduz a capacidade da via para receber veículos particulares em $20 \%$ e reduz o número de vagas de estacionamento na rua em 10\% (PFAFFENBICHLER, EMBERGER, SHEPHERD, 2010). 


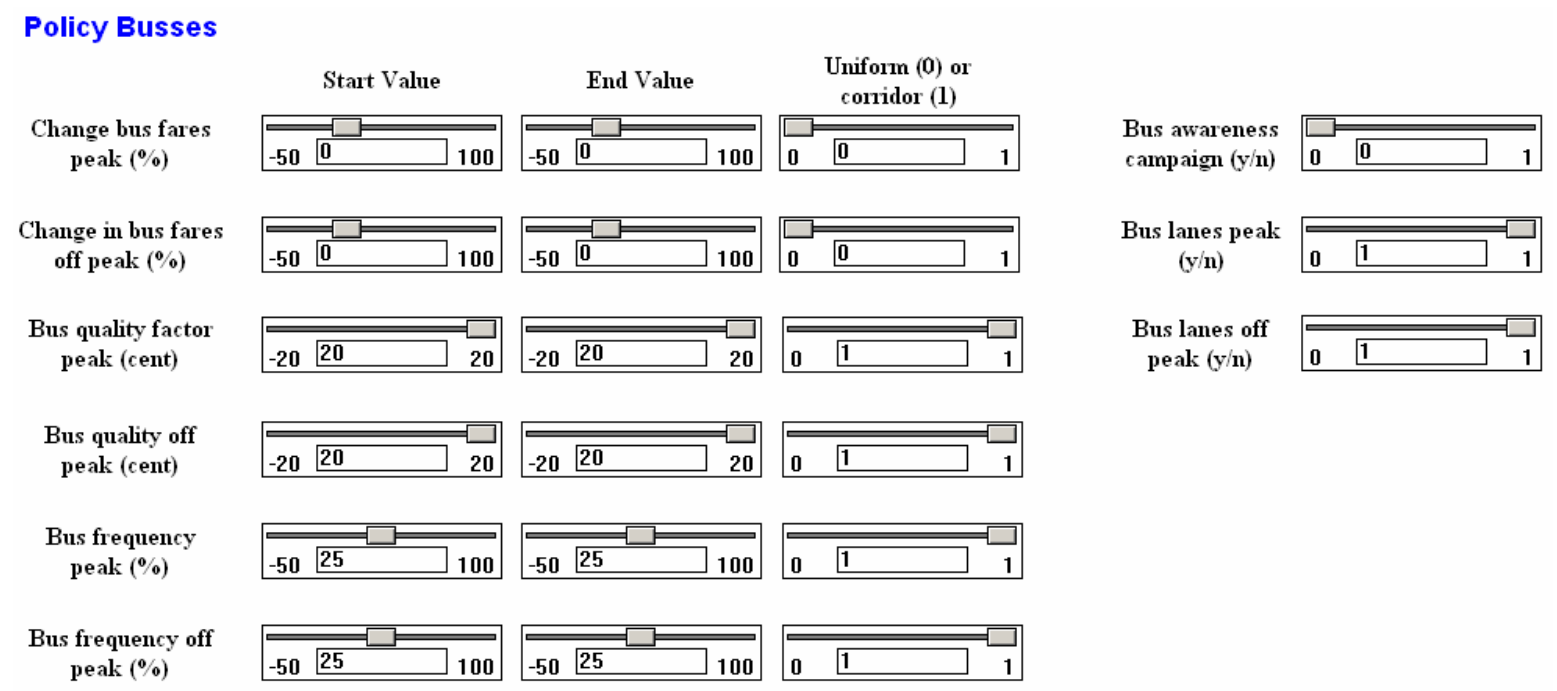

Start/End
Time

Figura 4 - Ajustes nos instrumentos de políticas no simulador (Flight Simulator): exemplo da análise de corredor de trólebus na cidade de Leeds. Fonte: Pfaffenbichler,

Emberger e Shepherd (2010)

\subsection{Submodelos de Transporte}

Os submodelos de transportes de passageiros contemplam a geração de viagens, a distribuição de viagens e a escolha do modo de transporte. A geração de viagens calcula o número de viagens que começam ou terminam em uma determinada zona, a distribuição de viagens aloca o número total de viagens a todos os pares origem-destino (O-D) e a escolha do modo distribui as viagens para os diferentes meios de transporte, normalmente em termos de porcentagem. Esses elementos são os três primeiros passos do modelo clássico de transporte (ORTÚZAR; WILLUMSEN, 2001), sendo calculados simultaneamente por um modelo gravitacional (maximização de entropia). Os modos de transporte considerados no MARS são: lento (não-motorizado: a pé ou bicicleta), carro, transporte público (ônibus) e transporte público (trem). Em algumas aplicações do MARS as motocicletas são consideradas, separadamente, como um meio de transporte.

O resultado final de uma etapa de simulação do modelo de transporte apresenta velocidade média de percurso, distribuição dos comprimentos de viagem, custos médios e número de viagens por meio de transporte, por par O-D, dividido em dois motivos (trabalho e outros), nos períodos de pico e fora de pico. Os resultados são combinados para a determinação da acessibilidade geral, que é transferida para o modelo de uso do solo. 
Para facilitar o entendimento dos conceitos do MARS por parte de seus usuários (planejadores, políticos e acadêmicos), foram desenvolvidos diagramas de circuitos causais, tanto para o modelo de transporte como para o modelo de uso do solo. A Figura 5 apresenta os fatores que afetam o número de viagens diárias de carro de uma zona à outra. Começando com o circuito B1, que é uma realimentação de equilíbrio, nota-se que o aumento de viagens diárias por carro ocorre com o aumento da atratividade do carro e aumenta o tempo de procura por uma vaga de estacionamento. Isso, por sua vez, diminui a atratividade da utilização de carro, o que demonstra a natureza de equilíbrio do circuito B1. O circuito B2 representa o efeito de congestionamento, pois com o aumento do número de viagens de carro há diminuição da velocidade, os tempos de viagem aumentam e a atratividade do carro diminui. $\mathrm{O}$ circuito $\mathrm{B} 3$, que também é uma realimentação de equilíbrio, mostra o impacto nos custos de combustível, sendo que no caso urbano, com o aumento de velocidade há redução no consumo de combustível.

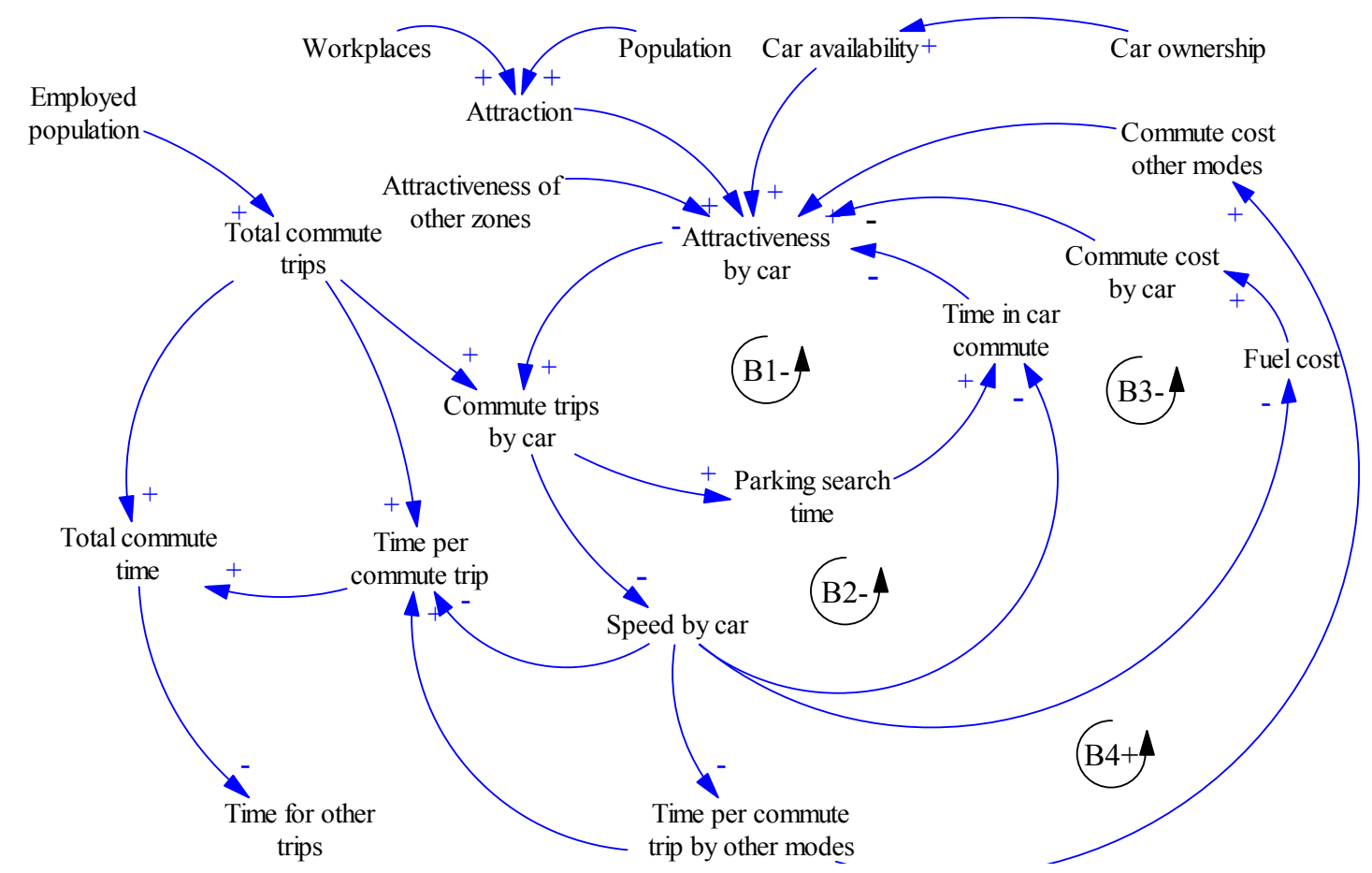

Figure 5 - Diagrama de circuitos causais no Modelo de Transporte - viagens pendulares.

\subsection{Submodelos de uso do solo}

O modelo de uso do solo simula, com base no princípio de mercados concorrenciais e considerando restrições como disponibilidade de terreno, o desenvolvimento de novas moradias ou empreendimentos nas diferentes zonas. O modelo residencial é dividido em 
desenvolvimento de unidades habitacionais, dirigido pelos empreendedores imobiliários (oferta), e em escolha de localização de residências por parte da população (procura). Para o setor de trabalho, o processo de decisão sobre onde investir e construir empreendimentos é feito pelos próprios empreendedores, com base nas informações de acessibilidade decorrentes do modelo de transporte, que levam em consideração as forças de mercado dentro das zonas. Portanto, no MARS há um modelo simplificado que combina o desenvolvimento (oferta) com a localização (demanda). O resultado final de uma etapa de simulação do modelo de uso do solo é a previsão da população e a distribuição dos postos de trabalho.

\subsubsection{Submodelos de criação e localização de unidades habitacionais}

A Figura 6 mostra diagramas de circuitos causais para a criação de unidades habitacionais e para a escolha da localização por parte dos residentes. O circuito $\mathrm{H} 1$ é uma realimentação de equilibrio que mostra que a atratividade de uma determinada zona para o empreendedor é função da receita que ele poderá obter que, por sua vez, depende da demanda por habitação, que está relacionada com o número de habitações existentes e à evolução prevista no número de habitações. À medida que novas moradias são construídas, aumenta o estoque, o que reduz a demanda, com redução da receita e, portanto, da atratividade. 0 circuito H2 é de reforço, pois com novas residências há redução da demanda e, também, da receita e, consequentemente, do preço da terra, o que, por sua vez, torna o desenvolvimento da região mais atraente para o empreendedor, quando todos os outros elementos são iguais. O circuito H3 representa a limitação de terras disponíveis para ocupação, ou seja, com a redução de terras disponíveis há redução da atratividade. $O$ circuito $\mathrm{H} 4$ é em continuidade ao $\mathrm{H} 3$, representando o efeito da disponibilidade de terras no preço da terra.

Os circuitos de desenvolvimento das unidades habitacionais estão ligados à escolha dos locais de moradia. Em primeiro lugar, os principais elementos que influenciam a escolha da localização são as despesas com moradia, a acessibilidade e a qualidade da área (algo de difícil mensuração, que pode ser associado, por exemplo, à quantidade de área verde em um bairro, como em Viena, ou à renda média, como em Leeds) (PFAFFENBICHLER, EMBERGER, SHEPHERD, 2010). O circuito principal na escolha residencial é o M1, que é uma realimentação de equilíbrio, pois quanto mais pessoas se mudam para uma determinada região, maior é a demanda, maiores são as despesas com moradia, o que causa, portanto, redução de atratividade. O circuito M2 é, também, de equilíbrio, e mostra que, com o aumento do número de residentes, ocorre aumento de congestionamento, o que reduz a acessibilidade aos locais de trabalho e, consequentemente, a atratividade da região. 


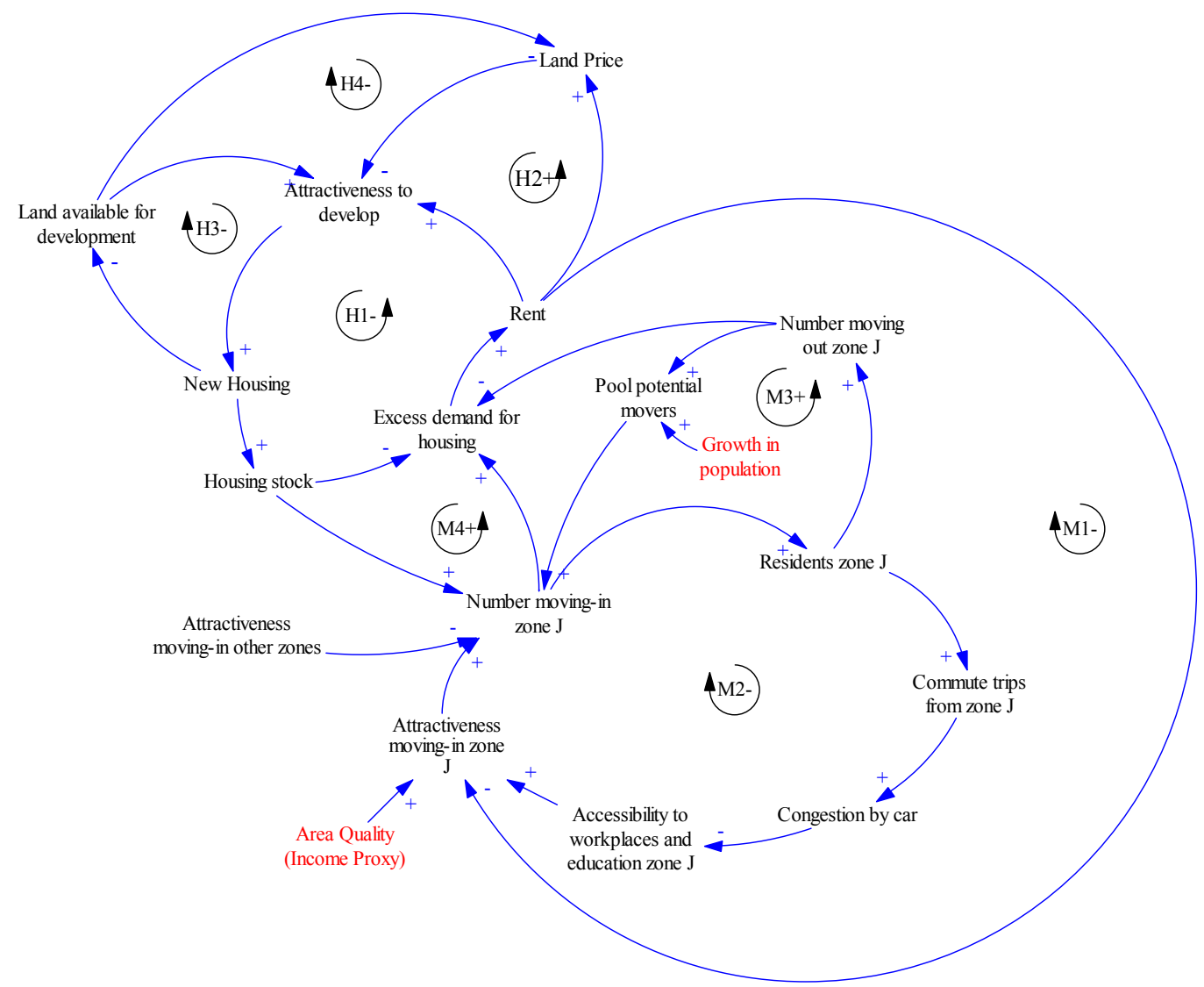

Figura 6 - Diagrama de circuitos causais para o desenvolvimento de unidades habitacionais.

O circuito M3 é uma realimentação positiva, que mostra simplesmente que o aumento do número de residentes em uma zona também aumenta o potencial de saída de residentes (10\% dos residentes por ano, por exemplo). Isso aumenta o leque de potenciais migrantes, que inclui também o crescimento da população. O circuito M4 também é uma realimentação positiva que estende o circuito $\mathrm{H} 1$, ou seja, com o aumento de residentes há aumento de demanda, que aumenta atratividade. Deve-se destacar que o estoque habitacional disponível pode limitar o número de pessoas que podem se mudar para uma determinada zona, sendo o excesso de demanda realocado para outras zonas (MAYERTHALER; HALLER; EMBERGER, 2009a; 2009b).

O circuito M3 é uma realimentação positiva, que mostra simplesmente que o aumento do número de residentes em uma zona também aumenta o potencial de saída de residentes (10\% dos residentes por ano, por exemplo). Isso aumenta o leque de potenciais migrantes, que inclui também o crescimento da população. O circuito M4 também é uma realimentação positiva que estende o circuito $\mathrm{H} 1$, ou seja, com o aumento de residentes há aumento de demanda, que aumenta atratividade. Deve-se destacar que o estoque habitacional disponível pode limitar o número de pessoas que podem se mudar para uma determinada 
zona, sendo o excesso de demanda realocado para outras zonas (MAYERTHALER; HALLER; EMBERGER, 2009a; 2009b).

\subsubsection{Submodelo de localização de postos de trabalho}

Há duas abordagens diferentes para a modelagem da localização de postos de trabalho. Inicialmente, novos empreendimentos são controlados por taxas de crescimento econômico exógenas, enquanto que a disponibilidade de terras utilizáveis, o preço da terra e a acessibilidade são utilizados por um modelo de transporte gravitacional (Modelo Logit) para distribuir os postos de trabalho entre as zonas individuais. Em segundo lugar, o MARS permite a previsão do encolhimento de certas zonas até a "morte" dos setores industriais, ou seja, considera parâmetros, estimados através de análises empíricas, que permitem ao modelo simular mudanças de zonas primordialmente industriais em zonas residenciais.

\subsection{Módulo de Composição da Frota e Emissão de Poluentes}

É usado para converter a quilometragem percorrida e a velocidade do veículo, calculadas no modelo de transporte do MARS, em emissões de poluentes atmosféricos, tais como $\mathrm{NO}_{\mathrm{x}}$, $\mathrm{CO}_{2}$ etc. Compreende as previsões de evolução da composição da frota para as diferentes regiões (Europa e Ásia, por exemplo), feitas a partir de modelos de alto nível, como o POLES e o ASTRA, que, respectivamente, simulam os mercados mundiais de energia e transportes para a União Européia (SHEPHERD et al., 2008), visando apresentar cenários de como os avanços tecnológicos podem afetar as emissões futuras de gases do efeito estufa.

\subsection{Módulo de Avaliação e Análise}

Vários indicadores são calculados, como, por exemplo, repartição por meio de transporte, distribuição da população, consumo de combustível, tempo médio de viagem por meio de transporte, economia de tempo de viagem, custos de acidentes, emissões de $\mathrm{CO}_{2}$ etc. Esses indicadores podem ser apresentados como valores globais ao longo do tempo (para cada ano) ou na forma de valores desagregados, por meio de transporte, por tipo de viagem e pelo período do dia (pico e fora de pico), visualizados em gráficos ou tabelas. É interessante apresentar os resultados aos decisores de forma espacial, através de mapas temáticos. Desta forma alguns resultados podem, também, ser exibidos em termos de evolução no espaço e no tempo, mediante o uso de uma ferramenta dinâmica de SIG (AniMap), desenvolvida especificamente para uso no MARS. 
O Animap é um programa computacional de SIG dinâmico, desenvolvido especificamente para uso com o MARS (EMBERGER; RIEDL, 2007). Séries temporais, como a distribuição de modos de transporte nas zonas, conforme modelado pelo MARS, são transmitidas automaticamente para o Animap, que permite a análise de um único cenário ou a comparação de diferentes cenários. A Figura 7 mostra um exemplo com o desenvolvimento da população em 30 anos na cidade de Leeds, Inglaterra, comparando um cenário com corredor de trólebus com a situação básica "não fazer nada". A representação no Animap facilita a visualização de como os moradores se mudaram, ao longo do tempo, para as zonas afetadas pelo corredor, que estão, agora, melhor servidas por transportes públicos.

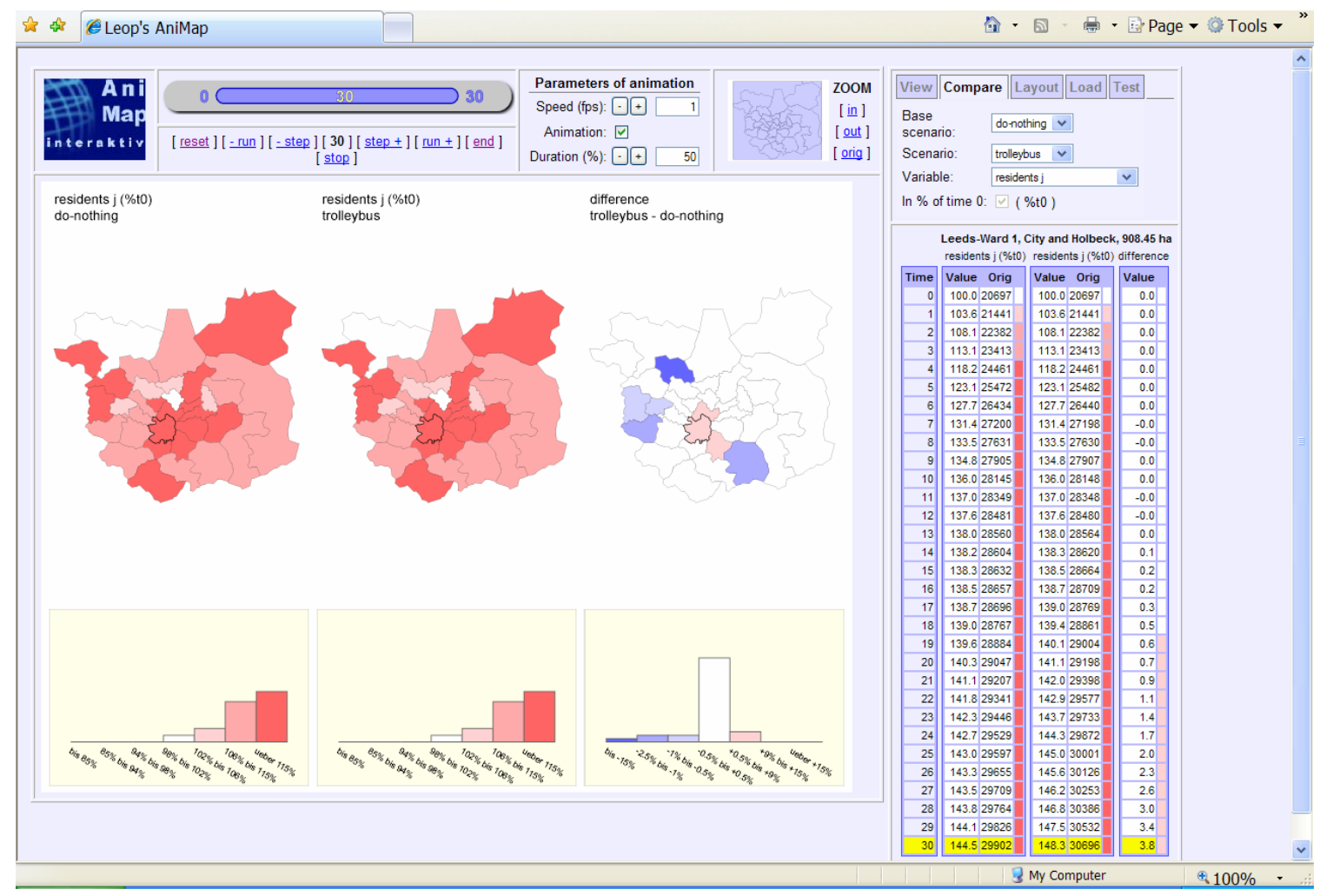

Figura 7 - Exemplo de apresentação dos resultados do MARS no AniMap: efeito do corredor de trólebus sobre a localização de residências em Leeds, Inglaterra. Fonte: Pfaffenbichler, Emberger e Shepherd (2010).

\subsection{Aplicações do Modelo MARS}

O desenvolvimento do sistema MARS, que foi primeiramente calibrado para a cidade de Viena, começou em 2000. Hoje é um modelo amplamente testado e vem sofrendo melhorias constantes a cada nova cidade onde é aplicado em estudos de desenvolvimento urbano sustentável. Atualmente, o MARS está sendo aplicado em 16 cidades da Europa e Ásia e está em fase de desenvolvimento nos Estados Unidos, na cidade de Washington, D.C. 
O MARS já foi aplicado em diferentes contextos urbanos, sendo que a maior dificuldade enfrentada foi em sua aplicação a cidades asiáticas, que são muito diferentes do contexto europeu. Os desafios dessa aplicação estavam relacionados à disponibilidade de dados, modos de transportes bem diferenciados e grandes diferenças no nível de moradias. Uma avaliação da possibilidade de transferência do MARS para cidades asiáticas é apresentada por Emberger, Pfaffenbichler e Jaensirisak (2005), mas a falta de dados históricos impediu uma investigação completa, conforme apresentado em detalhes por Pfaffenbichler (2008).

Antes da transferência do modelo MARS para uma cidade com diferentes características, costumes e infraestrutura de transportes, como Porto Alegre, uma cidade brasileira de grande porte, é importante conhecer outras experiências e que tipo de adequações foram realizadas. Pfaffenbichler (2008), a esse respeito, destaca que a transferência dos modelos de uso do solo e transporte do MARS deve ser precedida por estudos de experiências realizadas em outras cidades, comparando-se os resultados do modelo com os dados observados, por um longo período de tempo, o que, até o momento, só foi realizado para a cidade de Viena. Pfaffenbichler, Emberguer e Sepherd (2010) apresentam conceitos relacionados à validação e a transferência do MARS para outras cidades e discutem alguns exemplos de aplicação.

\subsubsection{MARS VIENA}

O modelo original MARS, ajustado inicialmente para a cidade de Viena, utiliza os 23 distritos administrativos municipais como zonas de análise. Contando, na época do desenvolvimento do modelo, com muitos dados demográficos, socioeconômicos e de viagens a trabalho dos Censos de 1981, 1991 e alguns do Censo de 2001, foi ajustado um modelo baseado em dados de 1981, o qual o autor denominou de MARS81 (PFAFFENBICHLER, 2003; PFAFFENBICHLER, 2008), cujo processo está esquematizado na Figura 8.

Foi, primeiramente, realizada a calibração transversal ("cross sectional") dos submodelos de transportes para a divisão modal observada em 1981. Esse procedimento foi seguido da calibração dos submodelos de uso do solo para as mudanças ocorridas no período de 1981 a 1991 na população, no número de unidades habitacionais e nos postos de trabalho de Viena. Posteriormente o MARS81 foi utilizado para validar a capacidade do modelo de estimar mudanças: no sistema de transportes, no período de 1981 a 1991; no número de unidades habitacionais, de 1991 a 1998; e na população, de 1991 a 2001.

Na sequência (Figura 9), foi ajustado um modelo baseado em dados da cidade de Viena em 1991 (MARS91). Os submodelos de transportes foram, então, ligeiramente recalibrados 
para a divisão modal observada em 1991. Os submodelos de uso do solo foram recalibrados para o desenvolvimento de unidades habitacionais entre 1991 e 1998 e o desenvolvimento populacional ocorrido entre 1991 e 2001. Os dados do Censo de 2001 relativos a postos de trabalho e viagens por motivo de trabalho ainda não estavam disponíveis.

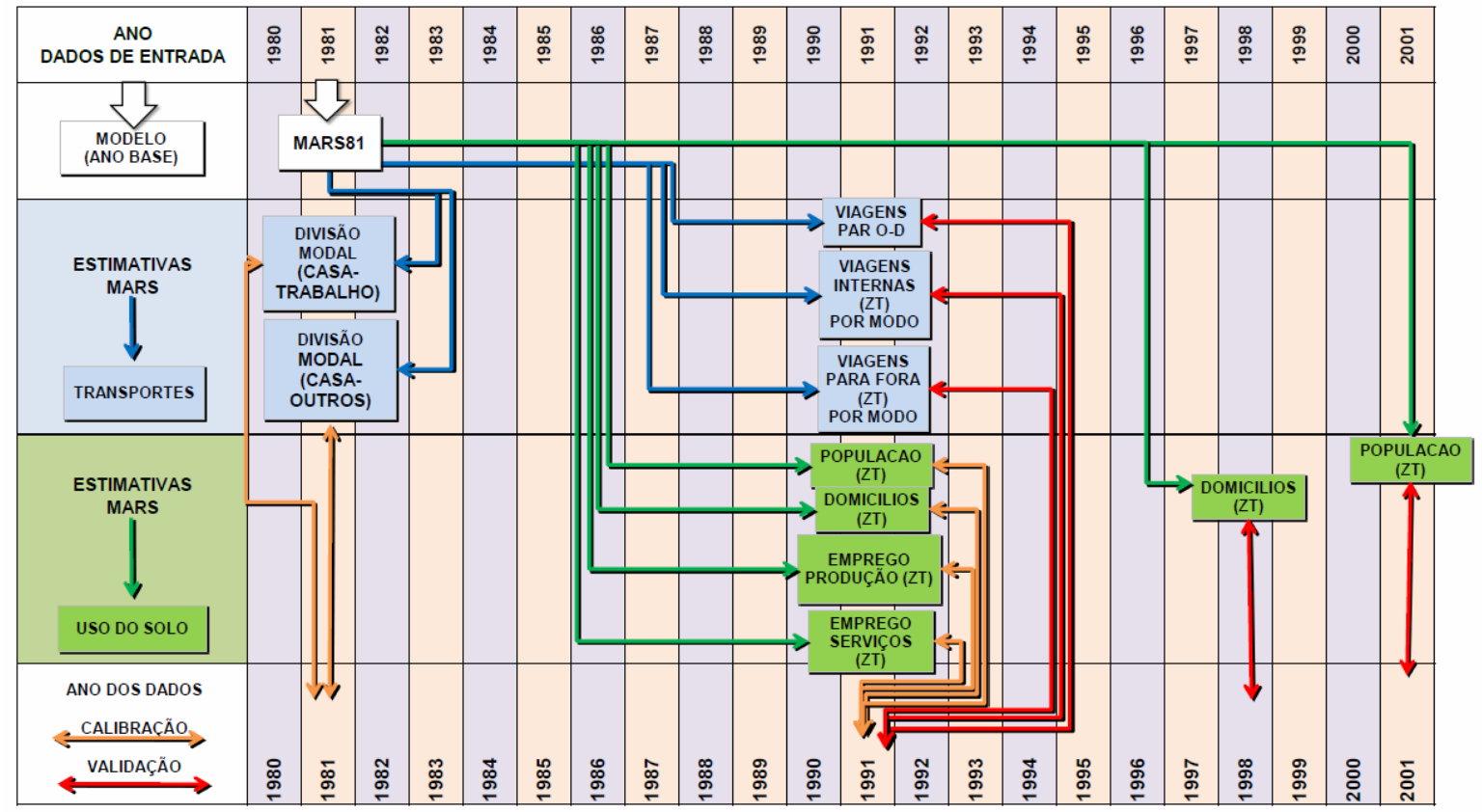

Figura 8 - Esquema do processo de ajuste do MARS81 para a cidade de Viena.

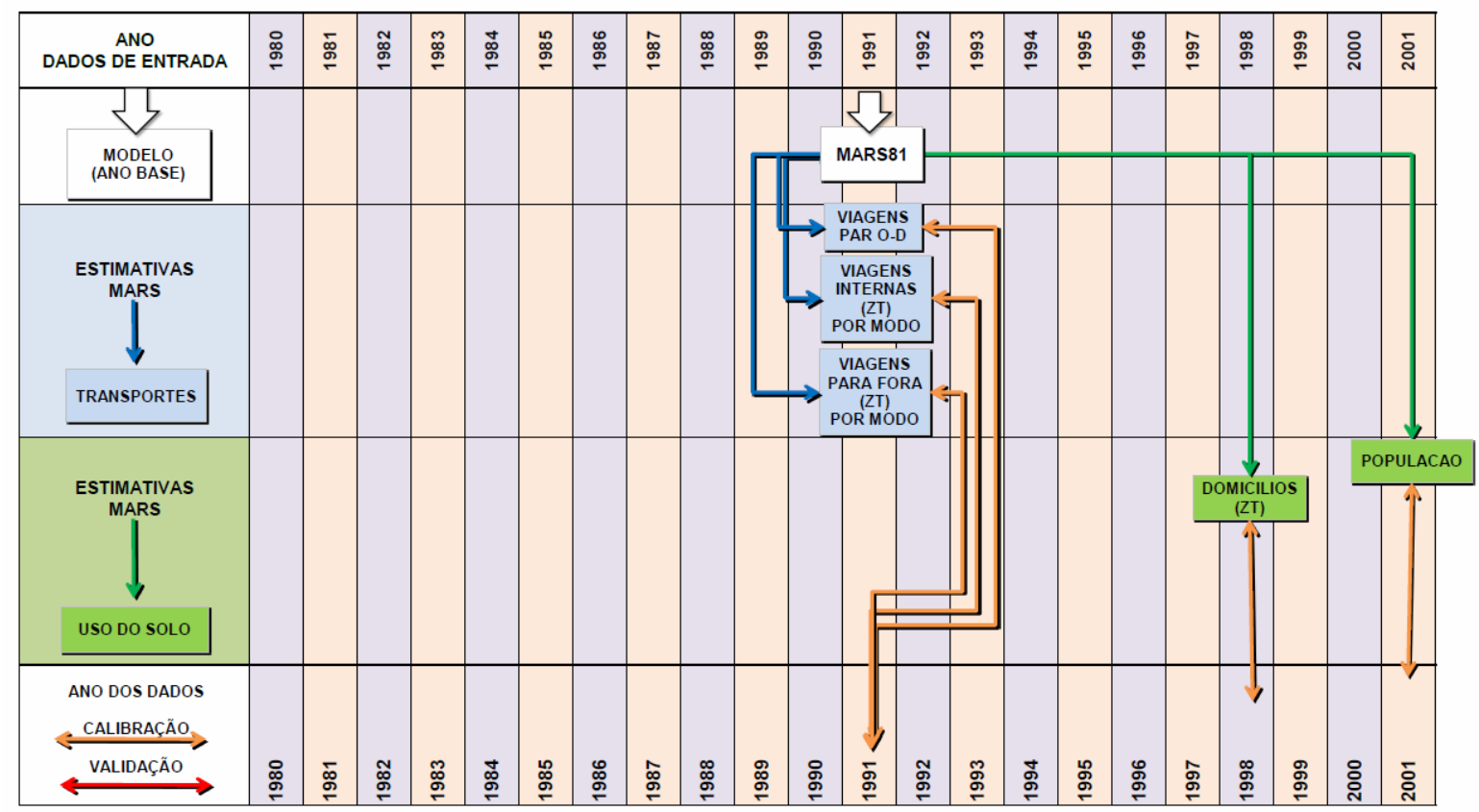

Figura 9 - Esquema do processo de ajuste do MARS91 para a cidade de Viena.

Para aplicação do MARS Viena em estudos para avaliação de políticas de mobilidade foi ajustado um modelo com ano-base 2001. Quanto às tendências demográficas e socioeconômicas regionais, entre 1991 e 2001, houve um crescimento significativo da 
população nos arredores de Viena, enquanto que na cidade de Viena a população ficou estagnada. Por outro lado, o produto interno bruto regional de Viena e dos arredores ao sul está acima da média da União Européia, enquanto que os arredores ao norte apresentam PIB regional abaixo da média européia.

Segundo Pfaffenbichler $(2003,2008)$ os Planos de Desenvolvimento Urbano e de Tráfego, desenvolvidos para a cidade em 1994, definiam políticas e medidas de planejamento urbano e de transportes com objetivo de redução dos impactos do tráfego sobre o ambiente e a saúde, aumento de segurança no trânsito e de redistribuição do espaço urbano para pedestres e ciclistas. Para atingir estes objetivos era necessário adotar medidas para a redução da expansão urbana e dos volumes de tráfego e intensificar o uso de transporte público e dos modos lentos, ou slow modes (pedestres e bicicleta).

Os impactos dos projetos de transportes previstos no plano e dos já em andamento, foram estimados utilizando o modelo MARS Viena 2001 e os resultados foram comparados com os objetivos da cidade de Viena. Foi, então, avaliado se os projetos contribuíram ou não, para que os objetivos fossem atingidos. Além disto, o estudo de caso avaliou a possibilidade de atingir os objetivos oficiais de Viena e, no caso positivo, quais medidas seriam necessárias. Detalhes do estudo de caso e dos resultados obtidos podem ser verificados em Pfaffenbichler $(2003,2008)$.

No projeto PROSPECTS (Procedures for Recommending Optimal Sustainable Planning of European City Transport Systems) um conjunto comum de política com foco em tarifas e frequência de transportes públicos (pico e entrepico) e de preços de combustíveis para veículos particulares foi testado para Viena e outras cinco cidades européias (Edimburgo, Helsinque, Madri, Oslo, Estocolmo) com o uso do MARS. Outros instrumentos, como investimentos em infraestrutura, taxas de circulação (pedágios) e de estacionamento foram analisados, somente, em algumas das cidades (PFAFFENBICHLER; EMBERGER, 2003).

Outro exemplo de aplicação do MARS Viena é o apresentado por Guzmán Garcia et al. (2008), onde políticas de taxação de combustível e de eficiência tecnologia foram testadas. O estudo procura explorar os impactos da implementação destas políticas, em longo prazo, não apenas nas emissões de $\mathrm{CO}_{2}$, mas também no desenvolvimento urbano e nos padrões de mobilidade. A fim de comparar os resultados obtidos, três áreas urbanas foram estudas com o uso do MARS: Leeds, Viena e Madrid.

Conforme destacam os pesquisadores, um dos grandes desafios no desenvolvimento do modelo é a disponibilidade de dados. Para o projeto PROSPECTS, por exemplo, como dados do ano de 2001 não estavam disponíveis para todos os parâmetros, os dados mais atuais disponíveis foram usados em seu lugar. Ainda que a situação em Viena seja 
considerada como muito favorável, no estudo apresentado por Guzmán Garcia et al. (2008), devido à indisponibilidade de alguns dados, o modelo de transportes foi calibrado para se ajustar à repartição modal agregada e aos dados de viagens pendulares do censo de 2001 .

\subsubsection{MARS MADRI}

A Região Metropolitana de Madri é o maior conglomerado urbano da Espanha e o terceiro da Europa, depois de Londres e Paris. A preocupação com a mobilidade cresce continuamente, pois o número de viagens em um dia de trabalho já era superior a 14 milhões em 2001, com um aumento de 40\% em relação a 1996. A explicação é que, além do crescimento da população, houve aumento de $20 \%$ no número de viagens por pessoa, passando de 2,16 viagens por dia, em 1996, para 2,60 viagens por dia, em 2004 (PFAFFENBICHLER, 2008).

A importância da região central de Madri tem decrescido em relação às suas áreas periféricas, fenômeno característico da expansão urbana. Assim, na segunda metade do Século XX a população de Madri dobrou, mas a população na periferia cresceu 26 vezes, num processo de suburbanização que aumenta a dependência do automóvel particular.

A região de Madri ("Comunidad de Madrid") está situada no centro da Espanha, cobre aproximadamente $8.000 \mathrm{~km}^{2}$ e tem uma população de aproximadamente 5,4 milhões de habitantes. Está caracterizada por um rápido desenvolvimento de moradias e de negócios nos seus arredores, sendo o tráfego dominado pelo elevado número de viagens pendulares para o centro da cidade.

Embora Madri tenha um sistema de metrô eficiente e 55\% das viagens pendulares sejam por transporte público, os níveis de congestionamento na hora-pico são elevados, pois as viagens de carro são mais numerosas durante o período de pico do que no restante do dia. O sistema de transporte público por ônibus é, por essa razão, pouco atrativo.

Uma das medidas para mitigar os problemas de congestionamento foi a implantação de um corredor para ônibus e veículos com alta taxa de ocupação (HOV - High Occupancy Vehicles) no trecho norte da Rodovia A6, numa extensão de $12,3 \mathrm{~km}$ com duas faixas reversíveis e $3,8 \mathrm{~km}$ com uma única faixa para conexão com Moncloa. O sistema, que custou 3,3 milhões de euros por quilômetro, tem três pontos de acesso/saída, operando da seguinte forma:

- Acesso apenas de ônibus e veículos com alta taxa de ocupação:

○ para Madri: das 6:00 às 12:30, de segunda-feira a sexta-feira;

○ de Madri: das 13:30 às 22:00, de segunda-feira a sexta-feira; 
- Acesso sem restrições nos finais de semana e feriados.

Anteriormente à implantação do corredor, a situação da rodovia A6 era problemática, com muitos congestionamentos. Porém, houve melhoria significativa, tanto que a maior confiabilidade dos serviços de ônibus suburbanos fez com que houvesse aumento substancial de viagens, passando de $24 \%$ do total, em 1991, para 36\% em 2001.

A calibração do MARS-Madri foi da forma convencional, já detalhada para o MARS-Viena. 0 submodelo de transportes foi calibrado com os dados da pesquisa domiciliar de 1996 (Tabela 4), procurando-se ajustar as matrizes O-D de viagens casa-trabalho (total), por automóvel, transporte público e modo lento (a pé e bicicletas), durante o pico da manhã e também num período de 24 horas.

Tabela 4 - Divisão modal em Madri obtida em pesquisa domiciliar realizada em 1996.

\begin{tabular}{lccc}
\hline \multicolumn{1}{c}{ Período } & Lento & Transporte Público & Automóvel \\
\hline Pico da Manhã (7:00 - 9:00) & $26,7 \%$ & $37,7 \%$ & $35,6 \%$ \\
Total (24 horas) & $36,8 \%$ & $34,0 \%$ & $29,2 \%$ \\
\hline
\end{tabular}

Os submodelos de uso do solo foram calibrados para se ajustar às mudanças de moradias, número de residentes e postos de trabalho por setor econômico, entre 1996 e 2001. Não houve teste extensivo do modelo MARS-Madri. Os efeitos medidos do corredor de ônibus sobre a rodovia A6 foram comparados com os resultados previstos, em termos de mudanças na participação do transporte público na divisão modal (PFAFFENBICHLER, 2008).

\subsubsection{MARS HANÓI}

O MARS-Hanói foi desenvolvido dentro de um projeto de pesquisa, denominado SPARKLE ("Sustainability Planning for Asian cities making use of Research, Know-how and Lessons from Europe"), financiado pela União Européia. O objetivo principal do SPARKLE era testar a capacidade de transferência de princípios e métodos de planejamento europeus (o modelo MARS, inclusive) às condições do sudeste asiático (PFAFFENBICHLER, 2008; EMBERGER; PFAFFENBICHLER; JAENSIRISAK, 2005).

As diferenças entre Ásia e Europa são muito relevantes para a modelagem de transportes e uso do solo. Em razão da alta porcentagem de pessoas abaixo da linha de pobreza, as escolhas do modo de transporte e da localização de moradias e do local de trabalho são muito mais restritas na Ásia do que na Europa. Além disso, o sistema de transportes nas cidades asiáticas é muito heterogêneo, ou seja, diferentes meios de transporte compartilham 
o mesmo espaço viário (pedestres, bicicletas, motocicletas, "tuk-tuk", automóveis, ônibus etc.). As elevadas diferenças de velocidade nesse sistema de transportes heterogêneo resultam em graves problemas de segurança.

O MARS-Hanói cobriu uma área de $920 \mathrm{~km}^{2}$, subdividida em 14 zonas, com 3,1 milhões de habitantes. O número de proprietários de carro é ainda muito baixo, mas a taxa de motorização combinada (carro e motocicleta) atinge níveis tão altos quando os da Europa. Consequentemente, o modo motocicloviário foi considerado um modo de transporte independente.

A disponibilidade de dados é um problema até mesmo na Europa, mas é, obviamente, um problema ainda maior no sudeste asiático. Nenhum dado detalhado estava disponível para a calibração do MARS-Hanói, tendo-se que estimar parâmetros específicos para a obtenção de valores plausíveis de divisão modal.

Nenhum teste formal do modelo MARS-Hanói foi efetuado. Porém, o "flight simulator" do MARS foi testado em seminários de trabalho, em Ho Chi Minh City, Danang e Hanói, cada um com a participação de 20 a 30 especialistas do ministério, de municípios e de universidades, que tiveram a oportunidade de usar o "flight simulator" sozinhos no último dos três dias de trabalho.

\subsubsection{MARS LEEDS}

A população total na área de estudo no ano de 2001 era de 728.000 pessoas, assumindo-se uma taxa de crescimento de 0,28\% a.a. nos próximos 30 anos. Estima-se, assim, um aumento total de $8,75 \%$ no período (mais 64.000 habitantes). O número de postos de trabalho, no mesmo período, terá um crescimento esperado de $27 \%$, enquanto que a propriedade de automóvel deverá crescer $0,50 \%$ a.a., com um aumento total de $16 \%$.

Os dados para a calibração do modelo MARS-Leeds foram adaptados de diferentes fontes, todas recentes. As viagens pendulares ao trabalho foram calibradas considerando-se $20 \%$ nos modos lentos, $28 \%$ nos transportes públicos e $52 \%$ em automóveis particulares, assumindo-se que não houve alteração de 2000 a 2005. As viagens realizadas por motivos não relacionados ao trabalho foram assim distribuídas: $25 \%$ nos modos lentos, $22 \%$ nos transportes públicos e $53 \%$ em veículos particulares.

Outros dados utilizados para a calibração foram obtidos do Plano de Desenvolvimento de Leeds e do Manual Econômico de Leeds, de 2002, num processo que consistiu no ajuste dos resultados do MARS-Leeds com a evolução prevista para os primeiros cinco anos, em vez de calibração com o desenvolvimento ocorrido num dado período (por exemplo, de 1991 a 2001) (GUZMÁN GARCIA et al., 2008). 
Outros detalhes da aplicação do MARS Leeds são apresentados por Pfaffenbichler, Emberguer e Shepherd (2010), destacando o MARS como uma ferramenta flexível, podendo ser utilizada não só na análise de cenários, como na otimização de políticas e para treinamento de tomadores de decisão. Os autores apresentam um exemplo de aplicação dos instrumentos de calibração, que permitem a avaliação de sensibilidade dos parâmetros, e o melhor ajuste dos submodelos às características locais, facilitando, desta forma, a transferência do MARS para outras cidades.

Um desenvolvimento recente de ligação entre o MARS e o modelo de alocação de tráfego SATURN (VAN VLIET, 2010) é, também, apresentado através de uma aplicação para a cidade de LEEDS (SHEPHERD et al., 2010, KOH; SHEPERD, 2009, PFAFFENBICHLER; EMBERGUER; SHEPHERD, 2010). Com esta conexão é possível compatibilizar os tempos de viagem entre cada par O-D e as funções custo/oferta do MARS com um modelo de rede mais detalhado.

\subsubsection{MARS EDIMBURGO}

O modelo MARS foi aplicado para a cidade de Edimburgo, Escócia, no contexto do projeto STEPs (2006), sendo apresentado como um modelo estratégico de interação do uso do solo e transportes, em que indicadores de acessibilidade são calculados a partir dos efeitos dos transportes sobre a localização dos postos de trabalho e das residências, enquanto que o uso do solo fornece as origens e destinos para os modelos de transportes.

Várias ferramentas de modelagem são utilizadas no projeto, com a finalidade de simular cenários de transportes e de fornecimento de energia e para obter respostas quantitativas sobre os efeitos de tais cenários. O MARS-Edimburgo considerou a cidade de Edimburgo e a região de Lothian, num total de 25 zonas, que tinham, em 2001, uma população de 1.070 .000 habitantes.

O modelo MARS-Edimburgo foi baseado no Plano Diretor de Uso do Solo (Edinburgh and Lothian Structure Plan), desenvolvido em 2000, e que forneceu uma descrição e a evolução de diversas características da região. Em termos populacionais, a previsão é de que a região de Lothian tenha o maior crescimento populacional na Escócia, com um aumento de 50.000 pessoas no período 2001-2015, em que o número de moradias poderá aumentar em 52.000 , sendo $37 \%$ do total habitadas por pessoas solteiras. O Plano mostrou, ainda, um aumento significativo de pessoas idosas, com $43 \%$ da população com mais de 45 anos em 2015 , comparado a $37 \%$ em 2000 , e que o número de pessoas com idade superior a 85 anos deve aumentar em $25 \%$. 
A economia tem tido um rápido crescimento, sendo a taxa atual de desemprego na região de Lothian de 3,5\%, a mais baixa já registrada. Está previsto, até 2015, um crescimento de 30.000 postos de trabalho, com aumento de $7 \%$ na produção industrial na parte oeste de Lothian, e geração de novos empregos nos setores financeiros, de varejo e de serviços.

Quanto aos transportes, a propriedade de automóveis aumentou 50\% em Edimburgo desde 1991, quando $46 \%$ das famílias de Lothian não possuíam um carro. Para 2015, a previsão é de que as viagens pendulares da região de Lothian para Edimburgo subirão a 100.000, ante as atuais 88.000 , e que 42.000 entrarão na cidade diariamente em viagens de trabalho.

Em resposta a essas tendências e previsões, a cidade de Edimburgo tem trabalhado com as autoridades das localidades em seu entorno para elaborar planos de transporte, considerando, principalmente, a inclusão de linhas de veículos leves sobre trilhos (VLT).

No modelo MARS Edimburgo o ano-base é 2001. Dois grupos de pessoas, com e sem acesso a carro, são considerados, havendo, também, subdivisão entre viagens pendulares e não-pendulares. São incluídas as viagens por meios não-motorizados e o modelo de geração de viagens utiliza o conceito de orçamento para tempo de viagem constante. $O$ período entre picos é considerado não congestionado.

O modelo de uso do solo considera as preferências por localização residencial e de trabalho com base na acessibilidade, na disponibilidade de terra, na renda média e na quantidade de área verde disponível nas 25 zonas. O crescimento da população total na área de estudo, bem como as mudanças de local de trabalho, são adotados de forma exógena, com o modelo MARS-Edimburgo determinando a localização e os padrões de mobilidade.

Na solução de referência do MARS-Edimburgo, assume-se que a população crescerá a uma taxa de $0,606 \%$ a.a., nos próximos 25 anos, e a uma taxa de 0,2\% a.a. até completar os 30 anos do período de análise, com um aumento total de $17,5 \%$, ou seja, com um adicional de 187.000 moradores.

Também com base no Plano Diretor de Uso do Solo, a previsão é de que haja um crescimento de $24 \%$ nos postos de trabalho. A taxa média de propriedade de automóveis, atualmente, é de 370 carros por 1.000 habitantes, prevendo-se um crescimento de 1,2\% a.a. No cenário de referência, a frota de veículos é composta por carros médios, com consumo de combustível calculado em função da velocidade média ao quadrado e da proporção de carros a diesel no total da frota.

\subsubsection{MARS BARI}

Os dados utilizados foram obtidos de fontes oficiais (Câmara Municipal de Bari, Governo Regional, escritórios locais do Automóvel Clube da Itália e da Agência de Planejamento 
Metropolitano de Planejamento da região de Bari), embora alguns dados adicionais, como, por exemplo, o custo do terreno e os valores de aluguel, para as diferentes zonas de Bari, tenham sido conseguidos junto a especialistas, pois não há estatísticas oficiais na Itália e as empresas imobiliárias são muito reservadas na divulgação de seus dados (CIRCELLA, 2008).

O MARS-Bari foi desenvolvido para a região metropolitana de Bari, Itália, que tem uma população de quase 1,5 milhões de habitantes (400.000 na cidade principal). O sistema de zoneamento inclui 54 zonas, urbanas e suburbanas, considerando cinco diferentes modos de transporte: carro, moto (que representa quase 10\% das viagens no centro de Bari), ônibus, transporte ferroviário e modo lento (pedestres e ciclistas).

O modelo de transportes do MARS-Bari foi desenvolvido à semelhança de outras aplicações do MARS, mas com a adição do modo motocicleta. Assim, foi desenvolvida a função "acesso a motocicleta", que representa a disponibilidade do modo moto para os usuários. A disponibilidade total de modos de transporte variou de três (para os não-condutores) a quatro (ou não usuário de carro ou não usuário de motocicleta) ou cinco (todos os modos).

Dados de localização de moradias e de atividades de transportes, relativos a 2005/2006, foram usados para ajustar os parâmetros do modelo e calibrar submodelos específicos do MARS-Bari. Foram utilizados dados do Censo de 2001 e dados adicionais publicados pelo Instituto Italiano de Estatística (ISTAT), referentes a 2005 e 2006 (localização de moradias e de atividades econômicas). Os dados de transporte foram obtidos com o Governo Regional (2001 e 2005/2006) e com a Agência de Planejamento Metropolitano (2007/2008).

\subsubsection{MARS WASHINGTON, D.C.}

O MARS-Washington ainda não chegou às fases de calibração e validação, embora já tenha sido constatada a falta de dados de períodos anteriores, havendo apenas dados associados a cinco cenários que o órgão de planejamento local simulou utilizando um modelo de previsão tradicional ("modelo de quatro etapas"). A intenção é, portanto, calibrar o modelo MARS-Washington para um dos cenários e, em seguida, validá-lo com alguns dos outros cenários (HARDY, 2009).

Os dados disponíveis são dos anos de 2003 a 2007, sendo intenção, também, verificar se dados imediatamente disponíveis (por exemplo, Google, Censo Norte-Americano e sites imobiliários, como www.zillow.com) podem ser usado para alimentar o modelo MARS e permitir a obtenção de resultados aceitáveis. Para tanto, foi crido um algoritmo (Figura 10) que usa dados de velocidade disponíveis na internet (Google Maps) para estimar as velocidades de fluxo livre e nos períodos de pico. Grande parte dos dados econômicos veio 
do censo dos EUA, enquanto que os dados relativos a viagens de transporte público estavam prontamente disponíveis no Google Transit. Os valores dos imóveis também foram calculados a partir de dados obtidos na internet (www.zillow.com).

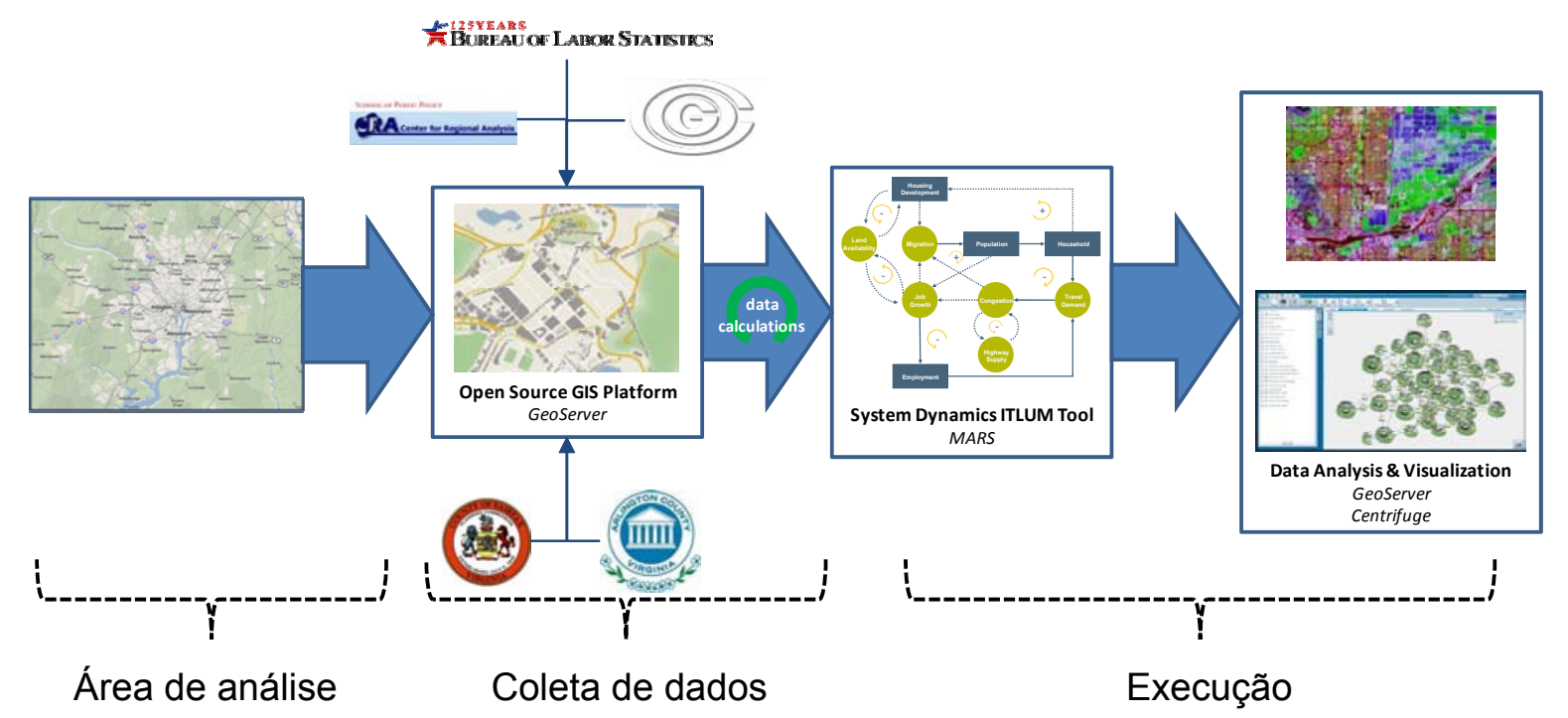

Figura 10 - Esquema do desenvolvimento do MARS-Washington, D.C. Fonte: Hardy, 2009

O foco do MARS-Washington é testar e, se possível, contribuir para a viabilização do uso de ferramentas de modelagem mais simples e que utilizem dados prontamente disponíveis para alimentar os modelos de uso do solo e transportes, utilizados no processo de tomada de decisão.

O desenvolvimento do MARS-Washington procura responder à seguinte pergunta: quais as possibilidades e limitações do uso de um sistema de modelagem dinâmica, em relação à abordagem convencional, para dar suporte ao planejamento metropolitano?

O método de trabalho considera estudo de caso e técnica de Delfos (painel de especialistas). O estudo de caso modelará Washington, D.C. com uso de ferramentas de análise dinâmica de sistemas, permitindo que diferentes cenários, anteriormente identificados e avaliados pelo Conselho de Governo de Washington com uso de modelo de planejamento regional convencional, sejam comparados com os resultados do MARSWashington. A técnica de Delfos, aplicada mediante entrevistas com especialistas, testará a hipótese de que modelagem dinâmica de sistemas melhora o processo de planejamento, fornecendo maior suporte ao desenvolvimento de políticas públicas.

Os resultados do MARS-Washington, se positivos, poderão servir para a aplicação do modelo MARS em outras regiões dos EUA, em virtude da abordagem mais simples e por utilizar dados prontamente disponíveis na internet. 


\subsubsection{MARS ÁUSTRIA}

A área de estudo do MARS-Áustria compreende todo o território nacional, com 120 zonas, baseadas na subdivisão distrital da Áustria e que incluem os 23 distritos municipais de Viena. Uma vantagem de se adotar a estrutura distrital é que inclui cidades que têm seu próprio estatuto, ou seja, são administrativamente separadas do seu distrito central. Dessa forma, pode-se representar de maneira mais adequada as interações centro-periferia, como os fluxos pendulares e a expansão urbana. Além disso, para muitos fatores o nível distrital é o nível mais detalhado de disponibilidade de informação (MAYERTALLER; HALLER; EMBERGER, 2009a, 2009b).

As zonas do modelo são muito heterogêneas (Tabela 5), compreendendo áreas altamente urbanizadas, áreas com predominância do setor de serviços, que geram muitas viagens pendulares, áreas esparsamente povoadas, voltadas à produção agrícola, e regiões montanhosas influenciadas pelo turismo, onde há concentração populacional pelas limitações impostas pelos vales alpinos. Consequentemente, a diversidade é muito maior do que a encontrada em modelos usuais de aglomerados urbanos.

Tabela 5 - Estatística Descritiva da Área do Estudo de Caso na Áustria.

\begin{tabular}{lcccc}
\hline Indicador & População & $\begin{array}{c}\text { Densidade } \\
\left.\text { População [hab./km }{ }^{2}\right]\end{array}$ & $\begin{array}{c}\text { Total de Postos } \\
\text { Trabalho }\end{array}$ & $\begin{array}{c}\text { Empregos Setor } \\
\text { Serviços [\%)] }\end{array}$ \\
\hline \hline Total & 7.795 .786 & - & $2,933,438$ & - \\
\hline Mínimo & 1.696 & 20 & 522 & 41 \\
\hline Máximo & 237.810 & 25.345 & 145,137 & 91 \\
\hline Média & 64.428 & 93 & 24,243 & 64 \\
\hline Indicador & $\begin{array}{c}\text { Área Total } \\
{\left[\mathrm{km}^{2}\right]}\end{array}$ & $\begin{array}{c}\text { Área Não Desenvolvida } \\
{[\% \text { do total] }}\end{array}$ & $\begin{array}{c}\text { Preço da Terra } \\
\left(\text { EUR/m }{ }^{2}\right)\end{array}$ & $\begin{array}{c}\text { Aluguel de Moradia } \\
\left(\mathrm{EUR} / \mathrm{m}^{2} / \mathrm{mês}^{2}\right)\end{array}$ \\
\hline Total & 83.859 & - & - & - \\
\hline Mínimo & 1 & 7 & 14 & 1,63 \\
\hline Máximo & 3.270 & 98 & 577 & 4,02 \\
\hline Média & 693 & 89 & 204 & 2,60 \\
\hline
\end{tabular}

O MARS-Áustria apresenta estrutura policêntrica (Figura 11), em que Viena, as capitais provinciais e outros centros regionais constituem áreas de atração de viagens pendulares (EMBERGER; MAYERTALLER; HALLER, 2010). O modelo da Áustria foi calibrado com dados de 2001, ano de início de todas as simulações. Com a falta de alguns dados, especialistas foram consultados, particularmente para estimar dados para o modelo de transportes, como o tempo de busca de local para estacionamento e o valor das taxas de estacionamento. 


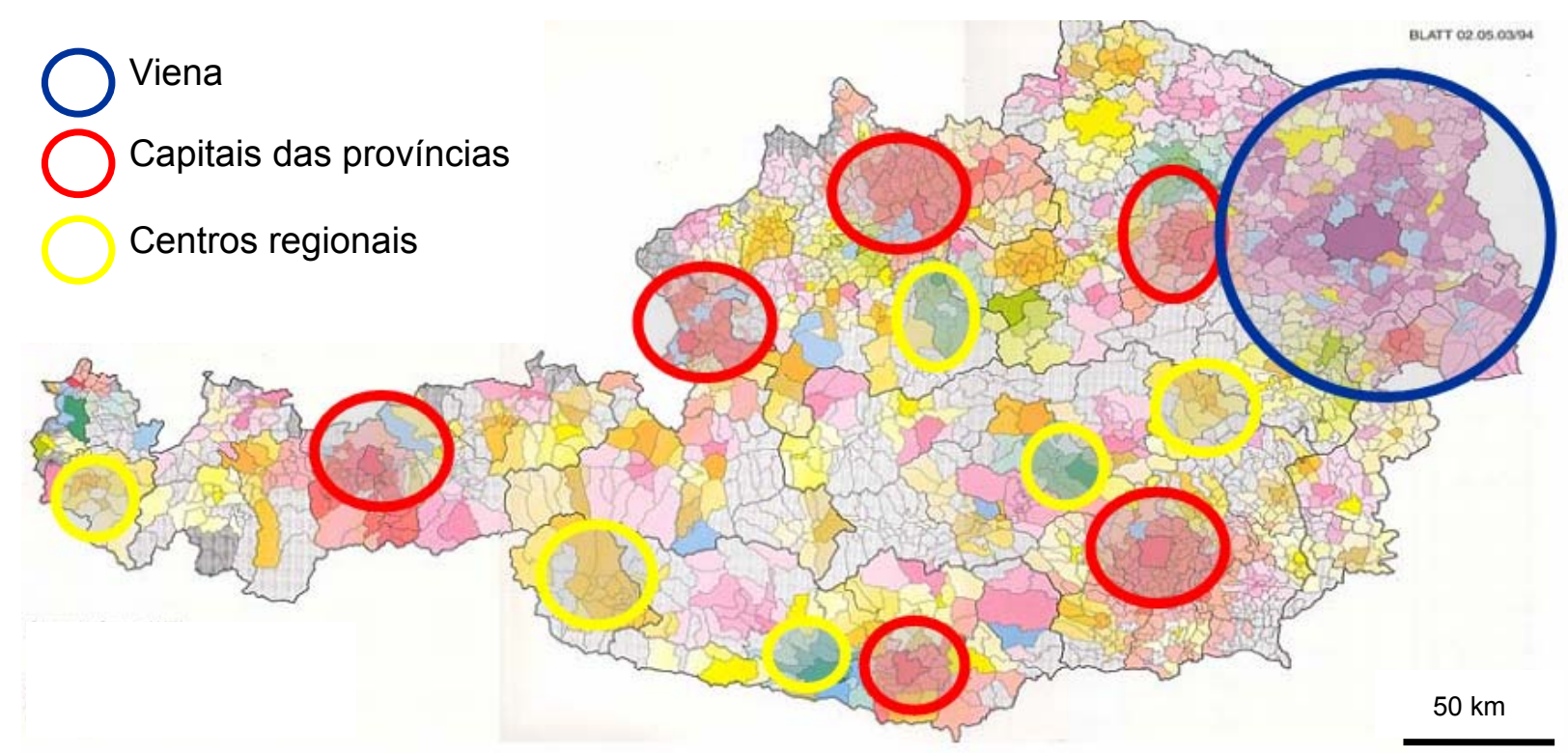

Figura 11 - Estrutura policêntrica do MARS-Áustria, representando áreas de atração de viagens pendulares

Fonte: Emberger, Mayertaller e Haller (2010).

\subsection{Considerações Finais}

O MARS é um modelo complexo de interação de uso do solo e transportes, totalmente implementado no VENSIM, que pode ser usado para estudos de caso, otimização de políticas e atividades de ensino. Apesar da complexidade de suas análises, é amigável e de fácil entendimento, mesmo para os inexperientes.

O MARS foi desenvolvido durante um período de mais de dez anos e foi calibrado com dados empíricos, contendo parâmetros de escolha do modo de transporte que são transferíveis a outras cidades, ao menos na Europa. A estrutura do modelo pode ser facilmente adaptada para atender às necessidades de uma determinada cidade e, como foi desenvolvido para Leeds, a ferramenta de calibração direta do VENSIM mostrou-se útil na determinação dos coeficientes de uso do solo para escolha do local de moradia. A simulação da interação de políticas de transporte e de uso do solo ao longo de um período de 30 anos, em combinação com o SIG dinâmico AniMap, permite ao usuário avaliar visualmente a evolução espacial e, assim, ter uma melhor compreensão dos processos envolvidos.

Como esperado, com a disseminação de seu uso, o MARS tem sido submetido a um processo de ampliação, mediante adição de grupos domiciliares, finalidades de viagem e meios de transporte, e de aprofundamento, com consideração de menores zonas. Mas, ao mesmo tempo, tem sido mantida a preocupação em se evitar problemas relacionados com o excesso de detalhes, que exigiriam a mineração de dados para a criação de um modelo, um 
maior tempo de execução das simulações e, ao final, resultariam em um volume de dados exagerado. Além disso, tem sido demonstrado que o nível típico de análise do MARS já apresenta muito bons resultados em termos de validação estatística, quando comparado com abordagens mais detalhadas.

O MARS é uma ferramenta útil, que permite aos planejadores facilmente testar e identificar os impactos de diferentes combinações de instrumentos de política, aprendendo como os elementos estão interrelacionados, identificar sinergias e contradições e entender como os efeitos dos lapsos de tempo atuam sobre sistemas tão complexos como o transporte e o uso do solo. Pode ser utilizado como um modelo estratégico, útil para as análises iniciais de alternativas, com as vantagens de rapidez de ajustes e de tempo de execução, além da apresentação automática dos resultados com o AniMap. É, portanto, um complemento e não um substituto para os modelos mais detalhados, podendo, ao contrário desses, fornecer respostas rápidas. 


\section{ESTATÍSTICA ESPACIAL EM ANÁLISES URBANAS E DE TRANSPORTES}

O uso de computação para modelagem e simulação na análise de sistemas urbanos já ostenta uma longa história. A influência do computador nesta área se deu de forma direta e indireta uma vez que a computação digital tornou possível, também, o aprimoramento dos métodos estatísticos e outros utilizados em pesquisa (por exemplo, programação matemática). Conforme destacam Páez e Scott (2004), a história da análise urbana é, portanto, entrelaçada com a do computador, por um lado, e com o desenvolvimento de métodos estatísticos e matemáticos, de outro. A adoção de sistemas de informação geográfica (SIG) é um exemplo recente da tradição da análise urbana de incorporar com rapidez o desenvolvimento tecnológico. No entanto os autores salientam que não foi o mesmo caso com novos métodos de análise espacial - em particular, a estatística espacial.

Só recentemente essa situação começou a mudar. Muitos pesquisadores destacaram a importância de considerar os efeitos espaciais na análise urbana e transporte. Páez e Scott (2004) fazem uma revisão de técnicas e exemplos de aplicações que ilustra quão significativamente a aplicação de estatística espacial pode auxiliar na tarefa de analisar os processos urbanos, tanto de transportes como de uso do solo. O objetivo dos autores foi o de cobrir as principais questões técnicas de análise espacial, ou seja, a associação espacial, a heterogeneidade espacial e o problema da unidade de área modificável (também conhecido como MAUP, na sigla em inglês). Para Páez e Scott (2004) há uma tendência incipiente e promissora para a aplicação de métodos estatísticos espaciais cada vez mais sofisticados na análise urbana. 


\subsection{Aplicação de Estatística Espacial}

Para compreender a relevância do assunto e como se dá a aplicação de análise estatística espacial em estudos urbanos e de transportes, primeiramente é importante entender quatro questões importantes:

1) Quais são os principais conceitos e questões técnicas em análise e estatística espacial, ou seja, quais os efeitos espaciais que devem ser considerados;

2) Quais os tipos de dados espaciais a serem analisados (taxonomia dos dados espaciais);

3) Quais as ferramentas e técnicas de estatística espacial a serem empregadas;

4) Qual a área de aplicação, ou seja, o que se pretende estudar no amplo campo de estudo das análises urbanas e de transportes.

Os 26 estudos sintetizados na Tabela 1, apresentada no item 2.3 do Capítulo 2, são referências úteis para a compreensão de como cada uma das questões acima é abordada na análise da mobilidade urbana. A Tabela 1 dá subsídios para uma melhor compreensão de cada uma das aplicações, onde é indicada, qual a questão analítico espacial avaliada e em que campo e subcampo da análise de sistemas urbanos e de transportes se insere.

Existem diversas técnicas e ferramentas estatísticas para detectar efeitos espaciais e analisar os dados sob esses efeitos. A escolha do método mais apropriado vai depender do fenômeno espacial em análise e dos tipos de dados em questão, que podem ser eventos pontuais, dados discretos (agregados em área), contínuos ou em rede. Paez e Scott (2004) destacam que, na análise urbana, independentemente das questões metodológicas e das unidades de análise (forma de agregação), uma característica da maioria dos processos é o fato de que são intrinsecamente espaciais e, além disso, espaço-dependentes, ou seja, o que ocorre em um local é parcialmente afetado por eventos em outros locais.

Os autores destacam que os conceitos de contiguidade espacial, proximidade e/ou conectividade são elementos importantes dos processos urbanos e que diversos processos espaciais relevantes para a análise urbana, como por exemplo, difusão espacial, troca e transferência, interação espacial e segmentação, foram identificados na literatura sobre a análise de dados espaciais (HAINING, 2000; KRIEGER, 1991; LANDIS; ZHANG, 2000).

Processos espaciais que se traduzem em agrupamentos e/ou dispersão, ou como variação sistemática no espaço, violam premissas básicas de independência e de homogeneidade implícita nas análises estatísticas convencionais. A violação de pressupostos, por sua vez, leva à perda de informação, parâmetros tendenciosos e/ou ineficientes e a possibilidade de sérias falhas nas conclusões e nas políticas adotadas (GRIFFITH; LAYNE, 1999). 
Dadas essas potenciais armadilhas, não é surpresa que efeitos espaciais muitas vezes sejam considerados como perturbações. Cada vez mais, no entanto, eles são percebidos como oportunidades para obtenção de conhecimento mais aprofundado sobre os processos em estudo. Porém, independentemente do ponto de vista adotado, existem fortes argumentos metodológicos e conceituais favoráveis à adoção de métodos de estatística espacial para a análise dos processos urbanos.

\subsection{Ferramentas de Estatística Espacial}

Conforme apresentado no item 2.3, de 26 estudos, 24 se preocupam com os efeitos de associação espacial, ou seja, com a dependência espacial, que é, também, o foco das análises espaciais deste trabalho. As ferramentas da ESDA (Exploratory Spatial Data Analysis) são as indicadas para detectar tais efeitos.

Dentre as diversas ferramentas e técnicas estatísticas para a análise e modelagem de dados com efeitos espaciais, as técnicas de Regressão Espacial, que fazem parte das ferramentas da CSDA (Confirmatory Spatial Data Analysis), são as mais aplicadas em estudos de mobilidade urbana. Dos 26 estudos sintetizados na Tabela 1, 14 utilizam tais ferramentas (BENDER; HWANG, 1985; BOLDUC; DAGENAIS; GAUDRY, 1989; BOLDUC; LAFERRIERE; SANTAROSSA, 1992, 1995; HAIDER; MILLER, 2000; WANG, 2001; KAWAMURA; MAHAJAN, 2005; VICHIENSAN et al., 2006; CHALERMPONG, 2007; HACKNEY et al., 2007ª 2007b; CZADO; PROKOPENKO, 2008; ZHOU; KOCKELMAN, 2008; RIBEIRO; ANTUNES, 2009).

\subsubsection{Ferramentas da ESDA - Exploratory Spatial Data Analysis}

As ferramentas de análise exploratória de dados espaciais (ESDA) têm como objetivo visualizar e descrever distribuições espaciais, identificar padrões de associação espacial (aglomerados espaciais ou clusters), identificar observações atípicas (valores extremos ou outliers) ou a existência de instabilidades espaciais (não-estacionaridade). Wise, Haining e Ma (1998) salientam que, nesse grupo, os métodos são descritivos e não confirmatórios, desejando-se, através deles, detectar padrões, elaborar hipóteses e estimar modelos espaciais. As técnicas são visuais, geralmente com uso de instrumental computacional gráfico, e poucas transformações são efetuadas sobre os dados originais.

Segundo Câmara et al. (2002), a caracterização da dependência espacial mostra como os valores estão correlacionados no espaço. Uma das funções utilizadas para estimar quanto o valor de um atributo observado em uma região é dependente dos valores dessa mesma variável nas localizações vizinhas é a autocorrelação espacial. O índice / de Moran indica, através de valores normalizados, que variam de $-1 \mathrm{a}+1$, o quanto cada área analisada é 
semelhante à sua vizinhança imediata. Quanto mais próximos de zero, menor a autocorrelação espacial, ao passo que valores próximos de -1 ou +1 indicam presença de autocorrrelação espacial positiva ou negativa, respectivamente. Assim, o índice I de Moran é muito útil para a análise na etapa inicial da modelagem de transportes, permitindo a identificação de características da variável dependente e das variáveis explicativas candidatas.

O diagrama de espalhamento de Moran (Moran Scatterplot), utilizado para obtenção das variáveis espaciais globais (ou indicadores globais de dependência espacial), é construído com base nos valores normalizados da variável em análise $(Z)$, que são comparados com a média dos valores dos vizinhos $(\mathrm{Wz})$ em um gráfico bidimensional dividido em quatro quadrantes. O índice I de Moran é equivalente ao coeficiente de regressão linear, que indica a inclinação da reta de regressão $(\alpha)$ de $W z$ em $Z$, sendo que os quadrantes podem ser interpretados como:

- Q1 (valores positivos e médias positivas) e Q2 (valores negativos e médias negativas): indicam pontos de associação espacial positiva, no sentido que uma localização possui vizinhos com valores semelhantes;

- Q3 (valores negativos e médias positivas) e Q4 (valores positivos e médias negativas): indicam pontos de associação espacial negativa, no sentido que uma localização possui vizinhos com valores distintos.

O diagrama de espalhamento de Moran também pode ser apresentado como um mapa bidimensional, o Box Map, em que cada polígono é apresentado indicando-se seu quadrante no diagrama de espalhamento. Enquanto os indicadores globais, como o I de Moran, fornecem um único valor como medida de associação espacial para todo o conjunto de dados, os indicadores locais produzem um valor específico para cada área, permitindo, assim, a identificação de agrupamentos de áreas com valores de atributos semelhantes (clusters), valores anômalos (outliers) e com mais de um regime espacial. Anselin (1995) refere-se aos indicadores como estatística LISA (Local Indicators of Spatial Association), que devem satisfazer dois requisitos:

- Permitir a identificação de padrões significativos de associação espacial;

- A soma dos indicadores LISA, para todas as observações, deve ser proporcional ao índice global de associação espacial.

A significância estatística do uso do índice de Moran local é computada de forma similar ao caso do índice global. Depois de calculado o índice para cada área, permuta-se, aleatoriamente, o valor das demais áreas, até ser obtida uma pseudodistribuição para a qual 
se possam computar os parâmetros de significância. Neste caso, os mapas (LISA Map e Moran Map) indicam as regiões que apresentam correlação local significativamente diferente do resto dos dados, pois são áreas com dinâmica espacial própria, ou seja, "bolsões" de não-estacionaridade, e merecem análise detalhada. Autocorrelação com significância superior a 95\% indica, a princípio, áreas com grande semelhança em relação a seus vizinhos.

Neste trabalho, é através dos índices de Moran Locais que são obtidas as variáveis espaciais introduzidas nos modelos de demanda por transporte como indicadores locais de dependência espacial, denominadas de variáveis espaciais locais. Todos esses índices e ferramentas de visualização da ESDA são, também, muito úteis no diagnóstico dos modelos em estudo, por permitir a análise da distribuição espacial dos resíduos.

\subsubsection{Ferramentas da CSDA - Confirmatory Spatial Data Analysis}

Tipicamente, quando se faz uma análise de regressão procura-se encontrar um bom ajuste entre os valores preditos pelo modelo e os valores observados da variável dependente. Além disso, procura-se descobrir quais das variáveis explicativas contribuem de forma significativa para o relacionamento linear. A hipótese padrão é que as observações não são correlacionadas e, portanto, os resíduos $\varepsilon_{i}$ do modelo são independentes e nãocorrelacionados com a variável dependente, além de apresentar Distribuição Normal com média zero e variância constante. No caso de dados onde está presente a dependência espacial, é muito pouco provável que a hipótese padrão de observações não correlacionadas seja verdadeira. No caso mais comum, os resíduos continuam apresentando a autocorrelação espacial presente nos dados, que pode se manifestar por diferenças regionais sistemáticas, ou ainda por uma tendência espacial contínua.

Dessa forma, a investigação dos resíduos da regressão, em busca de sinais da estrutura espacial, pode fornecer um indicativo da necessidade da utilização de um modelo de regressão espacial. As ferramentas usuais de análise gráfica e o mapeamento dos resíduos podem fornecer a primeira indicação de que os valores observados estão mais correlacionados do que seria esperado sob uma condição de independência (FOTHERINGHAM; BRUNDSDON; CHARLSTON, 2000). Somado à análise gráfica, podese fazer uso de testes estatísticos para verificação de autocorrelação espacial nos resíduos da regressão, como, por exemplo, a análise do índice I de Moran.

A análise de regressão em dados espaciais incorpora, na modelagem, a dependência espacial entre os dados, melhorando o poder preditivo do modelo. Primeiramente, faz-se a análise exploratória com intuito de identificar a estrutura de dependência nos dados, visando à definição da forma de incorporação dessa dependência ao modelo de regressão. 
Os modelos utilizados neste estudo são o modelo espacial auto-regressivo misto (Spatial Auto Regressive = SAR ou Spatial Lag Model) e o modelo do erro espacial (Conditional Auto Regressive = CAR ou Spatial Error Model).

\section{SAR (Spatial Auto Regressive)}

No modelo SAR (ou LAG, como é denominado neste estudo) a autocorrelação espacial ignorada é atribuída à variável dependente $Y$. Considera-se a dependência espacial através da adição, ao modelo de regressão, de um novo termo na forma de uma relação espacial para a variável dependente. Formalmente, Anselin (2002) apresenta o modelo SAR pela Equação 1.

$$
Y=\rho W Y+X \beta+\varepsilon
$$

onde:

- $\mathrm{Y}=$ variável dependente;

- $\mathrm{X}=$ variáveis independentes;

- $\beta=$ coeficientes de regressão;

- $\varepsilon=$ erros aleatórios com média zero e variância $\sigma^{2}$;

- $\mathrm{W}$ = matriz de vizinhança espacial ou matriz de ponderação espacial;

- $\rho=$ coeficiente espacial autoregressivo.

A hipótese nula para a não existência de autocorrelação é que $\rho=0$. A idéia básica é incorporar a autocorrelação espacial como componente do modelo.

\section{CAR (Conditional Auto Regressive)}

O segundo tipo de modelo de regressão espacial com parâmetros globais, também referido como Spatial Error Model, considera que os efeitos espaciais são um ruído, ou perturbação, ou seja, fator que precisa ser removido. Neste caso, os efeitos da autocorrelação espacial são associados ao termo de erro $\varepsilon$ e o modelo pode ser expresso pela Equação (2).

$$
Y=X \beta+\varepsilon, \quad \varepsilon=\lambda W \varepsilon+\xi
$$

onde:

- $W \varepsilon=$ erros com efeito espacial; 
- $\xi=$ erros aleatórios com média zero e variância $\sigma^{2}$;

- $\lambda=$ coeficiente autoregressivo.

A hipótese nula para a não existência de autocorrelação é que $\lambda=0$, ou seja, o termo de erro não é espacialmente correlacionado.

Câmara et al. (2002) salientam que, na prática, a distinção entre os dois tipos de modelos de regressão espacial com parâmetros globais é difícil, pois, apesar da diferença nas suas motivações, eles são muito próximos em termos formais. Esses modelos estão incluídos em ambientes de estatística espacial avançados, como nos softwares SpaceSat ${ }^{\mathrm{TM}}, \mathrm{S}$-Plus ${ }^{\mathrm{TM}}, \mathrm{R}$ e GeoDA, de domínio público.

\section{Modelos com indicadores Locais e Globais de dependência espacial}

Outra forma de considerar a dependência espacial nos modelos de regressão, analisada neste estudo, é com a introdução de indicadores de autocorrelação espacial (Globais e Locais) como variáveis explicativas, somados às variáveis tradicionais, no modelo de regressão múltipla. São definidas variáveis espaciais globais, associadas aos quadrantes do diagrama de Moran (indicador global), e variáveis espaciais locais, a partir da consideração de indicadores locais de autocorrelação espacial (LISA).

Da mesma forma que nos modelos tradicionais, os alternativos requerem rigor na análise de significância das variáveis incluídas, para não onerar o modelo com variáveis desnecessárias. Dentre os métodos analisados por Lopes (2005), foi verificado que a combinação dos dois tipos de variáveis espaciais (globais e locais) foi mais eficiente do que a consideração dessas variáveis isoladamente. Quanto às variáveis explicativas, as que se mostraram mais significativas nos modelos foram também aquelas que apresentaram índices de autocorrelação espacial significativos. $O$ efeito espacial se mostrou mais evidente nas variáveis taxas por unidade de área (densidade populacional, densidade de domicílios e densidade de veículos particulares).

\section{Diagnóstico de modelos com efeitos espaciais}

A análise gráfica dos resíduos é o primeiro passo para a avaliação da qualidade do ajuste da regressão. Mapear os resíduos é uma etapa importante no diagnóstico do modelo, buscando indícios de ruptura dos pressupostos de independência. Uma alta concentração de resíduos positivos (ou negativos) numa parte do mapa é um bom indicador da presença de autocorrelação espacial. Para um teste quantitativo, o mais comum é utilizar o índice I de Moran sobre os resíduos. 
Como os estimadores e os diagnósticos tradicionais de regressão não levam em conta os efeitos espaciais, as inferências, como, por exemplo, as indicações de qualidade de ajuste baseadas somente no $\mathrm{R}^{2}$ (coeficiente de determinação), podem ser incorretas. As consequências são similares às que acontecem quando uma variável explicativa significativa é omitida do modelo de regressão. Quando se quer comparar um ajuste obtido por um modelo de regressão padrão com um ajuste obtido por um dos modelos cuja especificação considera a autocorrelação espacial, uma medida como o $\mathrm{R}^{2}$ não é mais confiável.

O método mais usual de seleção de modelos de regressão baseia-se nos valores de máxima verossimilhança dos diferentes modelos, ponderando pela diferença no número de parâmetros estimados. Nos modelos com estrutura de dependência - espacial ou temporal utilizam-se os critérios de informação onde a avaliação do ajuste é penalizada por uma função do número de parâmetros. Cabe observar que é necessário ainda levar em conta o número de parâmetros independentes ao se incluir funções espaciais nos modelos. Para cada nova variável em modelo de regressão, acrescenta-se um parâmetro.

Usualmente a comparação de modelos é feita utilizando o logaritmo da máxima verossimilhança, que é o que possui melhor ajuste para os dados observados. O Critério de Informação de Akaike (AIC) é expresso pela Equação (3).

$$
A I C=-2 \times L I K+2 k
$$

onde:

- LIK: é o log de verossimilhança maximizado;

- k: é o número de coeficientes de regressão.

Segundo esse critério, o melhor modelo é o que possui menor valor de AIC (Câmara et al., 2002). Diversos outros critérios de informação estão disponíveis nas ferramentas de estatística espacial, a maior parte dos quais são variações do AIC, com mudanças na forma de penalização de parâmetros ou observações. 


\section{MÉTODO}

Para atender ao objetivo geral proposto para esta pesquisa o método de desenvolvimento do trabalho foi estruturado em tarefas interligadas divididas em cinco "Blocos de Análise", com características distintas, que procuram atender cada um dos objetivos específicos descritos no item 1.2 do Capitulo 1. A denominação de "Blocos" é mais adequada que etapas uma vez que a conclusão das tarefas de cada um pode ou não ser dependente da finalização das tarefas do outro. Um esquema geral do método é apresentado na Figura 12 e é abordado em mais detalhe na sequência deste capítulo.

Para aplicação do método, é fundamental, primeiramente, definir a cidade brasileira de grande porte para o estudo de caso. Esta é a primeira etapa do método apresentada no item 5.1 deste capítulo. Para uma melhor compreensão do que se pretende ao final de cada "Bloco", cujas análises estão diretamente relacionadas às características da área de estudos primeiramente definida, é apresentada, na sequência, uma rápida descrição das análises e objetivos específicos relacionados a cada um. Maiores detalhes dos métodos aplicados em cada conjunto de análises são apresentados nos itens 5.2 a 5.6 e respectivos subitens.

Conforme esquematizado na Figura 12, cada bloco está estruturado de forma a atender um dos cinco objetivos específicos, conforme segue:

\section{- Bloco 1 - Obtenção de Modelos Espaciais}

A sequência de tarefas neste bloco visa à avaliação de técnicas que considerem efeitos decorrentes da distribuição espacial das atividades urbanas. O que se pretende é estimar modelos espaciais capazes de amenizar a dependência espacial 
dos resíduos das estimativas de demanda por transporte, eventualmente verificadas nos resultados de modelos tradicionais;

\section{- Bloco 2 - Ajuste de um Modelo LUTI Dinâmico}

A sequência de tarefas neste bloco pode ocorrer paralelamente às tarefas do Bloco 1 e visa avaliar a viabilidade de se executar cada etapa do processo de ajuste de um modelo LUTI Dinâmico para a área de estudos. O que se pretende, ao final do Bloco 2, é obter um modelo LUTI Dinâmico ajustado à área de estudos;

\section{- Bloco 3 - Obtenção e a ajuste de um Modelo LUTI Dinâmico e Espacial}

A sequência de tarefas neste bloco depende da finalização das tarefas dos dois blocos anteriores. Ao combinar as técnicas e considerando os efeitos espaciais resultantes das análises do Bloco 1 com o modelo LUTI Dinâmico ajustado no Bloco 2, visa-se avaliar a viabilidade de se obter um modelo LUTI Dinâmico e Espacial. O que se pretende, ao final do Bloco 3 é obter um modelo LUTI Dinâmico e Espacial ajustado à área de estudos;

\section{- Bloco 4 - Avaliação do Modelo LUTI Dinâmico e Espacial}

A sequência de tarefas neste bloco é dependente da conclusão dos dois blocos anteriores, pois, ao combinar os resultados das análises dos Blocos 2 e 3, visa-se verificar a hipótese que a consideração dos efeitos espaciais na modelagem de transportes resultará em melhorias para o Modelo LUTI Dinâmico inicial (Bloco 2). O que se pretende, ao final do Bloco, é quantificar os benefícios obtidos ao considerar efeitos de dependência espacial nos submodelos de transporte (Modelo LUTI Dinâmico e espacial - Bloco 3) ao comparar a qualidade do ajuste dos dois modelos LUTI Dinâmicos (com ou sem efeitos espaciais).

- Bloco 5 - Verificação da viabilidade de aplicação do modelo como ferramenta de apoio à decisão na análise de políticas de mobilidade urbana sustentável

A sequência de tarefas deste bloco vai depender dos resultados obtidos nos Blocos 2, 3 e 4, porém está condicionada à conclusão, pelo menos, das análises contidas no Bloco 2. Visa-se avaliar a viabilidade de aplicação do modelo LUTI Dinâmico (Bloco 2) ou, dependendo dos resultados das análises dos Blocos 3 e 4, do modelo LUTI Dinâmico e Espacial, como uma ferramenta de apoio à decisão na análise de políticas de mobilidade urbana sustentável. O que se pretende, ao final do bloco é verificar a capacidade do modelo de reproduzir e simular cenários de políticas de mobilidade, assim como de fornecer, como resultados, indicadores relacionados às questões de mobilidade sustentável e atender o objetivo geral desta pesquisa. 


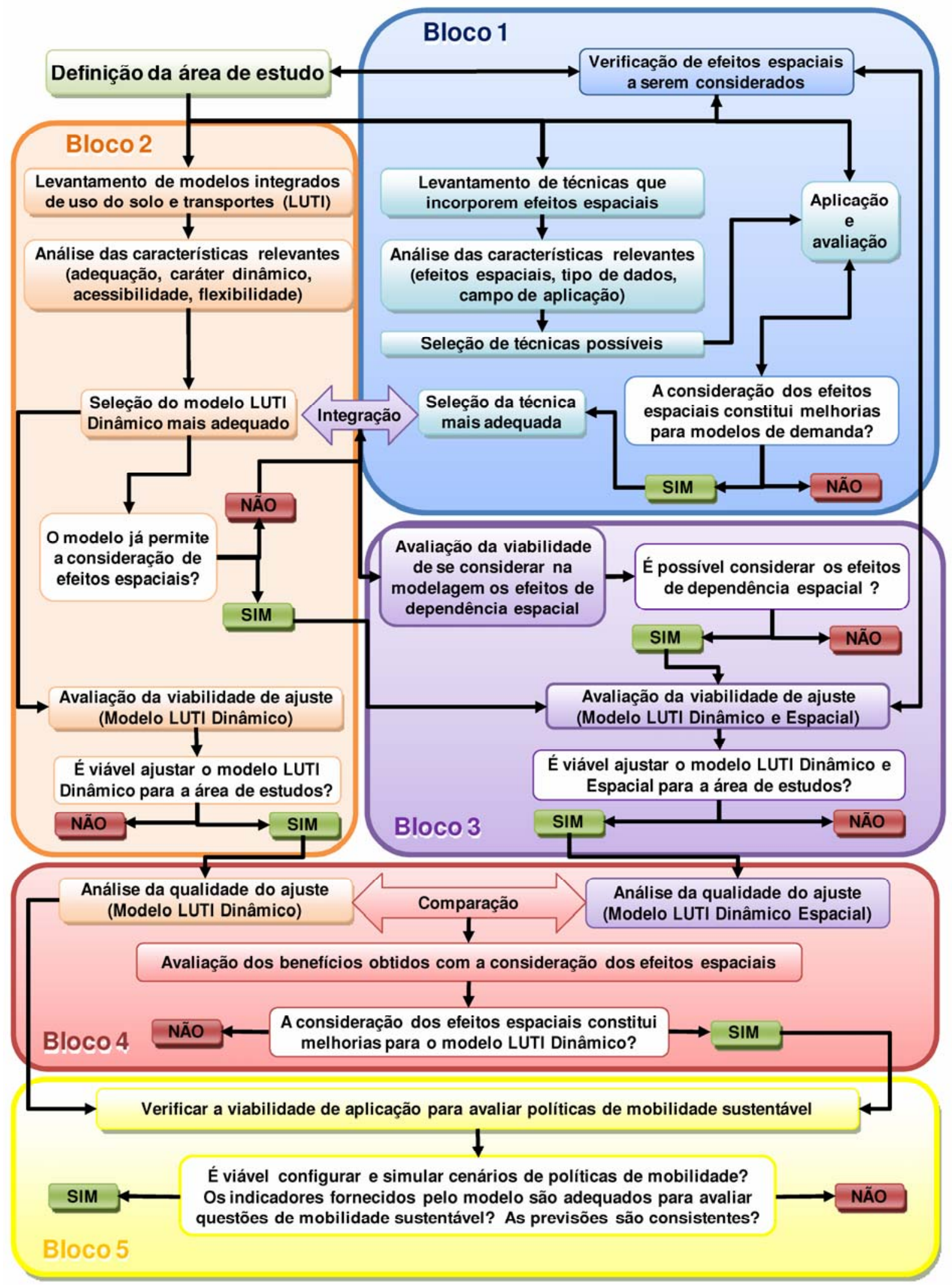

Figura 12 - Esquema do método aplicado e a divisão dos cinco Blocos de análise. 


\subsection{Definição da Área de Estudos}

É a etapa que compreende a definição da cidade brasileira de grande porte para a qual se pretende implementar uma ferramenta de apoio à decisão às políticas urbanas de mobilidade sustentável. Esta definição é determinante para estabelecer diretrizes para as análises contidas em cada um dos cinco blocos que compõem o método (Figura 12), assim como vai influenciar diretamente nos resultados que serão obtidos ao longo do processo.

\subsection{Bloco 1 - Obtenção de Modelos Espaciais}

Existem diferentes métodos e técnicas que permitem considerar os efeitos espaciais na modelagem de demanda por transportes. Por outro lado, é preciso definir se existem e quais são as variáveis afetadas pelo efeito da dependência espacial e que poderão contribuir como variáveis espaciais nos modelos. Portanto, para obtenção de modelos espaciais capazes de amenizar a dependência espacial dos resíduos das estimativas de demanda por transportes, as análises contidas no Bloco 1 iniciam com a verificação dos efeitos espaciais a serem considerados.

\subsubsection{Verificação dos efeitos espaciais a serem considerados}

O foco deste estudo são os efeitos de dependência espacial que podem afetar modelos de geração de viagens. Sendo assim, o primeiro passo é o levantamento, com base em dados de pesquisa O-D, de todas as variáveis candidatas para modelos de geração de demanda, considerando produção e atração, por modo e por motivos de viagens.

Posteriormente, através de ferramentas da ESDA, é realizada a análise exploratória espacial dessas variáveis para detectar índices significativos de autocorrelação espacial. A existência de autocorrelação espacial significativa, tanto para as variáveis dependentes, como para variáveis explicativas candidatas dos modelos de demanda, é indício que o efeito pode ser transmitido aos resíduos e perturbar os resultados das estimativas.

\subsubsection{Obtenção de modelos espaciais mais adequados}

Primeiramente é realizado um levantamento, na literatura, de técnicas que incorporem efeitos espaciais. A seleção de ferramentas e técnicas a serem empregadas vai depender da análise de características relevante e a compatibilidade com o estudo, tais como:

\section{i. Quais os efeitos espaciais a serem avaliados?}

No caso deste estudo o foco é o efeito de dependência espacial. 
ii. Quais os tipos de dados espaciais a serem analisados?

Dados de demanda por transportes são dados de áreas, geralmente agregados em Zonas de Tráfego (ZTs).

iii. Qual a área de aplicação, ou seja, o que se pretende estudar no amplo campo de estudo das análises urbanas e de transportes?

No caso deste estudo o foco são modelos de demanda por transportes, mais especificamente modelos de geração de viagens.

Posteriormente estas técnicas são aplicadas para a área de estudo levando em conta os efeitos espaciais verificados no item 5.2.1. O que se pretende é estimar modelos espaciais para a área de estudos capazes de amenizar a dependência espacial dos resíduos das estimativas de demanda por transporte, eventualmente verificadas nos resultados de modelos tradicionais (que não consideram os efeitos espaciais).

Sendo assim, o método aplicado avaliar as diferentes técnicas e selecionar os modelos espaciais mais adequados para a área de estudos é baseado em trabalhos anteriores (LOPES; SILVA, 2004; LOPES, 2005; LOPES; SILVA, 2005; LOPES; BRONDINO; SILVA; 2005). Praticamente todo o processo ocorre em ambiente SIG, mais especificamente com a utilização do software GeoDA. O software GeoDa (ANSELIN, 2003, 2004) contempla tanto as ferramentas de Análise Exploratória de Dados Espaciais (ESDA ou AEDE) como as de Análise Confirmatória (CSDA ou ACDE), através de regressão espacial. Dessa forma, tanto a obtenção das variáveis espaciais como a calibração dos modelos ocorre através desse software.

Para a calibração e validação dos modelos são utilizadas bases de dados de pesquisas de origem e destino (O-D) realizadas em dois períodos distintos na cidade definida inicialmente para o estudo de caso:

- "Ano base" - dados utilizados para calibração de modelos de demanda por transportes e também para diagnóstico dos melhores modelos, ou seja, daqueles que são usados para estimativas de viagens futuras, tanto por métodos tradicionais (modelos tradicionais) como através de métodos que introduzem variáveis que medem o grau de dependência espacial (modelos espaciais);

- "Ano meta" - dados da pesquisa do ano de projeção das viagens, que servem de base para a avaliação da qualidade das estimativas futuras de viagens obtidas através da aplicação tanto dos modelos tradicionais como dos modelos espaciais.

A qualidade do ajuste de tais modelos pode ser avaliada através da análise dos valores de diversos testes estatísticos apresentados nos relatórios fornecidos pelo software, para cada 
modelo ajustado, tais como o $R^{2}$ (coeficiente de determinação), o $R_{\text {aj }}^{2}$ (coeficiente de determinação ajustado) e o AIC (Critério de Informação de AKAIKE), entre outros.

Por sua vez, o poder preditivo dos modelos é avaliado através de algumas medidas de desempenho, tais como o ERM (Erro Relativo Médio) e o Índice de Moran dos erros. Para as variáveis, são feitas verificações de significância, presença de multicolinearidade e presença de dependência espacial, que também é verificada para os resíduos, os quais também são objeto de verificação para confirmar se apresentam distribuição normal e homocedasticidade.

Para verificar a eficiência dos modelos espaciais, os resultados são comparados com aqueles fornecidos pelo modelo de regressão múltipla que melhor se ajustar aos dados do "ano-base", denominado aqui de modelo tradicional, o qual não incluiu nenhuma informação sobre a distribuição espacial dos dados.

O passo seguinte é a validação do modelo espacial, ou seja, a aplicação do modelo mais ajustado aos dados do "ano-base" para "estimativas futuras", utilizando-se, como base de dados para aferição do desempenho do modelo, as informações de pesquisa O-D do "anometa". Como parâmetros de comparação, são utilizados resultados de estimativas para o ano-meta, obtidos pelo modelo tradicional.

Os melhores resultados encontrados, para cada conjunto de dados analisados, tanto na etapa de calibração como na de validação dos modelos, indicarão se existem efeitos espaciais comprometendo os resultados do modelo tradicional e, se existirem, qual é o melhor modelo espacial para aplicação nesta pesquisa.

Deve-se salientar que todos os passos aqui apresentados devem ser aplicados para todos os modelos de geração de viagem, ou seja, todos os que compreendem a primeira etapa do modelo tradicional de quatro etapas. Sendo assim, devem ser testados modelos de produção de viagens e também de atração de viagens, considerando os diferentes modos e motivos de viagens.

\subsection{Bloco 2 - Ajuste de um Modelo LUTI Dinâmico}

Existem diversos modelos desenvolvidos no mundo que consideram variáveis de uso do solo e transporte de forma integrada (Modelos LUTI) e alguns que consideram esta integração de forma dinâmica (Modelo LUTI Dinâmico). As análises do Bloco 2 têm o intuito de avaliar a viabilidade de se executar cada etapa do processo de ajuste de um modelo LUTI Dinâmico para a cidade brasileira definida. Portanto para a obtenção de um modelo LUTI Dinâmico ajustado à área de estudos, primeiramente, devem ser levantados e 
avaliados os modelos existentes, para a escolha do mais adequado aos propósitos desta pesquisa e aplicação no estudo de caso.

\subsubsection{Seleção de um Modelo LUTI Dinâmico.}

Compreende o levantamento dos principais modelos desenvolvidos no mundo que consideram variáveis de uso do solo e transporte de forma dinâmica e integrada. Para a seleção do modelo mais adequado para aplicação nesta pesquisa devem ser avaliadas algumas características relevantes, tais como:

i. Qual é o propósito do modelo? É adequado aos propósitos do estudo? Para estar adequado aos objetivos desta pesquisa o modelo escolhido deve ser capaz de reproduzir e simular cenários relacionados a políticas de mobilidade e fornecer indicadores adequados às questões de mobilidade urbana sustentável.

ii. O modelo é acessível para uso?

Deve ser uma ferramenta de fácil acesso e disponível para aplicação.

iii. Qual é a flexibilidade do modelo para incluir indicadores de dependência espacial?

Se o modelo escolhido não considera os efeitos de dependência espacial, deve ter flexibilidade suficiente para que se possa alterar a estrutura e incluir os modelos espaciais de geração de viagens.

\subsubsection{Avaliação da viabilidade de ajuste do Modelo LUTI Dinâmico}

Implica em verificar a possibilidade de ajuste do modelo às características de evolução da cidade definida para o estudo de caso, para que seja capaz de produzir estimativas futuras o mais próximo possível da realidade. Contempla a verificação de todos os passos que irão permitir a calibração dos submodelos e também a validação desses para previsões futuras.

Nesta etapa é importante já estar familiarizado com a ferramenta escolhida de forma a compreender quais são os dados necessários e formatos requeridos pelo modelo, assim como qual é a forma de alimentação (entrada de dados) e os procedimentos para calibração.

Para o ajuste à realidade brasileira é importante entender, não só os dados de entrada como o papel que cada um vai desempenhar como variável inicial ou parâmetro local nos diversos submodelos de uso do solo e transportes. A forma de análise e obtenção dos indicadores necessários e também a forma de proceder possíveis adequações será necessária não só 
para introdução dos modelos espaciais, como para verificar a viabilidade de compatibilizar o modelo com a realidade brasileira.

\section{Levantamento, tratamento e análise dos dados}

Além dos dados de entrada para o ano base (início da simulação), serão necessários dados históricos para calibração e validação do modelo para a cidade definida para o estudo de caso. Esses dados dizem respeito a informações demográficas e socioeconômicas, transportes e viagens, uso do solo, assim como uma série de informações relacionadas ao cadastro imobiliário da cidade.

\section{Calibração e validação do modelo}

A compreensão dos conceitos de "calibração" e "validação" na modelagem de uso do solo e transportes é de vital importância. Portanto, define-se calibração como a estimativa de certos parâmetros do modelo de forma a ajustar os resultados das estimativas a um conjunto de dados observados, enquanto que validação é o processo para avaliar a conformidade entre os resultados da simulação, utilizando-se o modelo calibrado, e os dados observados. Deve-se ressaltar que os conjuntos de dados utilizados na calibração e na validação devem ser diferentes, o que exige, por exemplo, dados históricos de diferentes bases.

Primeiramente, deve ser realizada a calibração transversal ("cross sectional") dos submodelos de transportes para a divisão modal observada no ano base. Esse procedimento é seguido da calibração dos submodelos de uso do solo para as mudanças ocorridas, num período de aproximadamente 10 anos, na população, no número de unidades habitacionais e nos postos de trabalho da área de estudo.

O objetivo da etapa de validação é aumentar a credibilidade dos resultados do modelo. O método de validação normalmente usado é a análise ex-post, ou seja, o modelo calibrado para o ano base é utilizado para validar a capacidade de estimar mudanças, no sistema de transportes, para um horizonte de aproximadamente 10 anos e no número de unidades habitacionais e população para um horizonte de aproximadamente 20 anos.

São requeridos, portanto, dados históricos de pelo menos três diferentes anos, distribuídos num período de pelo menos vinte anos. No caso da não existência de dados anteriores suficientes para a validação, ou de só existirem dados atuais para calibrar o modelo, fica a questão: como validar as projeções futuras do modelo?

Uma saída, utilizada neste trabalho, é através da meta-análise, que é uma forma de investigação científica em que, não dados empíricos, mas sim os resultados de pesquisas 
científicas é que são os objetos da análise. Considerando-se o foco desta pesquisa, a metaanálise é uma forma válida de validação cruzada de modelos para aumentar a confiabilidade e a credibilidade das suas estimativas, ao comparar, sistematicamente, os resultados de previsões com diferentes ferramentas, em diferentes locais, porém baseadas em hipóteses semelhantes.

\subsection{Bloco 3 - Obtenção e Ajuste de um Modelo LUTI Dinâmico e Espacial}

As análises do Bloco 3 dependem da conclusão e resultados das análises dos Blocos 1 e 2 e contemplam a avaliação da viabilidade de se considerar, na modelagem de transportes, os efeitos de dependência espacial eventualmente existentes. Visa-se obter um Modelo LUTI Dinâmico e Espacial ajustado à área de estudos.

Caso o Modelo LUTI Dinâmico, selecionado no Bloco 2, já permita a consideração de efeitos espaciais, a avaliação da viabilidade de ajuste do Modelo LUTI Dinâmico e Espacial, segue o mesmo método apresentado no item 5.3 (Bloco 2), porém considerando-se os indicadores de dependência espaciais resultantes das análises apresentadas no item 5.2 (Bloco 1).

Caso contrário, é incluída uma etapa adicional na análise: a verificação da possibilidade e forma de combinação dos modelos espaciais, resultantes das análises do Bloco 1 , com o Modelo LUTI Dinâmico ajustado no Bloco 3 (ver Figura 12). Em outras palavras, esta etapa prevê a verificação de ajustes que deverão ser realizados na estrutura do modelo no sentido de alterar a configuração dos submodelos de geração de viagens, para se adequarem aos modelos espaciais resultantes do Bloco 1, assim como na adequação dos dados de entrada, de maneira a permitir a inserção de novas variáveis, os indicadores espaciais, também definidos no Bloco 1.

\subsection{Bloco 4 - Avaliação do Modelo LUTI Dinâmico e Espacial}

As análises do Bloco 4 dependem da conclusão dos dois blocos anteriores. Com a avaliação do modelo LUTI Dinâmico e Espacial (Bloco 3), visa-se verificar a hipótese que a consideração dos efeitos espaciais na modelagem de transportes resultará em melhorias para o Modelo LUTI Dinâmico inicial (Bloco 2). Através da análise comparativa da qualidade do ajuste dos dois modelos avaliam-se os benefícios obtidos ao considerar efeitos de dependência espacial nos submodelos de transporte. Os métodos de avaliação de ajuste devem ser compatíveis com modelos espaciais (conforme apresentado no item 5.2). 


\subsection{Bloco 5 - Verificação da viabilidade de aplicação do modelo como ferramenta de apoio à decisão na análise de políticas de mobilidade urbana sustentável}

As análises contidas no Bloco 5 contemplam o último objetivo específico visando alcançar o objetivo geral da pesquisa, no entanto, só serão viabilizada se, pelo menos, as análises contidas no Bloco 2 forem concluídas (Ajuste de um Modelo LUTI Dinâmico). Vão, também depender dos resultados obtidos nas análises dos Blocos 3 e 4.

Visa-se avaliar a viabilidade de aplicação do modelo como uma ferramenta de apoio à decisão na análise de políticas de mobilidade urbana sustentável. Caso os resultados das análises dos Blocos 3 e 4 sejam positivos (vide Figura 12), o modelo a ser aplicado e avaliado é o modelo LUTI Dinâmico e Espacial (Bloco 3), caso contrário, será aplicado e avaliado o Modelo LUTI Dinâmico, sem consideração dos efeitos espaciais (Bloco 2). No entanto, seja qual for o modelo LUTI Dinâmico a ser avaliado, para que atenda ao objetivo geral desta pesquisa é necessário que:

i. Seja capaz de reproduzir e simular cenários de políticas de mobilidade;

ii. Seja capaz de realizar projeções em longo prazo (horizonte de 30 anos) e permitir análises dos impactos de cada cenário através de indicadores relacionados às questões de mobilidade sustentável,

iii. Seja consistente em suas previsões.

5.6.1. Definição de cenários - políticas de mobilidade urbana sustentável

Para que seja possível aplicar o modelo e avaliar a sua capacidade de reproduzir cenários de políticas de mobilidade urbana sustentável, o primeiro passo é a definição das diferentes alternativas a serem simuladas no modelo. Uma vez que não existe uma única definição para a mobilidade sustentável é importante definir alguns conceitos gerais, que permitirão estabelecer diretrizes para a definição dos cenários.

Entende-se mobilidade como algo que vai além do número de viagens por pessoa por dia, mas algo que também está relacionado com saúde (física e psicológica), sociedade, economia e ambiente. Adicionalmente, entende-se a mobilidade sustentável como aquela que minimiza os efeitos negativos do transporte relacionados à poluição do meio ambiente, aos acidentes de trânsito, aos tempos perdidos em congestionamentos, à exclusão social, aos altos custos de viagens, ao consumo de energia não renovável. Desta forma, políticas de mobilidade urbana sustentável podem ser definidas como aquelas que busquem a 
otimização dos deslocamentos diários das pessoas e bens, em função da preservação da saúde, da integridade social, do meio ambiente e da eficiência e eficácia econômicas.

Portanto os cenários a serem simulados e avaliados devem ser definidos com base nos conceitos gerais somados a experiências práticas de sucesso registradas em bibliografias nacionais e internacionais, levando-se em conta a compatibilidade com as características locais e a possibilidade de serem transferidas ao contexto nacional. Além disto, possíveis planos já definidos para a área de estudo podem, também, servir de diretrizes para a definição dos diferentes cenários a serem simulados e avaliados.

\subsubsection{Configuração, simulação e análise dos impactos dos cenários}

Uma vez estabelecidos os cenários que serão simulados, o modelo dever ter meios de permitir a configuração de forma a representar as características definidas para cada um de forma satisfatória. Além disto, como geralmente são realizadas análises de vários cenários, para a escolha do melhor, é desejável que a interface de configuração seja amigável.

Uma vez configurados os cenários, o modelo deve ser capaz de simular as alternativas com projeções em longo prazo (horizonte de 30 anos). Da mesma forma, para viabilizar a análise de vários cenários é desejável que o modelo não consuma tanto tempo de simulação. Avalia-se a facilidade para executar as projeções e o tempo de simulação.

Para avaliação dos impactos de cada cenário o modelo deve ser capaz de fornecer, como resultados, indicadores de mobilidade urbana sustentável, com base nos conceitos gerais definidos no item anterior.

\subsubsection{Análise da consistência das projeções - Meta-análise}

O modelo deve ser consistente em suas previsões. Avalia-se a consistência dos resultados através da técnica de meta-análise. A meta-análise é uma forma de investigação em que, no lugar de dados empíricos, resultados de outras pesquisas científicas são os objetos da análise. Considerando-se o foco desta pesquisa, a meta-análise é uma forma de validação cruzada de modelos de uso do solo e transportes para aumentar a confiabilidade e a credibilidade das suas estimativas, ao comparar, sistematicamente, os resultados de previsões com diferentes ferramentas, porém baseadas em hipóteses semelhantes.

Portanto para que a consistência dos resultados possa ser avaliada, é preciso verificar a existência de outras aplicações de modelos de uso do solo e transportes, para avaliar diferentes cenários de mobilidade urbana sustentável. Além disto, é necessário ter acesso aos resultados destas aplicações para que possam ser comparados aos resultados desta pesquisa, porém sempre levando em conta as características locais e o contexto nacional. 


\section{APLICAÇÃO DO MÉTODO E ANÁLISES DOS RESULTADOS}

Uma aplicação do método apresentado no Capítulo 5 é discutida neste capítulo, iniciando com a definição da área de estudo, apresentada no item 6.1. Esta definição, conforme estabelecida no método (item 5.1), é o primeiro passo para as análises, as quais seguem a ordem e a divisão dos cinco blocos definidos, conforme esquematizado na Figura 12 e apresentados nos itens 5.2 a 5.6 e seus respectivos subitens. Ao final das análises de cada Bloco, que são apresentadas nos itens 6.2 a 6.6, apresentam-se algumas conclusões parciais em relação a cada um dos cinco objetivos específicos desta pesquisa.

\section{1. Área de Estudo}

A cidade escolhida para aplicação do método foi Porto Alegre, capital do Rio Grande do Sul, de forma a dar continuidade a pesquisas anteriores (LOPES, 2005, por exemplo). A cidade pertence à mesorregião metropolitana de Porto Alegre, que é a maior região metropolitana do sul do país e a quarta do Brasil, com 3.959.807 habitantes (INSTITUTO BRASILEIRO DE GEOGRAFIA E ESTATÍSTICA, 2007). Na capital gaúcha, para onde foi ajustado o modelo, residiam, no mesmo ano, 1,43 milhão de pessoas, sendo a décima cidade mais populosa do Brasil.

Porto Alegre, apesar de possuir um transporte público de qualidade, através de ônibus em um sistema que oferece uma boa cobertura da cidade e trafegando em corredores exclusivos nas vias mais movimentadas, tendo, também, táxis, lotações e microônibus, já vem enfrentando problemas de mobilidade. Acidentes, congestionamentos e custo da passagem muitas vezes elevado para boa parte da população, indicam a necessidade de 
avaliação de planos integrados que proporcionem melhorias à mobilidade urbana. Algumas iniciativas, tais como, estudos para implantação de sistemas de transporte multimodal e integrado, de BRT (Bus Rapid Transit), de ciclovias, entre outros, indicam a percepção, pelos órgãos municipais, de que problemas existem e medidas devem ser tomadas. Mais detalhes dos estudos podem ser verificados em Portais da Cidade (PORTO ALEGRE); EPE (2006); PITMUrb (BRASIL, 2006), Plano Diretor Cicloviário de Porto Alegre (PORTO ALEGRE, 2009).

No entanto, os esforços de integração entre planejamento urbano e mobilidade ainda são tímidos entre os órgãos da Prefeitura Municipal de Porto Alegre e os estudos carecem de uma ferramenta de suporte à decisão que permita a avaliação dos planos e das variáveis envolvidas de forma dinâmica e integrada. Por todos esses motivos, Porto Alegre se constitui em uma cidade adequada para o estudo de caso desta pesquisa.

\subsection{Bloco 1 - Obtenção de Modelos Espaciais}

As análises apresentadas neste bloco têm o intuito de investigar técnicas mais adequadas aos dados de Porto Alegre que amenizem possíveis perturbações em modelos de geração de viagens decorrentes da presença do efeito de dependência espacial. Ao final deste bloco espera-se obter os modelos espaciais mais adequados para, posteriormente, integrar a um modelo LUTI Dinâmico, atendendo ao primeiro objetivo específico desta pesquisa. 0 primeiro passo, conforme definido no método, é a análise exploratória espacial das variáveis envolvidas para detectar efeitos de dependência espacial, a qual é apresentada no subitem 6.2.1. Portanto, primeiramente é preciso definir qual é a variável dependente em análise e quais as variáveis explicativas candidatas.

Dando continuidade à pesquisa de Lopes (2005), o estudo exploratório, que havia sido aplicado aos dados de 1974 e aos dados de 1986 da cidade de Porto Alegre, foi desta vez aplicado aos dados mais recentes obtidos através de Entrevista Domiciliar para Pesquisa de Origem e Destino realizada em 2003, EDOM 2003 (PORTO ALEGRE, 2004). Além do modelo com indicadores Locais e Globais de dependência espacial resultante do método desenvolvido por Lopes (2005), o qual foi denominado de modelo Alternativo, outras formas de consideração de efeitos espaciais foram investigadas e posteriormente avaliadas.

O foco para a avaliação das diferentes técnicas continuou sendo a estimativa de VPBD (Viagens Produzidas de Base Domiciliar), tendo-se 1974 como "ano base", para calibração e diagnóstico dos modelos espaciais, porém, desta vez, 2003 como "ano meta", para avaliação da qualidade das estimativas futuras. Os resultados das estimativas foram comparados com o modelo tradicional de regressão múltipla que incluía duas variáveis 
explicativas (População total e Frota de veículos particulares). O subitem 6.2.2 apresenta, como resultado da revisão bibliográfica, as técnicas de modelagem espacial selecionadas e a as análises que resultaram na técnica mais adequada a esta pesquisa. No subitem 6.2.3 apresenta-se as conclusões finais das análises do Bloco 1.

\subsubsection{Verificação dos efeitos espaciais a serem considerados}

A análise exploratória espacial das variáveis envolvidas na modelagem de geração de viagens aqui apresentada tem dois objetivos:

i. Detectar presença de índices significativos de autocorrelação espacial, que são indícios de que os efeitos podem ser transmitidos aos resíduos do modelo e, consequentemente, perturbar os resultados das estimativas;

ii. Avaliar um método para a definição de indicadores de dependência espacial e suas inclusões como variáveis espaciais em modelos de demanda por transportes. Mais especificamente, obter os modelos Alternativos, com indicadores Locais e Globais de dependência espacial que serão avaliados.

O intuito, através da análise de estimativas de VPBD, é definir um método que facilite as próximas análises, necessárias para o prosseguimento da pesquisa, que contempla a investigação de variáveis explicativas espaciais para outras variáveis dependentes menos agregadas. A análise mais desagregada é possível para os dados da EDOM 2003, podendo-se investigar modelos espaciais para viagens produzidas e, também, viagens atraídas, de base domiciliar, considerando o modo e o motivo da viagem.

O método é baseado em ferramentas ESDA e CSDA. Avalia-se a relação entre as variáveis espaciais significativas para os modelos alternativos, que serão ajustados nas próximas etapas (item 6.2.2), e as características espaciais (índices de autocorrelação espacial globais e locais) das variáveis tradicionais que deram origem a elas. A observação dos resultados do estudo de Lopes (2005) e da continuidade da investigação apresentada por Lopes, Brondino e Silva (2005, 2006 e 2007) permitiu estabelecer as seguintes hipóteses:

i. Se existirem variáveis explicativas com índices significativos de autocorrelação espacial, a introdução de variáveis espaciais pode melhorar o poder preditivo do modelo;

ii. As variáveis que servirão de base para obtenção das variáveis espaciais serão as que apresentam índices de autocorrelação espacial significativos;

iii. Haverá variáveis espaciais com significância estatística para o modelo se houver indicadores de autocorrelação espacial (Globais ou Locais) correlacionados espacialmente com a variável dependente; 
iv. As variáveis espaciais Globais mais significativas para o modelo serão as que apresentarem maior correlação espacial com a variável dependente na análise dos Box Maps. Serão variáveis binárias (dummy), associadas aos quadrantes do diagrama de Moran (indicador global) para a variável explicativa em análise. Ou seja, para uma determinada variável explicativa " $X$ " podem ser definidas quatro variáveis explicativas espaciais globais (X_Q1, X_Q2 , X_Q3 e X_Q4);

v. As variáveis espaciais Locais mais significativas para o modelo serão as que apresentarem maior correlação espacial com a variável dependente na análise dos Moran Maps. Serão os indicadores LISA para a variável explicativa em análise. Ou seja, para uma determinada variável explicativa "X" pode ser definida uma variável espacial local (LISA_X).

Sendo assim, a definição de variáveis espaciais para especificação de um modelo Alternativo, para determinado período, inicia com a análise exploratória das variáveis envolvidas, neste caso, a variável dependente (VPBD) e as variáveis explicativas candidatas observadas neste período, em busca da presença de autocorrelação espacial. Também são investigadas as mesmas variáveis ponderadas por área. Este estudo tem o intuito de, inicialmente, descobrir se existem efeitos de autocorrelação espacial significativos (hipótese i.) e que variáveis podem estar perturbando o desempenho do modelo (hipótese ii.), para posteriormente, como base nisto, descobrir se existem variáveis espaciais significativas (hipótese iii.) e encontrar os melhores indicadores para o modelo (hipóteses iv. e v.).

Conforme pode ser verificado na Tabela 6, para os dois períodos (1974 e 2003), as variáveis que apresentam maiores índices de autocorrelação espacial são as que têm seus valores ponderados pela área, o que pode ser explicado pelo fato de que, conforme o critério adotado para divisão das ZTs, os efeitos da MAUP (Modifiable Areal Unit Problem) podem acabar por camuflar os efeitos da Autocorrelação Espacial existente nas variáveis. Tal efeito se mostrou mais evidente também na variável dependente VPBD quando ponderada pela área (D_VPBD).

Analisando-se os dados da Tabela 6 verifica-se que a dependência espacial das variáveis é mais evidente para os dados de 1974, em razão do Índice I de Moran ser mais elevado. A variável mais afetada é D_DOM, seguida por D_FRO e D_POP. Pode-se concluir que as variáveis sofrem os efeitos da autocorrelação espacial.

Posteriormente à análise que indicou as variáveis D_POP, D_DOM e D_FRO como as que têm os maiores índices de autocorrelação espacial, foi verificado, através da análise de correlação espacial destas variáveis com a variável dependente, qual seria a mais indicada e quais e que tipos de indicadores (Globais ou Locais) poderiam contribuir de forma mais 
significativa para o modelo Alternativo ajustado aos dados de 1974. Para tanto, fez-se a comparação de características coincidentes nos Box Maps, para definição das variáveis espaciais globais, e dos Moran Maps, para as variáveis espaciais locais (Figuras 13 e 14).

Tabela 6 - Autocorrelação espacial das variáveis de 1974 e 2003 (I de Moran)

Variável Descrição:

I de Moran (1974) I de Moran (2003)

\begin{tabular}{llll}
\hline POP & População total por ZT & 0,21 & 0,20 \\
\hline DOM & Número total de domicílios por ZT & 0,28 & 0,13 \\
\hline FRO & Frota particular total por ZT & 0,43 & 0,23 \\
\hline D_POP & Densidade populacional (POP $\left./ \mathrm{km}^{2}\right)$ & 0,73 & 0,57 \\
\hline D_DOM & Densidade de domicílios (DOM $\left./ \mathrm{km}^{2}\right)$ & 0,78 & 0,68 \\
\hline D_FRO & Densidade da frota particular $\left(\mathrm{FRO} / \mathrm{km}^{2}\right)$ & 0,76 & 0,64 \\
\hline VPBD & Viagens produzidas de base domiciliar & 0,34 & 0,14 \\
\hline D_VPBD & Densidade de VPBD (VPBD $\left./ \mathrm{km}^{2}\right)$ & 0,75 & 0,66 \\
\hline
\end{tabular}

Analisando-se os mapas e procedendo-se a contagem de ZTs coincidentes nos Box Maps (conforme o exemplo apresentado na Figura 13), verificou-se que as variáveis mais correlacionadas espacialmente com VPBD são D_FRO e D_POP, com 56\% de áreas coincidentes, enquanto D_DOM apresentou $42 \%$ de coincidência. Como as variáveis Globais são definidas por variáveis binárias para os quadrantes, fez-se necessário analisar quais quadrantes são mais correlacionados. O quadrante 2 (Q2) para a variável D_FRO apresentou o maior percentual (28\%), seguido por quadrante 2 (Q2) para a variável D_POP (27\%), quadrante 1 (Q1) para D_FRO (24\%) e quadrante 1 (Q1) para D_POP (23\%).

A análise dos indicadores locais de dependência espacial mais significativos foi através da análise de coincidência nos Moran Maps (conforme exemplo apresentado na Figura 14), que mostrou D_DOM e D_POP com 63\% de ZTs coincidentes, seguidas por D_FRO com 61\%. Considerando-se apenas os quadrantes cujos indicadores locais são significativos, os percentuais de coincidência são de 17\% para D_POP e D_FRO e de 16\% para D_DOM.

Para os dados de 2003, a variável D_POP que se apresentou mais correlacionada espacialmente com VPBD apresentou apenas $20 \%$ de ZTs coincidentes no Box Map. Na análise dos Moran Maps, nenhuma área em quadrante significativo apresentou coincidência. Verificou-se, desta forma, que não existe, para os dados de 2003, a mesma correlação espacial observada entre os dados de 1974, considerando a variável dependente VPBD e as variáveis explicativas correspondentes. 


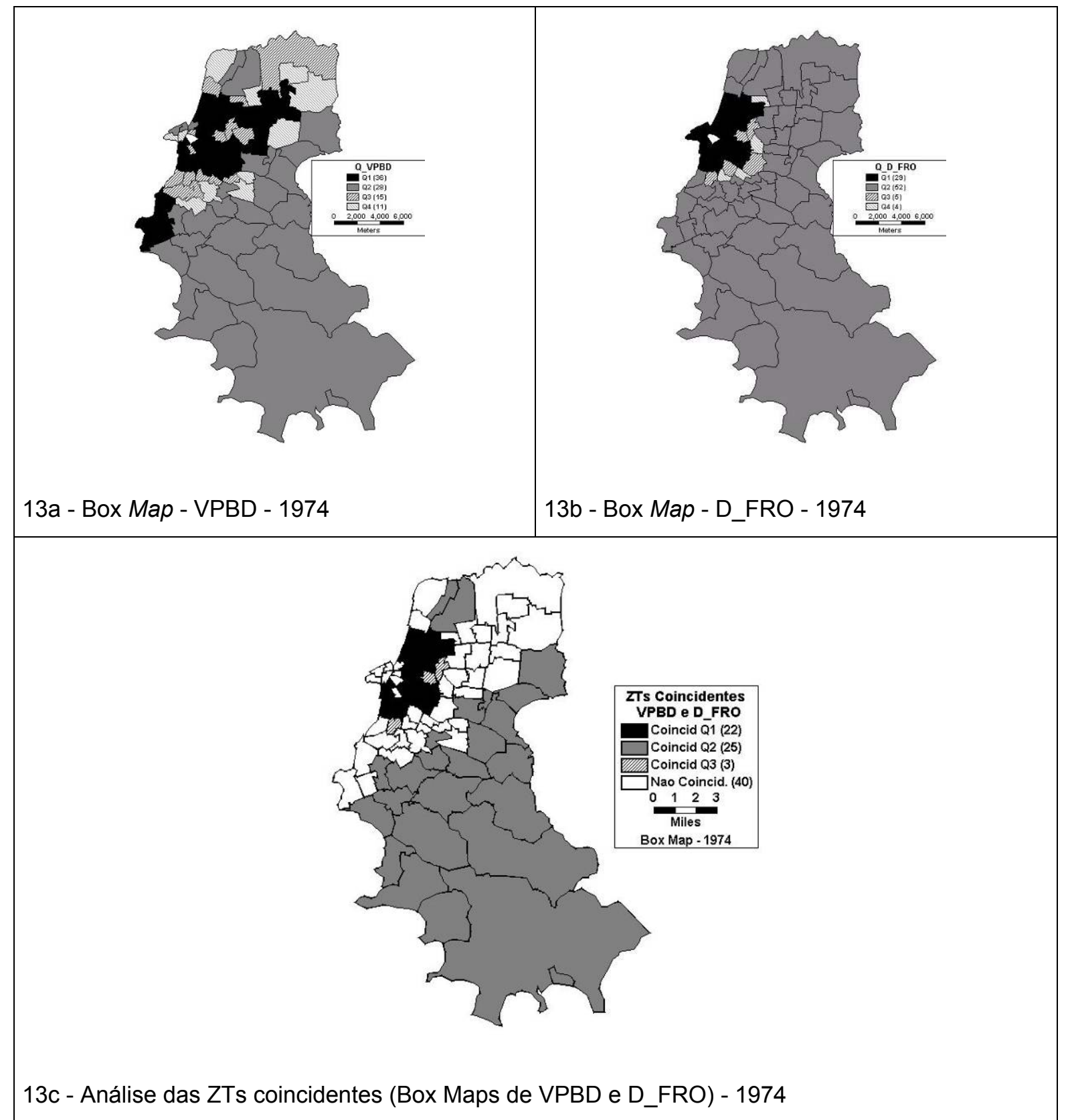

Figura 13 - Exemplo de análise de correlação espacial para obtenção de variáveis espaciais globais - Box Maps dos dados de 1974 (VPBD e D_FRO)

\section{Variáveis candidatas a variáveis espaciais para VPBD}

Tomando-se por base as cinco hipóteses iniciais e, também, os resultados das análises espaciais apresentadas pode-se concluir que, como os índices de autocorrelação espacial são significativos para os dados de 1974 e menos significativos para os dados 2003 é mais provável que algum ruído seja transmitido para o modelo tradicional de VPBD ajustado aos dados de 1974 do que para o modelo ajustado aos dados de 2003. Da mesma forma, é mais provável que a consideração de variáveis espaciais resulte em melhorias para o modelo de 1974 do que para o modelo de 2003. 


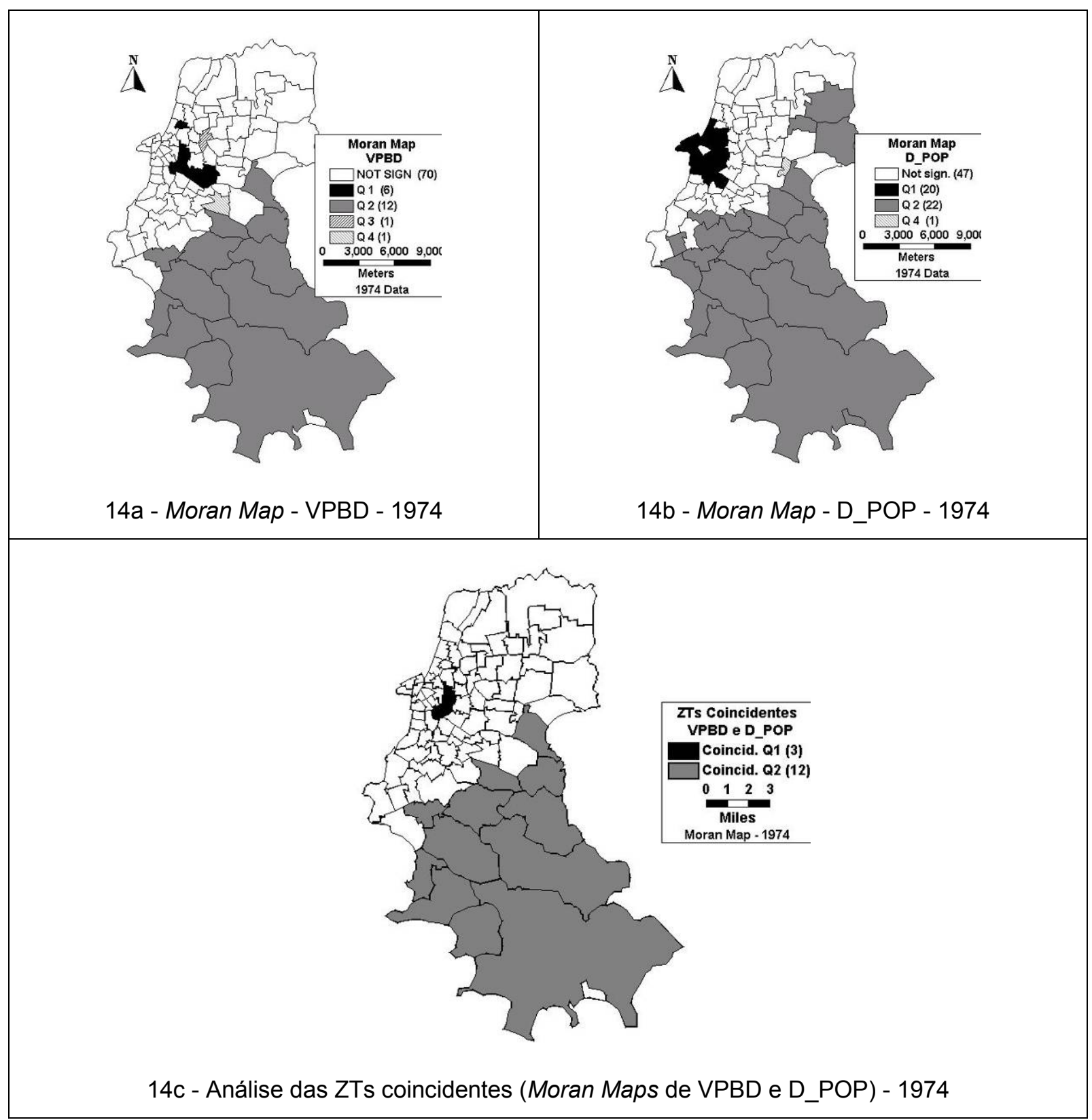

Figura 14 - Exemplo de análise de correlação espacial para obtenção de variáveis espaciais locais - Moran Maps dos dados de 1974 (VPBD e D_POP)

Considerando-se, ainda, o método de especificação do modelo espacial Alternativo, concluise que para obtenção de um modelo espacial para VPBD ajustado aos dados de 1974, as variáveis candidatas como variáveis espaciais globais, em ordem decrescente de probabilidade de apresentarem significância para o modelo, são: D_FRO_Q2; D_POP_Q2; D_FRO_Q1 e D_POP_Q1. Da mesma forma, conclui-se que as variáveis candidatas como variáveis espaciais locais, em ordem decrescente de probabilidade de apresentarem significância para o modelo, são: LISA_D_DOM e LISA_D_POP, seguidas de LISA_D_FRO. 
No caso dos dados de 2003, se houver algum efeito de dependência espacial perturbando as estimativas de VPBD através do modelo Tradicional, a variável espacial capaz de amenizar a transmissão deste efeito aos resíduos é a variável espacial global D_POP_Q2. Com base nestes resultados e nas análises apresentadas no item 6.2.2, as cinco hipóteses são testadas e é avaliada a validade do método para a definição de variáveis espaciais mais significativas para especificação de modelos Alternativos.

\subsubsection{Obtenção de modelos espaciais mais adequados}

Adicionalmente, aos modelos com indicadores Locais e Globais de dependência espacial ou modelos Alternativos (LOPES, 2005), outras formas de consideração de efeitos espaciais foram investigadas para aplicação e avaliação. Dentre as técnicas aplicadas nos vinte e seis (26) estudos apresentados na Tabela 1 (item 2.3 do Capítulo 2), foram selecionadas aquelas com foco em efeitos de dependência espacial (24 estudos). Dentre estes, vinte (20) estudos usam algum tipo de técnica de regressão espacial. Dentre as técnicas de regressão espacial mais aplicadas está o modelo espacial Auto-Regressivo Misto (Spatial Auto Regressive = SAR ou Spatial Lag Model), com oito (8) aplicações e o modelo do Erro Espacial (Conditional Auto Regressive = CAR ou Spatial Error Model), com dez (10) aplicações, todas elas bem sucedidas. Duas (2) aplicações usam uma variação do modelo de erro espacial.

Considerando apenas os seis (6) estudos que envolvem a modelagem de demanda por transportes e dados de áreas, quatro (4) estudos aplicam, com sucesso, o modelo de Erro Espacial, sendo que um destes estudos aplica, também, o modelo Auto-Regressivo Misto. Estes dois modelos são de fácil aplicação, pois estão disponíveis através do Software GeoDa, de domínio público na internet (GEODA CENTER, s. d.).

Com base no exposto, concluiu-se que os modelos espaciais mais adequados para aplicação e avaliação com o intuito de selecionar a técnica mais adequada para os dados de Porto Alegre foram: o modelo de Erro Espacial, o modelo Auto-Regressivo Misto e os modelos Alternativos (Global e Local). As três técnicas de modelagem espacial foram então aplicadas e os resultados das estimativas foram comparados com os obtidos através da técnica usualmente aplicada de análise de regressão múltipla, denominada de modelo Tradicional, o qual, ajustado aos dados de 1974, incluía duas variáveis explicativas (População total e Frota de veículos particulares) para estimativa de VPBD.

\section{Regressão múltipla - Modelo Tradicional - dados de 1974 - (T74)}

Inicialmente, ajustou-se, através do software GeoDa, o modelo de Regressão Múltipla T74 (Tabela 7) para os dados de 1974, utilizando-se como variáveis independentes os valores padronizados de população (POPpd) e frota (FROpd), já verificadas como as mais 
significativas entre as variáveis tradicionais explicativas para VPBD em 1974. Maiores detalhes da escolha e da padronização destas variáveis podem ser verificados em Lopes (2005), Lopes e Silva (2005) e Lopes, Brondino e Silva $(2005,2006)$. O valor do $R^{2}$ ajustado obtido foi de 0,91 , indicando que o modelo explica bem a variância da variável dependente (VPBD). Os testes $t$-Student realizados para os parâmetros do modelo revelaram que todos são significativos a um nível de significância de $5 \%$.

O software GeoDa fornece, como possível indicador de multicolinearidade, o número de condição da matriz $X^{\prime} X$, que corresponde à razão entre o maior e o menor dos autovalores dessa matriz. A análise dos autovalores da matriz $X^{\prime} X$ pode identificar a natureza aproximada da dependência linear entre as variáveis independentes, possibilitando, dessa forma, a deteção da existência de multicolinearidade. Assim, quando o número de condição é superior a 30, diz-se que a matriz é mal condicionada e há um forte indicativo da presença de multicolinearidade entre as variáveis independentes. Para o modelo T74, obteve-se um número de condição igual a 2,31, indicando que as variáveis independentes são não correlacionadas. Além do número de condição, diferenças significativas entre os valores do $\mathrm{R}^{2}$ e o $\mathrm{R}^{2}$ ajustado também podem fornecer indícios da existência de multicolinearidade.

A análise de normalidade do resíduo é testada através do Teste de Jarque-Bera. Para o modelo Tradicional T74, o valor desta estatística ficou igual a 27,52, indicando que a hipótese de Distribuição Normal foi rejeitada a um nível de significância de $5 \%(p=0,000)$. Os valores das estatísticas de teste para homocedasticidade do resíduo ficaram conflitantes, uma vez que o Teste de Breusch-Pagan $(p=0,030)$ e o de White $(p=0,002)$ rejeitam a hipótese de homocedasticidade e o Teste de Koenker-Bassett não rejeitou a hipótese $(\mathrm{p}=$ 0,217 ), todos num nível de significância de $5 \%$. Uma vez que dois testes rejeitaram, a opção foi por assumir que o resíduo não apresenta variância constante. Esses resultados, resumidos na Tabela 7 , indicam a não adequabilidade do modelo ajustado.

A análise do modelo prossegue com um diagnóstico para verificar a dependência espacial. Para este estudo, o software fornece as seguintes estatísticas: I de Moran (erro), Multiplicador de Lagrange (lag), Multiplicador de Lagrange Robusto (lag), Multiplicador de Lagrange (erro), Multiplicador de Lagrange Robusto (erro) e Multiplicador de Lagrange (SARMA). Dessas estatísticas, somente o Multiplicador de Lagrange Robusto (lag) foi considerado não significativo ( $p=0,338$ ). Dessa forma, a hipótese de existência de autocorrelação espacial não foi rejeitada. A significância da estatística Multiplicador de Lagrange (erro) $(\mathrm{p}=0,000)$ sugeriu a especificação de um modelo de Erro Espacial (ERR74), apresentado na Tabela 7. 


\section{Regressão espacial - Modelo de Erro Espacial - dados de 1974 - (ERR74)}

No modelo ERR74 o valor de $\lambda$ (coeficiente espacial autoregressivo - LAMBDA) estimado foi de 0,645 e, pelo teste $z$ aplicado, foi considerado altamente significativo, assim como os outros parâmetros do modelo. O valor do Log-Verossimilhança (LIK) igual a -787,01, obtido para este modelo, aumentou em relação ao obtido para o modelo tradicional $\mathrm{T74}$, cujo valor foi de -802,34. Observou-se, também, uma queda nos valores das estatísticas AIC e SC (Schuarz Criterion), de 1610,68 (modelo T74) para 1580,02 (modelo ERR74) e de 1618,18 (modelo T74) para 1587,52 (modelo ERR74). Essas observações conduzem à conclusão de que o modelo ERR74 ajustou-se melhor aos dados. Entretanto, o Teste de Breusch-Pagan rejeita a hipótese de homocedasticidade $(p=0,002)$, enquanto que o Teste da Razão de Verossimilhança (Likelihood Ratio) ainda sugere a existência de dependência espacial $(p=0,000)$. Esses resultados indicam que, apesar da melhora relativa com relação ao modelo Tradicional T74, o modelo de Erro Espacial ERR74 ainda não está bem especificado.

\section{Regressão múltipla com indicadores locais e globais de dependência espacial - Modelo Alternativo Global Local - Dados de 1974 (AGL74)}

O passo seguinte foi ajustar um modelo que inclui os indicadores locais e globais de dependência espacial, como variáveis espaciais, e refazer a estimativa por Mínimos Quadrados Ordinários. O modelo Alternativo do tipo AGL foi o que melhor se ajustou aos dados de 1974 nos estudos anteriores. As variáveis incluídas foram LISA_DPOPpd, LISA_DDOMpd, que representam os indicadores locais de dependência espacial padronizados para densidade populacional e densidade de domicílios, respectivamente, e também a variável DFRO_Q2, que é a variável binária para o quadrante 2 da densidade da frota. O coeficiente $\mathrm{R}^{2}$ ajustado para o modelo Alternativo AGL74 foi de 0,95 (Tabela 7).

Os testes $t$-Student efetuados para os parâmetros do modelo AGL74 indicaram que todos são significativos a um nível de $5 \%$ de significância. O número de condição fornecido foi de 9,04 , indicando que as variáveis independentes utilizadas não são altamente correlacionadas. Por sua vez, o Teste de Jarque-Bera não rejeitou a hipótese de normalidade dos resíduos, enquanto que os testes de Breusch-Pagan e Koenker-Bassett indicaram a não rejeição da hipótese de que os resíduos apresentam variância constante (Tabela 7). 
Tabela 7 - Resumo dos modelos estudados e resultados obtidos nas estimativas.

\begin{tabular}{|c|c|c|c|c|c|c|c|c|c|}
\hline & & & \multicolumn{3}{|c|}{$\begin{array}{c}\text { MODELOS AJUSTADOS } \\
\text { PARA } 1974\end{array}$} & \multicolumn{4}{|c|}{$\begin{array}{c}\text { MODELOS DE } 1974 \\
\text { CALIBRADOS PARA } 2003\end{array}$} \\
\hline \multirow{2}{*}{\multicolumn{3}{|c|}{ RESULTADOS DA CALIBRAÇÃO }} & \multirow{2}{*}{$\begin{array}{c}\text { TRAD } \\
\text { T74 }\end{array}$} & \multicolumn{2}{|c|}{ ALTERNATIVOS } & \multirow{2}{*}{$\begin{array}{c}\text { TRAD } \\
\text { T03 }\end{array}$} & \multicolumn{3}{|c|}{ ALTERNATIVOS } \\
\hline & & & & ERR74 & AGL74 & & LAG03 & ERR03 & AGL03 \\
\hline \multirow{15}{*}{ 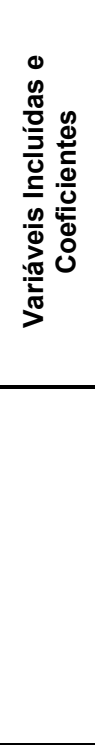 } & \multirow{3}{*}{ Tradicionais } & CONSTANTE & 12195,39 & 12228,53 & 13208,62 & 22297,67 & 24187,01 & 22267,34 & 23544,71 \\
\hline & & POP_pd & 3911,28 & 4024,45 & 4222,64 & 13313,16 & 13371,81 & 14307,39 & 14347,30 \\
\hline & & FRO_pd & 2576,06 & 2224,64 & 2121,47 & 2784,55 & 2983,45 & 2116,31 & 2215,73 \\
\hline & Lag coeff. (Rho) & W_VPBD & & & & & $-0,08428$ & & \\
\hline & Lag coeff. (Lambda) & LAMBDA & & 0,64521 & & & & 0,45726 & \\
\hline & \multirow{3}{*}{$\begin{array}{l}\text { Indicadores } \\
\text { Globais e Locais } \\
\text { Dep. Espacial }\end{array}$} & DFRO_Q2 & & & $-1753,66$ & & & & $-2737,394$ \\
\hline & & LISA_DPOPpd & & & 1819,50 & & & & 202,05 \\
\hline & & LISA_DDOMpd & & & $-2930,96$ & & & & 469,29 \\
\hline & \multirow{7}{*}{ Diagnóstico } & $\mathbf{R}^{2}$ & 0,92 & 0,95 & 0,96 & 0,97 & 0,97 & 0,98 & 0,98 \\
\hline & & $\mathrm{R}^{2} \mathrm{AJ}$ & 0,91 & * & 0,95 & 0,97 & * & * & 0,98 \\
\hline & & LIK & $-802,341$ & $-787,01$ & $-773,20$ & $-838,703$ & $-835,54$ & $-833,58$ & $-824,05$ \\
\hline & & sc & 1618,18 & 1587,52 & 1573,40 & 1690,91 & 1689,07 & 1680,65 & 1675,09 \\
\hline & & AIC & 1610,68 & 1580,02 & 1558,40 & 1683,41 & 1679,07 & 1673,15 & 1660,09 \\
\hline & & ERM & $12 \%$ & $15 \%$ & $10 \%$ & $12 \%$ & $14 \%$ & $12 \%$ & $12 \%$ \\
\hline & & I_Moran (erro) & 0,43 & 0,46 & 0,06 & 0,22 & 0,17 & 0,32 & $-0,01$ \\
\hline \multirow{6}{*}{ 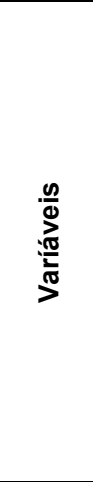 } & \multirow{2}{*}{ Significância } & $T$-statistic & Satisf. & * & Satisf. & Satisf. & * & * & Não S. \\
\hline & & Z-value & * & Satisf. & * & * & Satisf. & Satisf. & * \\
\hline & Multicolinearidade & $\begin{array}{l}\text { Número de } \\
\text { Condição da } \\
\text { Matriz }\end{array}$ & $\begin{array}{l}\text { Satisf. } \\
(2,30)\end{array}$ & * & $\begin{array}{l}\text { Satisf. } \\
(9,04)\end{array}$ & $\begin{array}{l}\text { Satisf. } \\
(2,98)\end{array}$ & * & * & $\begin{array}{l}\text { Satisf. } \\
(9,386)\end{array}$ \\
\hline & \multirow{3}{*}{$\begin{array}{l}\text { Dependência } \\
\text { Espacial }\end{array}$} & $\begin{array}{l}\text { ML (Lag) } \\
\text { (p-value) }\end{array}$ & $\begin{array}{l}\text { Não S. } \\
(0,001)\end{array}$ & * & $\begin{array}{l}\text { Satisf. } \\
(0,340)\end{array}$ & $\begin{array}{l}\text { Não S. } \\
(0,017)\end{array}$ & * & * & $\begin{array}{l}\text { Satisf. } \\
(0,239)\end{array}$ \\
\hline & & $\begin{array}{l}\text { ML Robusto } \\
\text { (Lag) } \\
\text { (p-value) }\end{array}$ & $\begin{array}{l}\text { Satisf. } \\
(0,338)\end{array}$ & * & $\begin{array}{l}\text { Satisf. } \\
(0,502)\end{array}$ & $\begin{array}{l}\text { Não S. } \\
(0,002)\end{array}$ & * & * & $\begin{array}{l}\text { Satisf. } \\
(0,243)\end{array}$ \\
\hline & & $\begin{array}{l}\text { Likelihood } \\
\text { Ratio } \\
\text { (p-value) } \\
\end{array}$ & * & $\begin{array}{l}\text { Não S. } \\
(0,000)\end{array}$ & * & * & $\begin{array}{l}\text { Não S. } \\
(0,012)\end{array}$ & $\begin{array}{l}\text { Não S. } \\
(0,001)\end{array}$ & * \\
\hline \multirow{8}{*}{$\begin{array}{l}\stackrel{n}{o} \\
\stackrel{0}{0} \\
\frac{0}{9} \\
\stackrel{0}{x}\end{array}$} & Distribuição Normal & $\begin{array}{l}\text { Jarque-Bera } \\
\text { (p-value) }\end{array}$ & $\begin{array}{l}\text { Não S. } \\
(0,000)\end{array}$ & * & $\begin{array}{l}\text { Satisf. } \\
(0,669)\end{array}$ & $\begin{array}{l}\text { Satisf. } \\
(0,416)\end{array}$ & * & * & $\begin{array}{l}\text { Satisf. } \\
(0,527)\end{array}$ \\
\hline & \multirow{3}{*}{ Homocedasticidade } & $\begin{array}{l}\text { Breusch- } \\
\text { Pegan } \\
\text { (p-value) }\end{array}$ & $\begin{array}{l}\text { Não S. } \\
(0,030)\end{array}$ & $\begin{array}{c}\text { Não } \\
\text { S. }(0,002)\end{array}$ & $\begin{array}{l}\text { Satisf. } \\
(0,191)\end{array}$ & $\begin{array}{l}\text { Não S. } \\
(0,043)\end{array}$ & $\begin{array}{l}\text { Não S. } \\
(0,014)\end{array}$ & $\begin{array}{l}\text { Não S. } \\
(0,013)\end{array}$ & $\begin{array}{l}\text { Satisf. } \\
(0,180)\end{array}$ \\
\hline & & $\begin{array}{l}\text { Koenker- } \\
\text { Bassett } \\
\text { (p-value) }\end{array}$ & $\begin{array}{l}\text { Satisf. } \\
(0,217)\end{array}$ & * & $\begin{array}{l}\text { Satisf. } \\
(0,285)\end{array}$ & $\begin{array}{l}\text { Satisf. } \\
(0,074)\end{array}$ & * & * & $\begin{array}{l}\text { Satisf. } \\
(0,299)\end{array}$ \\
\hline & & $\begin{array}{l}\text { White } \\
\text { (p-value) }\end{array}$ & $\begin{array}{l}\text { Não S. } \\
(0,002)\end{array}$ & * & * & $\begin{array}{l}\text { Não S. } \\
(0,005)\end{array}$ & * & * & * \\
\hline & \multirow{4}{*}{$\begin{array}{l}\text { Dependência } \\
\text { Espacial }\end{array}$} & $\begin{array}{l}\text { de Moran } \\
\text { (erro) } \\
\text { (p-value) }\end{array}$ & $\begin{array}{l}\text { Não S. } \\
(0,000)\end{array}$ & * & $\begin{array}{l}\text { Satisf. } \\
(0,087)\end{array}$ & $\begin{array}{l}\text { Não S. } \\
(0,000)\end{array}$ & * & * & $\begin{array}{l}\text { Satisf. } \\
(0,687)\end{array}$ \\
\hline & & $\begin{array}{l}\text { ML (erro) } \\
\text { (p-value) }\end{array}$ & $\begin{array}{l}\text { Não S. } \\
(0,000)\end{array}$ & * & $\begin{array}{l}\text { Satisf. } \\
(0,322)\end{array}$ & $\begin{array}{l}\text { Não S. } \\
(0,001)\end{array}$ & * & * & $\begin{array}{l}\text { Satisf. } \\
(0,874)\end{array}$ \\
\hline & & $\begin{array}{l}\text { ML Robusto } \\
\text { (erro) } \\
\text { (p-value) }\end{array}$ & $\begin{array}{l}\text { Não S. } \\
(0,000)\end{array}$ & * & $\begin{array}{l}\text { Satisf. } \\
(0,470)\end{array}$ & $\begin{array}{l}\text { Não S. } \\
(0,000)\end{array}$ & * & * & $\begin{array}{l}\text { Satisf. } \\
(0,946)\end{array}$ \\
\hline & & $\begin{array}{l}\text { ML SARMA } \\
\text { (p-value) }\end{array}$ & $\begin{array}{l}\text { Não S. } \\
(0,000)\end{array}$ & * & $\begin{array}{l}\text { Satisf. } \\
(0,489)\end{array}$ & $\begin{array}{l}\text { Não S. } \\
(0,000)\end{array}$ & * & * & $\begin{array}{l}\text { Satisf. } \\
(0,499)\end{array}$ \\
\hline Notas: & $\begin{array}{r}\text { Satisf. - } \\
\text { Não S. - } \\
\text { * } \\
\text { Em Negrito - }\end{array}$ & \multicolumn{8}{|c|}{$\begin{array}{l}\text { Resultado do teste satisfatório (boa qualidade do ajuste do modelo) } \\
\text { Resultado do teste não satisfatório (má qualidade do ajuste do modelo) } \\
\text { Não existente para este modelo } \\
\text { Os melhores resultados obtidos }\end{array}$} \\
\hline
\end{tabular}


Além disso, pôde-se observar um aumento no LIK para -773,2 e uma diminuição nas estatísticas AIC e SC, cujos valores obtidos foram 1558,4 e 1573,4, respectivamente. Esses resultados indicam a superioridade do modelo Alternativo AGL74 em relação aos modelos Tradicional T74 e de Erro Espacial ERR74, previamente ajustados. Como esperado, os resultados do diagnóstico de dependência espacial rejeitaram a hipótese de autocorrelação espacial dos resíduos. A superioridade deste modelo também pode ser verificada nos Moran Maps da Figura 15, que apresentam a dispersão dos resíduos dos três modelos analisados.

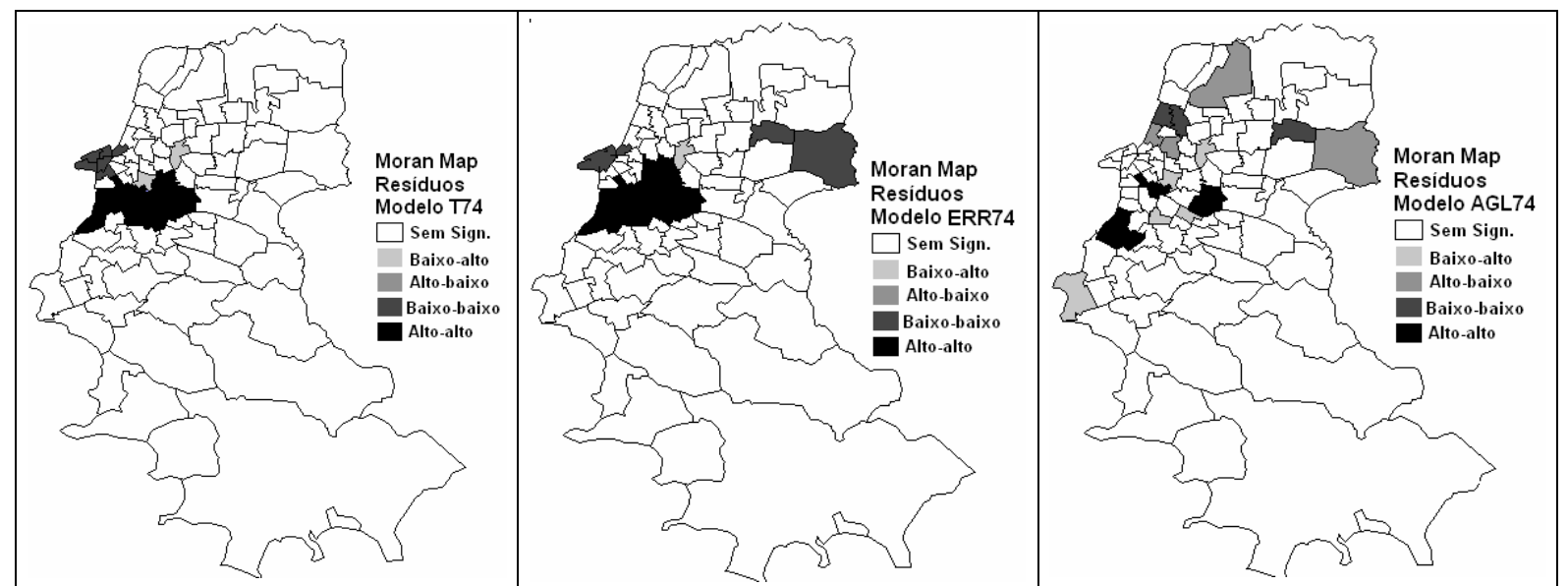

Figura 15 - Distribuição espacial dos resíduos das estimativas com os modelos Tradicional (T74), de Erro Espacial (ERR74) e Alternativo Global Local (AGL74).

\section{Validação do Modelo Alternativo Global Local (AGL74)}

A sequência do estudo foi a aplicação do modelo AGL74 para "estimativas futuras", utilizando-se, desta vez, como base de dados para aferição do desempenho do modelo, as informações de pesquisa O-D de 2003. Como parâmetros de comparação, foram utilizadas as estimativas para o ano 2003, fornecidas pelo modelo T74. Pôde-se observar que os valores de VPBD, estimados pelos dois modelos para o ano 2003, são significativamente mais baixos, representando valores 59\% (modelo AGL74) e 55\% (modelo T74) dos observados na realidade (EDOM 2003).

Isso indica que os coeficientes das variáveis nos modelos ajustados para 1974 estão subestimando o fenômeno em estudo. Acredita-se que os altos valores de erros nas estimativas para 2003, cujos agrupamentos significativos podem ser observados na Figura 16, podem ser explicados pela dinâmica apresentada pelo desenvolvimento urbano, que acarretaram, ao longo desses quase 30 anos, alterações nas relações entre as diferentes variáveis com o fenômeno estudado, modificando inclusive os padrões espaciais. 


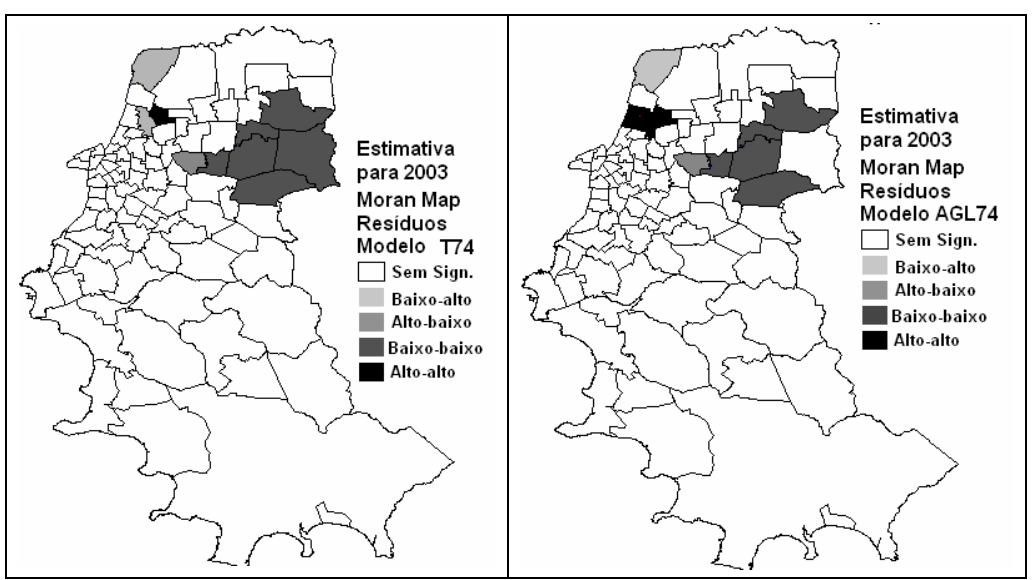

Figura. 16 - Distribuição espacial dos erros das estimativas futuras (2003) com os modelos Tradicional (T74) e Alternativo Global Local (AGL74).

A alteração nos padrões espaciais das viagens produzidas de base domiciliar de 1974 para 2003 pode ser observada nos mapas temáticos da Figura 17. Enquanto que em 1974 as zonas com maior número de viagens eram localizadas na região central, em 2003 percebese um espalhamento com tendência para a região leste, sudoeste e sudeste do município.

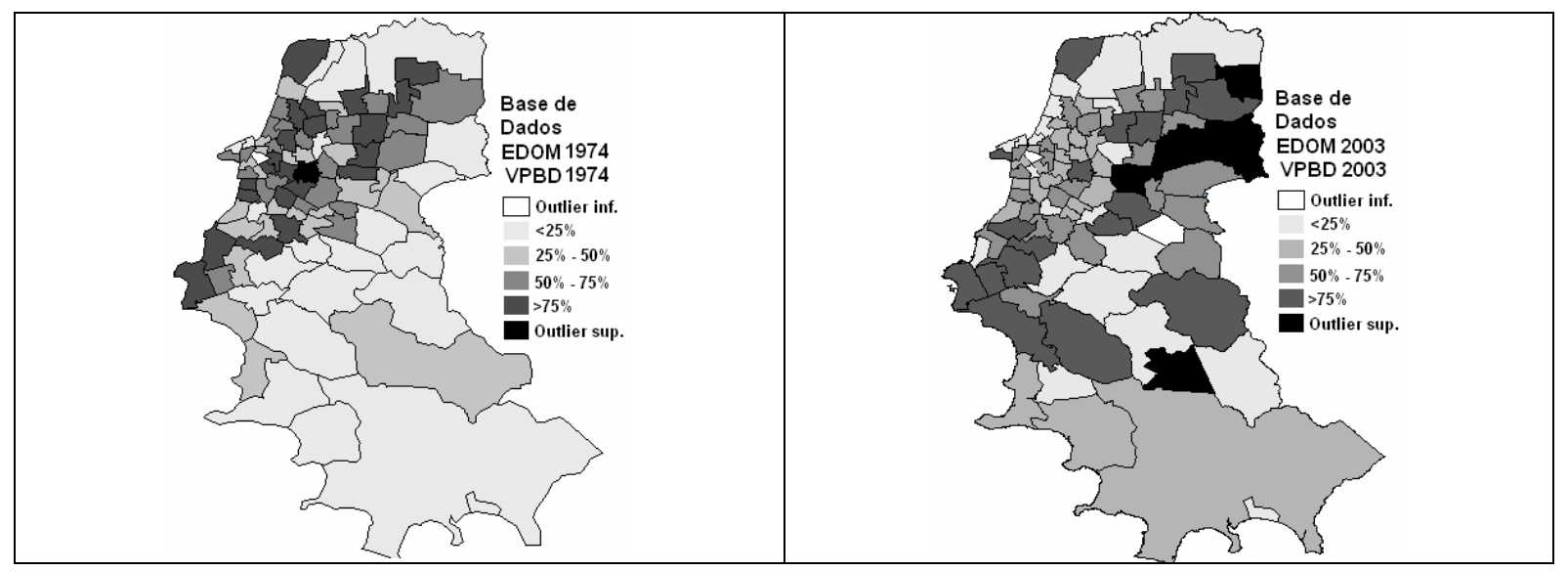

Figura 17 - Distribuição espacial de VPBD em 1974 e em 2003.

\section{Regressão Múltipla - Modelo Tradicional - dados de 2003 - T03}

Com o intuito de entender melhor a dinâmica e as alterações espaciais observadas, ajustase, inicialmente, para os dados de 2003, o mesmo modelo Tradicional, que agora recebe o nome de T03 (Tabela 7). Verifica-se uma grande diferença dos coeficientes em relação aos modelos ajustados para 1974. Essa diferença é significativa para a variável população $(3,4$ vezes maior) e para a constante do modelo (1,8 vezes maior). Porém, a variável frota, que é a segunda variável tradicional incluída, se mantém dentro da mesma ordem de grandeza. Como os valores das variáveis estão padronizados para os dados dos dois períodos, os resultados indicam que a variável População no ano de 2003 passou a exercer maior impacto na demanda em relação ao ano de 1974, enquanto que o mesmo não ocorreu em relação à variável Frota. 
Como pode ser observado na Tabela 7, o modelo T03 apresentou um valor de $\mathrm{R}^{2}$ ajustado igual a 0,97, indicando que o modelo explica bem a variância da variável dependente VPBD. Os testes $t$-Student realizados indicaram que todos os parâmetros do modelo T03 são significativos a um nível de $5 \%$ de significância. O número de condição obtido foi de 2,98, indicando que as variáveis independentes não são altamente correlacionadas. As mesmas ferramentas utilizadas para analisar os resíduos foram utilizadas no diagnóstico do modelo T03 e todos os testes realizados indicaram que as hipóteses de distribuição normal e homocedasticidade não foram rejeitadas a um nível de $5 \%$ de significância. Por sua vez, os testes para dependência espacial rejeitaram a hipótese de inexistência de autocorrelação espacial. Dessa forma, sugere-se o ajuste de um modelo de LAG espacial e outro de erro espacial, apresentados na Tabela 7 como LAG03 e ERR03, respectivamente.

\section{Regressão Espacial - Modelo Espacial Autoregressivo - dados de 2003 - LAG03}

O valor de $\rho$ (coeficiente espacial autoregressivo - $W_{-} V P B D$ ) igual a $-0,084$ obtido para o modelo LAG03 foi considerado significativo pelo teste $z$ empregado, assim como todos os outros parâmetros do modelo. Por outro lado, o Teste de Breusch-Pagan indicou a rejeição da hipótese de que os resíduos apresentam variância constante. O teste da Razão de Verossimilhança rejeitou a hipótese de não existência de autocorrelação espacial. Esses resultados indicam que o modelo LAG03 não é adequado (Tabela 7).

\section{Regressão Espacial - Modelo de Erro Espacial - dados de 2003 - ERR03}

Para o modelo ERR03, observou-se um valor de $\lambda(L A M B D A)$ igual a 0,46 , o qual também foi considerado significativo pelo teste $z$ empregado, como também o foram os outros parâmetros estimados. O teste de Breusch-Pagan e o teste da Razão de Verossimilhança, respectivamente, continuam apontando a rejeição da hipótese de homocedasticidade e a existência de autocorrelação espacial. Dessa forma, o modelo ERR03 também é inadequado para o ajuste pretendido.

\section{Regressão Múltipla com indicadores Locais e Globais de dependência espacial - Modelo Alternativo Global Local - dados de 2003 - AGL03}

Assim como foi feito para 1974, as variáveis de caráter espacial foram adicionadas ao conjunto, o que culminou no modelo AGL03, apresentado na Tabela 7. Com exceção dos coeficientes estimados para LISA_DPOPpd e LISA_DDOMpd, todos os outros parâmetros são significativos a um nível de $5 \%$ de significância. $O$ valor de $R^{2}$ ajustado foi igual a 0,98 e as hipóteses de normalidade e homocedasticidade do resíduo não foram rejeitadas a um nível de $5 \%$ de significância. O número de condição fornecido foi de 9,386, indicando que 
as variáveis independentes não são altamente correlacionadas. Os testes para diagnóstico de dependência espacial, por sua vez, rejeitaram a hipótese de autocorrelação espacial.

A Tabela 7 apresenta um resumo com todos os modelos e os resultados ( $p$-values) dos testes estatísticos analisados. Estão em destaque os melhores valores obtidos. Como pode ser observado, o modelo AGL03 foi o que apresentou maior valor para o LIK e os menores valores para $A I C$ e $S C$, indicando que este modelo é superior aos outros três na qualidade do ajuste, quando esses critérios são observados. Mais uma vez, observa-se que a inclusão de variáveis espaciais e posterior ajuste por Mínimos Quadrados Ordinários levaram a uma melhor qualidade de ajuste também para este conjunto de dados.

Como mencionado anteriormente, a idéia nesta etapa foi calibrar os modelos para 2003 com as mesmas variáveis ajustadas para 1974 e verificar o impacto nos coeficientes e os resultados dos modelos em estudo para esta base de dados. No entanto, apesar dos bons resultados do modelo AGL03, a verificação de que duas variáveis espaciais, entre as três incluídas, foram consideradas não significativas, levou à investigação de variáveis mais ajustadas aos dados de 2003. Sendo assim, da mesma forma que foi realizado para a base de 1974 e que culminou no modelo AGL74, ajustou-se um modelo para 2003 através do algoritmo stepwise.

\section{Regressão Múltipla com indicador Global de dependência espacial - Modelo Alternativo Global - dados de 2003 - AG03}

O processo que teve início com 18 variáveis potenciais da base de dados (6 tradicionais, 3 espaciais Locais e 9 espaciais Globais) resultou no modelo Alternativo AG03, apresentado na Tabela 8, que introduz, entre 3 variáveis tradicionais (POP_pd, FRO_pd e DOM_pd), uma variável espacial Global (DPOP_Q2).

As variáveis tradicionais representam os valores padronizados de população, frota e domicílios por ZT e a variável espacial representa as ZTs no quadrante 2 para a variável de densidade populacional, que é um indicador global de autocorrelação espacial. Como pode ser observado, todos os testes analisados apresentaram resultados satisfatórios e os valores de LIK, AIC e SC, assim como o ERM, que também foi analisado para todos os modelos, foram superiores ao modelo anteriormente ajustado.

Sendo assim, a hipótese de que a inclusão de indicadores de dependência espacial entre as variáveis melhora o poder preditivo do modelo foi confirmada. A superioridade dos modelos Alternativos AGL03 e AG03 sobre o modelo Tradicional T03 também pode ser observada nos Moran Maps da Figura 18, que apresentam as zonas com resíduos altos e baixos em agrupamentos significativos. O modelo T03 apresenta maior número de zonas agrupadas 
em regiões com resíduos baixos (negativos) e com resíduos altos (positivos), indicando uma tendência de subestimar ou superestimar as estimativas em determinadas regiões.

Tabela 8 - Resumo do modelo mais ajustado para os dados de 2003.

\begin{tabular}{|c|c|c|c|}
\hline & \multirow{2}{*}{\multicolumn{2}{|c|}{ MODELOS MAIS AJUSTADO PARA 2003}} \\
\hline & & & \\
\hline \multirow{2}{*}{\multicolumn{2}{|c|}{ RESULTADOS DA CALIBRAÇÃO }} & & ALTERNATIVO \\
\hline & & & AG03 \\
\hline \multirow{12}{*}{ 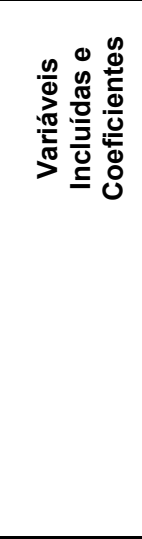 } & \multirow{5}{*}{$\begin{array}{l}\text { Tradicionais } \\
\text { Indicador Global de } \\
\text { Dependência Espacial }\end{array}$} & CONSTANTE & 22947,23 \\
\hline & & POP_pd & 7386,85 \\
\hline & & FRO_pd & 1305,66 \\
\hline & & DOM_pd & 7385,37 \\
\hline & & DPOP_Q2 & $-1538,432$ \\
\hline & \multirow{7}{*}{ Diagnóstico } & $\mathbf{R}^{2}$ & 0,98 \\
\hline & & $\mathbf{R}^{2} \mathbf{A J}$ & 0,98 \\
\hline & & LIK & $-815,86$ \\
\hline & & SC & 1654,23 \\
\hline & & AIC & 1641,73 \\
\hline & & ERM & $10 \%$ \\
\hline & & I_Moran (erro) & 0,02 \\
\hline \multirow{4}{*}{ 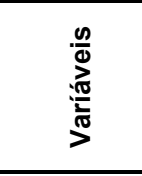 } & Significância & $T$-statistic & Satisf. \\
\hline & Multicolinearidade & Número de Condição da Matriz & Satisf. $(13,307)$ \\
\hline & \multirow{2}{*}{ Dependência Espacial } & ML (Lag) (p-value) & Satisf. $(0,352)$ \\
\hline & & ML Robusto (Lag) (p-value) & Satisf. $(0,317)$ \\
\hline \multirow{7}{*}{ 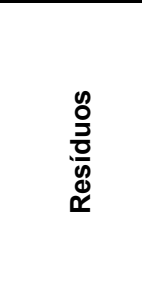 } & Distribuição Normal & Jarque-Bera ( $p$-value) & Satisf. $(0,866)$ \\
\hline & \multirow{2}{*}{ Homocedasticidade } & Breusch-Pegan (p-value) & Satisf. $(0,126)$ \\
\hline & & Koenker-Bassett (p-value) & Satisf. $(0,171)$ \\
\hline & \multirow{4}{*}{ Dependência Espacial } & I de Moran (erro) (p-value) & Satisf. $(0,455)$ \\
\hline & & $M L$ (erro) ( $p$-value) & Satisf. $(0,750)$ \\
\hline & & ML Robusto (erro) ( $p$-value) & Satisf. $(0,628)$ \\
\hline & & ML SARMA (p-value) & Satisf. $(0,577)$ \\
\hline \multirow[t]{3}{*}{ Nota: } & Satisf. - & \multicolumn{2}{|c|}{ Resultado do teste satisfatório (boa qualidade do ajuste do modelo) } \\
\hline & Não S. - & \multirow{2}{*}{\multicolumn{2}{|c|}{$\begin{array}{l}\text { Resultado do teste não satisfatório (má qualidade do ajuste do modelo) } \\
\text { Os melhores resultados obtidos }\end{array}$}} \\
\hline & Em Negrito - & & \\
\hline
\end{tabular}

\section{Regressão Múltipla - Modelo Tradicional melhor ajustado - dados de 2003 - T03aj}

Com o intuito de verificar que variáveis tradicionais mais se ajustam aos dados de 2003 e realizar o diagnóstico do modelo resultante, foi aplicado, para a base de dados de 2003, o mesmo procedimento de ajuste de um modelo somente com variáveis tradicionais, através do algoritmo stepwise. Desta vez, apresentaram-se como variáveis explicativas mais significativas para VPBD, além de população e frota, o numero de domicílios e a densidade da frota (frota $/ \mathrm{km}^{2}$ ). Verificou-se que o modelo Tradicional ajustado para 2003, com os valores padronizados dessas quatro variáveis, apresentou um bom desempenho. $O$ valor do $R^{2}$ ajustado obtido foi bastante alto $(0,98)$ e os testes $t$-Student realizados para os parâmetros do modelo também revelaram que todos são significativos a um nível de 
significância de $5 \%$. Além disso, os testes estatísticos rejeitaram a presença de autocorrelação espacial, o que pode ser constatado pelo valor do I de Moran do erro (-0,002 e $p$ value $=0,359)$ e, também, através do Moran Map não indicando a presença de agrupamentos significativos de resíduos positivos e/ou negativos.

Os resultados indicaram que, apesar de ter sido necessário especificar um modelo Alternativo para os dados de 1974 na tentativa de corrigir os problemas de dependência espacial apresentados, para os dados de 2003, como tal problema não foi verificado, não se justifica a especificação de um novo modelo Alternativo.

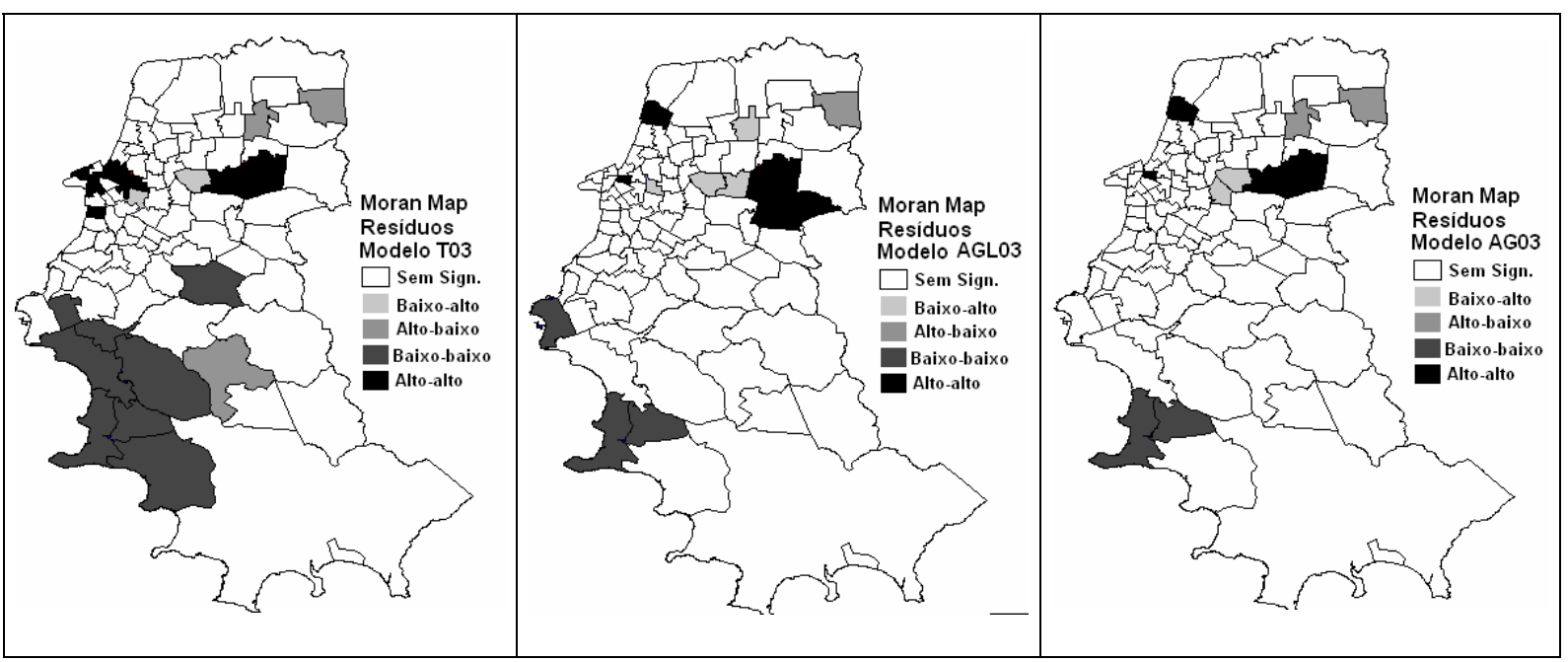

Figura 18 - Distribuição espacial dos resíduos das estimativas obtidos com os modelos Tradicional (T03), Alternativo Global Local (AGL03) e Alternativo Global (AG03).

\subsubsection{Conclusões das análises do Bloco 1}

Com as análises aqui apresentadas verificou-se que, considerando a estimativa de VPBD para os dados de Porto Alegre, existem variáveis afetadas pelo efeito de dependência espacial. No entanto, este efeito é bem mais evidente para os dados de 1974 do que para os dados de 2003. Concluiu-se que a dinâmica do desenvolvimento urbano pode acarretar alterações nos padrões espacias da cidade e que o processo de espalhamento urbano pode ser uma explicação para os índices mais baixos de autocorelação espacial verificados em 2003. Isto sugere a necessidade de uma investigação mais detalhada da evolução destes padrões ao longo do tempo. Acredita-se que exista uma tendência de formação de subcentros urbanos na periferia, criando novos aglomerados espacias e tendendo também a aumentar novamente os índices de autocorrelação espacial.

Nenhuma das cinco hipóteses iniciais quanto à obtenção de indicadores de dependência espacial foi refutada. Foram verificados altos valores para o I de Moran entre os dados de 
1974 e a inclusão de variáveis espaciais amenizou o problema, impedindo que estes efeitos fossem transmitidos de forma significativa para os resíduos das estimativas de VPBD (hipótese i). As variáveis que serviram de base para obtenção de variáveis espacias com maior significância estatística foram as que apresentaram maiores índices de autocorrelação espacial, ou seja, as variáveis ponderadas pela área da ZT (hipótese ii). Explorar os efeitos da MAUP pode ser um caminho para tentar explicar este fenômeno.

As hipóteses iii, iv e v, também não foram refutadas, pois, conforme visto nas análises do modelo alternativo ajustado para 1974 (AGL74), apresentam significância estatística, além das duas variáveis socioeconômicas tradicionais (POP e FRO), uma variável espacial global (D_FRO_Q2) e duas variáveis espaciais locais (LISA_D_DOM e LISA_D_POP). Ou seja, conforme a hipótese iii, as variáveis D_FRO e D_DOM e D_POP apresentarm correlação espacial com a variável dependente VPBD, na análise dos Box Maps e Moran Maps, e apresentaram grau de significância estatística para o modelo, compatíveis com o grau de correlação espacial, destas, com a variável dependente.

O mesmo foi observado para os dados de 2003, uma vez que no modelo Alternativo que melhor se ajustou (AG03) somente uma variável espacial global apresentou significância estatística (D_POP_Q2), que foi a mesma que correspondeu ao único indicador que apresentou uma leve correlação espacial com a variável dependente. Este fator, somado aos índices mais baixos de autocorrelação espacial para as variáveis de 2003, justificaram o fato de que a especificação de um modelo espacial para VPBD é importante para 1974, porém não necessária para 2003.

Entre as três técnicas de modelagem espaciais avaliadas, o modelo de Erro Espacial, o modelo Auto-Regressivo Misto e os modelos Alternativos (Global e Local), a última foi a que se mostrou mais eficiente e, portanto, selecionada como base para obtenção dos modelos espaciais na sequência da pesquisa. O método avaliado, de seleção de variáveis espaciais para especificação dos modelos Alternativos se mostrou eficiente, uma vez que as cinco hipóteses não foram refutadas. A aplicação deste método nas próximas etapas desta pesquisa, quando forem investigados outros modelos de geração de viagens (atração de viagens e modelos mais desagregados por modo e motivo de viagem), facilitará o processo de especificação destes modelos. 


\subsection{Bloco 2 - Ajuste de um Modelo LUTI Dinâmico}

As análises apresentadas neste item constituem o Bloco 2 do método, cujo intuito é avaliar a viabilidade de se ajustar um modelo LUTI Dinâmico à cidade de Porto Alegre atendendo o segundo objetivo especifico desta pesquisa. O primeiro passo foi o levantamento de modelos LUTI existentes, para a seleção do mais adequado aos propósitos desta pesquisa.

\subsubsection{Seleção de um Modelo LUTI Dinâmico}

Após a análise preliminar de mais de vinte alternativas, foi selecionado para aplicação nesta pesquisa o modelo MARS (Metropolitan Activity Relocation Simulator). Trata-se de um modelo estratégico, dinâmico e integrado de uso do solo e transportes, desenvolvido por Pfaffenbichler (2003) na Universidade de Tecnologia de Viena, Áustria. O MARS é baseado em Sistemas Dinâmicos, usando a plataforma do software Vensim ${ }_{\circledast}$. A hipótese básica subjacente ao MARS é que os assentamentos urbanos e as atividades a eles inerentes são sistemas auto-organizados. O desenvolvimento do sistema MARS começou no ano 2000.

Muitas razões levaram a escolha do modelo MARS para aplicação nesta pesquisa:

- É um modelo amplamente testado e vem sofrendo melhorias constantes a cada nova cidade onde é aplicado para estudos de desenvolvimento urbano sustentável. Hoje o MARS encontra-se em operação em 16 cidades da Europa e da Ásia e em fase de desenvolvimento nos Estados Unidos, na cidade de Washington, D.C.

- Foi originalmente desenvolvido e calibrado para a cidade de Viena, que apresenta dimensões e população semelhantes às da cidade de Porto Alegre - RS, onde está sendo desenvolvido o estudo de caso desta pesquisa.

- Está prevista, também, a integração do MARS com o modelo de simulação e alocação de tráfego SATURN (Simulation and Assignment of Traffic in Urban Road Network) (VAN VLIET, 2010) desenvolvido na Universidade de Leeds, Inglaterra. Trata-se de um projeto antigo dos pesquisadores das instituições onde os dois modelos foram concebidos, cuja concretização constituirá mais um passo do contínuo processo de melhorias do MARS (PFAFFENBICHLER, 2008). O SATURN já é utilizado pela EPTC desde 2000, portanto Porto Alegre representa uma excelente oportunidade de análise da aplicação integrada dos dois modelos.

Já existe uma relação de parceria entre as universidades de Leeds (ITS) e de Viena (TUW), além do contato estabelecido entre o Prof. Antônio Nelson Rodrigues da Silva (STT-EESCUSP) e o Prof. Paul Pfaffenbichler da TUW, que já esteve no Brasil como professor visitante. 
Assim, há maior facilidade para o desenvolvimento do trabalho com as duas ferramentas (MARS e SATURN) fundamentais para a pesquisa.

A flexibilidade do modelo MARS, permitindo melhorias, também foi fundamental na escolha, uma vez que se pretende incorporar as variáveis espaciais. E, avaliando-se o modelo MARS através da verificação dos itens relevantes, conforme check list já discutido, os resultados obtidos demonstram que o modelo atende aos objetivos desta pesquisa:

Qual o propósito e adequação ao estudo de planos estratégicos de mobilidade sustentável?

O propósito do MARS é de natureza estratégica, avaliando a capacidade de políticas urbanas para promover a sustentabilidade. O MARS é parte de uma estrutura de busca de melhores combinações de políticas. Foi desenvolvido para permitir a avaliação de estratégias de uso do solo e de transportes sem necessidade excessiva de dados;

Como são consideradas as variáveis importantes para o tema?

As variáveis endógenas do MARS são: desenvolvimento de unidades habitacionais, área verde disponível, aluguel, preço da terra, distribuição de moradores que se mudam do local, distribuição de moradores que se mudam para o local, fator de demanda de unidades habitacionais, distribuição de postos de trabalho no setor secundário, distribuição de postos de trabalho do setor terciário, número de viagens, distribuição das viagens, divisão modal, velocidade dos automóveis, acessibilidade e consumo de combustíveis fósseis. São variáveis exógenas: taxa de crescimento potencial de residentes, taxa de crescimento de postos de trabalho (indústria e serviços), taxa de crescimento de proprietários de veículos particulares, renda familiar, tamanho da família, mobilidade potencial da família, desenvolvimentos tecnológicos, consumo de combustíveis, políticas. Foram excluídas do MARS as variáveis: transporte de cargas, desenvolvimento econômico geral, processo de envelhecimento da população e escolha de rotas para os veículos particulares. Cabe salientar que a inclusão da última seria contemplada com a conexão direta MARS-SATURN.

O modelo inclui, como elementos endógenos, fatores que podem mudar significativamente ao longo do período de análise?

O período de análise considerado quando do uso do MARS deve ser superior a 20 anos, sendo 30 anos o valor mais utilizado. Dois fatores que podem mudar significativamente durante o período de análise são: o número de proprietários de veículos particulares e os avanços tecnológicos para redução do consumo de combustíveis. No entanto, taxas de crescimento para essas duas variáveis podem ser definidas.

O nível de agregação dos dados e das análises do modelo é compatível com o propósito do estudo? 
A busca da sustentabilidade é um processo que envolve múltiplas atividades. A hipótese subjacente ao MARS é que os sistemas de transporte e uso do solo urbano são autoorganizáveis. Não é necessário conhecer o comportamento exato de cada elemento individualmente para predizer o comportamento global de um sistema auto-organizável. Desta forma, parece apropriado utilizar, neste caso, um elevado nível de agregação espacial e dos grupos de indivíduos, especialmente se a preocupação é a sustentabilidade vista de forma agregada e objetiva.

O modelo considera os efeitos da dependência espacial ou permite a inclusão de tais indicadores?

O modelo não considera os efeitos da dependência espacial, mas tem flexibilidade suficiente para que se possa alterar sua estrutura no sentido de permitir inserir novas variáveis e substituir os submodelos de transporte pelos modelos espaciais de transporte.

\subsubsection{Avaliação da viabilidade de ajuste do modelo MARS à cidade de Porto Alegre}

O ajuste de um modelo dinâmico de uso do solo e transportes implica em deixá-lo adequado às características de evolução de uma determinada cidade, com capacidade para produzir estimativas futuras o mais próximo possível da realidade. Sendo assim, para o ajuste do modelo MARS para uma determinada cidade, este processo contempla todos os passos, que permitem a alimentação do modelo, calibração dos submodelos de uso do solo e de transportes e também a validação desses para previsões futuras.

O inicio do processo de ajuste do modelo MARS à cidade de Porto Alegre (MARS POA) ocorreu juntamente com a etapa de qualificação para uso da ferramenta. Primeiramente foi analisado como ocorreu o processo de ajuste do modelo MARS para a cidade de Viena, no sentido de entender que variáveis obter e que fontes de dados buscar, para seguir o mesmo método para o ajuste do MARS POA. O aprofundamento sobre a função de cada variável nos submodelos, as interrelações entre eles e as características das variáveis de saída ocorreu nas etapas de alimentação e de calibração do modelo, durante o treinamento prático. Algumas dificuldades foram enfrentadas nas primeiras fases de ajuste do MARS POA. Além disso, algumas alternativas tiveram de ser analisadas para resolver os problemas de transferência do modelo para a realidade brasileira.

A qualificação para o uso do MARS iniciou em estudo teórico introduzido através de disciplina ministrada pelo seu criador, Prof. Paul Pfaffenbichler, como professor visitante no Departamento de Transportes da EESC-USP. Posteriormente, o treinamento prático ocorreu através de um estágio de seis meses na Universidade Tecnológica de Viena, no programa de doutorado sanduíche com apoio da CAPES, sob supervisão do Prof. Paul Pfaffenbichler. 
O aprendizado sobre o MARS foi aprofundado através do ajuste do modelo MARS POA, o que possibilitou a melhor compreensão das variáveis de entrada, as respectivas funções nos submodelos e forma dos dados de saída do modelo para calibração e validação. Juntamente com o supervisor e em discussões com outros pesquisadores da TUW, da Áustria e de outros países da Europa, com diferentes experiências de ajuste de modelos MARS para as diversas cidades do mundo onde já foi ou está sendo implantado, foi possível compreender o processo e definir os passos necessários até a validação do modelo. No período de estágio foram, também, discutidos os primeiros passos para a conexão MARSSATURN, com o Prof. Simon Shepherd (ITS, Leeds) assim como foram verificadas as possibilidades para introduzir as variáveis espaciais.

\section{Análise da viabilidade de transferência do MARS para o contexto brasileiro}

Antes da transferência do modelo MARS para uma cidade com diferentes características, costumes e infraestrutura de transporte, como é o caso de Porto Alegre, é importante conhecer outras experiências e que tipo de adequações foram realizadas.

O MARS já foi aplicado em várias outras cidades, em diferentes contextos. No entanto o maior desafio foi a aplicação do MARS para o contexto de cidades asiáticas, que são bem diferenciadas em relação à Europa. Os desafios desta aplicação estavam relacionados à disponibilidade de dados, modos de transportes bem diferenciados e grandes diferenças no nível de moradias.

Foram avaliados os processos de ajuste e adequações do MARS para oito aplicações do modelo, apresentadas no item 3.7 do Capítulo 3. Entre estas, está o modelo original ajustado para Viena, para o qual foi realizada a análise mais detalhada, procurando seguir, na medida do possível, o mesmo processo de ajuste para Porto Alegre.

\section{Levantamento, tratamento e análise dos dados}

Para o criador do MARS, a coleta de dados é uma das etapas mais importantes do ajuste de um modelo. Sem dados de boa qualidade mesmo o melhor modelo produz resultados ruins. Para o modelo integrado de uso do solo e transportes MARS uma quantidade considerável de dados é necessária. Para facilitar a coleta de dados, foi desenvolvida a "interface de dados para o usuário do MARS" (MARS data user interface) em MS Excel® (Figura19). 


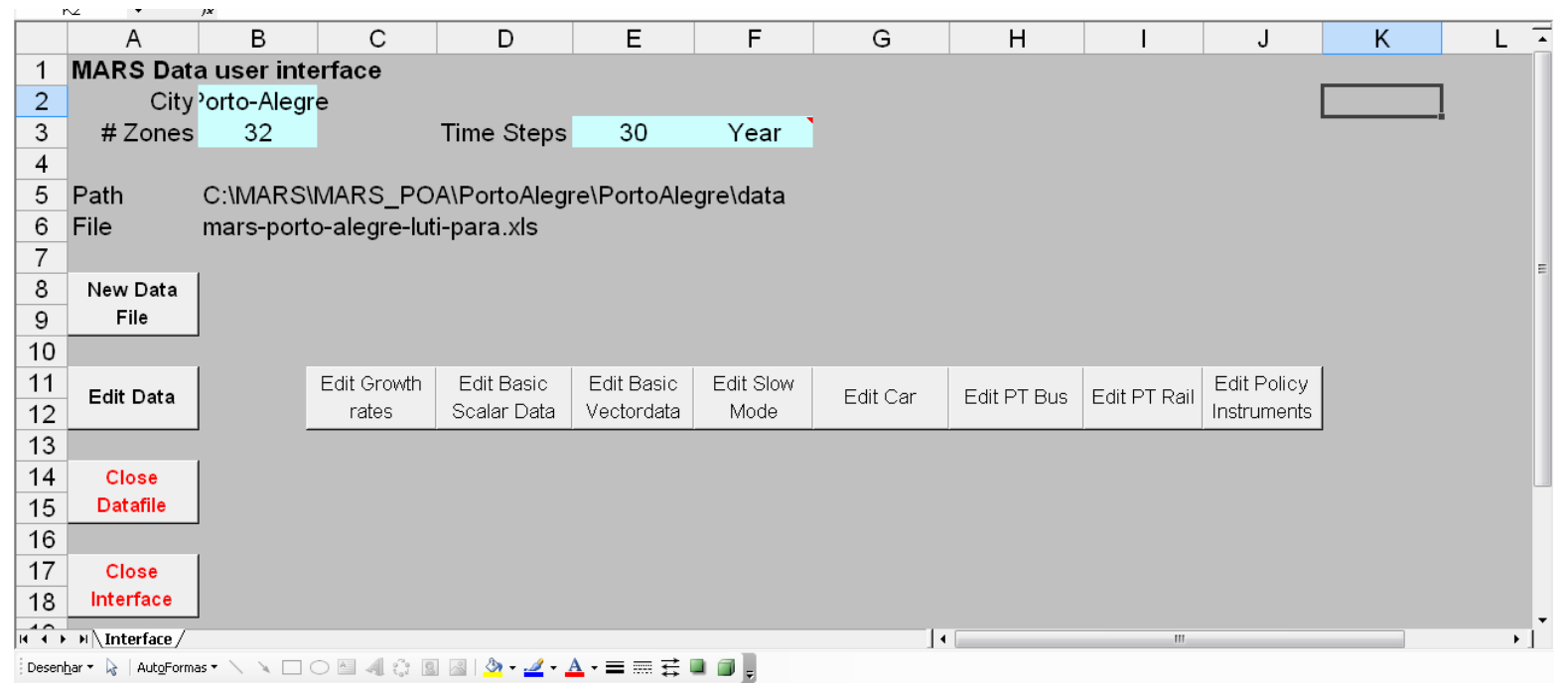

Figura 19 - Interface para alimentação do modelo MARS - "interface de dados para o usuário do MARS" (MARS data user interface) em MS Excel®.

Também foi criado, pelo autor do MARS, um Guia de Coleta de Dados (mais detalhes em: Guidance to data collection using the MARS data user, interface disponível na página virtual do MARS), que explica como usar a interface e esclarece detalhes sobre cada uma das noventa (90) variáveis, que são alimentadas através de vinte nove (29) diferentes planilhas. As varáveis foram organizadas em oito (8) grupos, conforme as características específicas e níveis de agregação. Cada um destes grupos aparece nos botões da interface e, por sua vez, abrem uma ou várias planilhas para alimentação das diferentes variáveis, dentro do módulo de configuração de cenários. Os grupos são compostos de variáveis com as seguintes características:

1. Taxas de crescimento (Growth Rates): são quatro (4) variáveis que se referem às taxas de crescimentos anuais (por exemplo, população residente, postos de trabalho por setor e posse de veículos particulares) para cada ano do período de análise, que é definido a priori como 30 anos;

2. Dados Escalares Básicos (Basic Scalar Data): são dezesseis (16) variáveis que representam valores médios para a área de estudo e são ajustados para o ano base. Referem-se a: mobilidade da população; características de moradia; capacidade das vias; velocidade média de pedestres; taxa de ocupação de veículos; percentual da população com carteira de motorista; custos percebidos pelo usuário na decisão de viajar de carro; quilometragem percorrida por ano pelo transporte público;

3. Dados Vetoriais Básicos (Basic Vector Data): são vinte cinco (25) variáveis que se referem aos dados por zona de tráfego (ZT). São eles: residentes e domicílios, condição de moradia, emprego, posse de veículos, área e desenvolvimento possível de usos residenciais, comércio e serviço ou industriais, e valor médio da terra; 
4. Modo Lento (Slow Mode): matriz de distâncias entre ZTs para o modo a pé e bicicleta; 5. Automóvel (Car): são dezesseis (16) variáveis vetoriais (para cada ZT) que são dados relativos ao uso do automóvel particular (por exemplo, tempo médio de caminhada da origem e/ou destino para o local de estacionamento; tempo médio para encontrar vaga no local de destino; estacionamentos - custo, vagas disponíveis). Além destas, mais seis (6) matrizes O-D de velocidade, distância e custo de pedágio, devem ser informadas para a"hora pico" e de "entre pico";

6. TP Ônibus (PT Bus): são onze (11) matrizes O-D e referem-se ao transporte público (TP) por ônibus (distância média percorrida; intervalos (headways) médios; tempo médio gasto em transbordo; percentual do TP que opera em vias segregadas; velocidade média; custos). Estes dados também são informados para a "hora pico" e de "entre pico";

7. TP Trilhos (PT Rail): são onze (11) matrizes O-D análogas ao "PT Bus", mas para modos de grande capacidade sobre trilhos;

8. Políticas (Policy Instruments): contempla o módulo de configuração das diferentes políticas a serem testadas e que poderão ser facilmente manipuladas e combinadas pelo usuário através da ferramenta "Flight simulator".

Além dos dados de entrada para o ano base (início da simulação) que são as mais de 90 variáveis apresentadas, são necessários, também, dados de viagem (por modo e por motivo), para o ano base e para anos posteriores, a fim de possibilitar a calibração e validação dos submodelos de transportes para a cidade definida. Da mesma forma são necessárias informações demográficas, socioeconômicas e de uso do solo, de anos posteriores para testar o ajuste dos submodelos de uso do solo. Sendo assim, uma estratégia razoável é definir como ano-base de vinte a trinta anos antes da data atual, ou seja, a data mais antiga em que exista registro das informações necessárias e, desta forma, possibilitar o uso de dados mais recentes para validar o modelo.

\section{Modelo MARS POA - Levantamento das possíveis fontes de dados}

Foram levantados todos os dados existentes que permitissem a alimentação, calibração e validação do modelo MARS para Porto Alegre (MARS POA). Sendo assim, além dos dados de entrada para o ano base (início da simulação) e que servem para calibração do modelo, foram levantadas todas as possíveis fontes de dados históricos posteriores, para a validação do modelo. O estudo de caso para a cidade de Porto Alegre contou com dados de:

1. Pesquisas de Origem e Destino (O-D) através de Entrevista Domiciliar realizadas em 1974 (EDOM 74) para a RMPA (Região Metropolitana de Porto Alegre), em 
1986 (EDOM 86) e a EDOM 2003, para a cidade de Porto Alegre (RIO GRANDE DO SUL, 1976, 1989; PORTO ALEGRE, 2004);

2. Instituto Brasileiro de Geografia e Estatística (IBGE): Dados de população e emprego dos censos demográficos de 1970, 1980, 1991 e 2000 e das contagens populacionais de 1996 e 2007 (IBGE, 1973, 1982, 1991, 1996, 2003, 2007). Alguns destes dados já estavam georreferenciados por setores censitários nas bases internas da EPTC - Empresa Pública de Transportes e Circulação de Porto Alegre;

3. Departamento de Trânsito do Estado do Rio Grande do Sul (DETRAN-RS): dados históricos de posse de veículos desde 1980 (dados internos) e estatísticas de frota e condutores disponíveis na web (DETRAN-RS);

4. Prefeitura Municipal de Porto Alegre (PMPA):

a. Secretaria Municipal da Fazenda (SMF): dados internos do cadastro imobiliário sobre pesquisa de valores do terreno realizada de 1995 a 2008 e levantamento anual de imóveis para o Imposto Predial Territorial Urbano (IPTU) de 2008;

b. Secretaria de Planejamento Municipal (SPM): Dados de uso do solo do I Plano Diretor de Desenvolvimento Urbano de Porto Alegre (I PDDU) de 1979, do Plano Diretor de Desenvolvimento Urbano e Ambiental (PDDUA) e de estudos sobre transporte urbano e sobre vazios urbanos realizados nas décadas de 70 e 80, respectivamente (PORTO ALEGRE, 1978, 1979, 1989, 1999);

5. EPTC: Dados internos das bases georreferenciadas de transporte, trânsito e rede viária, estatísticas de acidentes de trânsito e de viagens de transporte público, resultados de pesquisas de tráfego e de transporte público, assim como dados de modelo de simulação e alocação de tráfego (SATURN);

6. SECOVI-RS (Sindicato da Habitação) e SINDUSCON-RS (Sindicato da Indústria da Construção Civil) - Dados Imobiliários diversos fornecidos mediante solicitação.

\section{Definição do Ano Base e do Zoneamento}

Com a existência de dados de viagem da EDOM 74 (RS, 1976) e, além disto, com os dados socioeconômicos, demográficos e de uso do solo para a década de 70 (IBGE, 1973 e PORTO ALEGRE, 1979) pretendia-se ajustar, inicialmente, um modelo MARS para Porto Alegre com dados de 1974. Os submodelos de transporte seriam calibrados para a divisão modal observada em 1974 e os submodelos de uso do solo seriam calibrados para as 
mudanças ocorridas durante o período de 1974 a 1980 na população, no número de unidades habitacionais e nos postos de trabalho, com base nos dados do Censo (IBGE, 1982).

Para o processo de validação dos submodelos de transporte e de uso do solo do MARS POA74 seriam usadas as bases de dados da EDOM 86 e da EDOM 2003 (RS, 1989; PORTO ALEGRE, 2004) e os dados dos Censos de 1991 e 2000 (IBGE, 1991, 2003). Mesmo sabendo-se que muitos dados não existiam em meio digital e outros dados deveriam ser estimados, ainda não se sabia a dimensão do trabalho e do problema, sem antes avaliar o que se tinha.

Estando o MARS-POA74 baseado em grande parte nos dados da EDOM 74 utilizou-se, para Porto Alegre, o zoneamento definido para a referida pesquisa. O modelo de Porto Alegre resultou em 96 áreas de análise baseadas nas 96 Zonas de Tráfego (ZTs) definidas para a cidade de Porto Alegre em 1974.

\section{Modelo MARS-POA74}

Iniciou-se então o processo de compilação, análise e tratamento dos dados para a alimentação do modelo MARS-POA74. Como são muitas variáveis envolvidas e que deveriam ser retiradas de diferentes fontes, estando em diferentes formatos, níveis de agregação e zoneamentos, foi necessário criar uma planilha de acompanhamento, que foi denominada de "Guia de Coleta de Dados". A planilha, baseada na similar desenvolvida pelo criador do MARS, foi útil para auxiliar no processo de coleta quando da solicitação dos dados aos órgãos responsáveis, pois constavam todas as variáveis já traduzidas para o português, com a explicação mais detalhada. Além disto, foi essencial para acompanhar o andamento do processo de coleta e de alimentação dos dados no modelo e para a avaliação da real situação para esta etapa do processo de ajuste do MARS. As Tabelas 9 a 11 apresentam um resumo dos resultados dos registros na "Guia de Coleta de Dados" para o MARS-POA74, cuja análise levou a desistência do ajuste do modelo com ano base 1974.

A Guia de Coleta de Dados para Porto Alegre foi organizada da seguinte forma:

1. Uma coluna com todos os dados divididos pela função - no caso das Tabelas 9 a 11 são dados para a alimentação do modelo. Estes, por sua vez são subdivididos pela característica e nível de agregação (cinco subdivisões destacadas nas linhas amarelas), e ainda pelo tipo de dados (se de população, emprego, moradia, características de mobilidade, infraestrutura de transportes e uso do solo). Sendo assim, as 90 variáveis de alimentação do modelo foram agrupadas como segue: 
2. Taxas anuais de crescimento, que são 4 variáveis para a área de estudo e para os 30 anos de análise desde o ano-base. Ou seja, 120 células a serem preenchidas no modelo, cujos totais são apresentados nas linhas de cor lilás "SITUAÇÃO PARA RODAR O MODELO", nas colunas denominadas VAR e ANOS (Tabela 9).

3. Dados escalares básicos, que são indicadores do ano-base para a área de estudo. São 16 variáveis ao todo e 16 células a serem preenchidas (linha lilás, colunas VAR e ÁREA, Tabela 9);

4. Dados Vetoriais Básicos, que são dados por área de análise, ou seja, para cada uma das 96 ZTs de Porto Alegre. São ao todo 25 variáveis e 2400 células a serem preenchidas (Tabela 10);

5. Dados Vetoriais de Automóvel, da mesma forma que o anterior, são dados para as 96 ZTs de cada uma das 16 variáveis, ou seja, 1536 células a serem preenchidas (Tabela 10);

6. Matrizes O-D, ou seja, 9216 células (96 x 96), que devem ser preenchidas para as 29 variáveis nesta categoria. São 7 variáveis referentes ao uso de automóvel, 11 referentes ao uso de transporte público por ônibus (foram incluídas nesta categoria, para Porto Alegre, as vans denominadas "Táxi Lotação") e 11 referentes ao uso de transporte público sobre trilhos (Tabela 11);

7. Duas colunas que indicam, no topo, o ANO BASE do modelo. No caso das Tabelas 9 a 11, o ano referência para os dados a serem obtidos é 1974. Logo abaixo as colunas COLETA e INPUT, cujas células podem ser preenchidas com "OK" (verde) ou "no aguardo" (amarela), ou "não seria possível obter as variáveis" (laranja), sendo assim:

a. COLETA: Somente seria OK (verde), caso já se tivesse adquirido o material, fonte de dados, de onde pudessem ser retiradas as informações para a referida variável. Quando os dados já haviam sido solicitados aos órgãos responsáveis, mas estavam no aguardo do recebimento, a respectiva célula era amarela. Se já se constatava a não existência do referido dado, a célula era laranja;

b. INPUT: Só seria preenchida com OK (verde) caso todo o tratamento do dado já tivesse sido realizado para adequá-lo as exigências de formato e unidades requeridas pelo modelo. Ficaria amarelo enquanto os dados estivessem no 
aguardo, ou ainda em processo de tratamento. Da mesma forma, a célula laranja indicaria a impossibilidade de obter tal variável.

8. Na coluna "IMPL. FUT.", destacada em magenta no cabeçalho, era preenchido com "SIM" se a variável apenas seria considerada em anos subsequentes, caso não existisse uma determinada infraestrutura ou política na época, ou mesmo, se pudesse ser modificada posteriormente. Por exemplo, no caso da variável Moradia (Área construída/Área do terreno, Tabela 10), que indica um índice determinado pelos planos diretores de desenvolvimento urbano (PDDU), o IA (índice de aproveitamento) sofreria mudança para algumas áreas com a implementação de PDDUs futuros. Da mesma forma, as variáveis relacionadas com estacionamentos de curta permanência não existiam em 1974, porém a chamada Área Azul (estacionamentos com parquímetros) seria implantada mais tarde em Porto Alegre, no decorrer dos 30 anos de análise. O mesmo se aplica para o Transporte Público por Táxi Lotação e sobre trilhos. Todas estas variáveis deveriam ser alimentadas no módulo específico de "Configuração de Políticas" (Tabela 9).

9. As 4 colunas em tons de azul representam problemas verificados nos dados para obtenção das referidas variáveis e foram divididos em 4 categorias diferentes:

a. Problema 1 - Diz respeito à forma dos dados, que poderiam ser mapas, tabelas e relatórios em papel, relatórios muito extensos e desagregados (muito detalhados), para os quais deveria ser verificada a possibilidade e quais tratamentos seriam necessários para transformá-los em um dado digital, compatível com o formato solicitado pelo modelo;

b. Problema 2 - Diz respeito à não existência do referido dado. Neste caso deveria ser verificada a possibilidade de serem estimados de forma indireta, com base em dados de outra época, em outras fontes, ou através da análise de outras informações combinadas.

c. Problema 3 - Diz respeito ao nível de agregação de dados. Entravam nesta categoria, por exemplo, dados com diferentes formas de zoneamento que não coincidiam com as ZTs definidas para 1974. Dados obtidos por setores censitários, ou por bairros, ou mesmo derivados e estimados por pesquisas O-D posteriores deveriam passar por processo de compatibilização com os limites do zoneamento definido para o MARS POA1974. 
d. Problema 4 - Diz respeito à incongruência (contradição, incoerência) verificada em alguns dados, quando comparados com outras fontes, ou até outras variáveis da mesma fonte, com as quais deveria existir certa coerência. Por exemplo, o número de viagens a trabalho de uma determinada ZT contando apenas a primeira viagem do dia de cada pessoa não poderia ser maior que o número de pessoas empregadas naquela $\mathrm{ZT}$.

10. As 4 colunas em tons de verde dizem respeito às soluções encontradas e/ou tratamentos aplicados para resolver os problemas verificados. Foram divididos em 4 categorias diferentes, indicadas por:

a. DIG - Significa que os dados foram de alguma forma transformados em formato digital (digitalizados) para que as informações pudessem ser extraídas e transformadas na variável em questão. Diferentes processos foram aplicados como, por exemplo, escanear um mapa originalmente em papel ou fotografá-lo em partes, no caso de mapas muito grandes, escanear ou digitar uma tabela etc.

b. SIG - Significa que a informação passou por algum processo de geoprocessamento, ou análise espacial em SIG, como, por exemplo:

i. Importar e georreferenciar imagens de mapas e a partir destas criar um arquivo de dados geográficos em SIG contendo as áreas com os atributos correspondentes (por exemplo, para obtenção das áreas de análise do MARS-POA74 com base nas ZTs da EDOM 74);

ii. Importar e georreferenciar uma tabela de dados com base em endereços para obter um arquivo de dados geográficos de pontos com os atributos correspondentes (por exemplo, as pesquisas de valores de terreno da SMF da PMPA foram fornecidas em tabelas com o endereço dos terrenos);

iii. Submeter a algum procedimento de análise espacial, como:

1. Sobreposição de camadas de áreas para obtenção dos dados de zoneamentos diferentes (setores censitários do IBGE, Unidades de Estruturação Urbana dos PDDUs, por exemplo) adequando-os às áreas de análise adotadas para o modelo; 
2. Sobreposição da camada das áreas de análise com camadas de dados em rede para estimar dados de transportes (dados vetoriais de automóvel ou matrizes O-D de TP, por exemplo);

3. Sobreposição da camada das áreas de análise com camadas de dados em pontos (obtenção dos dados vetoriais de valores médios de terreno, por exemplo);

4. Estimativas de dados que não existiam para determinadas áreas através da análise de vizinhança (valor do terreno, por exemplo);

c. CALC - Significa que a informação passou por algum processo de cálculo, ou análise estatística para estimar o dado, obter a variável como requerida pelo modelo, ou derivar a partir de outros dados (por exemplo, as taxas anuais de crescimento foram calculadas a partir de dados históricos de aumento da população, do número de empregos e da posse de veículos; todos os dados de valor monetário tiveram de ser transformados para valores em Euros, além de serem transportados para o valor da época de análise);

d. ADOT - Significa que, na falta do dado estes foram adotados com base em outras experiências semelhantes. Entra nesta condição o julgamento de especialista, que permite adotar um valor com base na experiência e no conhecimento empírico da área em análise;

11. A coluna "Nada a Fazer" significa que o dado não existe e nenhuma solução foi considerada plausível para se estimar algum valor;

12. Finalmente, na coluna "FONTE", constam as fontes de onde foram obtidos os dados, ou nas quais foram baseadas as estimativas. 
Tabela 9 - Guia de coleta de dados - MARS-POA74 - Taxas de crescimento e dados escalares básicos

\begin{tabular}{|c|c|c|c|c|c|c|c|c|c|c|c|c|c|c|c|c|c|}
\hline \multirow{3}{*}{\multicolumn{3}{|c|}{ DADOS PARA ALIMENTAÇÃO DO MARS }} & & & \multicolumn{13}{|c|}{ SITUAÇÃO } \\
\hline & & & \multirow{3}{*}{\begin{tabular}{|l|} 
VAR \\
\end{tabular}} & \multirow[b]{3}{*}{ ANOS } & \multirow{2}{*}{\multicolumn{2}{|c|}{\begin{tabular}{|c|} 
ANO BASE \\
1974 \\
\end{tabular}}} & \multirow{3}{*}{$\begin{array}{l}\text { IMPL. } \\
\text { FUT. }\end{array}$} & \multicolumn{4}{|c|}{ PROBLEMAS } & \multicolumn{4}{|c|}{ POSSIVEIS SOLUCÕES } & \multirow{3}{*}{$\begin{array}{l}\text { NADA A } \\
\text { FAZER }\end{array}$} & \multirow{3}{*}{ FONTE } \\
\hline & & & & & & & & 1 & 2 & 3 & 4 & DIG & SIG & CALC & ADOT & & \\
\hline \multicolumn{3}{|c|}{ TAXAS ANUAIS DE CRESCIMENTO (PARA 30 ANOS) } & & & Coleta & INPUT & & & & & & & & & & & \\
\hline \multicolumn{2}{|c|}{ Residentes } & & 1 & 30 & OK & OK & & $\mathrm{x}$ & & & & $\mathrm{x}$ & & $\mathrm{x}$ & & & IBGE (1970 a 2007) \\
\hline \multirow{2}{*}{\multicolumn{2}{|c|}{ Postos de Trabalho }} & Setor de Produção & 1 & 30 & OK & OK & & $\mathrm{x}$ & & & & $x$ & & $x$ & & & IBGE (1970 a 2007) \\
\hline & & Setor de Serviços & 1 & 30 & OK & OK & & $x$ & & & & $x$ & & $\mathrm{x}$ & & & IBGE (1970 a 2007) \\
\hline \multicolumn{3}{|c|}{ Posse de veículo } & 1 & 30 & OK & OK & & $\mathrm{x}$ & & & & $\mathrm{x}$ & & $\mathrm{x}$ & & & EDOM 74; DETRAN-RS \\
\hline \multicolumn{3}{|c|}{ SITUAÇÃO PARA RODAR O MODELO } & 4 & 120 & $100 \%$ & $100 \%$ & $0 \%$ & $100 \%$ & $0 \%$ & $0 \%$ & $0 \%$ & $100 \%$ & $0 \%$ & $100 \%$ & $0 \%$ & $0 \%$ & \\
\hline \multicolumn{3}{|c|}{ DADOS ESCALARES BÁSICOS (ÁREA DE ESTUDO) } & VAR & AREA & Coleta & INPUT & & & & & & & & & & & \\
\hline \multirow{2}{*}{ Mobilidade } & \multicolumn{2}{|c|}{$\begin{array}{l}\text { Número médio de viagens por pess. } \\
\text { empregada e dia de trabalho }\end{array}$} & 1 & 1 & OK & OK & & & $x$ & & & & & & $x$ & & MARS VIENA \\
\hline & \multicolumn{2}{|c|}{ Tempo médio diário em deslocamento } & 1 & 1 & OK & OK & & & $x$ & & & & & & $x$ & & EDOM 2003; VIENA \\
\hline \multirow{2}{*}{ Moradia } & \multicolumn{2}{|c|}{ Tempo médio numa mesma moradia } & 1 & 1 & OK & OK & & & $x$ & & & & & & $x$ & & MARS VIENA \\
\hline & \multicolumn{2}{|c|}{ Unidades habitacionais planejadas no ano } & 1 & 1 & OK & OK & & & $x$ & & & & & & $x$ & & MARS VIENA \\
\hline \multirow{2}{*}{$\begin{array}{l}\begin{array}{l}\text { Vel. Media } \\
\text { (pedestres) }\end{array} \\
\end{array}$} & & Pico $(\mathrm{km} / \mathrm{h})$ & 1 & 1 & OK & OK & & & $x$ & & & & & & $x$ & & MARS VIENA \\
\hline & & Entrepico $(\mathrm{km} / \mathrm{h})$ & 1 & 1 & OK & OK & & & $x$ & & & & & $x$ & $x$ & & MARS VIENA \\
\hline & \multirow{2}{*}{$\begin{array}{l}\text { Limiar } \mathrm{p} / \\
\text { aumento de } \\
\text { capacidade }\end{array}$} & $\%$ aumento & 1 & 1 & OK & OK & & & $x$ & & & & & $x$ & $x$ & & VIENA; POA \\
\hline & & $\begin{array}{l}\text { Vel. Minima aceitável } \\
(\mathrm{km} / \mathrm{h})\end{array}$ & 1 & 1 & OK & OK & & & $x$ & & & & & $x$ & $\mathrm{x}$ & & VIENA; POA \\
\hline & \multirow{2}{*}{$\begin{array}{l}\text { Taxa de } \\
\text { ocupação } \\
\text { (Auto) }\end{array}$} & Viagem trabalho & 1 & 1 & OK & OK & & $x$ & $x$ & & & & & $x$ & $x$ & & EDOM 74; VIENA \\
\hline & & Viagem não trabalho & 1 & 1 & OK & OK & & $x$ & $x$ & & & & & & $x$ & & EDOM 74; VIENA \\
\hline \multirow[t]{4}{*}{$\begin{array}{l}\text { Auto e } \\
\text { Moto }\end{array}$} & $\begin{array}{l}\text { Pesssoas } \\
\text { com }\end{array}$ & Empregados & 1 & 1 & OK & OK & & & $x$ & & & & & & $x$ & & MARS VIENA \\
\hline & Habilitação & Todos & 1 & 1 & OK & OK & & & $x$ & & & & & & $x$ & & MARS VIENA \\
\hline & $\begin{array}{r}\text { Outros custos } \\
\text { excluindo gá } \\
\text { desgast }\end{array}$ & $\begin{array}{l}\text { que dependem da distância } \\
\text { s. como lubrificantes, pneu, } \\
\text { veículo, etc (Euro/km) }\end{array}$ & 1 & 1 & OK & OK & & & $x$ & & & & & & $x$ & & FIPAI/USP \\
\hline & Percentual d & $\begin{array}{l}\text { este custo que é percebido } \\
\text { elo usuário }(\%):\end{array}$ & 1 & 1 & OK & OK & & & $x$ & & & & & & & & MARS VIENA \\
\hline Transporte & Veículo km & Hora pico & 1 & 1 & OK & OK & & $x$ & & & & & & & & & EDOM 74 \\
\hline Público & $\begin{array}{l}\text { ano base } \\
(\mathrm{km} / \mathrm{a})\end{array}$ & Entrepico & 1 & 1 & OK & OK & & $x$ & & & & & & & & & EDOM 74 \\
\hline SITUAÇÃC & O PARA ROI & JAR O MODELO & 16 & 16 & $100 \%$ & $100 \%$ & $0 \%$ & $25 \%$ & $88 \%$ & $0 \%$ & $0 \%$ & $0 \%$ & $0 \%$ & $25 \%$ & $81 \%$ & $0 \%$ & \\
\hline
\end{tabular}

A situação para rodar o modelo aparece ao final de cada uma das subdivisões de dados, e assim como os totais de variáveis e de células a serem preenchidas, apresenta a situação em relação ao percentual de dados já coletados e, também, já alimentados no modelo. Da mesma forma, são apresentados os percentuais de cada problema encontrado, assim como das possíveis soluções. Porém, a informação que realmente pesou na desistência de um ajuste do modelo MARS-POA74 foi o percentual de dados na situação "Nada a Fazer". Esta situação foi verificada para 4\% dos "Dados Vetoriais Básicos", 63\% dos "Dados Vetoriais de Automóvel", $43 \%$ das "Matrizes de automóveis" e $45 \%$ das "Matrizes de transporte público por ônibus" (ver Tabelas 10 e 11).

Considerando os TOTAIS, apresentados ao final da Tabela 11, onde são calculados os resultados para todas as noventa (90) variáveis, destaca-se que são $44 \%$ do total de dados que apresentam a situação "Nada a Fazer". Para o cálculo dos totais foram considerados os pesos de cada tipo de dado, considerando a dificuldade para obtenção em termos de estimativas. Por exemplo, para um dado do tipo matriz são 9216 células a serem estimadas para cada variável no caso da não existência do dado, enquanto que para um dado escalar é apenas uma célula a ser estimada para cada variável. Sendo assim, uma variável do tipo Matriz tem peso 9216 (no caso deste estudo que são 96 ZTs), uma variável do tipo vetorial 
tem peso 96, a do tipo escalar tem peso 1 e as taxas de crescimento tem peso 30 , já que devem ser estimadas para cada ano de análise.

Tabela 10 - Guia de coleta de dados - MARS POA74 - dados vetoriais básicos e de automóvel.

\begin{tabular}{|c|c|c|c|c|c|c|c|c|c|c|c|c|c|c|c|c|c|}
\hline \multirow{3}{*}{\multicolumn{3}{|c|}{ DADOS PARA ALIMENTAÇÃO DO MARS }} & & & \multicolumn{13}{|c|}{ SITUAÇÃO } \\
\hline & & & \multirow{3}{*}{\begin{tabular}{|l|} 
\\
VAR \\
\end{tabular}} & \multirow[b]{3}{*}{ AREAS } & \multirow{2}{*}{\multicolumn{2}{|c|}{\begin{tabular}{|c|} 
ANO BASE \\
1974 \\
\end{tabular}}} & \multirow{3}{*}{\begin{tabular}{|l} 
IMPL. \\
FUT.
\end{tabular}} & \multicolumn{4}{|c|}{ PROBLEMAS } & \multicolumn{4}{|c|}{ POSSÍVEIS SOLUCÕES } & \multirow{3}{*}{\begin{tabular}{c|} 
NADA A \\
FAZER
\end{tabular}} & \multirow{2}{*}{ FONTE } \\
\hline & & & & & & & & 1 & 2 & 3 & 4 & DIG & SIG & CALC & ADOT & & \\
\hline DADOS & VETORIAIS BÁS & ICOS (ZT - ANO BASE) & & & Coleta & INPUT & & & & & & & & & & & \\
\hline \multirow{4}{*}{ Domicilios } & \multicolumn{2}{|c|}{ Habitantes (pessoas) } & 1 & 96 & OK & OK & & $\mathrm{x}$ & & & & $\mathbf{x}$ & $\mathbf{x}$ & & & & EDOM 74 \\
\hline & \multicolumn{2}{|c|}{ Habitantes Empregados (Pess Econ. Ativas) } & 1 & 96 & OK & OK & & $x$ & & & & $x$ & $x$ & & & & EDOM 74 \\
\hline & \multicolumn{2}{|c|}{ Renda Média Domiciliar [Euro/month] } & 1 & 96 & OK & OK & & $\mathrm{x}$ & & & & $\mathbf{x}$ & $\mathrm{x}$ & & & & EDOM 74 \\
\hline & \multicolumn{2}{|c|}{ Habitantes por Domicilio } & 1 & 96 & OK & OK & & $\mathrm{x}$ & & & & $\mathbf{x}$ & $\mathrm{x}$ & & & & EDOM 74 \\
\hline & \multicolumn{2}{|c|}{ Custo médio mensal [Euro/m²] } & 1 & 96 & OK & & & & $x$ & & & & $x$ & $x$ & & & IBGE 1970; EDOM 86 \\
\hline Moradia & Área média por $r$ & noradia $\left[\mathrm{m}^{2}\right]$ & 1 & 96 & OK & & & & $x$ & & & & $x$ & $x$ & & & IBGE 1970; EDOM 86 \\
\hline Ther auria & Área Contruída/t & Área de Terreno (IA PDDU) & 1 & 96 & OK & & SIM & $\mathbf{x}$ & & $\mathrm{x}$ & & $\mathrm{x}$ & $\mathbf{x}$ & $\mathbf{x}$ & & & PDDU 1979, 1997 \\
\hline & Moradias não oc & upadas & 1 & 96 & & & & & $\mathrm{x}$ & & & & & & & $\mathrm{x}$ & \\
\hline & Postos de Trabal & & 1 & 96 & OK & & & $\mathbf{x}$ & & & & $\mathbf{x}$ & $\mathbf{x}$ & & & & EDOM 74 \\
\hline & $\%$ por setor & Produção & 1 & 96 & OK & & & $x$ & & & & $x$ & $x$ & & & & EDOM 74 \\
\hline & \%ol selul & Serviço & 1 & 96 & OK & & & $x$ & & & & $x$ & $x$ & & & & EDOM 74 \\
\hline Trabalho & $\begin{array}{l}\text { № Médio } \\
\text { Postos de }\end{array}$ & Produção & 1 & 96 & OK & OK & & & $\mathrm{x}$ & & & & & & $\mathrm{x}$ & & MARS LEEDS \\
\hline & $\begin{array}{l}\text { Trabalho por } \\
\text { empresa }\end{array}$ & Serviço & 1 & 96 & OK & OK & & & $\mathrm{x}$ & & & & & & $\mathrm{x}$ & & MARS LEEDS \\
\hline & Área média por & Produção & 1 & 96 & OK & OK & & & $x$ & & & & & & $x$ & & MARS LEEDS \\
\hline & empresa [m²] & Serviço & 1 & 96 & OK & OK & & & $x$ & & & & & & $\mathrm{x}$ & & MARS LEEDS \\
\hline Posse & Posse Auto (por & 1000 res) & 1 & 96 & OK & & & $x$ & $x$ & & & $x$ & $x$ & & & & EDOM 74 \\
\hline Veículos & Posse Moto (por & 1000 res) & 1 & 96 & OK & & & & $x$ & & & & & $x$ & & & EDOM 86 \\
\hline & Área $\left[\mathrm{km}^{2}\right]$ & & 1 & 96 & OK & OK & & $x$ & & & & $x$ & $x$ & & & & ZT EDOM 74 \\
\hline & \% Ainda desocu & pada & 1 & 96 & OK & & & $x$ & & $x$ & & & $x$ & $x$ & & & PDDU 1979, PMPA- \\
\hline & $\%$ da area & Uso Residencial & 1 & 96 & OK & & & $x$ & & $x$ & & & $x$ & $x$ & & & PDDU 1979, EDOM 74 \\
\hline Área e & $\begin{array}{l}\text { desocupada } \\
\text { que pode ser }\end{array}$ & Uso Economico & 1 & 96 & OK & & & $x$ & & $x$ & & & $x$ & $x$ & & & PDDU 1979 \\
\hline $\begin{array}{l}\text { Desenv. } \\
\text { Urbano }\end{array}$ & & De proteção ambiental & 1 & 96 & OK & & & $x$ & & $x$ & & & $x$ & $x$ & & & PDDU 1979 \\
\hline & É permitida & Industrial? & 1 & 96 & OK & & & $x$ & & $x$ & & & $x$ & $x$ & & & PDDU 1979 \\
\hline & uso & de Comércio e Serviço? & 1 & 96 & OK & & & $x$ & & $x$ & & & $x$ & $x$ & & & PDDU 1979 \\
\hline & Custo do terreno & [Euro/m²] & 1 & 96 & & & & & $x$ & $x$ & & & $x$ & $x$ & & & PMPA-SMF (1995 A \\
\hline SITUAÇÃC & O PARA RODA & RO MODELO & 25 & 2.400 & $92 \%$ & $36 \%$ & $4 \%$ & $64 \%$ & $40 \%$ & $32 \%$ & $0 \%$ & $40 \%$ & $76 \%$ & $44 \%$ & $16 \%$ & $4 \%$ & \\
\hline DADOS & VETORIAS DE & AUTOMÓVEL (POR ZT) & VAR & AREAS & Coleta & INPUT & & & & & & & & & & & \\
\hline & & Caminhada da Orig. até vaga & 1 & 96 & & & & & $x$ & & & & & & & $\mathrm{x}$ & \\
\hline & Entrepico & P/ encontrar uma vaga & 1 & 96 & & & & & $x$ & & & & & & & $x$ & \\
\hline de & & Caminhada da vaga até dest & 1 & 96 & & & & & $x$ & & & & & & & $x$ & \\
\hline estacion. & & Caminhada da Orig. até vaga & 1 & 96 & & & & & $x$ & & & & & & & $x$ & \\
\hline & Pico & $\mathrm{P} /$ encontrar uma vaga & 1 & 96 & & & & & $x$ & & & & & & & $x$ & \\
\hline & & Caminhada da vaga até dest & 1 & 96 & & & & & $x$ & & & & & & & $x$ & \\
\hline & & Custo Longa Perman. (Euro) & 1 & 96 & & & & & $x$ & & & & & & & $x$ & \\
\hline & & $\%$ vagas cobradas LP-VLP & 1 & 96 & & & & & $x$ & & & & & & & $\mathrm{x}$ & \\
\hline & Entrepico & Custo Curta Perman. (Euro// & 1 & 96 & OK & & SIM & & $x$ & & & & $x$ & $x$ & & & EDOM 2003; EPTC \\
\hline & & $\%$ Vagas Cobradas CP-VCP & 1 & 96 & OK & & SIM & & $x$ & & & & $x$ & $x$ & & & EDOM 2003; EPTC \\
\hline Custo & & $\%$ Vagas Cobradas LP-CP & 1 & 96 & OK & & SIM & & $x$ & & & & $x$ & $x$ & & & EDOM 2003; EPTC \\
\hline Estacion. & & Custo Longa Perman. (Euro) & 1 & 96 & & & & & $\mathrm{x}$ & & & & & & & $\mathrm{x}$ & \\
\hline & & $\%$ vagas cobradas LP-VLP & 1 & 96 & & & & & $x$ & & & & & & & $x$ & \\
\hline & Pico & Custo Curta Perman. (Euro// & 1 & 96 & OK & & SIM & & $x$ & & & & $\bar{x}$ & $x$ & & & EDOM 2003; EPTC \\
\hline & & $\%$ Vagas Cobradas CP-VCP & 1 & 96 & OK & & SIM & & $x$ & & & & $x$ & $x$ & & & EDOM 2003; EPTC \\
\hline & & $\%$ Vagas Cobradas LP-CP & 1 & 96 & OK & & SIM & & $x$ & & & & $x$ & $\mathbf{x}$ & & & EDOM 2003; EPTC \\
\hline SITUAÇÃC & D PARA RODA & RO MODELO & 16 & 1.536 & $38 \%$ & $0 \%$ & $38 \%$ & $0 \%$ & $100 \%$ & $0 \%$ & $0 \%$ & $0 \%$ & $38 \%$ & $38 \%$ & $0 \%$ & $63 \%$ & \\
\hline
\end{tabular}


Tabela 11 - Guia de coleta de dados - MARS POA74 - Matrizes

\begin{tabular}{|c|c|c|c|c|c|c|c|c|c|c|c|c|c|c|c|c|c|}
\hline \multirow{3}{*}{\multicolumn{3}{|c|}{ DADOS PARA ALIMENTAÇÃO DO MARS }} & & & \multicolumn{13}{|c|}{ SITUAÇÃO } \\
\hline & & & \multirow{3}{*}{\multicolumn{2}{|c|}{\begin{tabular}{|l|} 
VAR. PARES \\
\end{tabular}}} & \multirow{2}{*}{\multicolumn{2}{|c|}{\begin{tabular}{|c|} 
ANO BASE \\
1974
\end{tabular}}} & \multirow{3}{*}{$\begin{array}{l}\text { IMPL. } \\
\text { FUT. }\end{array}$} & \multicolumn{4}{|c|}{ PROBLEMAS } & \multicolumn{4}{|c|}{ POSSÍVEIS SOLUCÕES } & \multirow{3}{*}{$\begin{array}{l}\text { NADA A } \\
\text { FAZER }\end{array}$} & \multirow{2}{*}{ FONTE } \\
\hline & & & & & & & & 1 & 2 & 3 & 4 & DIG & SIG & CALC & ADOT & & \\
\hline \multicolumn{3}{|c|}{ MATRIZ O-D (ZT X ZT) } & & & Coleta & INPUT & & & & & & & & & & & \\
\hline A pé/Bici & \multicolumn{2}{|c|}{ Matriz de distância (Km) } & 1 & 9216 & OK & OK & & & $\mathbf{x}$ & & & & $\mathrm{x}$ & $\mathbf{x}$ & & & SIG - EPTC \\
\hline \multirow{6}{*}{ Automóvel } & \multicolumn{2}{|c|}{ Matriz de distância (Km) } & 1 & 9216 & OK & OK & & & $\mathrm{x}$ & & & & $x$ & $\mathrm{x}$ & & & SIG - EPTC \\
\hline & \multicolumn{2}{|c|}{ Velocidade de fluxo livre $(\mathrm{km} / \mathrm{h})$} & 1 & 9216 & & & & & $\mathbf{x}$ & & & & & & & $\mathrm{x}$ & \\
\hline & \multirow{2}{*}{ Entrepico } & Velocidade $(\mathrm{km} / \mathrm{h})$ & 1 & 9216 & & & & & $x$ & & & & & & & $\mathrm{x}$ & \\
\hline & & Pedágio (Euro/deslocamento & 1 & 9216 & OK & OK & & & & & & & & & & 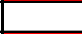 & NÃOÉ O CASO \\
\hline & \multirow{2}{*}{ Pico } & Velocidade $(\mathrm{km} / \mathrm{h})$ & 1 & 9216 & & & & & $\mathrm{x}$ & & & & & & & $\mathrm{x}$ & \\
\hline & & Pedágio (Euro/deslocamento & 1 & 9216 & OK & OK & & & & & & & & & & & NÃOÉ O CASO \\
\hline \multicolumn{3}{|c|}{ SITUAÇÃO PARA RODAR O MODELO } & 7 & 64.512 & $57 \%$ & $57 \%$ & $0 \%$ & $0 \%$ & $71 \%$ & $0 \%$ & $0 \%$ & $0 \%$ & $29 \%$ & $29 \%$ & $0 \%$ & $43 \%$ & \\
\hline \multirow{11}{*}{$\begin{array}{l}\text { Trasnsport } \\
\text { e Público } \\
\text { (Ônibus) } \\
\text { (lotação a } \\
\text { partir de } \\
1979, \\
1980, \\
1992,1994 \text { ) }\end{array}$} & \multicolumn{2}{|c|}{ Matriz de distância (Km) } & 1 & 9216 & & & $\operatorname{sim}$ & & $x$ & & & & $x$ & $x$ & & & SIG - EPTC \\
\hline & Distancia d & g ou Dest até a Parada & 1 & 9216 & & & $\operatorname{sim}$ & & $\mathbf{x}$ & & & & & & & $x$ & \\
\hline & \multirow{4}{*}{ Entrepico } & Headway (min) & 1 & 9216 & & & $\operatorname{sim}$ & & $x$ & & & & & & & $x$ & \\
\hline & & Tempo médio $\mathrm{p} /$ transbordo & 1 & 9216 & & & $\operatorname{sim}$ & & $x$ & & & & & & & $\mathrm{x}$ & \\
\hline & & $\%$ de TP segregado & 1 & 9216 & OK & & $\operatorname{sim}$ & & $x$ & & & & $x$ & $x$ & & & EPTC \\
\hline & & $\begin{array}{l}\text { Passagem por viagem } \\
\text { (Euro) }\end{array}$ & 1 & 9216 & OK & & sim & $x$ & & & & & $x$ & $x$ & & & EDOM 1974 \\
\hline & \multirow{4}{*}{ Pico } & Headway $(\mathrm{min})$ & 1 & 9216 & & & sim & & $x$ & & & & & & & $x$ & \\
\hline & & Tempo médio $\mathrm{p} /$ transbordo & 1 & 9216 & & & sim & & $x$ & & & & & & & $x$ & \\
\hline & & $\%$ de TP segregado & 1 & 9216 & OK & & sim & & $x$ & & & & $x$ & $x$ & & & EPTC \\
\hline & & $\begin{array}{l}\text { Passagem por viagem } \\
\text { (Euro) }\end{array}$ & 1 & 9216 & OK & & sim & $\mathbf{x}$ & & & & & $\mathbf{x}$ & $\mathbf{x}$ & & & EDOM 1974 \\
\hline & \multicolumn{2}{|c|}{ Velocidade Média no Corredor (Km/h) } & 1 & 9216 & OK & & sim & & & & & & & & & & EPTC \\
\hline SITUAÇÃC & O PARA R & AR O MODELO & 11 & 101.376 & $45 \%$ & $0 \%$ & $100 \%$ & $18 \%$ & $73 \%$ & $0 \%$ & $0 \%$ & $0 \%$ & $45 \%$ & $45 \%$ & $0 \%$ & $45 \%$ & \\
\hline & Matriz de di & cia $(\mathrm{Km})$ & 1 & 25 & OK & OK & $\operatorname{sim}$ & & & & & & & & & & SIG - EPTC \\
\hline & Distancia d & g ou Dest até a Parada & 1 & 25 & OK & OK & $\operatorname{sim}$ & & & $x$ & & & $x$ & $x$ & & & EDOM 2003 \\
\hline Trasporte & & Headway (min) & 1 & 25 & OK & OK & $\operatorname{sim}$ & & & $x$ & & & $x$ & $x$ & & & TRENSURB \\
\hline Público & Entrepico & Tempo médio p/ transbordo & 1 & 25 & OK & OK & sim & & & $\mathrm{x}$ & & & $\mathbf{x}$ & $\mathbf{x}$ & & & EDOM 2003 \\
\hline sobre & & $\%$ de TP segregado & 1 & 25 & OK & OK & sim & & & & & & & & & & $100 \%$ \\
\hline Trilhos & & Passagem por viagem (Euro & 1 & 25 & OK & OK & $\operatorname{sim}$ & & & & & & $x$ & $x$ & & & TRENSURB \\
\hline (TRENSUR & & Headway (min) & 1 & 25 & OK & OK & sim & & & & & & & & & & TRENSURB \\
\hline $\begin{array}{l}\text { B em POA, } \\
1985)\end{array}$ & Piro & Tempo médio $\mathrm{p} /$ transbordo & 1 & 25 & OK & OK & sim & & & & & & $x$ & $x$ & & & EDOM 2003 \\
\hline & Pico & $\%$ de TP segregado & 1 & 25 & OK & OK & sim & & & & & & & & & & $100 \%$ \\
\hline & & Passagem por viagem (Euro & 1 & 25 & OK & OK & $\operatorname{sim}$ & & & & & & & $x$ & & & TRENSURB \\
\hline & Velocidade & ia $(\mathrm{Km} / \mathrm{h})$ & 1 & 25 & OK & OK & $\operatorname{sim}$ & & & & & & & & & & TRENSURB \\
\hline SITUAÇÃC & O PARA R & AR O MODELO & 11 & 275 & $100 \%$ & $100 \%$ & $100 \%$ & $0 \%$ & $0 \%$ & $27 \%$ & $0 \%$ & $0 \%$ & $45 \%$ & $55 \%$ & $0 \%$ & $0 \%$ & \\
\hline & & TOTAIS & 90 & 170.235 & $50 \%$ & $22 \%$ & $60 \%$ & $12 \%$ & $72 \%$ & $0 \%$ & $0 \%$ & $1 \%$ & $39 \%$ & $39 \%$ & $0 \%$ & $44 \%$ & \\
\hline
\end{tabular}

Não foram avaliados, para o Modelo MARS POA74, os resultados de possíveis problemas para os dados que teriam implantação futura (IMPL. FUT), que, segundo o levantamento, representam $50 \%$ do total de variáveis (Tabela 11). Destaca-se ainda que apenas $29 \%$ do total de dados já estavam alimentados no modelo, pois muitos deles, apesar da situação de coleta já ter sido considerada adequada (“OK”), ainda deveriam passar por trabalhosos processos de tratamento para resolver os problemas encontrados.

O ajuste de um modelo com ano-base 1986, MARS POA86, para posterior validação com os dados da EDOM 2003, que seria a sequência natural, também não foi possível pelo problema de falta de dados para a totalidade da cidade na EDOM 86. A última saída encontrada foi iniciar o ajuste de um modelo com base nos dados da EDOM 2003 (MARS POA2003).

\section{Modelo MARS-POA2003}

O mesmo método aplicado ao MARS POA74, de acompanhamento do processo de coleta e alimentação de dados no modelo através da "Guia de Coleta de Dados", foi utilizado para o MARS POA2003 e, da mesma forma, foram registrados os problemas e as possíveis soluções. Os resultados estão resumidos nas Tabelas 12 a 14. Com base nos dados da 
EDOM 2003 foi adotado, como área de análise do MARS POA2003, o zoneamento desta pesquisa. Apesar de serem também 96 ZTs para Porto Alegre, os limites das áreas eram diferentes das ZTs 1974 para grande parte da cidade.

Em plena era de difusão de bancos de dados em SIG, acreditava-se que seria simples obter os dados do MARS POA2003, pois já existiam muitas informações em meio digital e, inclusive, georreferenciadas. Este era o caso da pesquisa O-D de 2003, cujos dados continham informações de coordenadas dos pontos de origem e de destino das viagens. Além disto, uma base georreferenciada de áreas com as UEUs ${ }^{1}$ do PDDUA também já existia em SIG. Bastaria, para esta, associar algumas informações que seriam necessárias às respectivas áreas, porém já estavam em tabelas em meio digital. Os setores censitários do Censo 2000, assim como várias outras bases de informações de transportes, também já existiam no banco de dados georreferenciado da PMPA e da EPTC.

O inconveniente de iniciar o processo de ajuste do MARS para Porto Alegre com dados de uma pesquisa O-D tão recente seria a falta de dados posteriores para a devida calibração dos modelos de uso do solo e, também, para validação de ambos os modelos (transporte e uso do solo), seguindo o mesmo método aplicado em Viena. Porém, sem outra opção, os problemas para as etapas de calibração e validação poderiam ser contornados com uso de outros dados, que, mesmo que não fossem os ideais, serviriam por hora. Além disto, com a proximidade de um novo Censo, a ser realizado em 2010, e, na ocasião de uma nova pesquisa O-D, a calibração e a validação dos modelos de uso do solo e de transportes do MARS POA2003 poderiam ser complementadas.

Contudo, algumas dificuldades foram encontradas já nas etapas de coleta e alimentação dos dados do MARS-POA2003. Estas dificuldades, registradas nas Tabelas 12 a 14, tornaram todo o processo muito lento. Quanto aos problemas encontrados, destaca-se em primeiro lugar o Problema 2 (não existência do dado), que ocorreu para $56 \%$ das variáveis, considerando a análise geral (ver TOTAL, na Tabela 14). O Problema 2 foi verificado para $81 \%$ dos "Dados Escalares Básicos" (Tabela 13), para 92\% dos "Dados Vetoriais Básicos" e $75 \%$ dos "Dados Vetoriais de Automóvel" (Tabela 14).

${ }^{1}$ Divisão territorial definida pelo PDDUA - Unidades de Estruturação Urbana - UEUs - são módulos estruturadores do Modelo Espacial definidos pela malha viária básica, podendo ser divididos em subunidades, denominadas de SubUEUs, quando englobarem regimes urbanísticos distintos. 
Tabela 12 - Guia de coleta de dados - MARS-POA2003 - Taxas de crescimento e dados escalares básicos.

\begin{tabular}{|c|c|c|c|c|c|c|c|c|c|c|c|c|c|c|c|c|c|}
\hline \multirow{3}{*}{\multicolumn{3}{|c|}{ DADOS PARA ALIMENTAÇÃO DO MARS }} & & & \multicolumn{13}{|c|}{ SITUAÇÃO } \\
\hline & & & & & \multirow{2}{*}{\multicolumn{2}{|c|}{$\begin{array}{c}\text { ANO BASE } \\
2003 \\
\end{array}$}} & \multirow{2}{*}{$\begin{array}{l}\text { IMPL. } \\
\text { FUT. }\end{array}$} & \multicolumn{4}{|c|}{ PROBLEMAS } & \multicolumn{4}{|c|}{ POSSIVEIS SOLUCÕES } & \multirow{2}{*}{$\mid \begin{array}{c}\text { NADA } \\
\text { A } \\
\text { FAZER }\end{array}$} & \multirow{2}{*}{ FONTE } \\
\hline & & & & & & & & 1 & 2 & 3 & 4 & DIG & SIG & CALC & ADOT & & \\
\hline \multicolumn{3}{|c|}{ TAXAS ANUAIS DE CRESCIMENTO (PARA 30 ANOS) } & VAR & ANOS & Coleta & INPUT & & & & & & & & & & & \\
\hline \multicolumn{2}{|c|}{ Residentes } & & 1 & 30 & OK & OK & & & & & & & & $\mathbf{x}$ & & & IBGE (2000 a 2010) \\
\hline \multirow{2}{*}{\multicolumn{2}{|c|}{ Postos de Trabalho }} & Setor de Produção & 1 & 30 & OK & OK & & & & & & & & $\mathbf{x}$ & & & IBGE (2000 a 2010) \\
\hline & & Setor de Serviços & 1 & 30 & OK & OK & & & & & & & & $\mathbf{x}$ & & & IBGE (1970 a 2010) \\
\hline \multicolumn{3}{|c|}{ Posse de veículo } & 1 & 30 & OK & OK & & & & & & & & $\mathbf{x}$ & & & DETRAN-RS \\
\hline \multicolumn{3}{|c|}{ SITUAÇÃO PARA RODAR O MODELO } & 4 & 120 & $100 \%$ & $100 \%$ & $0 \%$ & $0 \%$ & $0 \%$ & $0 \%$ & $0 \%$ & $0 \%$ & $0 \%$ & $100 \%$ & $0 \%$ & $0 \%$ & \\
\hline \multicolumn{3}{|c|}{ DADOS ESCALARES BÁSICOS (ÁREA DE ESTUDO) } & VAR & AREA & Coleta & INPUT & & & & & & & & & & & \\
\hline \multirow[t]{2}{*}{ Mobilidade } & \multicolumn{2}{|c|}{$\begin{array}{l}\text { Número médio de viagens por pess. empregada } \\
\text { e dia de trabalho }\end{array}$} & 1 & 1 & OK & OK & & & $\mathbf{x}$ & & & & & $\mathbf{x}$ & & & EDOM 2003 \\
\hline & \multicolumn{2}{|c|}{ Tempo médio diário em deslocamento } & 1 & 1 & OK & OK & & & $\mathbf{x}$ & & & & & $x$ & & & EDOM 2003 \\
\hline \multirow{2}{*}{ Moradia } & \multicolumn{2}{|c|}{ Tempo médio numa mesma moradia } & 1 & 1 & OK & OK & & & $\mathbf{x}$ & & & & & & $\mathrm{x}$ & & MARS VIENA \\
\hline & \multicolumn{2}{|c|}{ Unidades habitacionais planejadas no ano } & 1 & 1 & OK & OK & & & & & & & & & 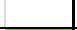 & & SINDUSCON-RS \\
\hline \multirow{2}{*}{$\begin{array}{l}\text { Vel. Media } \\
\text { (pedestres) }\end{array}$} & & Pico $(\mathrm{km} / \mathrm{h})$ & 1 & 1 & OK & OK & & & $\mathbf{x}$ & & & & & & $\mathbf{x}$ & & MARS VIENA \\
\hline & & Entrepico $(\mathrm{km} / \mathrm{h})$ & 1 & 1 & OK & OK & & & $\mathbf{x}$ & & & & & & $\bar{x}$ & & MARS VIENA \\
\hline & \multirow{2}{*}{$\begin{array}{l}\text { Limiar } \mathrm{p} / \\
\text { aumento de } \\
\text { capacidade }\end{array}$} & $\%$ aumento & 1 & 1 & OK & OK & & & $\mathbf{x}$ & & & & & $\mathbf{x}$ & $\mathbf{x}$ & & VIENA; POA \\
\hline & & Vel. Minima aceitável (km/h) & 1 & 1 & OK & OK & & & $\mathbf{x}$ & & & & & $x$ & $x$ & & VIENA; POA \\
\hline & \multirow{2}{*}{$\begin{array}{l}\text { Taxa de } \\
\text { ocupação } \\
\text { (Auto) }\end{array}$} & Viagem trabalho & 1 & 1 & OK & OK & & & $\mathbf{x}$ & & & & & $x$ & & & EDOM 2003 \\
\hline & & Viagem não trabalho & 1 & 1 & OK & OK & & & $\mathbf{x}$ & & & & & $\mathbf{x}$ & & & EDOM 2003 \\
\hline \multirow{4}{*}{$\begin{array}{l}\text { Auto e } \\
\text { Moto }\end{array}$} & \multirow{2}{*}{$\begin{array}{l}\text { Pesssoas } \\
\text { com } \\
\text { Habilitação }\end{array}$} & Empregados & 1 & 1 & ок & OK & & & $x$ & & & & & & $x$ & & EDOM 2003 \\
\hline & & Todos & 1 & 1 & OK & OK & & & $\mathbf{x}$ & & & & & $x$ & & & EDOM 2003 \\
\hline & \multicolumn{2}{|c|}{$\begin{array}{l}\text { Outros custos que dependem da distância } \\
\text { excluindo gás. como lubrificantes, pneu, } \\
\text { desgaste veículo, etc (Euro/km) }\end{array}$} & 1 & 1 & OK & OK & & & $\mathrm{x}$ & & & & & $\mathbf{x}$ & & & FIPAI/USP \\
\hline & Percentual c & $\begin{array}{l}\text { leste custo que é percebido pelo } \\
\text { usuário }(\%) \text { : }\end{array}$ & 1 & 1 & OK & OK & & & $\mathrm{x}$ & & & & & & $\mathrm{x}$ & & MARS VIENA \\
\hline Transporte & Veículo km & Hora pico & 1 & 1 & OK & OK & & & & & & & & & & & EPTC \\
\hline Público & $(\mathrm{km} / \mathrm{a})$ & Entrepico & 1 & 1 & OK & OK & & & & & & & & & & & EPTC \\
\hline SITUAÇÃO & O PARA ROL & JAR O MODELO & 16 & 16 & $100 \%$ & $100 \%$ & $0 \%$ & $0 \%$ & $81 \%$ & $0 \%$ & $0 \%$ & $0 \%$ & $0 \%$ & $50 \%$ & $44 \%$ & $0 \%$ & \\
\hline
\end{tabular}

Para os dados em "Matriz O-D" (Tabela 14), considerando as matrizes relativas aos modos A pé/Bicicleta e Automóvel, todas foram consideradas como dados não existentes e as matrizes tiveram que ser estimadas. Apenas duas matrizes $O-D$ de custo de pedágio não seriam necessárias, pois não é o caso no perímetro urbano de Porto Alegre. Sendo assim, as matrizes permaneceriam zeradas no modelo. Quanto às matrizes de transporte público, $45 \%$ delas não existiam e tiveram de ser estimadas.

O problema de incongruência dos dados (Problema 4) foi verificado para $11 \%$ do total de variáveis (Ver TOTAL - Tabela 14). Destacam-se, neste caso, os dados vetoriais sobre custo do estacionamento, que representam 25\% dos "Dados Vetoriais de Automóvel", e também os dados para duas matrizes O-D de velocidade de automóvel (hora pico e entre pico), que representam 29\% das matrizes O-D para carro. São variáveis cujos dados foram obtidos com base na EDOM 2003. No caso do custo de estacionamento, constavam no questionário da pesquisa O-D, as perguntas "usou estacionamento?" e "quanto pagou?". Muitos valores registrados pareciam discrepantes com a realidade, sendo alguns para mais e outros para menos. A análise detalhada dos dados indicou que poderiam ser resultantes de erro de digitação, ou até mesmo, de falta de entendimento da pergunta, pois algumas respostas poderiam ser até relacionadas a valores mensais, enquanto outras pareciam relacionadas a valores por hora. 
Tabela 13 - Guia de coleta de dados - MARS POA2003 - dados vetoriais básicos e de automóvel.

\begin{tabular}{|c|c|c|c|c|c|c|c|c|c|c|c|c|c|c|c|c|c|}
\hline \multirow{3}{*}{\multicolumn{3}{|c|}{ DADOS PARA ALIMENTAÇÃO DO MARS }} & & & \multicolumn{13}{|c|}{ SITUAÇÃO } \\
\hline & & & & & \multirow{2}{*}{\multicolumn{2}{|c|}{\begin{tabular}{|c|} 
ANO BASE \\
2003 \\
\end{tabular}}} & \multirow{3}{*}{$\begin{array}{l}\text { IMPL. } \\
\text { FUT. }\end{array}$} & \multicolumn{4}{|c|}{ PROBLEMAS } & \multicolumn{4}{|c|}{ POSSIVEIS SOLUCÕES } & \multirow{3}{*}{\begin{tabular}{|l} 
NADA \\
A \\
FAZER \\
\end{tabular}} & \multirow{3}{*}{ FONTE } \\
\hline & & & \multirow[b]{2}{*}{ VAR } & \multirow[b]{2}{*}{ AREAS } & & & & 1 & 2 & 3 & 4 & DIG & SIG & CALC & ADOT & & \\
\hline DADC & S VETORIAIS & BÁSICOS (ZT - ANO BASE) & & & Coleta & INPUT & & & & & & & & & & & \\
\hline \multirow{4}{*}{ Domicílios } & \multicolumn{2}{|c|}{ Habitantes (pessoas) } & 1 & 96 & OK & OK & & & & & & & & & & & EDOM 2003 \\
\hline & \multicolumn{2}{|c|}{ Habitantes Empregados (Pess Econ. Ativas) } & 1 & 96 & OK & OK & & & $\mathrm{x}$ & & & & & $\mathbf{x}$ & & & EDOM 2003 \\
\hline & \multicolumn{2}{|c|}{ Renda Média Domiciliar [Euro/month] } & 1 & 96 & OK & OK & & & $\mathbf{x}$ & & & & & $\mathbf{x}$ & & & EDOM 2003 \\
\hline & \multicolumn{2}{|c|}{ Habitantes por Domicilio } & 1 & 96 & OK & OK & & & $\mathbf{x}$ & & & & & $\mathbf{x}$ & & & EDOM 2003 \\
\hline & \multicolumn{2}{|c|}{ Custo médio mensal [Euro/m²] } & 1 & 96 & OK & OK & & $\mathbf{x}$ & $\mathbf{x}$ & $\mathbf{x}$ & & & $\mathbf{x}$ & $\mathbf{x}$ & & & SECOVI \\
\hline Moradia & Área média pc & $r$ moradia $\left[m^{2}\right]$ & 1 & 96 & OK & OK & & $x$ & $x$ & $x$ & & & $x$ & $x$ & & & IPTU 2008 \\
\hline mirania & Área Contruíd & a/Área de Terreno (IA PDDU) & 1 & 96 & OK & OK & & & $\mathbf{x}$ & $\mathbf{x}$ & & & $\mathbf{x}$ & $\mathbf{x}$ & & & PDDUA \\
\hline & Moradias não & scupadas & 1 & 96 & OK & OK & & $\mathbf{x}$ & $\mathbf{x}$ & $\mathrm{x}$ & & & $\mathbf{x}$ & $\mathbf{x}$ & & & SECOVI \\
\hline & Postos de Tra & alho & 1 & 96 & OK & OK & & & $\mathbf{x}$ & & & & & $\mathbf{x}$ & & & EDOM 2003 \\
\hline & \% por setor & Produção & 1 & 96 & OK & OK & & & $\mathbf{x}$ & & & & & $\mathbf{x}$ & & & EDOM 2003 \\
\hline & \% por setor & Serviço & 1 & 96 & OK & OK & & & $x$ & & & & & $x$ & & & EDOM 2003 \\
\hline Trabalho & $\begin{array}{l}\mathrm{N}^{\circ} \text { Médio } \\
\text { Postos de }\end{array}$ & Produção & 1 & 96 & OK & OK & & & $\mathrm{x}$ & & & & & & $\mathrm{x}$ & & MARS LEEDS \\
\hline & $\begin{array}{l}\text { Trabalho por } \\
\text { empresa }\end{array}$ & Serviço & 1 & 96 & OK & OK & & & $\mathbf{x}$ & & & & & & $\mathbf{x}$ & & MARS LEEDS \\
\hline & Área média & Produção & 1 & 96 & OK & OK & & $x$ & $x$ & & & & & $x$ & $x$ & & IPTU 2008 E LEEDS \\
\hline & & Serviço & 1 & 96 & OK & OK & & $x$ & $x$ & & & & & $x$ & $x$ & & IPTU 2008 E LEEDS \\
\hline Posse & Posse Auto ( $\mathrm{p}$ & or 1000 res) & 1 & 96 & OK & OK & & & $x$ & & & & & & & & EDOM 2003 \\
\hline Veículos & Posse Moto ( $\mathrm{p}$ & or 1000 res) & 1 & 96 & OK & OK & & & $x$ & & & & & & & & EDOM 2003 \\
\hline & Área $\left[\mathrm{km}^{2}\right]$ & & 1 & 96 & OK & OK & & & & & & & & & & & EDOM 2003 \\
\hline & $\%$ Ainda deso & supada & 1 & 96 & OK & OK & & $\mathbf{x}$ & $\mathbf{x}$ & $\mathbf{x}$ & & & $\mathbf{x}$ & $\mathbf{x}$ & & & IPTU 2008 \\
\hline & $\%$ da area & Uso Residencial & 1 & 96 & OK & OK & & & $x$ & $x$ & & & $x$ & $x$ & & & PDDUA \\
\hline Área e & $\begin{array}{l}\text { desocupada } \\
\text { que pode ser }\end{array}$ & Uso Economico & 1 & 96 & OK & OK & & & $x$ & $x$ & & & $x$ & $\mathbf{x}$ & & & PDDUA \\
\hline $\begin{array}{l}\text { Desenv. } \\
\text { Urbano }\end{array}$ & & De proteção ambiental & 1 & 96 & OK & OK & & & $x$ & $x$ & & & $x$ & $\mathbf{x}$ & & & PDDUA \\
\hline & $\begin{array}{l}\text { É permitida } \\
\text { ocupacão }\end{array}$ & Industrial? & 1 & 96 & OK & OK & & & $x$ & $x$ & & & $x$ & $x$ & & & PDDUA \\
\hline & para uso & de Comércio e Serviço? & 1 & 96 & OK & OK & & & $\mathbf{x}$ & $\mathbf{x}$ & & & $\mathbf{x}$ & $\mathbf{x}$ & & & PDDUA \\
\hline & Custo do terre & to $\left[\right.$ Euro $\left./ \mathrm{m}^{2}\right]$ & 1 & 96 & OK & OK & & & $\mathbf{x}$ & $\mathrm{x}$ & & & $\mathbf{x}$ & $\mathbf{x}$ & & & SMF (1995 A 2008) \\
\hline SITUAÇÃC & O PARA ROI & AR O MODELO & 25 & 2.400 & $100 \%$ & $100 \%$ & $0 \%$ & $24 \%$ & $92 \%$ & $44 \%$ & $0 \%$ & $0 \%$ & $44 \%$ & $76 \%$ & $16 \%$ & $0 \%$ & \\
\hline DADC & OS VETORIAS & DE AUTOMÓVEL (POR ZT) & VAR & AREAS & Coleta & INPUT & & & & & & & & & & & \\
\hline & & Caminhada da Orig. até vaga & 1 & 96 & OK & OK & & & & & & & & & & & EDOM 2003 \\
\hline Distância & Entrepico & P/ encontrar uma vaga (dest) & 1 & 96 & OK & OK & & & $x$ & & & & $x$ & $x$ & $x$ & & EDOM 2003 \\
\hline & & Caminhada da vaga até dest. & 1 & 96 & OK & OK & & & & & & & & & & & EDOM 2003 \\
\hline estacion. & & Caminhada da Orig. até vaga & 1 & 96 & OK & OK & & & & & & & & & & & EDOM 2003 \\
\hline & Pico & P/ encontrar uma vaga (dest) & 1 & 96 & OK & OK & & & $\mathbf{x}$ & & & & $\mathbf{x}$ & $\mathbf{x}$ & $\mathrm{x}$ & & EDOM 2003 \\
\hline & & Caminhada da vaga até dest. & 1 & 96 & OK & OK & & & & & & & & & & & EDOM 2003 \\
\hline & & Custo Longa Perman. (Euro/perm. & 1 & 96 & OK & OK & & & $\mathbf{x}$ & & $\mathrm{x}$ & & $\mathbf{x}$ & $\mathbf{x}$ & & & EDOM 2003; EPTC \\
\hline & & $\%$ vagas cobradas $L P-V L P$ & 1 & 96 & OK & OK & & & $\mathbf{x}$ & & & & $\mathbf{x}$ & $\mathbf{x}$ & & & EDOM 2003; EPTC \\
\hline & Entrepico & Custo Curta Perman. (Euro/perm. & 1 & 96 & OK & OK & & & $\mathbf{x}$ & & $\mathrm{x}$ & & $\mathbf{x}$ & $\mathrm{x}$ & & & EDOM 2003; EPTC \\
\hline & & $\%$ Vagas Cobradas CP-VCP & 1 & 96 & OK & OK & & & $x$ & & & & $x$ & $\mathbf{x}$ & & & EDOM 2003; EPTC \\
\hline Custo & & $\%$ Vagas Cobradas LP-CP & 1 & 96 & OK & OK & & & $x$ & & & & $x$ & $x$ & & & EDOM 2003; EPTC \\
\hline Estacion. & & Custo Longa Perman. (Euro/perm. & 1 & 96 & OK & OK & & & $\mathbf{x}$ & & $x$ & & $\mathbf{x}$ & $\mathbf{x}$ & & & EDOM 2003; EPTC \\
\hline & & $\%$ vagas cobradas LP-VLP & 1 & 96 & OK & OK & & & $x$ & & & & $x$ & $x$ & & & EDOM 2003; EPTC \\
\hline & Pico & Custo Curta Perman. (Euro/perm. & 1 & 96 & OK & OK & & & $\mathbf{x}$ & & $\mathrm{x}$ & & $\mathbf{x}$ & $\mathbf{x}$ & & & EDOM 2003; EPTC \\
\hline & & $\%$ Vagas Cobradas CP-VCP & 1 & 96 & OK & OK & & & $\mathbf{x}$ & & & & $\mathbf{x}$ & $\mathbf{x}$ & & & EDOM 2003; EPTC \\
\hline & & $\%$ Vagas Cobradas LP-CP & 1 & 96 & OK & OK & & & $x$ & & & & $x$ & $\mathbf{x}$ & & & EDOM 2003; EPTC \\
\hline SITUAÇÃ & O PARA ROI & AAR O MODELO & 16 & 1.536 & $100 \%$ & $100 \%$ & $0 \%$ & $0 \%$ & $75 \%$ & $0 \%$ & $25 \%$ & $0 \%$ & $75 \%$ & $75 \%$ & $13 \%$ & $0 \%$ & \\
\hline
\end{tabular}

No caso das matrizes O-D de velocidade de automóvel o problema foi outro. A idéia inicial era obter este dado através da divisão da Matriz de Distâncias médias para automóvel, que foi estimada com ferramentas de um SIG-T (SIG para transporte), pela matriz O-D de tempos médios, que seria gerada com base nas informações de tempo de viagem na pesquisa O-D de 2003. Porém, a falta de uma amostra suficiente dos dados resultou em velocidades inconsistentes. Este é um problema comum quando é necessário desagregar muito os dados de uma pesquisa O-D. No caso da matriz de velocidade de automóveis para hora pico, a amostra total teve de ser desagregada por modo de viagem (somente automóvel), por período (hora pico da manhã, das 7h às 9h) e por par O-D (96 x 96). 
Tabela 14 - Guia de coleta de dados - MARS POA2003 - Matrizes.

\begin{tabular}{|c|c|c|c|c|c|c|c|c|c|c|c|c|c|c|c|c|c|}
\hline \multirow{3}{*}{\multicolumn{3}{|c|}{ DADOS PARA ALIMENTAÇÃO DO MARS }} & & & \multicolumn{13}{|c|}{ SITUAÇÃO } \\
\hline & & & \multirow{3}{*}{\multicolumn{2}{|c|}{\begin{tabular}{|l|} 
VAR. PARES \\
\end{tabular}}} & \multirow{2}{*}{\multicolumn{2}{|c|}{\begin{tabular}{|c|} 
ANO BASE \\
2003
\end{tabular}}} & \multirow{3}{*}{$\begin{array}{l}\text { IMPL. } \\
\text { FUT. }\end{array}$} & \multicolumn{4}{|c|}{ PROBLEMAS } & \multicolumn{4}{|c|}{ POSSIVEIS SOLUCÕES } & \multirow{3}{*}{$\begin{array}{c}\text { NADA } \\
\text { A } \\
\text { FAZER } \\
\end{array}$} & \multirow[b]{2}{*}{ FONTE } \\
\hline & & & & & & & & 1 & 2 & 3 & 4 & DIG & SIG & CALC & ADOT & & \\
\hline \multicolumn{3}{|c|}{ MATRIZ O-D (ZT X ZT) } & & & Coleta & INPUT & & & & & & & & & & & \\
\hline A pé/Bici & \multicolumn{2}{|c|}{ Matriz de distância (Km) } & 1 & 9216 & OK & OK & & & $\mathrm{x}$ & & & & $x$ & $\mathbf{x}$ & & & SIG - EPTC \\
\hline \multirow{6}{*}{ Automóvel } & \multicolumn{2}{|c|}{ Matriz de distância (Km) } & 1 & 9216 & OK & OK & & & $x$ & & & & $x$ & $x$ & & & SIG - EPTC \\
\hline & \multicolumn{2}{|c|}{ Velocidade de fluxo livre $(\mathrm{km} / \mathrm{h})$} & 1 & 9216 & OK & OK & & & $\mathbf{x}$ & & & & $\mathbf{x}$ & $\mathbf{x}$ & & & EPTC \\
\hline & \multirow{2}{*}{ Entrepico } & Velocidade $(\mathrm{km} / \mathrm{h})$ & 1 & 9216 & OK & OK & & & $x$ & & $x$ & & $x$ & $x$ & & & EDOM 2003 -SATURN \\
\hline & & Pedágio (Euro/deslocamento) & 1 & 9216 & OK & OK & & & & & & & & & & & NÃO É O CASO \\
\hline & \multirow{2}{*}{ Pico } & Velocidade $(\mathrm{km} / \mathrm{h})$ & 1 & 9216 & OK & OK & & & $x$ & & $x$ & & $x$ & $x$ & & & EDOM 2003 -SATURN \\
\hline & & Pedágio (Euro/deslocamento) & 1 & 9216 & OK & OK & & & & & & & & & & & NÃOÉ O CASO \\
\hline \multicolumn{3}{|c|}{ SITUAÇÃO PARA RODAR O MODELO } & 7 & 64.512 & $100 \%$ & $100 \%$ & $0 \%$ & $0 \%$ & $71 \%$ & $\mathbf{0 \%}$ & $29 \%$ & $0 \%$ & $71 \%$ & $71 \%$ & $0 \%$ & $0 \%$ & \\
\hline \multirow{11}{*}{$\begin{array}{c}\text { Transporte } \\
\text { Público } \\
\text { (Ônibus) } \\
\text { (lotação a } \\
\text { partir de } \\
1979, \\
1980, \\
1992,1994 \text { ) }\end{array}$} & \multicolumn{2}{|c|}{ Matriz de distância $(\mathrm{Km})$} & 1 & 9216 & OK & OK & & & $\mathrm{x}$ & & & & $\mathrm{x}$ & $\mathbf{x}$ & & & SIG - EPTC \\
\hline & \multicolumn{2}{|c|}{ Distancia da Orig ou Dest até a Parada } & 1 & 9216 & OK & OK & & & & & & & & & & & EDOM 2003 \\
\hline & \multirow{4}{*}{ Entrepico } & Headway (min) & 1 & 9216 & OK & OK & & & $x$ & & & & $x$ & $x$ & & & EPTC - BRT \\
\hline & & Tempo médio $\mathrm{p} /$ transbordo & 1 & 9216 & OK & OK & & & & & & & & & & & EDOM 2003 \\
\hline & & $\%$ de TP segregado & 1 & 9216 & OK & OK & & & $\mathrm{x}$ & & & & $x$ & $x$ & & & EPTC - SIG \\
\hline & & Passagem por viagem (Euro) & 1 & 9216 & OK & OK & & & & & & & & & & & EPTC \\
\hline & \multirow{4}{*}{ Pico } & Headway (min) & 1 & 9216 & OK & OK & & & $x$ & & & & $x$ & $x$ & & & EPTC - BRT \\
\hline & & Tempo médio $\mathrm{p} /$ transbordo & 1 & 9216 & OK & OK & & & & & & & & & & & EDOM 2003 \\
\hline & & $\%$ de TP segregado & 1 & 9216 & OK & OK & & & $x$ & & & & $x$ & $x$ & & & EPTC - SIG \\
\hline & & Passagem por viagem (Euro) & 1 & 9216 & OK & OK & & & & & & & & & & & EPTC \\
\hline & Velocidade I & dia no Corredor $(\mathrm{Km} / \mathrm{h})$ & 1 & 9216 & OK & OK & & & & & & & & & & & EPTC \\
\hline SITUAÇÃO & O PARA RC & JAR O MODELO & 11 & 101.376 & $100 \%$ & $100 \%$ & $0 \%$ & $0 \%$ & $45 \%$ & $0 \%$ & $0 \%$ & $0 \%$ & $45 \%$ & $45 \%$ & $0 \%$ & $0 \%$ & \\
\hline & Matriz de dis & incia (Km) & 1 & 25 & OK & OK & & & & & & & & & & & SIG - EPTC \\
\hline & Distancia da & rig ou Dest até a Parada & 1 & 25 & OK & OK & & & & & & & & & & & EDOM 2003 \\
\hline & & Headway (min) & 1 & 25 & OK & OK & & & & & & & & & & & TRENSURB \\
\hline Público & Entrepico & Tempo médio $\mathrm{p} /$ transbordo & 1 & 25 & OK & OK & & & & & & & & & & & EDOM 2003 \\
\hline sobre & Entrepico & $\%$ de TP segregado & 1 & 25 & OK & OK & & & & & & & & & & & $100 \%$ \\
\hline $\begin{array}{l}\text { Trilhos } \\
\text { (TRENSUR }\end{array}$ & & Passagem por viagem (Euro) & 1 & 25 & OK & OK & & & & & & & & & & & TRENSURB \\
\hline$B$ em POA, & & Headway (min) & 1 & 25 & OK & OK & & & & & & & & & & & TRENSURB \\
\hline 1985) & Pico & Tempo médio $\mathrm{p} /$ transbordo & 1 & 25 & OK & OK & & & & & & & & & & & EDOM 2003 \\
\hline & Pico & $\%$ de TP segregado & 1 & 25 & OK & OK & & & & & & & & & & & $100 \%$ \\
\hline & & Passagem por viagem (Euro) & 1 & 25 & OK & OK & & & & & & & & & & & TRENSURB \\
\hline & Velocidade I & dia $(\mathrm{Km} / \mathrm{h})$ & 1 & 25 & OK & OK & & & & & & & & & & & TRENSURB \\
\hline SITUAÇÃO & O PARA RC & DAR O MODELO & 11 & 275 & $100 \%$ & $100 \%$ & $0 \%$ & $0 \%$ & $0 \%$ & $0 \%$ & $0 \%$ & $0 \%$ & $0 \%$ & $0 \%$ & $0 \%$ & $0 \%$ & \\
\hline & & TOTAIS & 90 & 170.235 & $100 \%$ & $100 \%$ & $0 \%$ & $0 \%$ & $56 \%$ & $1 \%$ & $11 \%$ & $0 \%$ & $55 \%$ & $56 \%$ & $0 \%$ & $0 \%$ & \\
\hline
\end{tabular}

Já era esperado que, para uma matriz O-D com 9.216 células, muitas resultassem vazias, porém somente 3.210 células foram preenchidas (35\%). Para praticamente dois terços dos pares O-D não houve viagens registradas pela população amostrada na pesquisa. Para muitas células a amostra resultante era muito pequena, o que tornava a estimativa suscetível a distorções. O problema era amenizado quando se agregavam as 96 ZTs nas 18 Macrozonas também definidas para a EDOM 2003. Em uma análise de número de amostras de viagem de automóvel para hora pico da manhã agregada em Macrozonas, foi verificado que a proporção era invertida em relação à anterior. Para $65 \%$ das 324 células $(18 \times 18)$ havia amostras, porém para $26 \%$ destas (56 células) este número era inferior a três entrevistados. Ou seja, mesmo agregando-se os dados em uma matriz menor, ainda era verificado o problema de distorções nas velocidades estimadas devido à amostra pequena.

O problema de nível de agregação dos dados, referente a limites distintos de zoneamento (Problema 3), foi verificado para 1\% das variáveis na análise geral (ver TOTAL, Tabela 14), porém representa $44 \%$ das variáveis do tipo "Dados Vetoriais Básicos" (Tabela 13). Estas correspondiam às informações imobiliárias e de uso do solo. As últimas eram agregadas em 
UEUs, zoneamento definido pelo PDDUA. No entanto, as primeiras, cujos dados ou eram agregados em bairros ou desagregadas por endereços, exigiram muito tempo em compilação, formatação e análise estatística e espacial antes de poderem ser alimentadas no modelo. Estas variáveis apresentavam, também, o problema da forma de como foram obtidos os dados originais (Problema 1).

Para o MARS POA2003, diferentemente do que ocorreu com o MARS POA74, para todos os problemas verificados foi encontrada alguma solução, ou uma combinação de várias soluções, o que resultou em $100 \%$ dos dados alimentados no modelo. No entanto, esta análise adicional tornou o processo de obtenção e alimentação de dados muito lento. Apenas para dar uma idéia geral do trabalho e tempo consumido na solução de problemas para obtenção das variáveis, será apresentado o processo de apenas uma variável.

Tomando, como exemplo, o processo de obtenção da variável "custo médio mensal de moradia" (valor de aluguel, condomínio, etc.) cuja unidade é Euro $/ \mathrm{m}^{2}$ (Tabela 13) foram extraídos e combinados dados de diferentes fontes. Foram fornecidos, pelo SECOVI/RS (Sindicato da Habitação), relatórios em arquivos não editáveis contendo tabelas com a oferta de imóveis para aluguel em Porto Alegre para Dezembro de 2000. As ofertas de imóveis estavam agregadas por bairro, porém para cada bairro, desagregadas por tipo (apartamento, casa, cobertura, $\mathrm{JK}^{2}$ ou Flat ${ }^{3}$ ) e ainda por número de dormitórios (de 1 a 5 dormitórios), contendo os valores máximos, mínimos e médios dos aluguéis, em $\mathrm{R} \$$. Em outros estudos do SECOVI/RS para o mesmo ano, havia estimativas de valor médio (em $\mathrm{R} \$ / \mathrm{m}^{2}$ ) e área média (em $\mathrm{m}^{2}$ ) para alguns tipos (JK, e apartamentos de 1, 2 e 3 dormitórios).

Primeiramente, as tabelas tiveram que ser extraídas do relatório, transformadas em arquivos editáveis e formatadas para poderem ser analisadas. Muito tempo foi consumido nesta etapa, pois se tratavam de 17 folhas de tabelas no arquivo original. Foram combinados, aos dados das tabelas, os dados de área média e valor médio/área, para os tipos de residências cuja informação existia. Para os demais tipos foi estimada a área média (julgamento de especialista) e, através do valor médio em $\mathrm{R} \$$ do aluguel informado nas tabelas, foi calculado o valor em $\mathrm{R} \$ / \mathrm{m}^{2}$. A partir daí, agregando-se os dados, foi calculado o valor médio de aluguel em $\mathrm{R} \$ / \mathrm{m}^{2}$ por bairro. Como as áreas dos bairros e das ZTs não têm limites coincidentes, foi ainda necessária uma análise espacial em SIG.

\footnotetext{
${ }^{2} \mathrm{JK}$ é apartamento pequeno de três cômodos: com banheiro, dormitório/sala e cozinha (integrada).

${ }^{3}$ Flat é apartamento pequeno com serviço de hotel.
} 
Para as análises espaciais, os dados dos valores calculados na etapa anterior foram importados para a base georreferenciada de bairros em SIG. As camadas de bairros e das ZTs 2003 foram sobrepostas e o valor médio por ZT foi estimado através de ferramenta especifica de análise espacial em SIG. Para algumas ZTs não havia a informação (por não existir oferta de aluguel para todos os bairros). Estes valores foram, então, estimados através de análise estatística espacial, calculando-se o valor médio das áreas vizinhas. Como todos os dados de valores monetários do modelo, estes também foram atualizados para o valor em R \$ para agosto de 2008 (mês de referência) depois convertidos para o valor em Euros da mesma época.

\section{Calibração e análise do ajuste do Modelo MARS-POA2003}

O ajuste de modelos para anos anteriores possibilitaria análises mais completas para calibração e validação do modelo para Porto Alegre. No entanto, a incompatibilidade dos dados das pesquisas O-D de 1974 e de 1986 com as necessidades do programa e a inexistência de alguns dados para estes períodos impossibilitaram o ajuste de um modelo MARS 1974 ou de um modelo MARS 1986.

Tendo de usar dados tão recentes para o ano-base, e, desta forma, não existindo, ainda, dados posteriores, ficou inviabilizada neste momento a calibração dos submodelos de uso do solo do MARS para Porto Alegre, uma vez que estes submodelos devem ser calibrado para as mudanças ocorridas num período de, aproximadamente, 10 anos na população, no número de unidades habitacionais e nos postos de trabalho da área de estudos.

Quanto aos submodelos de transportes, foi realizada a calibração transversal (cross-sectional) para a divisão modal observada em 2003, com base nos dados da pesquisa de origem e destino (EDOM 2003). Os primeiros resultados das estimativas do MARS foram desanimadores. O modelo subestimava os totais de viagens da hora pico (Casa-Trabalho), porém superestimava as viagens pelo modo "A pé / Bicicleta" invertendo os valores com as viagens por automóvel, que eram, por sua vez, subestimadas pelo modelo. As viagens do período de entre-pico (Casa-Outros) eram praticamente dobradas pelo modelo, porém alocando apenas $4 \%$ para o modo automóvel.

Estas distorções permitiram identificar alguns problemas de inconsistências entre algumas bases de dados. População empregada e número de viagens a trabalho, por exemplo, apresentavam grande inconsistência, uma vez que, em muitas zonas com base na EDOM 2003, o número de viagens a trabalho (considerando apenas a primeira viagem da pessoa) ultrapassava muito o número de pessoas empregadas. Outro fator que prejudicou as estimativas do MARS foram os valores da frota resultante da pesquisa $O D$, que eram incompatíveis com os dados do DETRAN. Estes problemas exigiram novas análises dos 
dados de entrada, para estimar novos valores para frota e novos fatores de aferição para as viagens de automóvel.

Tais problemas prejudicaram a primeira tentativa de calibração e atrasaram o processo, porém puderam ser contornados. Outros problemas menores foram surgindo durante 0 processo de calibração e eram então verificados e ajustados. Isto é normal, uma vez que muitos dados tiveram que ser estimados ou agregados de diferentes bases com diferentes zoneamentos.

Durante o processo de calibração foi possível avaliar melhor a sensibilidade do modelo aos parâmetros de entrada e compreender melhor o papel de cada um. Os dados escalares básicos (Tabelas 9 e 12) são parâmetros ajustados às características locais. Por exemplo, o "número médio de viagens por pessoa empregada e dia de trabalho" corresponde ao coeficiente $\beta$ da regressão, que multiplicado pelo número de residentes empregados por $\mathrm{ZT}$, estima a produção de viagens casa-trabalho. No entanto, ao invés de se obter este valor através da análise por regressão, o parâmetro é calculado com base nas características da região, aplicando-se o método apresentado por Pfaffenbichler (2003). O método resulta em um parâmetro que fornece um bom ajuste do modelo aos dados reais.

A verificação da conformidade das estimativas de viagens geradas com base domiciliar, por motivo trabalho (Casa-Trabalho) e por outros motivos (Casa-Outros) foi a etapa seguinte do processo. Ao final da calibração, as estimativas do MARS apresentaram $99 \%$ de conformidade com viagens geradas do tipo Casa-Trabalho e 92\% de conformidade com viagens geradas do tipo Casa-Outros (Tabela 15). Durante o processo, concomitante com a verificação dos dados gerais da geração de viagens, também era verificada a distribuição modal, pois este é um dado importante para entender que parâmetros deveriam ser reajustados no modelo.

Tabela 15 - Calibração do MARS-POA2003 - totais de viagem por modo e motivo

VIAGENS HORA-PICO

VIAGENS ENTRE-PICO

\begin{tabular}{|c|c|c|c|c|c|c|c|c|}
\hline \multirow{2}{*}{$\begin{array}{l}\text { EDOM } 2003 \\
\text { MODO }\end{array}$} & \multicolumn{4}{|c|}{ CASA-TRABALHO (OBSERVADO) } & \multicolumn{4}{|c|}{ CASA-OUTROS (OBSERVADO) } \\
\hline & A PÉ/BICI & TP & AUTO & TOTAL & A PÉ/BICI & TP & AUTO & TOTAL \\
\hline VIAGENS & 68.750 & 234.790 & 164.957 & 468.497 & 230.309 & 236.916 & 203.183 & 670.407 \\
\hline DIVISÃO MODAL & $15 \%$ & $50 \%$ & $35 \%$ & $100 \%$ & $34 \%$ & $35 \%$ & $31 \%$ & $100 \%$ \\
\hline MARS & \multicolumn{4}{|c|}{ CASA-TRABALHO-MARS } & \multicolumn{4}{|c|}{ CASA-OUTROS-MARS } \\
\hline MODO & A PÉ/BICI & TP & AUTO & TOTAL & A PÉ/BICl & TP & AUTO & TOTAL \\
\hline VIAGENS & 70.408 & 233.086 & 171.508 & 475.002 & 240.511 & 245.908 & 236.540 & 722.959 \\
\hline DIVISÃO MODAL & $15 \%$ & $49 \%$ & $36 \%$ & $100 \%$ & $33 \%$ & $34 \%$ & $33 \%$ & $100 \%$ \\
\hline ERRO (VIAGENS) & 1.658 & -1.704 & 6.551 & 6.505 & 10.203 & 8.992 & 33.357 & 52.552 \\
\hline ERRO RELATIVO & $\Rightarrow 2 \%$ & $\Rightarrow-1 \%$ & $\Rightarrow 4 \%$ & $\Rightarrow 1 \%$ & $\Rightarrow 4 \%$ & $\Rightarrow 4 \%$ & 亿 $16 \%$ & 它 $8 \%$ \\
\hline
\end{tabular}


A divisão modal estimada pelo MARS ficou bem compatível com a dos dados da EDOM2003. Conforme os dados da pesquisa, para viagens Casa-Trabalho a repartição modal em 2003 era de $15 \%$ para o modo A pé / Bicicleta, 50\% para o modo Transporte Público e $35 \%$ para o modo Automóvel. Conforme as estimativas do MARS a repartição modal ficou em 15\%, 49\% e 36\%, respectivamente (Tabela 15).

Como pode ser verificado também na Tabela 15, considerando as viagens Casa-Outros, conforme os dados da EDOM 2003 a repartição modal era de 34\%, 35\% e 31\%, para os modos A pé / Bicicleta, Transporte Público e Automóvel, respectivamente. Conforme as estimativas do MARS esta divisão ficou em 33\%, 34\% e 33\%, para os mesmos modos, respectivamente, o que representa um bom resultado.

Quanto aos dados de viagens produzidas e atraídas por zona de tráfego (ZT), considerando todos os modos, as estimativas do MARS apresentaram um ótimo ajuste, os quais foram avaliados através de análise de regressão entre dados reais e estimados (Equação 4).

$$
Y=X \beta+\alpha+\varepsilon
$$

onde:

- $\mathrm{Y}=$ valor estimado;

- $\mathrm{X}=$ valor observado;

- $\beta=$ coeficientes de regressão (inclinação da reta);

- $\alpha=$ constante (intercepto);

- $\varepsilon=$ erros aleatórios com média zero e variância $\sigma^{2}$;

Segundo Schnabel e Lohse $(1997)^{4}$ apud Pfaffenbichler (2003) a análise de regressão é um método adequado para analisar a conformidade entre os valores observados e estimados, onde um bom ajuste é caracterizado por:

- $\alpha$ em torno de 0 (zero),

- $\beta$ em torno de 1 (um) e

- $\mathrm{R}^{2}$ próximo de 1 (um).

\footnotetext{
${ }^{4}$ Schnabel, W. e Lohse, D. (1997). Grundlagen der Straßenverkehrstechnik und der Verkehrsplanung,
} Band 2: Verkehrsplanung; Verlag für Bauwesen, Berlin. p. 229 
As estimativas de viagens Casa-Trabalho produzidas por zona de tráfego, por todos os modos, apresentou um coeficiente de determinação $R^{2}$ de 0,97 , enquanto que $\circ R^{2}$ das mesmas viagens atraídas às ZTs foi de 0,96 . Quanto à inclinação das retas, que é representada pelos parâmetros $\beta$, também ficaram próximas ao valor ideal de $1,0\left(45^{\circ}\right)$. Conforme podem ser verificados nas equações das retas dos gráficos das Figuras 20 e 21, estes valores ficaram em 1,02 e 0,87, para viagens produzidas e atraídas, respectivamente.

Na mesma análise, porém por modos de viagem, os resultados do ajuste não foram tão bons como considerando todos os modos. O melhor ajuste foi verificado para o modo Transporte Público, com $\mathrm{R}^{2}$ de 0,89 para viagens produzidas e 0,96 para viagens atraídas, conforme podem ser verificados nas Figuras 22 e 23. O pior ajuste foi para as viagens "A pé / Bicicleta", com $\mathrm{R}^{2}$ de 0,41 para viagens produzidas e 0,22 para viagens atraídas e parâmetros $\beta$ de 0,84 e 0,67, respectivamente (Figuras 24 e 25). O ajuste do modo automóvel apresentou $\mathrm{R}^{2}$ de 0,75 para produção de viagens e de 0,85 para atração de viagens às ZTs (Figuras 26 e 27), enquanto os parâmetros de inclinação da reta também não ficaram ruins $(0,86$ e 0,87 , respectivamente). Estes resultados podem estar refletindo a falta de alguns dados específicos para os modos, que tiveram que ser estimados, principalmente no que diz respeito ao automóvel.

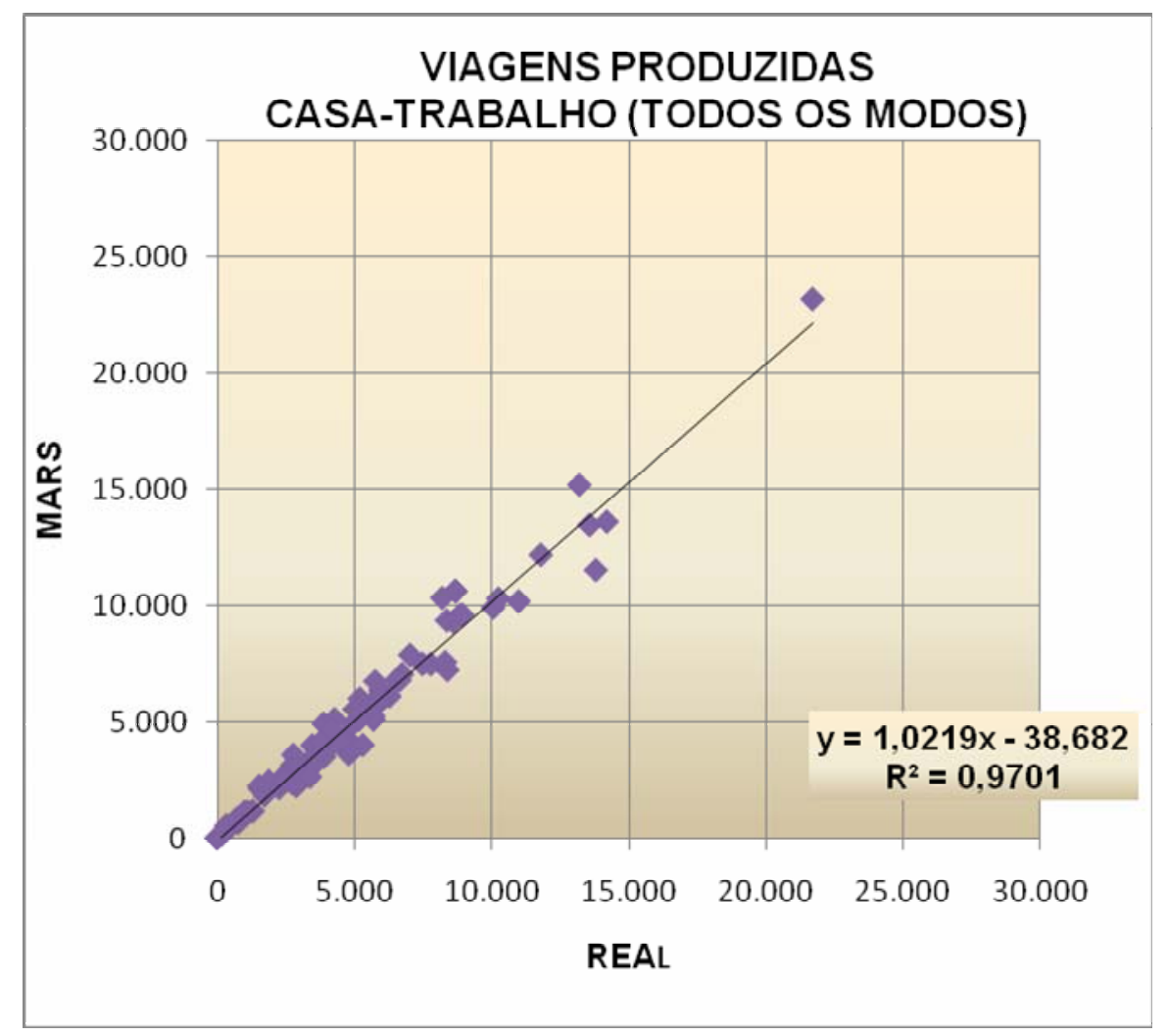

Figura 20 - Ajuste do MARS para viagens produzidas Casa-Trabalho - Todos os modos. 


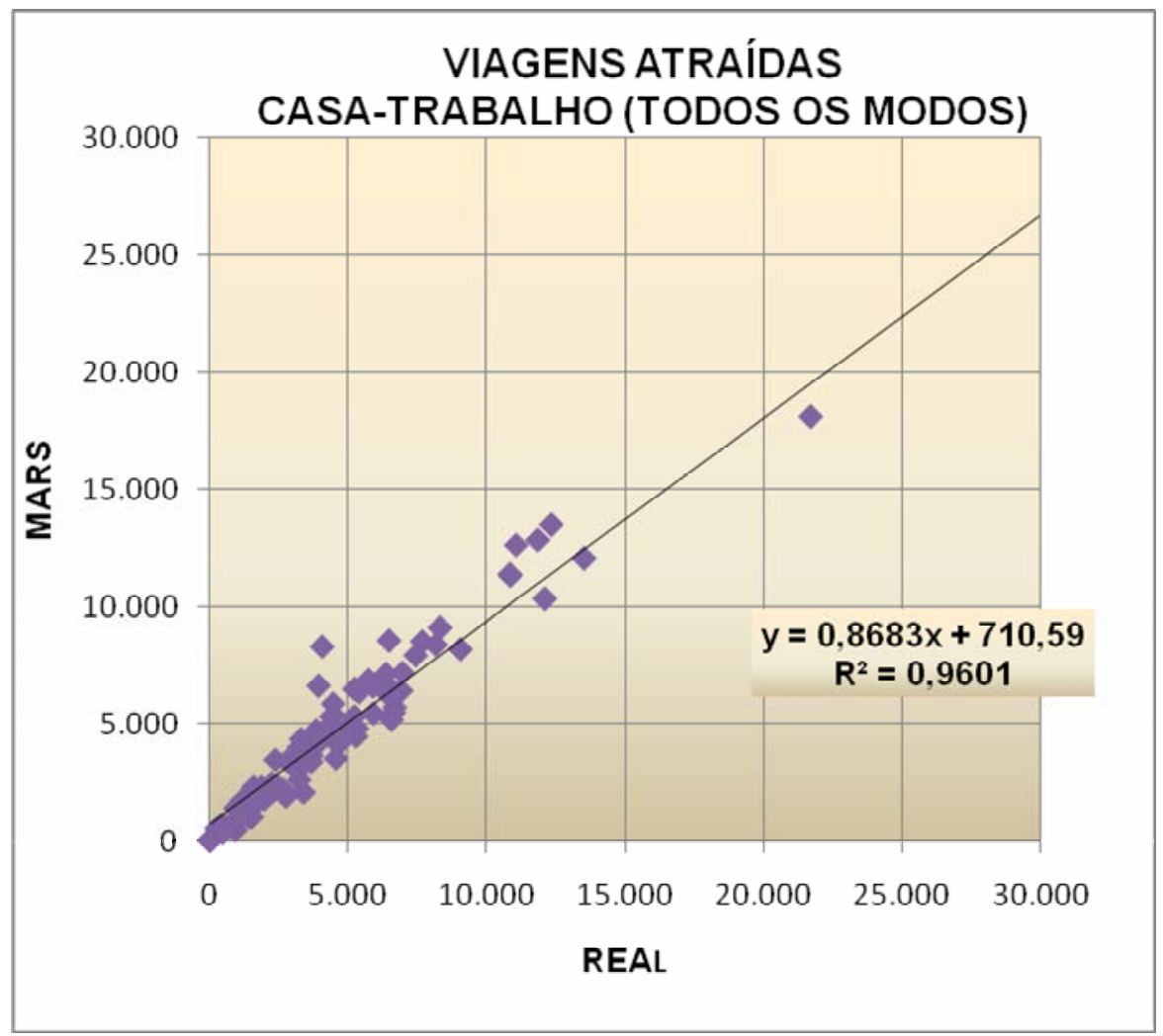

Figura 21 - Ajuste do MARS para viagens atraídas Casa-Trabalho - todos os modos.

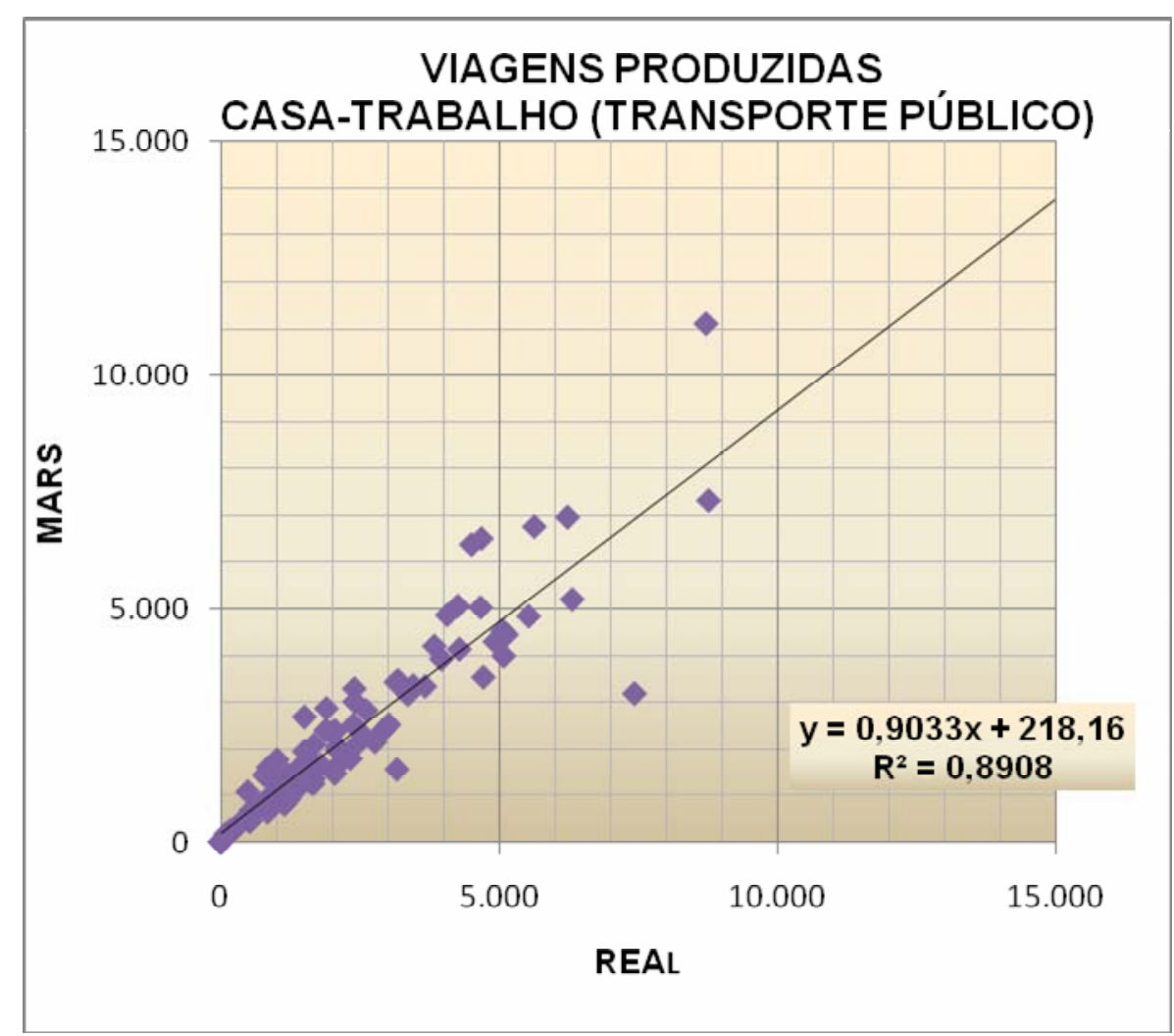

Figura 22 - Ajuste do MARS para viagens produzidas Casa-Trabalho - Transporte Público. 


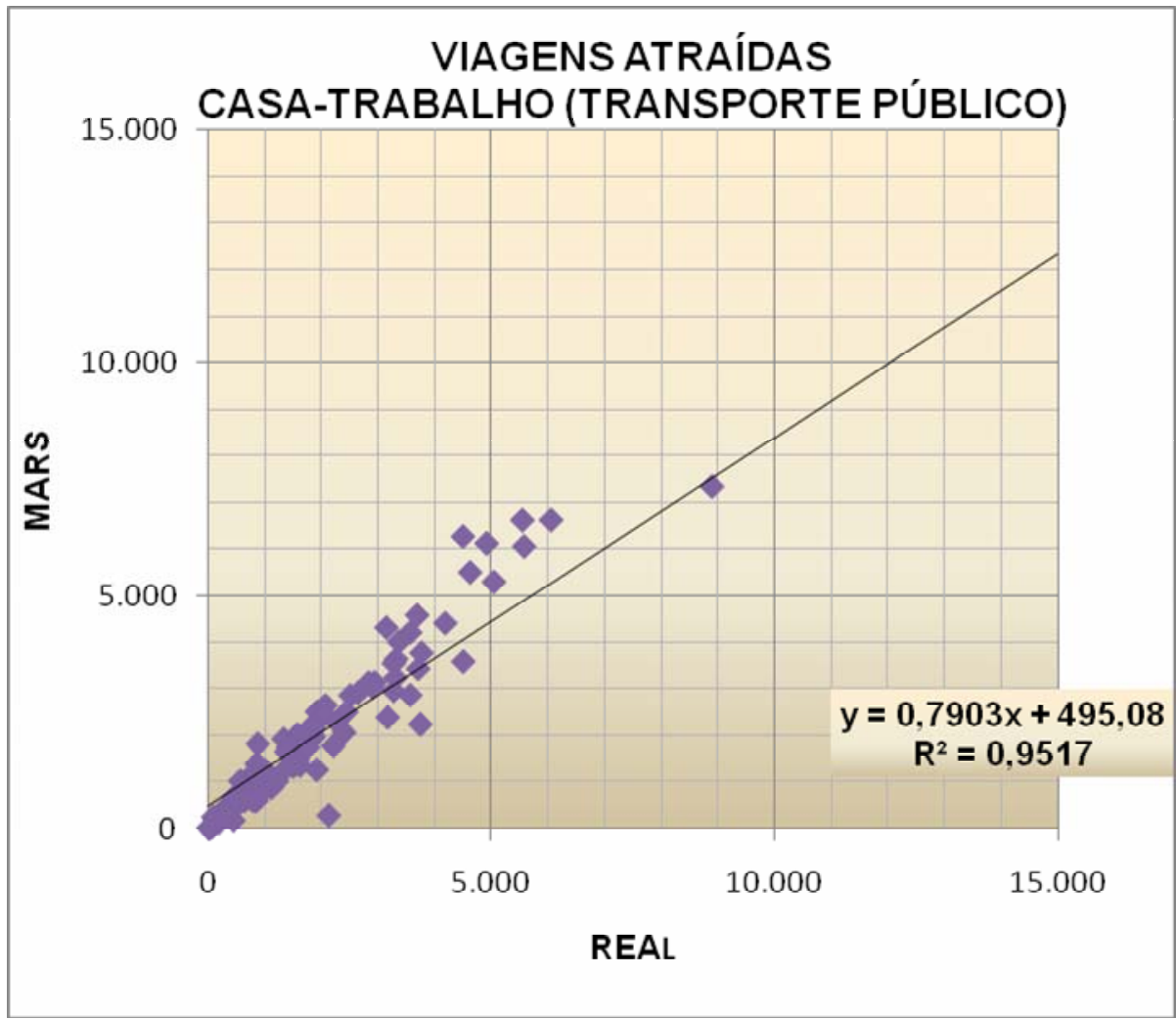

Figura 23 - Ajuste do MARS para viagens atraídas Casa-Trabalho - Transporte Público.

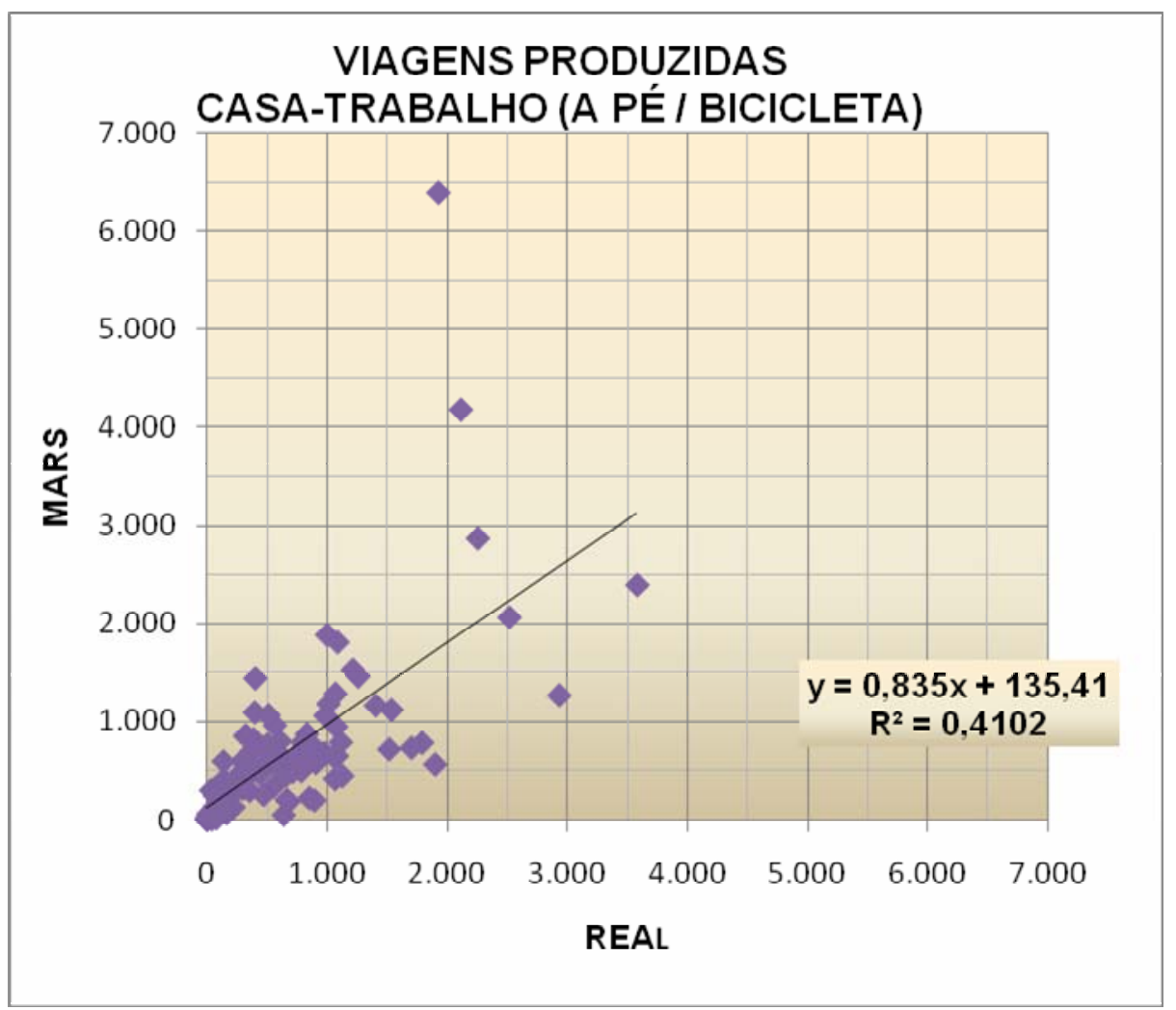

Figura 24 - Ajuste do MARS para viagens produzidas Casa-Trabalho - A pé / Bicicleta. 


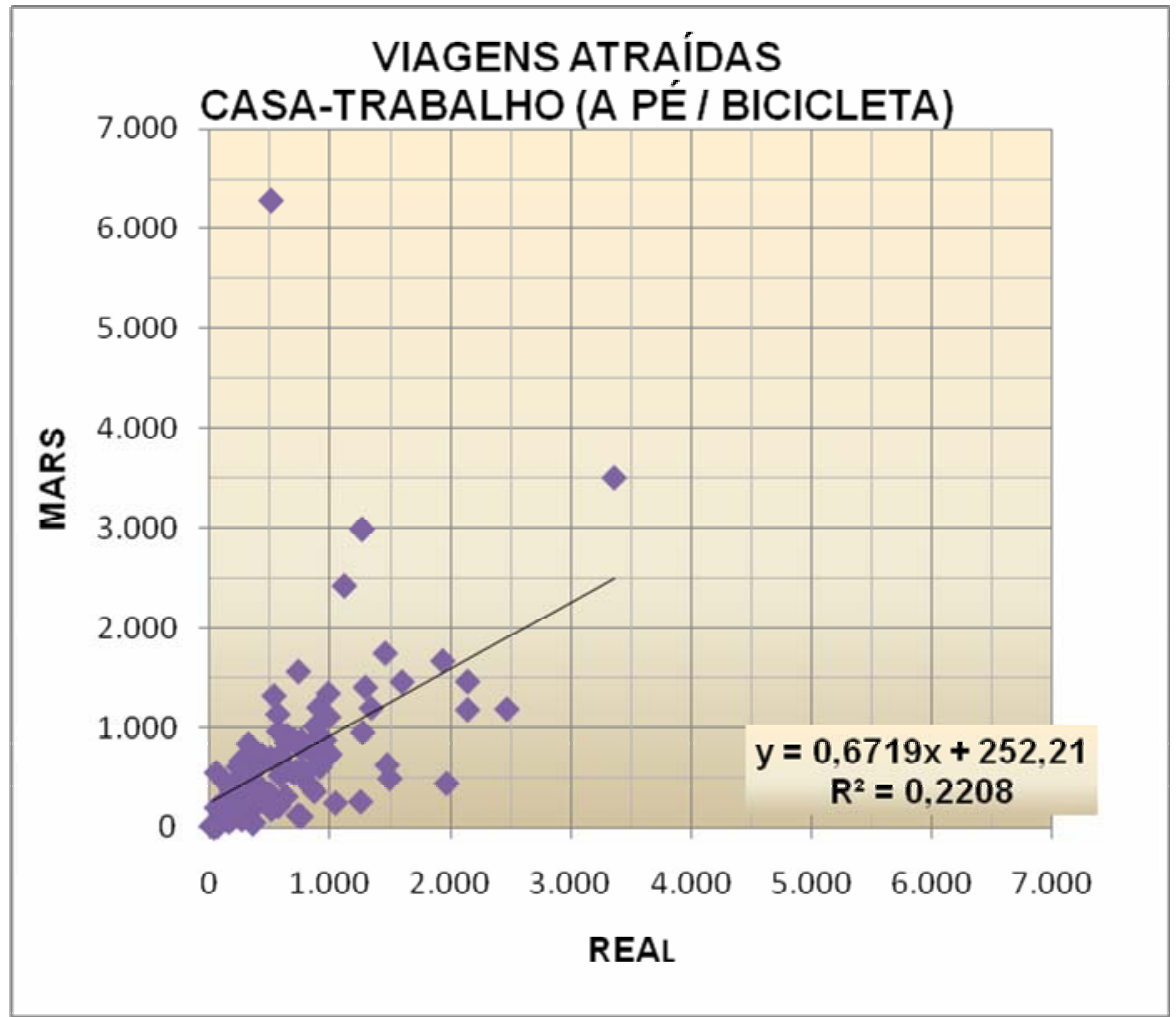

Figura 25 - Ajuste do MARS para viagens atraídas Casa-Trabalho - A pé / Bicicleta.

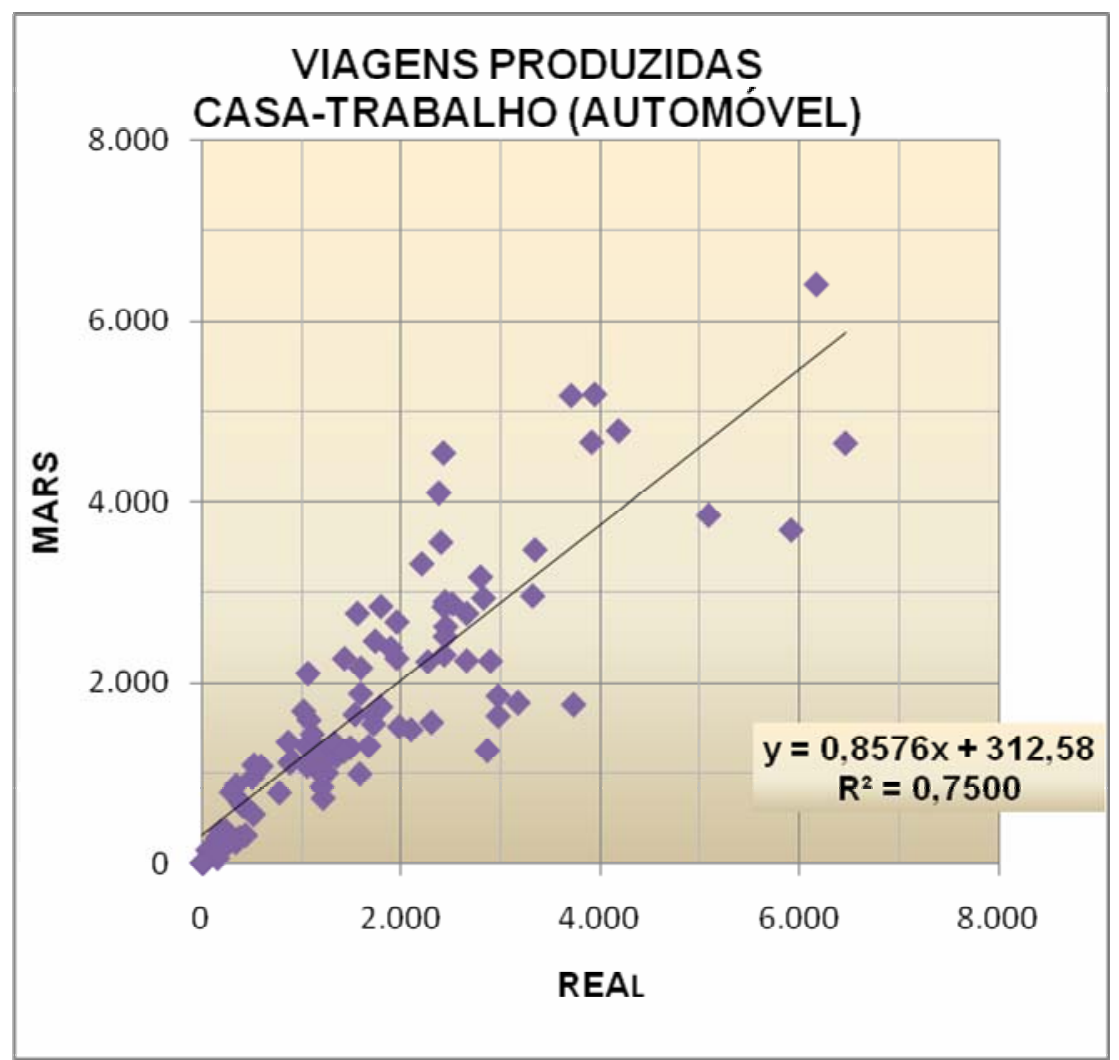

Figura 26 - Ajuste do MARS para viagens produzidas Casa-Trabalho - Automóvel 


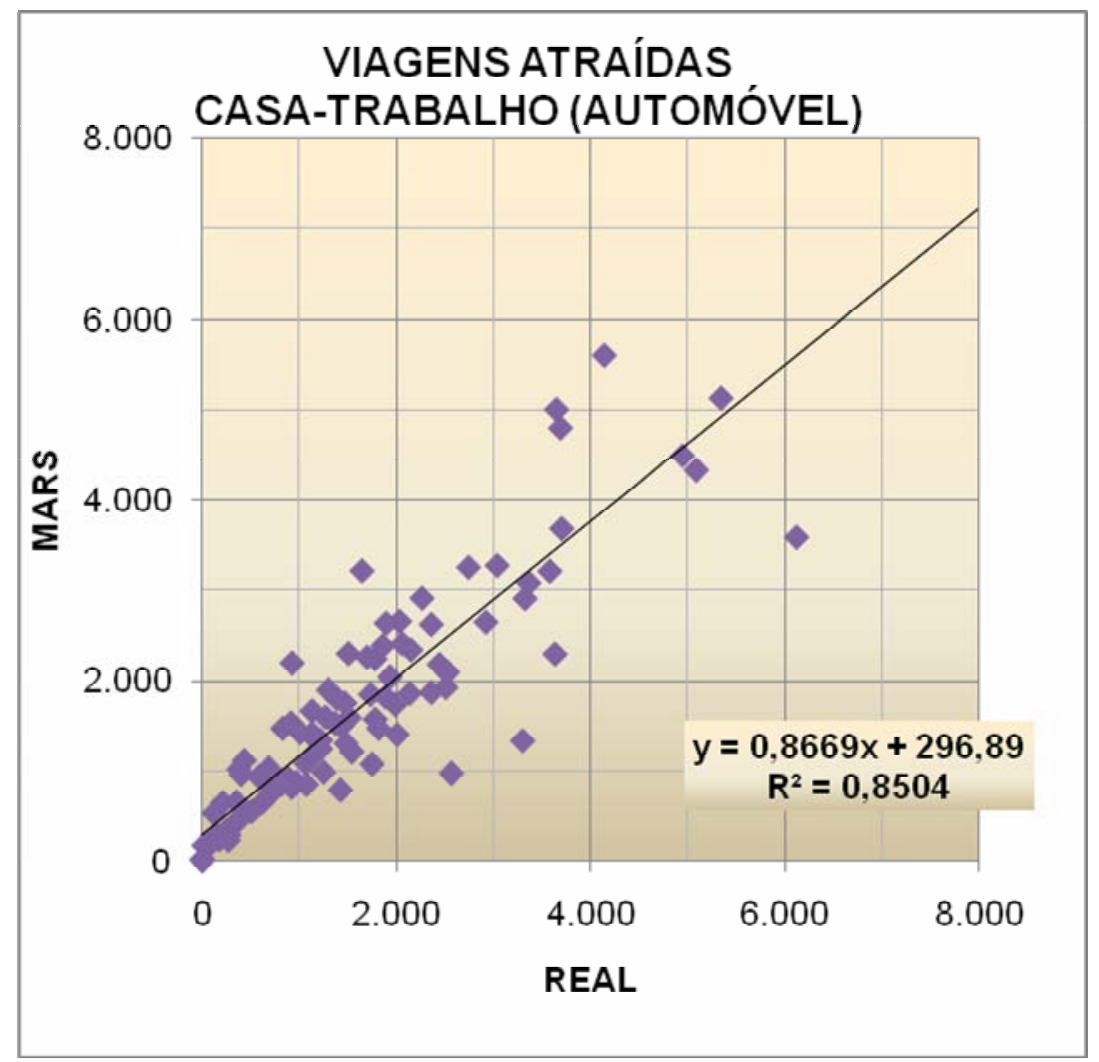

Figura 27 - Ajuste do MARS para viagens atraídas Casa-Trabalho - Automóvel

A qualidade do ajuste é inversamente proporcional ao detalhamento da análise, como, por exemplo, na análise de distribuição de viagens entre pares $O D$, em que os ajustes das estimativas do MARS não ficaram bons quando comparados com os dados reais. $\mathrm{O}$ ajuste considerando todos os modos para viagens entre pares O-D Casa-Trabalho ficou com $\mathrm{R}^{2}$ de 0,42 (Tabela 16 e Figura 28). O melhor ajuste foi verificado para o modo Transporte Público, com $R^{2}$ de 0,61 (Tabela 17 e Figura 29), e o pior para o modo lento, com $R^{2}$ igual a 0,12 .

Uma alternativa seria realizar uma análise mais detalhada dos motivos pelos quais essas zonas não compartilham viagens, entendendo-se que, de imediato, a solução mais razoável seria considerar zonas mais agregadas para análises com o Modelo MARS, tanto que essa hipótese foi confirmada ao se analisar a distribuição das viagens por zonas mais agregadas.

Considerando-se o zoneamento das 18 macrozonas estabelecidas na EDOM 2003, o $\mathrm{R}^{2}$ das estimativas de distribuição de viagens Casa-Trabalho, pelo modo lento, sobe para 0,64, e pelo modo Transporte Público sobe para 0,82. Como exemplo desta análise, apresenta-se o gráfico da Figura 30, para o modo Transporte Público, que pode ser comparado com o gráfico da Figura 29. Verifica-se que houve melhora, não só no valor do $R^{2}$, como do parâmetro $\beta$ (de 0,55 para 0,69 ), indicando que a linha de tendência da regressão se aproxima mais do valor ideal. Mesmo considerando-se os 47 Distritos de Tráfego, também 
definidos na EDOM 2003, as viagens Casa-Trabalho, pelo modo Transporte Público, continuaram apresentando um ajuste razoável $\left(R^{2}=0,78\right)$.

Para o modo automóvel, os ajustes da distribuição de viagens Casa-Trabalho por pares OD, fizeram o $\mathrm{R}^{2}$ variar de 0,58, considerando-se a matriz com as 96 ZTs, para 0,79, considerando-se a matriz das 18 macrozonas.

Conclui-se, portanto, que os problemas causados por um zoneamento muito desagregado têm um efeito em cascata, dificultando desde a coleta de dados, causando distorções em estimativas de dados de entrada, muitas vezes inexistentes, complicando a calibração e distorcendo as estimativas do modelo. Por todas essas considerações, concluiu-se que, em geral, os resultados das estimativas do submodelo de transportes do MARS para Porto Alegre ficaram bem razoáveis, podendo melhorar significativamente através da consideração de um zoneamento mais agregado.

Tabela 16 - Análise do ajuste do modelo MARS para distribuição de viagens entre pares O-D Casa-Trabalho, considerando todos os modos.

\begin{tabular}{|c|c|c|c|c|c|c|}
\hline \multicolumn{7}{|c|}{ DISTRIBUIÇÃO O-D - VIAGENS CASA-TRABALHO } \\
\hline \multicolumn{7}{|c|}{ (TODOS MODOS) } \\
\hline \multicolumn{7}{|c|}{ ANÁLISE GERAL (REAL X MARS) } \\
\hline PARES OD & ANÁLISE & REAL & MARS & DESVIO & $\begin{array}{c}\text { DESVIO } \\
\text { ABSOLUTO }\end{array}$ & $\begin{array}{c}\text { DESVIO } \\
\text { RELATIVO }\end{array}$ \\
\hline TOTAL & SOMA & 468.497 & 475.002 & 6.505 & 355.627 & 537 \\
\hline 9.216 & MÉDIA & 51 & 52 & 1 & 39 & $6 \%$ \\
\hline ANALISADOS & MÍNIMO & 0 & 0 & -1.666 & 0 & $-100 \%$ \\
\hline 9.216 & MÁXIMO & 2.807 & 6.119 & 5.602 & 5.602 & $2196 \%$ \\
\hline $100 \%$ & DESV. PADRÃO & 128 & 112 & 102 & 94 & $77 \%$ \\
\hline \multicolumn{2}{|c|}{ ANÁLISE DA REGRESSÃO } & \multicolumn{3}{|c|}{ COEFICIENTES } & \multicolumn{2}{|c|}{ AJUSTE } \\
\hline \multicolumn{2}{|c|}{ PARÂMETROS } & $\begin{array}{c}\alpha \\
\text { (intercepto) }\end{array}$ & \multicolumn{2}{|c|}{$\begin{array}{c}\beta \\
\text { (inclinação da reta) }\end{array}$} & \multicolumn{2}{|c|}{$\begin{array}{c}\mathbf{R}^{2} \\
\text { (Coeficiente de determinação) }\end{array}$} \\
\hline \multicolumn{2}{|c|}{ VALORES IDEAIS } & 0,00 & \multicolumn{2}{|c|}{1,00} & \multicolumn{2}{|c|}{1,00} \\
\hline \multicolumn{2}{|c|}{ VALORES OBTIDOS } & 22,82 & \multicolumn{2}{|c|}{0,56} & \multicolumn{2}{|l|}{0,42} \\
\hline \multicolumn{2}{|c|}{ DESVIO (Regressão - Ideais) } & 22,82 & \multicolumn{2}{|c|}{$-0,44$} & \multicolumn{2}{|c|}{$-0,58$} \\
\hline \multicolumn{2}{|c|}{ ANÁLISE } & REAL & MARS & \multicolumn{3}{|c|}{ DESVIO (MARS - REAL) } \\
\hline \multicolumn{2}{|c|}{$\begin{array}{l}\text { PARES OD COM VIAGENS } \\
\% \text { SOBRE TOTAL }\end{array}$} & $\begin{array}{l}3.871 \\
42 \%\end{array}$ & $\begin{array}{l}8.542 \\
93 \%\end{array}$ & \multicolumn{3}{|c|}{$\begin{array}{l}4.671 \\
51 \%\end{array}$} \\
\hline
\end{tabular}




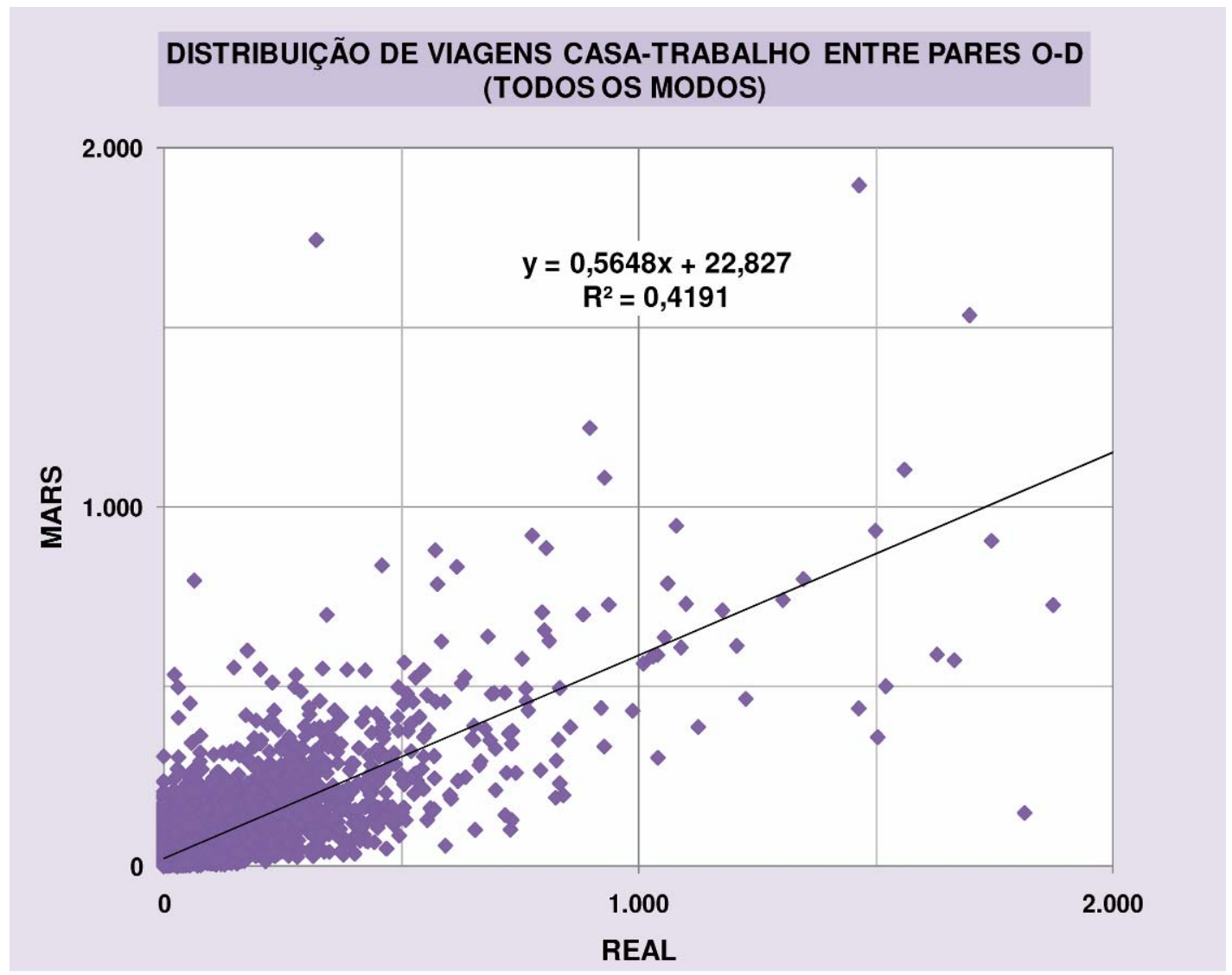

Figura 28 - Ajuste do modelo MARS para distribuição de viagens entre pares O-D Casa-Trabalho, considerando todos os modos.

Tabela 17 - Análise do ajuste do modelo MARS para distribuição de viagens entre pares O-D Casa-Trabalho, considerando modo Transporte Público.

\begin{tabular}{|c|c|c|c|c|c|c|}
\hline \multicolumn{7}{|c|}{ DISTRIBUIÇÃO O-D - VIAGENS CASA-TRABALHO } \\
\hline \multicolumn{7}{|c|}{ TRANSPORTE PÚBLICO } \\
\hline \multicolumn{7}{|c|}{ ANÁLISE GERAL (REAL X MARS) } \\
\hline PARES OD & ANÁLISE & REAL & MARS & DESVIO & $\begin{array}{l}\text { DESVIO } \\
\text { ABSOLUTO }\end{array}$ & $\begin{array}{l}\text { DESVIO } \\
\text { RELATIVO }\end{array}$ \\
\hline TOTAL & SOMA & 234.790 & 233.086 & -1.704 & 198.257 & -422 \\
\hline 9.216 & MÉDIA & 25 & 25 & 0 & 22 & $-5 \%$ \\
\hline ANALISADOS & MÍNIMO & 0 & 0 & -721 & $\mathbf{0}$ & $-100 \%$ \\
\hline 9.216 & MÁXIMO & 1.652 & 1.290 & 322 & 721 & $734 \%$ \\
\hline $100 \%$ & DESV. PADRÃO & 68 & 48 & 43 & 37 & $46 \%$ \\
\hline \multicolumn{2}{|c|}{ ANÁLISE DA REGRESSÃO } & \multicolumn{3}{|c|}{ COEFICIENTES } & \multicolumn{2}{|c|}{ AJUSTE } \\
\hline \multicolumn{2}{|c|}{ PARÂMETROS } & $\begin{array}{c}\alpha \\
\text { (intercepto) }\end{array}$ & \multicolumn{2}{|c|}{$\begin{array}{c}\beta \\
\text { (inclinação da reta) }\end{array}$} & \multicolumn{2}{|c|}{$\begin{array}{c}\mathbf{R}^{2} \\
\text { (Coeficiente de determinação) }\end{array}$} \\
\hline \multicolumn{2}{|c|}{ VALORES IDEAIS } & 0,00 & \multicolumn{2}{|c|}{1,00} & \multicolumn{2}{|c|}{1,00} \\
\hline \multicolumn{2}{|c|}{ VALORES OBTIDOS } & 11,40 & \multicolumn{2}{|c|}{0,55} & \multicolumn{2}{|c|}{0,61} \\
\hline \multicolumn{2}{|c|}{ DESVIO (Regressão - Ideais) } & 11,40 & \multicolumn{2}{|c|}{$-0,45$} & \multicolumn{2}{|c|}{$-0,39$} \\
\hline \multicolumn{2}{|c|}{ ANÁLISE } & REAL & MARS & \multicolumn{3}{|c|}{ DESVIO (MARS - REAL) } \\
\hline \multicolumn{2}{|c|}{$\begin{array}{l}\text { PARES OD COM VIAGENS } \\
\% \text { SOBRE TOTAL }\end{array}$} & $\begin{array}{l}3.009 \\
33 \%\end{array}$ & $\begin{array}{l}8.369 \\
91 \%\end{array}$ & \multicolumn{3}{|c|}{$\begin{array}{l}5.360 \\
58 \%\end{array}$} \\
\hline
\end{tabular}




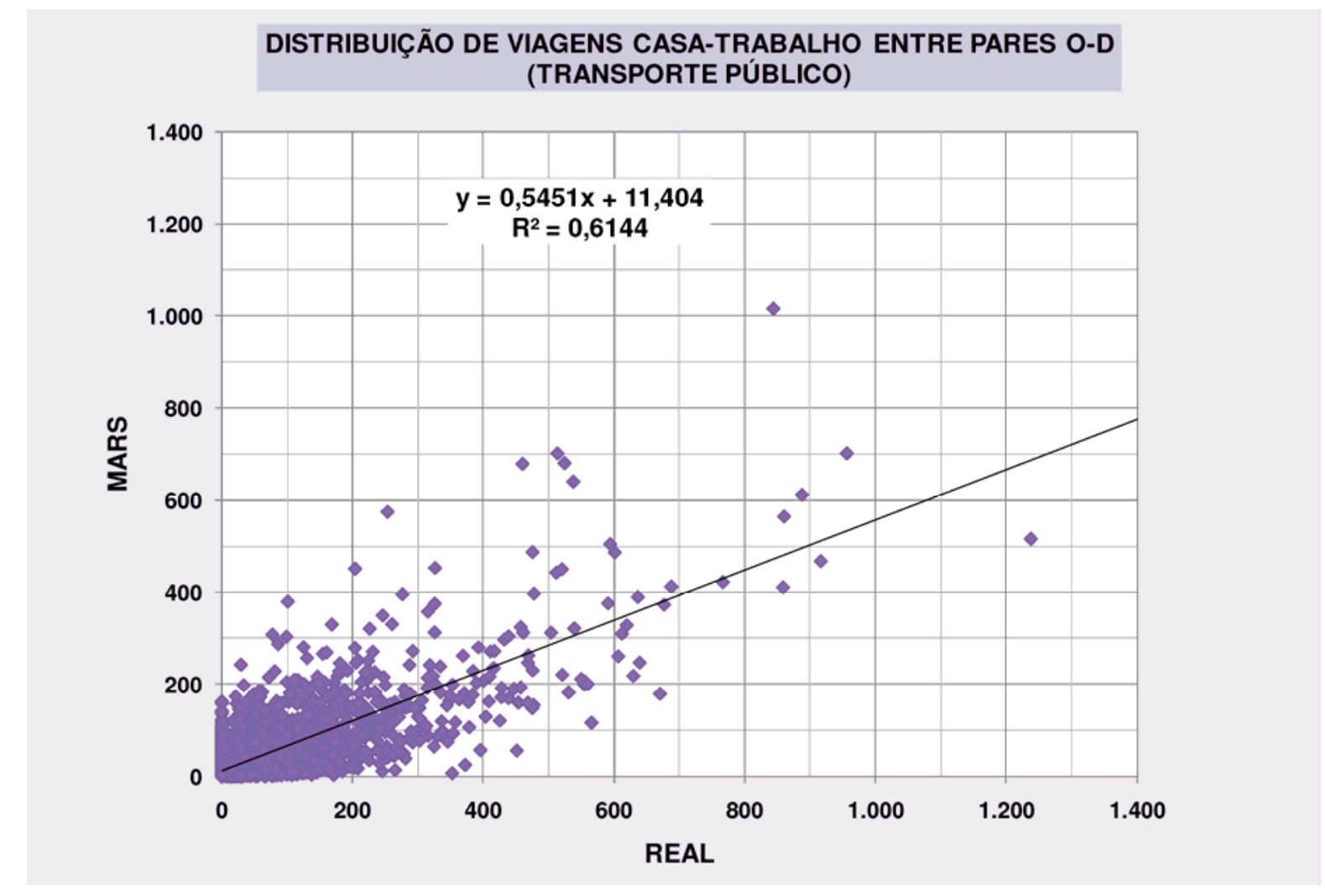

Figura 29 - Ajuste do modelo MARS para distribuição de viagens entre pares O-D CasaTrabalho, considerando modo Transporte Público. 


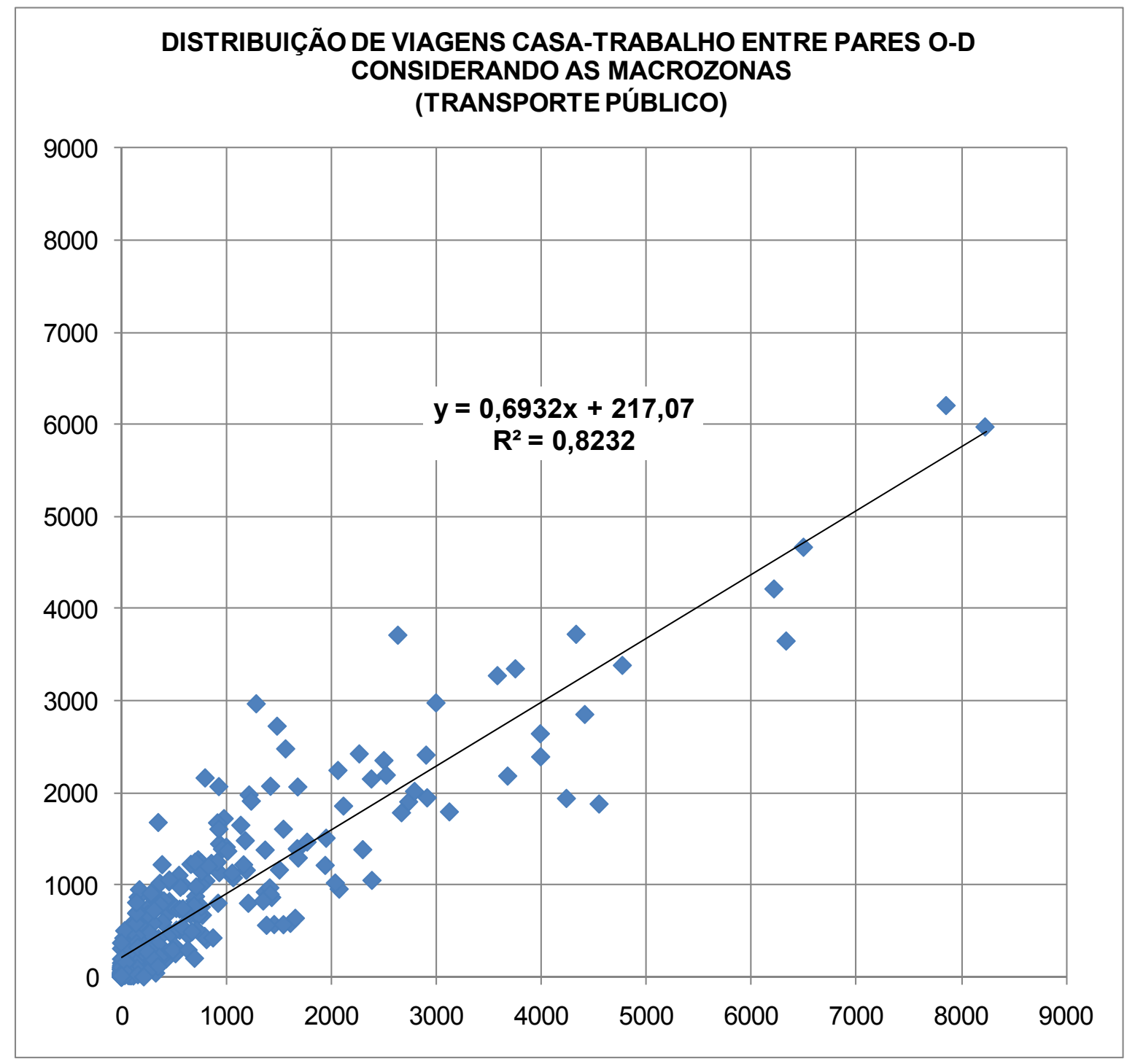

Figura 30 - Ajuste do modelo MARS para distribuição de viagens entre pares O-D para o modo Transporte Público, mas considerando Macrozonas.

\section{Validação do MARS POA2003 para projeções futuras}

Para validar o modelo para projeções futuras pelo método tradicional, é preciso dados da área de estudo, de uso do solo e de transportes, de pelo menos dois períodos, com dez anos de diferença, aproximadamente. Como já comentado anteriormente, devido à dificuldade de obtenção de dados históricos de Porto Alegre, adequados a esse fim, a aplicação do método tradicional de validação ficou impossibilitada.

Uma opção aqui sugerida como forma de validação é a da meta-análise, no entanto é preciso aplicar o modelo para a simulação de diferentes cenários e investigar a existência de outras aplicações semelhantes para que os resultados possam ser comparados e validados. 


\subsubsection{Considerações finais do Bloco 2}

O modelo LUTI selecionado para ajuste à cidade de Porto Alegre foi o modelo MARS. As características do MARS estão adequadas aos objetivos do estudo, destacando-se seu caráter dinâmico, essencial para a pesquisa, e a sua flexibilidade, permitindo adaptações ao contexto e a futura combinação com os modelos espaciais. Além disto, a disponibilidade do MARS para aplicação, inclusive incentivada pelo seu criador, somada as suas características estruturais, com um módulo de configuração de políticas de mobilidade, foram determinantes na escolha do modelo.

A tentativa de calibrar e validar o MARS para Porto Alegre, através do mesmo método realizado para o MARS Viena, não foi possível por falta de dados históricos. A obtenção de dados para alimentar um modelo com a complexidade de interação dinâmica entre uso do solo e transporte constitui, ainda hoje, um problema. No entanto, a análise de outras aplicações do MARS mostrou que este problema não é uma particularidade de Porto Alegre, e nem de cidades brasileiras. Simplificações do processo de ajuste por falta de dados foram verificadas para outras aplicações do MARS, inclusive em cidade de países desenvolvidos.

Acredita-se, no entanto, que o ajuste do modelo MARS POA 2003 esteja satisfatório e cumpre o objetivo do Bloco 2, podendo dar prosseguimento a pesquisa. Além disto, a organização dos dados coletados, para alimentar o Modelo MARS, com suas 90 variáveis, constitui um banco de dados sistematizado e georreferenciado para Porto Alegre e o embrião de um arquivo histórico de informações, indispensável para a calibração e validação de modelos, ou seja, útil para quaisquer atividades de planejamento.

A etapa de calibração permitiu uma melhor compreensão das relações entre as variáveis, do grau de sensibilidade e do papel dos dados escalares básicos como parâmetros comportamentais locais. O entendimento e bom ajuste destes parâmetros facilitam a transferência do MARS para outros contextos urbanos. O estudo prossegue visando à obtenção de um Modelo LUTI Dinâmico e Espacial através do MARS POA.

\subsection{Bloco 3 - Obtenção e ajuste de um Modelo LUTI Dinâmico e Espacial - MARS POA Espacial}

Como já comentado anteriormente, o MARS é um modelo amplamente testado e vem sofrendo melhorias constantes a cada nova cidade onde é aplicado para estudos de desenvolvimento urbano sustentável. Desta forma, a expectativa com a aplicação do MARS em Porto Alegre não foi diferente. Foram, então, estabelecidas duas propostas de inserção de melhorias no MARS, através do MARS POA. A primeira melhoria proposta neste estudo 
de caso contempla o terceiro objetivo específico desta pesquisa e a segunda está associada à escolha do modelo MARS e contempla um objetivo antigo do seu criador.

Sendo assim, as melhorias propostas através do MARS POA são: $i$. Inserção de variáveis espaciais e ii. Conexão dos modelos MARS e SATURN. A primeira, que constitui o foco inicial desta pesquisa, é abordada em mais detalhes na sequência. A segunda, não viabilizada no âmbito desta pesquisa, é apresentada em mais detalhes no item 7.2 (sugestões para trabalhos futuros).

Discutem-se aqui algumas formas possíveis para inserção de variáveis espaciais nos submodelos de transporte do MARS, visando a obtenção de um Modelo LUTI Dinâmico e Espacial. Seguindo o método proposto, conforme o item 5.2, apresenta-se, na sequência, a análise para definição dos indicadores de dependência espacial para dois submodelos de geração de viagens do MARS, através do método selecionado no item 6.2 e, também, o teste para verificar se as introduções dos indicadores escolhidos realmente representam melhorias para os submodelos.

\subsubsection{Formas para inserção de variáveis espaciais no MARS}

O MARS é um modelo flexível, portanto é possível fazer alterações na sua estrutura e, também, considerar novas variáveis. Uma forma mais simples de introdução de variáveis espaciais é através da inclusão destas como variáveis de entrada no modelo. As variáveis espaciais (Globais e Locais, conforme análises do item 6.2) seriam introduzidas da mesma forma que os "dados vetoriais básicos", com seus valores atribuídos para cada ZT. Neste caso, constituiriam novas variáveis de entrada para o MARS, cujos valores e coeficientes deveriam ser gerados externamente, através de análise espacial com uso de uma ferramenta específica de estatística espacial.

A Figura 31 apresenta, como um exemplo, a inserção de quatro variáveis espaciais globais para o modelo de produção de viagens na hora pico (total tours peak $i$ ), em letras vermelhas conforme padrão do MARS para variáveis de entrada, as quais representam os quatro quadrantes do Box Map para a variável população empregada (Q1_POPEMPRE, Q2_POPEMPRE, Q1_POPEMPRE, Q4_POPEMPRE). No MARS, as viagens geradas na hora pico são, essencialmente, viagens a trabalho. Ou seja, viagens produzidas ou atraídas por ZT, por motivo trabalho e por todos os modos de viagem (VPCTTM e VACTTM, respectivamente).

Parte do submodelo de transportes do MARS é apresentada na tela do software Vensim na Figura 31. Está destacado com a elipse verde o modelo de produção de viagens na hora pico (total tours peak i) ou VPCTTM, cuja equação aparece no módulo de edição de 
equações do programa (na parte superior à esquerda, também destacado com borda verde) já com as novas variáveis consideradas. Na parte superior à direita da Figura 31, com borda magenta, aparece a variável Q1_POPEMPRE no módulo de edição de equação do programa, como exemplo de como as variáveis de entrada do MARS, são localizadas nas planilhas do Excel e introduzidas nos modelos.

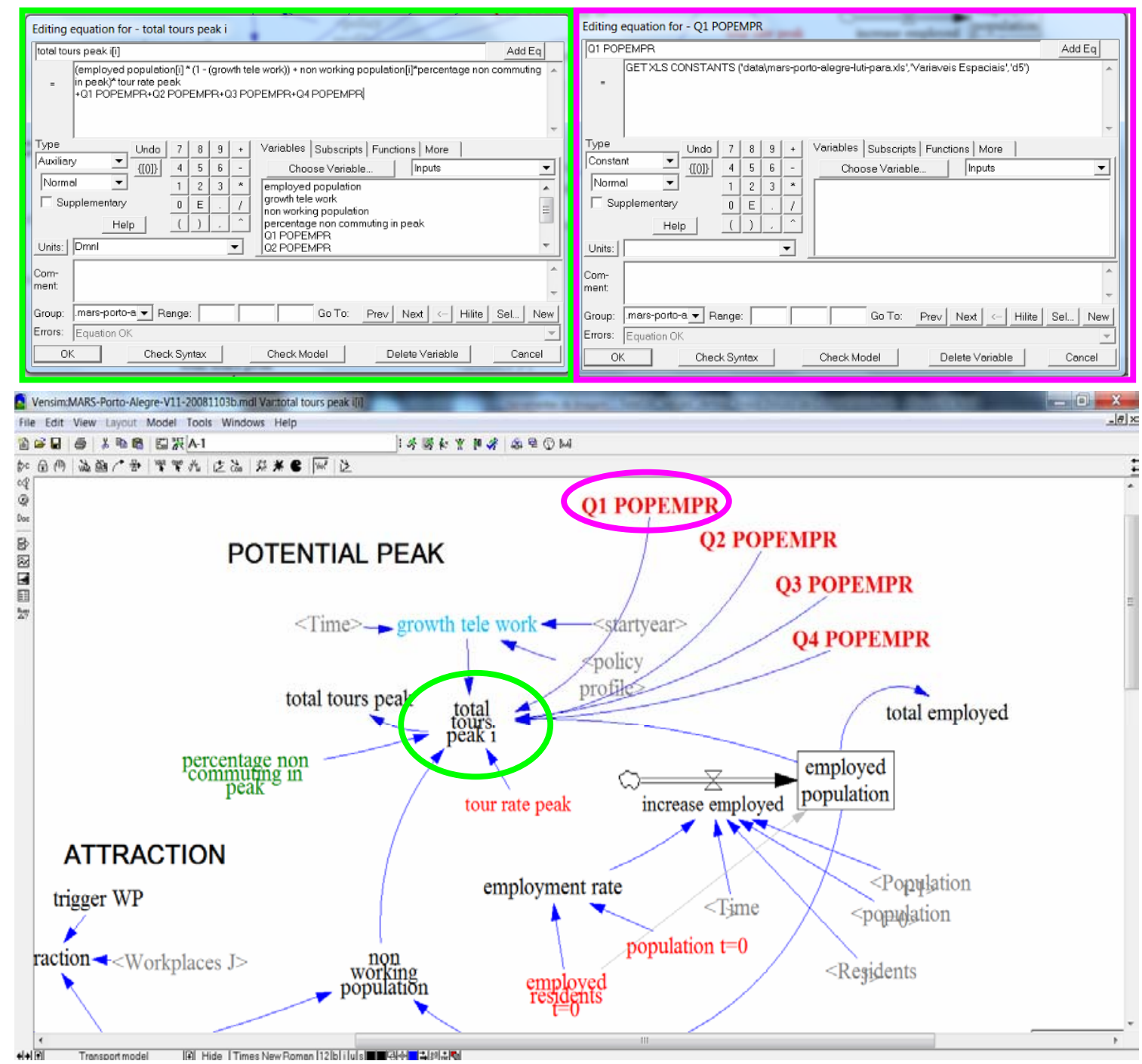

Figura 31 - Exemplo de inserção de variáveis espaciais como dados de entrada do MARS.

No caso apresentado, as variáveis espaciais seriam apenas definidas para o ano base e manteriam seus valores até o final do período de análise de 30 anos. No entanto, nas análises espaciais apresentadas no item 6.2 , foi verificado que estes padrões espaciais são dinâmicos e apresentam variação se considerado um longo período de análise. $O$ ideal seria, neste caso, que as variáveis espaciais fossem geradas, também, de forma dinâmica, aproveitando esta característica do MARS. 
Esta idéia requer um estudo mais aprofundo, para uma possível conexão do MARS com uma ferramenta de estatística espacial ou para gerar as variáveis espaciais na própria estrutura do modelo através do software $V_{\text {ensim }}$. O primeiro passo, para que a segunda opção seja possível, é a introdução da matriz de vizinhança para a área de estudos como outro dado de entrada do modelo. Com isto já seria possível gerar, dentro da própria estrutura do MARS, não só as variáveis espaciais globais, como várias outras características espaciais que seriam úteis para outros submodelos.

Um exemplo de submodelo que poderia se beneficiar com as informações de uma matriz de vizinhança é o submodelo para cálculos de velocidades para cada período de análise, que é baseado no efeito das relações fluxo-velocidade dos pares $O-D$, porém não leva em consideração o que ocorre nas ZTs intermediárias aos pares O-D. Com a matriz de vizinhança seria possível verificar quais $Z T$ s fazem parte das possíveis rotas entre os pares O-D e, assim, avaliar os efeitos dos fluxos destas na velocidade final entre cada par O-D.

Quanto à obtenção das variáveis espaciais globais, esta pode ser baseada no diagrama de espalhamento de Moran (Moran Scatterplot), que é construído com base nos valores normalizados da variável em análise (Z), que são comparados com a média dos valores dos vizinhos $(\mathrm{Wz})$. Os valores normalizados $(Z)$ para cada variável em análise são passíveis de cálculo já com os valores totais e por ZT gerados pelo MARS, para cada período de análise. O cálculo da média dos valores dos vizinhos $(\mathrm{Wz})$ ficaria viabilizado com a informação da matriz de vizinhança, que definiria os vizinhos de cada ZT. Um estudo mais aprofundado seria necessário para se obter o I de Moran, os indicadores locais de dependência espacial e para gerar os coeficientes das variáveis espaciais nos submodelos.

\subsubsection{Considerações finais do Bloco 3}

As análises apresentadas neste item confirmam que é possível atender ao terceiro objetivo específico desta pesquisa, ou seja, o de obter, a partir do MARS, um modelo que considere, além do uso do solo de forma dinâmica e integrada, também a distribuição espacial das atividades urbanas de forma explicita (MARS POA Espacial).

Através do modelo MARS, graças a sua flexibilidade, mostrou-se que é viável introduzir as características espaciais, de duas formas. Uma opção é considerando as variáveis espaciais de forma exógena, gerando os indicadores para cada ZT com uso de ferramentas de estatística espacial e introduzindo-os como parâmetros estáticos, nos modelos, ao longo do tempo. A segunda opção é através da consideração de variáveis espaciais endogenamente, gerando indicadores de dependência espacial dentro da estrutura do MARS, que seriam variáveis espaciais dinâmicas ao longo do tempo. 
No entanto, a opção de gerar as variáveis espaciais de forma endógena no modelo, que parece ser a opção mais indicada, pelas evidências de que os padrões espaciais não são estáticos, requer um estudo mais detalhado e criterioso. Conforme visto nas análises do Bloco 1, nem sempre as variáveis espaciais constituem melhorias para o modelo. Neste caso, seria preciso considerar uma forma de geração de índices de autocorrelação espacial e, também, de avaliação destes índices dentro da estrutura do MARS, para definir se os indicadores deveriam ou não ser considerados.

\subsection{Bloco 4 - Avaliação do MARS POA Espacial}

Para que a introdução de variáveis espaciais resulte em melhorias para o MARS, também se faz necessário analisar a distribuição espacial dos resíduos das estimativas dos submodelos, para verificar se a autocorrelação espacial das variáveis está, de alguma forma, perturbando os resultados estimados. A título de exemplo é apresentada a análise para dois submodelos de transportes do MARS através da primeira opção: variáveis espaciais exógenas.

As análises de demanda de viagens no MARS iniciam com as estimativas de viagens produzidas e de viagens atraídas por ZT, por motivo trabalho e por outros motivos, inicialmente por todos os modos agregados. A divisão modal no MARS é realizada juntamente com a estimativa da distribuição de viagens. As análises aqui apresentadas têm foco na primeira etapa da estimativa de demanda no MARS e nas viagens por motivo trabalho. A Figura 32 apresenta a distribuição espacial dos resíduos das estimativas do modelo MARS para as viagens produzidas e viagens atraídas por ZT, por motivo trabalho e por todos os modos de viagem (VPCTTM e VACTTM, respectivamente).

A distribuição espacial dos resíduos das estimativas de VPCTTM e VACTTM, cujos índices de autocorrelação espacial ficaram em 0,22 e 0,26, respectivamente, foi analisada através dos Moran Maps, gerados com o uso do software GeoDA. O índice de autocorrelação espacial maior para os resíduos de VACTTM, apesar de apresentar menos ZTs com índices locais de Moran significativos, em relação aos resíduos de VPCTTM, se deve ao fato de que, para a maioria destas ZTs, o índice é significativo a um nível de 1\% (para 9 das 15 ZTs). Para os resíduos de VPCTTM, seis ZTs apresentaram significância estatística a um nível de 1\% e 12 ZTs apresentaram significância estatística a um nível de 5\%.

Conforme já havia sido verificado na etapa de calibração, o ajuste do modelo de VPCTTM ficou ligeiramente melhor do que o de VACTTM, com $R^{2}$ igual a 0,97 e 0,96, respectivamente, na análise de regressão das estimativas com os dados reais. Também os 
coeficientes de regressão $\beta$ igual a 1,02 e 0,87, respectivamente, indicaram que a inclinação da reta está mais próxima de $45^{\circ}$ para VPCTTM.

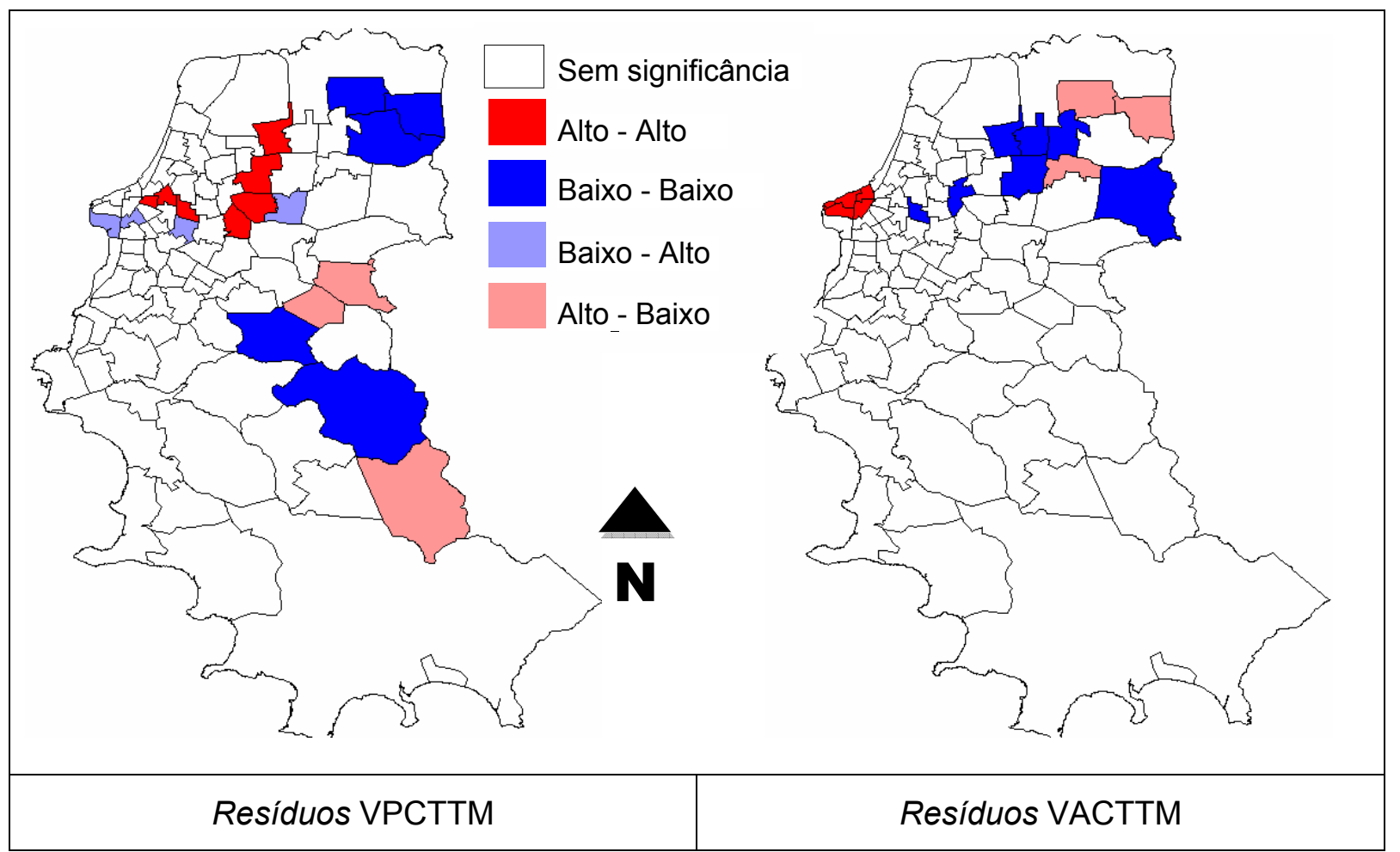

Figura 32 - Moran Maps para os resíduos das estimativas dos submodelos de produção e de atração de viagens do MARS: VPCTTM e VACTTM.

\subsubsection{Definição dos indicadores de dependência espacial}

Da mesma forma que apresentado no item 6.2, porém agora com foco nas características dos submodelos de transporte do MARS, para definição das variáveis espaciais foi, primeiramente, realizada a análise exploratória das variáveis envolvidas, para verificar a presença de autocorrelação espacial. A Tabela 18 apresenta os resultados da aplicação das ferramentas da ESDA para os dados de entrada do MARS POA, para definição de variáveis espaciais para os submodelos de VPCTTM (viagens produzidas Casa-Trabalho por todos os modos) e VACTTM (viagens atraídas Casa-Trabalho por todos os modos). Conforme os submodelos do MARS, as variáveis explicativas são POPEMPR (População Empregada por ZT) e POSTOST (total de postos de trabalho por ZT), para VPCTTM e VACTTM, respectivamente.

Conforme pode ser verificado nos resultados da Tabela 18, VACTTM apresenta um Índice de autocorrelação espacial (I de Moran) ligeiramente mais elevado do que VPCTTM $(0,23$ e 0,18 , respectivamente). Isto é explicado pelos mesmos índices das variáveis explicativas de cada submodelo, onde POSTOST apresenta valor de autocorrelação ligeiramente mais elevado do que POPEMPR, com I de Moran igual a 0,23 e 0,21, respectivamente. Como esperado, as variáveis explicativas, quando ponderadas por área (D_POPEMPR e 
D_POSTOST), mais uma vez apresentaram maiores índices de autocorrelação espacial $(0,39$ e 0,43$)$.

Tabela 18 - Autocorrelação espacial das variáveis de entrada do MARS POA 2003 - análise para a definição das variáveis espaciais para VPCTTM e VACTTM.

\begin{tabular}{llc}
\hline Variável & Descrição: & I de Moran (2003) \\
\hline POPEMPR & População empregada por ZT & 0,21 \\
\hline POSTOST & Número total de postos de trabalho por ZT & 0,23 \\
\hline D_POPEMPR & Densidade de população empregada (POPEMPRE $\left./ \mathrm{km}^{2}\right)$ & 0,39 \\
\hline D_POSTOST & Densidade de postos de trabalho (POSTOST $\left./ \mathrm{km}^{2}\right)$ & 0,43 \\
\hline VPCTTM & Viagens produzidas Casa-Trabalho por todos os modos & 0,18 \\
\hline VACTTM & Viagens atraídas Casa-Trabalho por todos os modos & 0,23 \\
\hline
\end{tabular}

As Figuras 33, 34 e 35 apresentam os Moran Maps para as variáveis dependentes (VPCTTM e VACTTM), para as variáveis explicativas (POPEMPR e POSTOST) e para as variáveis explicativas ponderadas por área (D_POPEMPR e D_POSTOST), respectivamente. A análise da correlação espacial das variáveis explicativas com as variáveis dependentes vai definir que variáveis espaciais locais podem ser significativas para as estimativas de VPCTTM e VACTTM.

Verifica-se, através da análise dos Moran Maps da Figura 33, que para VACTTM, mais ZTs apresentam significância estatística para os Índices Locais de Moran do que para VPCTTM (12 e 21 ZTs, respectivamente). Observa-se também que, para VACTTM, a maioria das ZTs com significância estatística do índice de Moran (14 ao todo) se concentra no Quadrante 2 (Baixo - Baixo). 


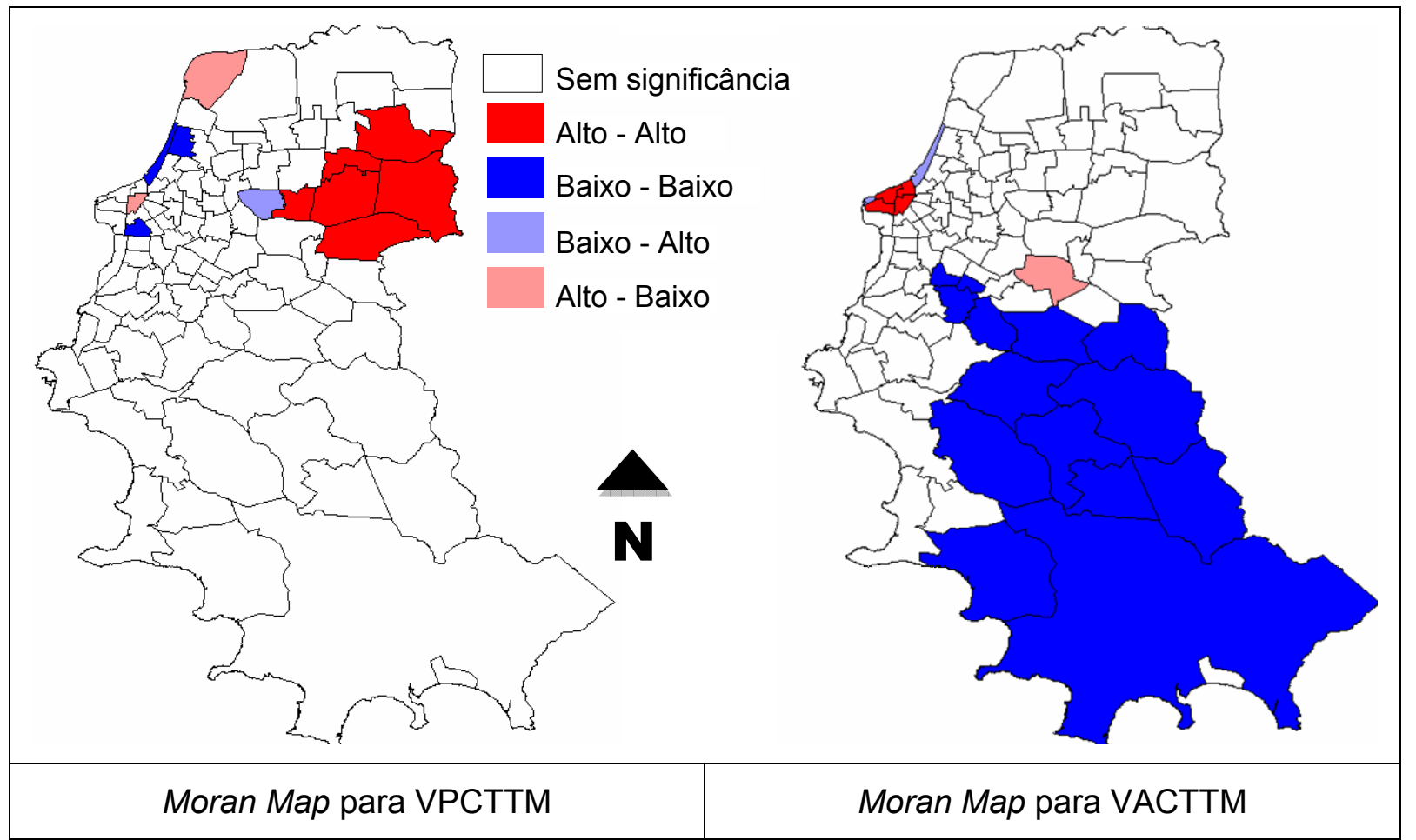

Figura 33 - Moran Maps para as variáveis dependentes VPCTTM e VACTTM.

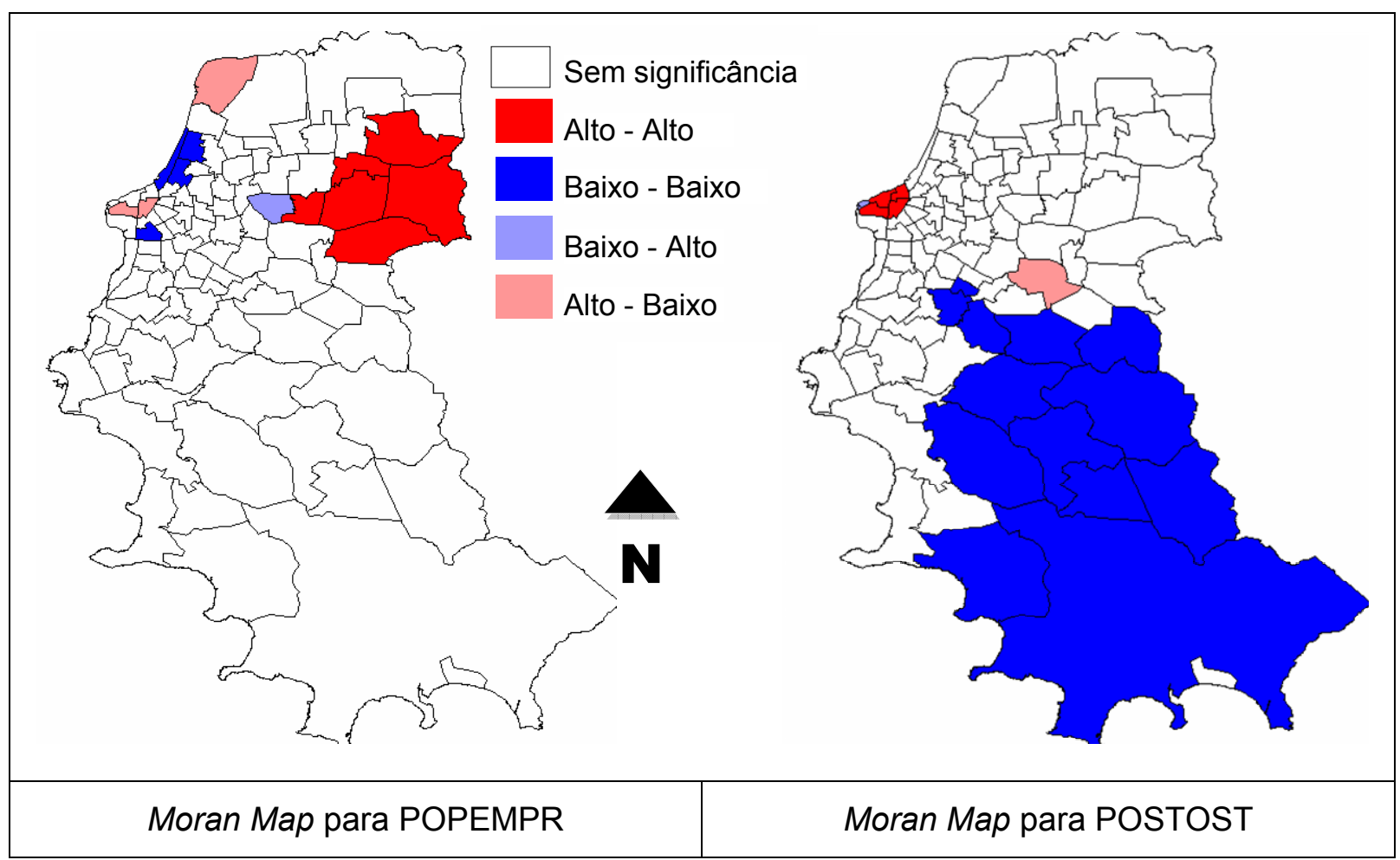

Figura 34 - Moran Maps para as variáveis explicativas POPEMPRE e POSTOST.

Para a definição dos indicadores de dependência espacial, com base nas análises apresentadas, no caso das estimativas de VPCTTM foi verificado que a variável explicativa D_POPEMPR foi a que apresentou maior índice de autocorrelação espacial, no entanto, ao 
se considerar as ZTs coincidentes nos Moran Maps, a mesma variável não apresentou correlação espacial com a variável dependente (Figuras 35 e 33, respectivamente). No entanto, a mesma análise para a variável explicativa POPEMPR indicou um alto nível de correlação espacial desta com VPCTTM (Figuras 34 e 35, respectivamente). No caso das estimativas VACTTM a variável explicativa D_POSTOST foi a que apresentou maior índice de autocorrelação espacial e também apresentou alta correlação espacial com VACTTM nas análises dos Moran Maps (Figuras 35 e 33).

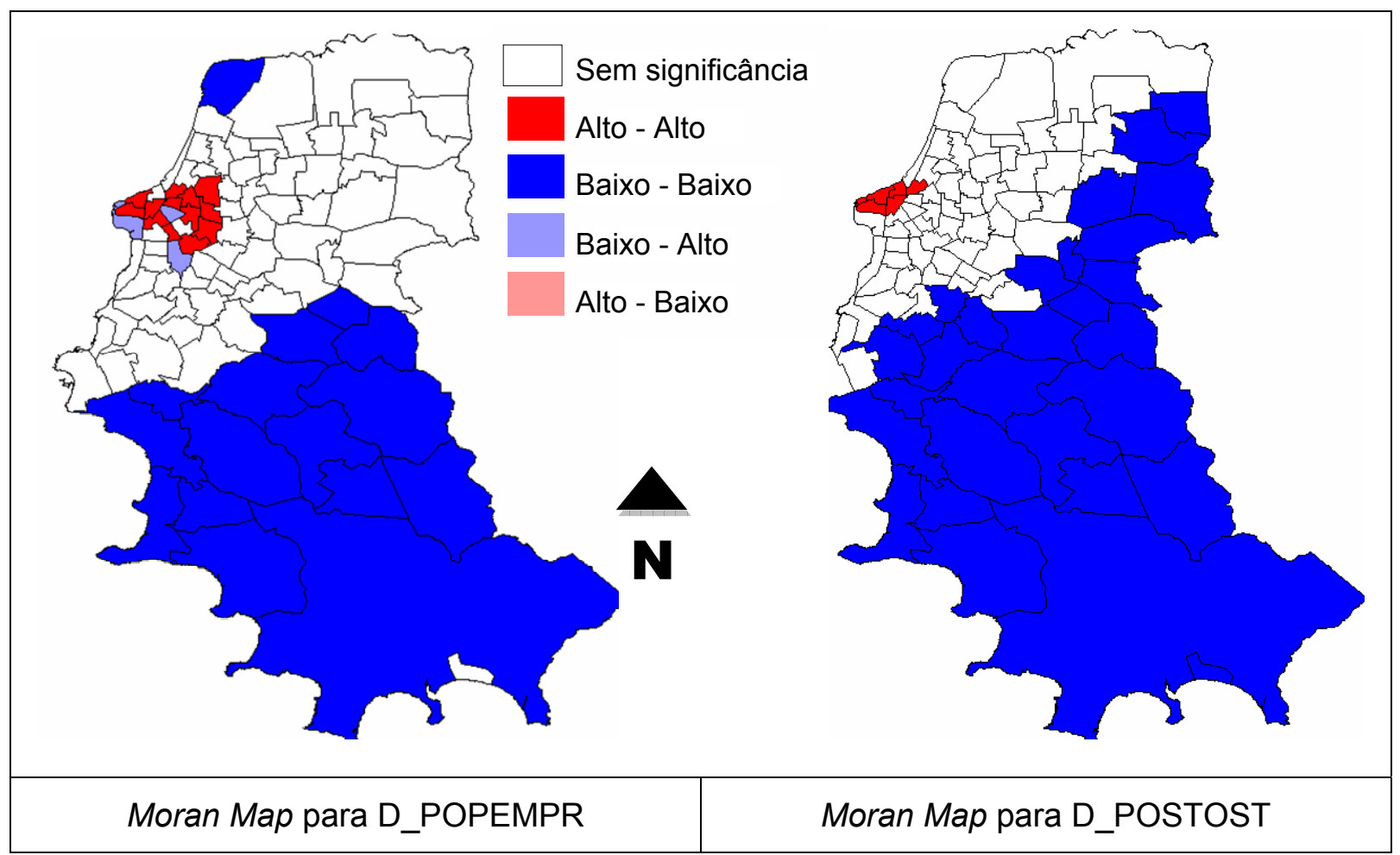

Figura 35 - Moran Maps para as variáveis explicativas ponderadas por área D_POPEMPRE e D_POSTOST.

Tais análises indicam os índices locais de Moran para POPEMPR como possíveis variáveis espaciais locais para as estimativas de VPTCTM e os índices locais de Moran para D_POSTOST como possíveis variáveis espaciais locais para as estimativas de VATCTM. Para verificar que variáveis espaciais globais podem ser significativas foi realizada a mesma análise da correlação espacial, porém através dos Box Maps (Figura 36 e 37).

$\mathrm{Na}$ análise dos Box Maps apresentados na Figura 36 verifica-se que, para a maioria das ZTs, existe coincidência de quadrantes entre a variável dependente e a variável explicativa (VPCTTM e POPEMPRE, respectivamente), indicando um alto nível de correlação espacial entre ambas. Pelo número de ZTs coincidentes em cada quadrante, apresentado entre parênteses ao lado de Q1, Q2, Q3 e Q4, na legenda do mapa correspondente, as variáveis POPEMPR_Q2, POPEMPR_Q1 POPEMPR_Q3 e POPEMPR_Q4 que representam os 
quadrantes de POPEMPR no Box Map, são indicadas, nesta ordem de preferência, como possíveis variáveis espaciais globais para a estimativa de VPCTTM.

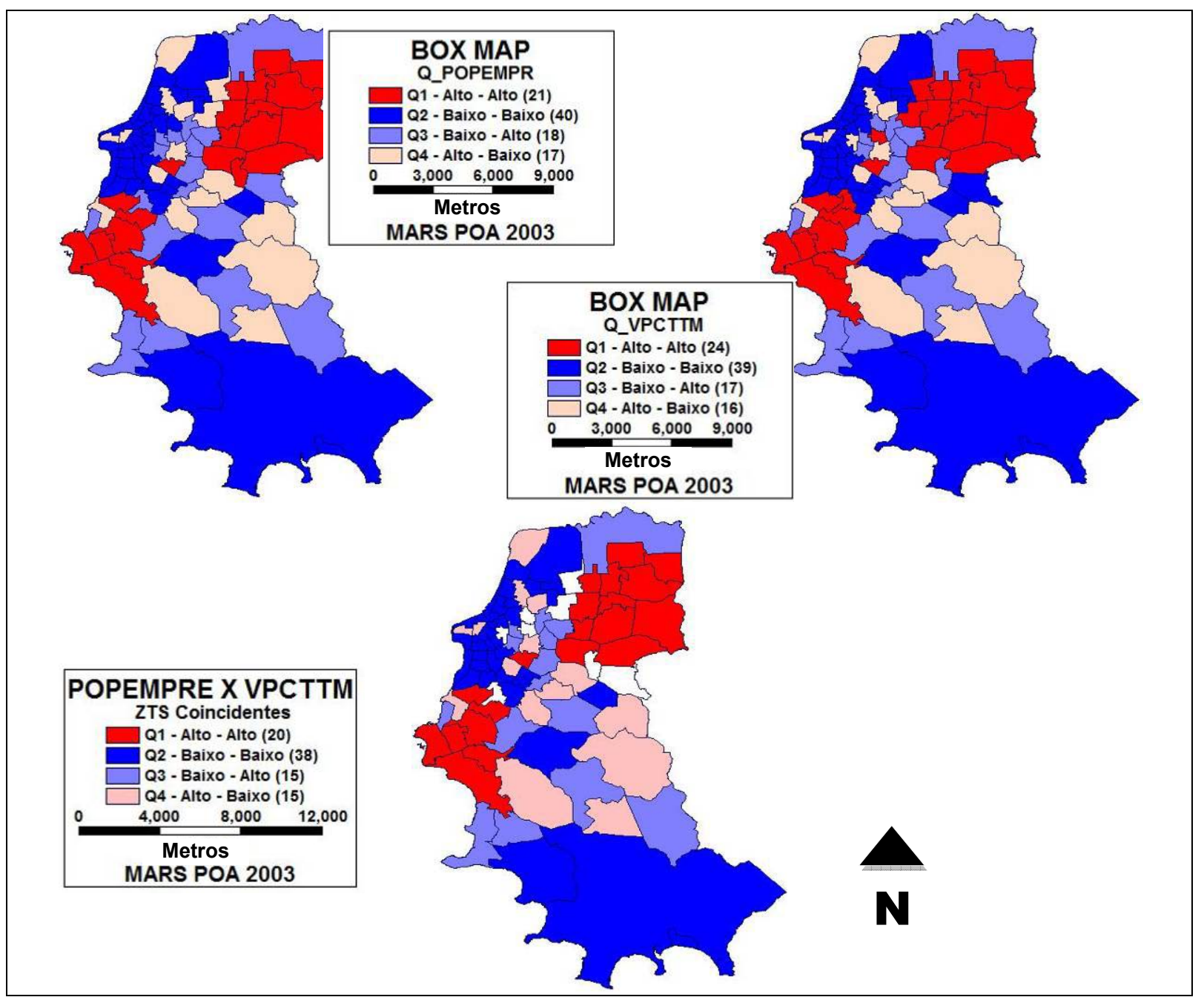

Figura 36 - Análise de correlação espacial para obtenção de variáveis espaciais globais Box Maps para POPEMPR e VPCTTM

$\mathrm{Na}$ análise apresentada na Figura 37, agora para VACTTM, verifica-se que para 56 das 96 ZTs existe coincidência de quadrantes entre a variável dependente e a variável explicativa (D_POSTOST). Neste caso, pelo número de ZTs coincidentes em cada quadrante, a variável D_POSTOST_Q2, com 40 ZTs coincidentes, é a primeira indicada como possível variável espacial global para a estimativa de VACTTM. 


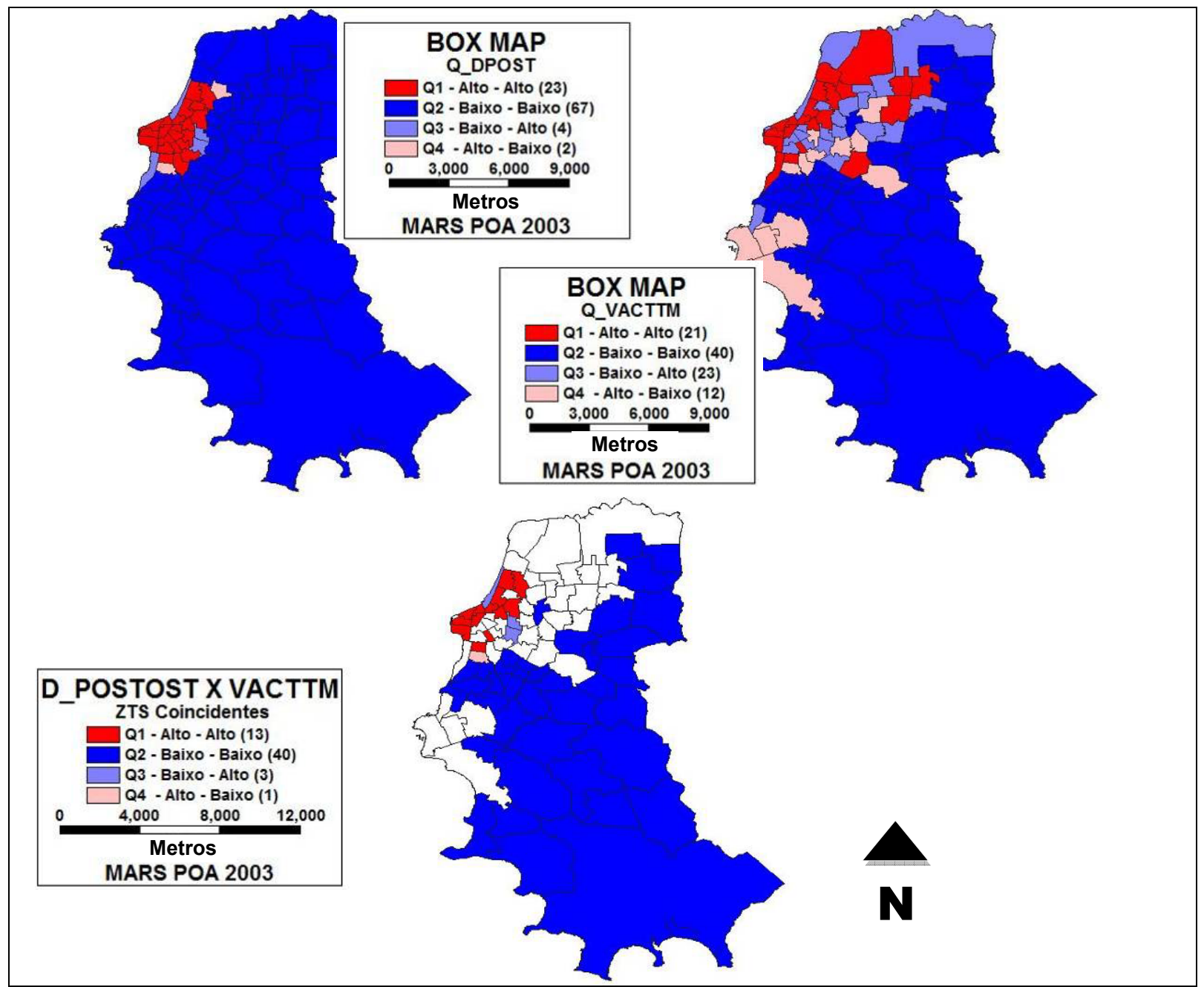

Figura 37 - Análise de correlação espacial para obtenção de variáveis espaciais globais Box Maps para D_POSTOST e VACTTM

\subsubsection{Análise da inserção de variáveis espaciais}

Embora ambos os submodelos do MARS analisados tenham apresentado bons ajustes, a análise dos resíduos das estimativas indicaram alguma presença de autocorrelação espacial. Com base nas variáveis indicadas no item anterior, foi realizada uma análise para verificar se a inserção das variáveis espaciais constitui melhoria para os resultados dos submodelos de VPCTTM E VACTTM. Foi, então, testada a inserção de variáveis espaciais globais e de variáveis espaciais locais para cada um dos submodelos. Os resultados dos modelos espaciais mais ajustados são apresentados nas Tabelas 19 a 21 (com os melhores resultados destacados "em negrito", para facilitar a análise) e também podem ser visualizados nas Figuras 38 a 40, sempre comparados com os resultados dos submodelos do MARS.

A Tabela 19 segue o mesmo padrão de análise apresentado no item 6.2, cujos resultados são fornecidos nos relatórios do software GeoDa. Em função disto, não existe, para os submodelos do MARS, os resultados para os mesmos testes. Para estes, na Tabela 19 só 
podem ser verificados os resultados para os coeficientes das variáveis, o ERM (erro relativo médio) e o I de Moran (erro), que indica a presença ou não de autocorrelação espacial dos resíduos, que também podem ser visualizado através dos Moran Maps das Figuras 38 e 39.

Tabela 19 - Resumo dos submodelos do MARS e dos modelos espaciais analisados para estimativa de VPCTTM e VACTTM e resultados obtidos.

\begin{tabular}{|c|c|c|c|c|c|c|c|c|}
\hline & \multirow{4}{*}{\multicolumn{2}{|c|}{ RESULTADOS DA CALIBRAÇÃO }} & \multirow{2}{*}{\multicolumn{3}{|c|}{ VPCTTM }} & \multirow{2}{*}{\multicolumn{3}{|c|}{ VACTTM }} \\
\hline & & & & & & & & \\
\hline & & & \multirow{2}{*}{$\frac{\text { MARS }}{\text { M }}$} & \multicolumn{2}{|c|}{ ALTERNATIVOS } & \multirow{2}{*}{$\frac{\text { MARS }}{M}$} & \multicolumn{2}{|c|}{ ALTERNATIVOS } \\
\hline & & & & AG & $A L$ & & AG & $A L$ \\
\hline \multirow{14}{*}{ 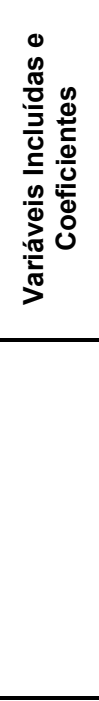 } & \multirow{3}{*}{ Tradicionais } & CONSTANTE & & & & $-0,560$ & & \\
\hline & & POPEMPR & 0,82 & 0,79 & 0,80 & & & \\
\hline & & POSTOST & & & & 1,253 & 0,800 & 0,806 \\
\hline & \multirow{2}{*}{$\begin{array}{c}\text { Variáveis Espaciais } \\
\text { Globais }\end{array}$} & POPEMPR_Q2 & & 146,44 & & & & \\
\hline & & D_POSTOST_Q2 & & & & & 69,551 & \\
\hline & \multirow{2}{*}{$\begin{array}{c}\text { Variáveis Espaciais } \\
\text { Locais }\end{array}$} & LISA_POPEMPR & & & $-56,24$ & & & \\
\hline & & LISA_D_POSTOST & & & & & & $-18,449$ \\
\hline & & $\mathbf{R}^{2}$ & & 0,99 & 0,99 & & 0,99 & 0,99 \\
\hline & & $\mathbf{R}^{2} \mathrm{AJ}$ & & 0,99 & 0,99 & & 0,99 & 0,99 \\
\hline & & LIK & & $-757,81$ & $-758,60$ & & $-644,04$ & $-646,79$ \\
\hline & Diagnóstico & SC & & 1524,52 & 1526,33 & & 1297,21 & 1297,58 \\
\hline & & AIC & & 1519,02 & 1521,20 & & 1292,08 & 1302,71 \\
\hline & & ERM & $11 \%$ & $11 \%$ & $11 \%$ & $18 \%$ & $8 \%$ & $5 \%$ \\
\hline & & I_Moran (erro) & 0,21 & 0,17 & 0,21 & 0,26 & $-0,02$ & 0,03 \\
\hline \multirow{4}{*}{ 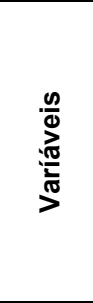 } & Significância & $T$-statistic & Satisf. & Não S. & Não S. & Satisf. & Satisf. & Não S. \\
\hline & Multicolinearidade & $\begin{array}{l}\text { Número de } \\
\text { Condição da } \\
\text { Matriz }\end{array}$ & & $\begin{array}{l}\text { Satisf. } \\
(1,31)\end{array}$ & $\begin{array}{l}\text { Satisf. } \\
(1,73)\end{array}$ & & $\begin{array}{l}\text { Satisf. } \\
(1,50)\end{array}$ & $\begin{array}{l}\text { Satisf. } \\
(2,57)\end{array}$ \\
\hline & \multirow{2}{*}{$\begin{array}{l}\text { Dependência } \\
\text { Espacial }\end{array}$} & $\begin{array}{l}\text { ML (Lag) } \\
\text { (p-value) }\end{array}$ & & $\begin{array}{l}\text { Satisf.. } \\
(0,681) \\
\end{array}$ & $\begin{array}{l}\text { Satisf. } \\
(0,354)\end{array}$ & & $\begin{array}{l}\text { Satisf. } \\
(0,923) \\
\end{array}$ & $\begin{array}{l}\text { Satisf. } \\
(0,363) \\
\end{array}$ \\
\hline & & $\begin{array}{l}\text { ML Robusto (Lag) } \\
\text { (p-value) }\end{array}$ & & $\begin{array}{l}\text { Satisf. } \\
(0,977) \\
\end{array}$ & $\begin{array}{l}\text { Satisf. } \\
(0,638)\end{array}$ & & $\begin{array}{l}\text { Satisf. } \\
(0,914)\end{array}$ & $\begin{array}{l}\text { Satisf. } \\
(0,371)\end{array}$ \\
\hline \multirow{8}{*}{ 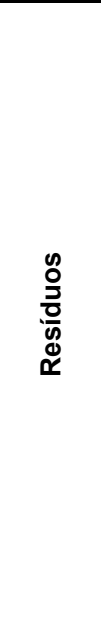 } & Distribuição Normal & $\begin{array}{l}\text { Jarque-Bera } \\
\text { (p-value) }\end{array}$ & & $\begin{array}{l}\text { Não S. } \\
(0,000)\end{array}$ & $\begin{array}{l}\text { Não S. } \\
(0,000)\end{array}$ & & $\begin{array}{l}\text { Não S. } \\
(0,000)\end{array}$ & $\begin{array}{l}\text { Não S. } \\
(0,004)\end{array}$ \\
\hline & \multirow{3}{*}{ Homocedasticidade } & $\begin{array}{l}\text { Breusch-Pegan } \\
\text { (p-value) }\end{array}$ & & $\begin{array}{l}\text { Não S. } \\
(0,000)\end{array}$ & $\begin{array}{l}\text { Não S. } \\
(0,000)\end{array}$ & & $\begin{array}{l}\text { Satisf. } \\
(0,999) \\
\end{array}$ & $\begin{array}{l}\text { Satisf. } \\
(0,999) \\
\end{array}$ \\
\hline & & $\begin{array}{l}\begin{array}{l}\text { Koenker-Bassett } \\
\text { (p-value) }\end{array} \\
\end{array}$ & & $\begin{array}{l}\text { Não S. } \\
(0,005)\end{array}$ & $\begin{array}{l}\text { Não S. } \\
(0,005)\end{array}$ & & $\begin{array}{l}\text { Satisf. } \\
(0,999)\end{array}$ & $\begin{array}{l}\text { Satisf. } \\
(0,999)\end{array}$ \\
\hline & & $\begin{array}{l}\text { White } \\
\text { (p-value) }\end{array}$ & & * & $\begin{array}{l}\text { Não S. } \\
(0,000)\end{array}$ & & * & * \\
\hline & \multirow{4}{*}{$\begin{array}{l}\text { Dependência } \\
\text { Espacial }\end{array}$} & $\begin{array}{l}\text { I de Moran (erro) } \\
\text { (p-value) }\end{array}$ & & $\begin{array}{l}\text { Não S. } \\
(0,002) \\
\end{array}$ & $\begin{array}{l}\text { Não S. } \\
(0,000)\end{array}$ & & $\begin{array}{l}\text { Satisf. } \\
(0,878) \\
\end{array}$ & $\begin{array}{l}\text { Satisf. } \\
(0,495) \\
\end{array}$ \\
\hline & & $\begin{array}{l}\text { ML (erro) } \\
\text { (p-value) }\end{array}$ & & $\begin{array}{l}\text { Não S. } \\
(0,006)\end{array}$ & $\begin{array}{l}\text { Não S. } \\
(0,001)\end{array}$ & & $\begin{array}{l}\text { Satisf. } \\
(0,700)\end{array}$ & $\begin{array}{l}\text { Satisf. } \\
(0,629)\end{array}$ \\
\hline & & $\begin{array}{l}\text { ML Robusto (erro) } \\
\text { (p-value) }\end{array}$ & & $\begin{array}{l}\text { Não S. } \\
(0,006)\end{array}$ & $\begin{array}{l}\text { Não S. } \\
(0,002)\end{array}$ & & $\begin{array}{l}\text { Satisf. } \\
(0,698)\end{array}$ & $\begin{array}{l}\text { Satisf. } \\
(0,648)\end{array}$ \\
\hline & & $\begin{array}{l}\text { ML SARMA } \\
\text { ( } p \text {-value) }\end{array}$ & & $\begin{array}{l}\text { Não S. } \\
(0,022)\end{array}$ & $\begin{array}{l}\text { Não S. } \\
(0,005)\end{array}$ & & $\begin{array}{l}\text { Satisf. } \\
(0,923)\end{array}$ & $\begin{array}{l}\text { Satisf. } \\
(0,596)\end{array}$ \\
\hline Notas & $\begin{array}{r}\text { Satisf. - } \\
\text { Não S. - } \\
\text { * } \\
\text { Em Negrito - }\end{array}$ & \multicolumn{7}{|c|}{$\begin{array}{l}\text { Resultado do teste satisfatório (boa qualidade do ajuste do modelo) } \\
\text { Resultado do teste não satisfatório (má qualidade do ajuste do modelo) } \\
\text { Não existente para este modelo } \\
\text { Os melhores resultados obtidos }\end{array}$} \\
\hline
\end{tabular}


Para uma melhor comparação do ajuste dos modelos avaliados, foi aplicado o método de análise de regressão entre dados reais e estimados pelos modelos para VPCTTM e VACTTM. Estes resultados são apresentados nas Tabelas 20 e 21, e nos gráficos da Figura 40.

Conforme os resultados apresentados na Tabela 19, não se justifica a inserção de variáveis espaciais pelos métodos avaliados para a estimativa de VPCTTM. Avaliando-se os resultados do modelo $A G$, que apresentou valores ligeiramente melhores que os do modelo AL, embora o I de Moran (erro) tenha indicado uma melhora em relação ao do submodelo do $\operatorname{MARS}(0,21$ para 0,17$)$, ainda é verificada a presença de autocorrelação espacial dos resíduos das estimativas de VPCTTM. Isto pode ser confirmado pelos resultados de todos os testes de dependência espacial dos resíduos, que apresentaram resultados não satisfatórios, e visualizado no Moran Map para o modelo AG, na Figura 38.

Quanto ao modelo AL para VPCTTM, uma ligeira melhora em relação ao submodelo do MARS é verificada na Tabela 20 e Figura 40, principalmente ao que se refere ao valor de $\alpha$ (de $-38,68$ para $-24,13$ ), que se aproximou um pouco mais do valor ideal. Porém todos os demais resultados para este modelo ficaram piores, inclusive, em relação ao modelo AG (Tabela 19 e Figura 38). Para ambos os modelos espaciais, nenhuma variável espacial apresentou significância estatística no teste $t$-student.

Tabela 20 - Análise comparativa do ajuste do modelo MARS e dos modelos espaciais analisados (AG e AL) para estimativa de VPCTTM.

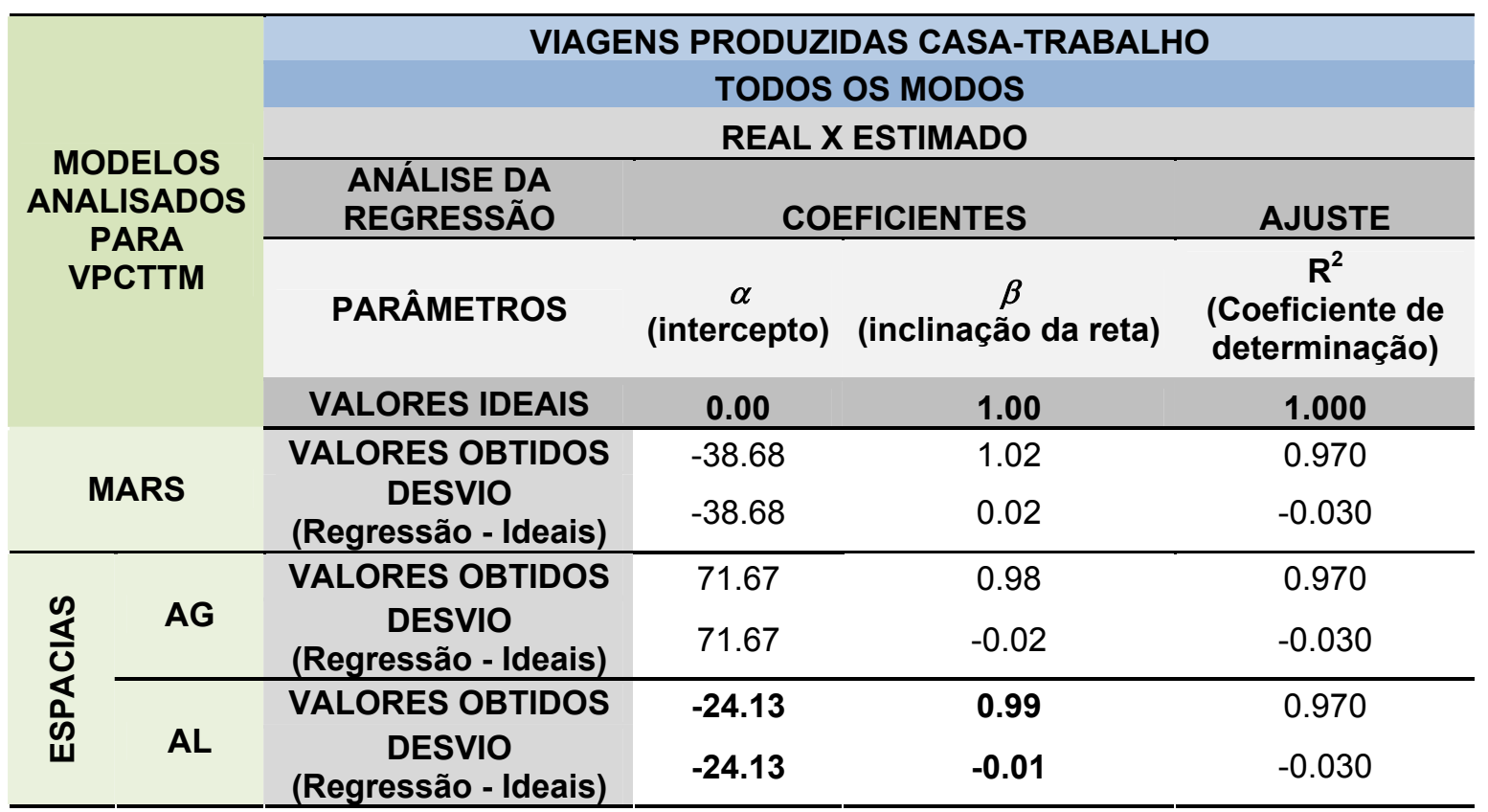




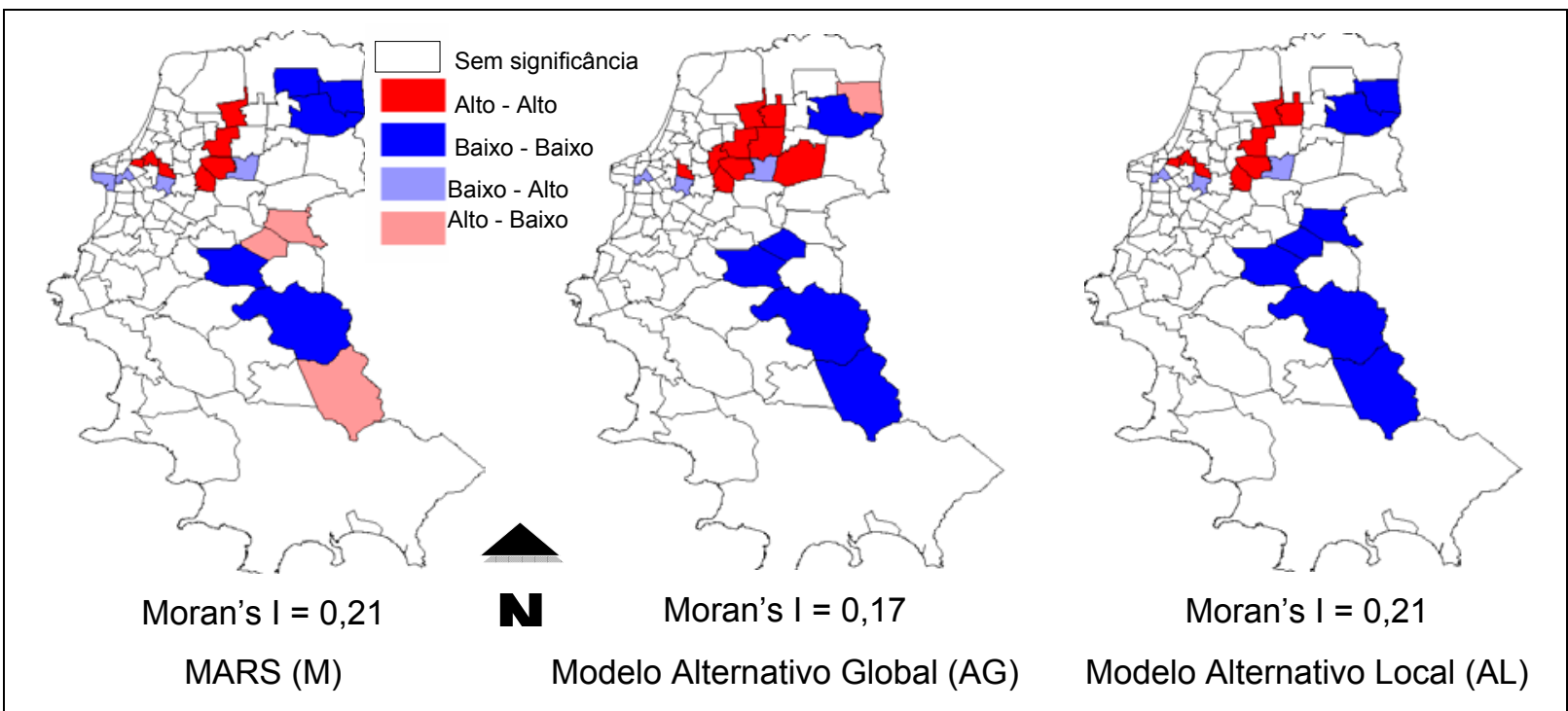

Figura 38 - Análise da distribuição espacial dos resíduos das estimativas de VPCTTM com 0 modelo MARS e os modelos espaciais AG e AL.

Tabela 21 - Análise comparativa do ajuste do modelo MARS e dos modelos espaciais analisados (AG e $A L)$ para estimativa de VACTTM.

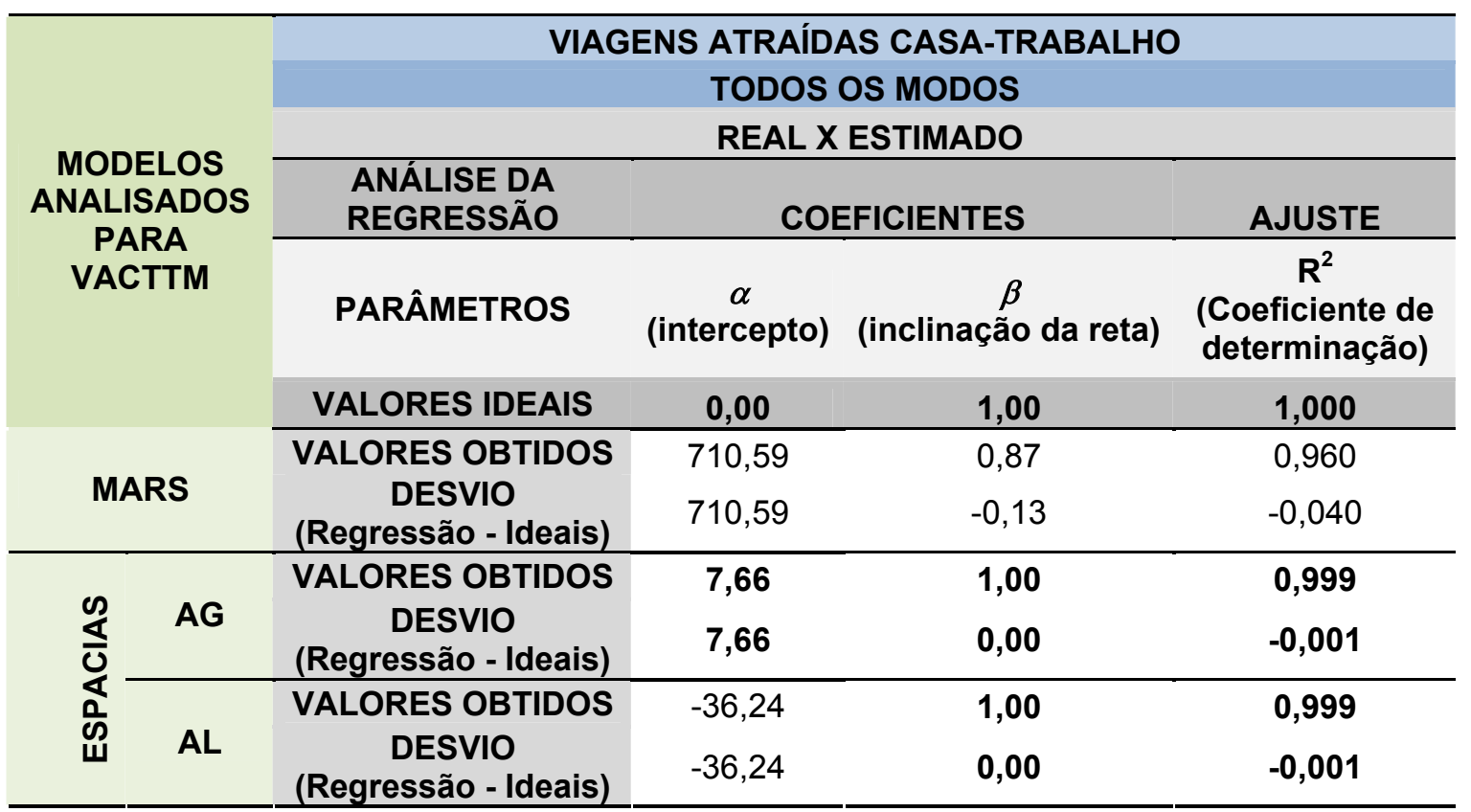

No caso das estimativas de VACTTM, os resultados foram diferentes. Ambos os modelos espaciais apresentaram resultados melhores para as estimativas, em relação ao submodelo do MARS. O modelo AG, no qual foi introduzida a variável espacial global D_POSTOST_Q2, apresentou resultados melhores na maioria dos testes, em relação ao modelo $A L$, no qual foi 
introduzida a variável espacial local LISA_D_POSTOST (Tabela 19) e somente a primeira se mostrou significativa para o modelo com resultado satisfatório para o teste $t$-student.

Para o modelo espacial AG, todos os resultados dos testes de autocorrelação espacial, tanto para as variáveis quanto para os resíduos, foram satisfatórios, indicando que não existe mais o efeito da dependência espacial perturbando os resultados do modelo (Tabela 19). O I de Moran (erro) melhorou significativamente com a introdução da variável espacial global (de 0,26 para -0,02). A superioridade em relação à distribuição espacial dos resíduos das estimativas deste modelo em relação ao submodelo do MARS pode ser visualizada na Figura 39.

O agrupamento de ZTs no quadrante 1 (Alto - Alto), indicando que o MARS estava subestimando as viagens atraídas para a região central da cidade não é mais verificado nas estimativas do modelo AG. Da mesma forma, não é mais verificado, no Moran Map do modelo AG, o agrupamento de ZTs no quadrante 2 (Baixo - Baixo) na região à leste do centro, indicando que aí o MARS superestimou as viagens atraídas em relação aos dados reais (Figura 39).

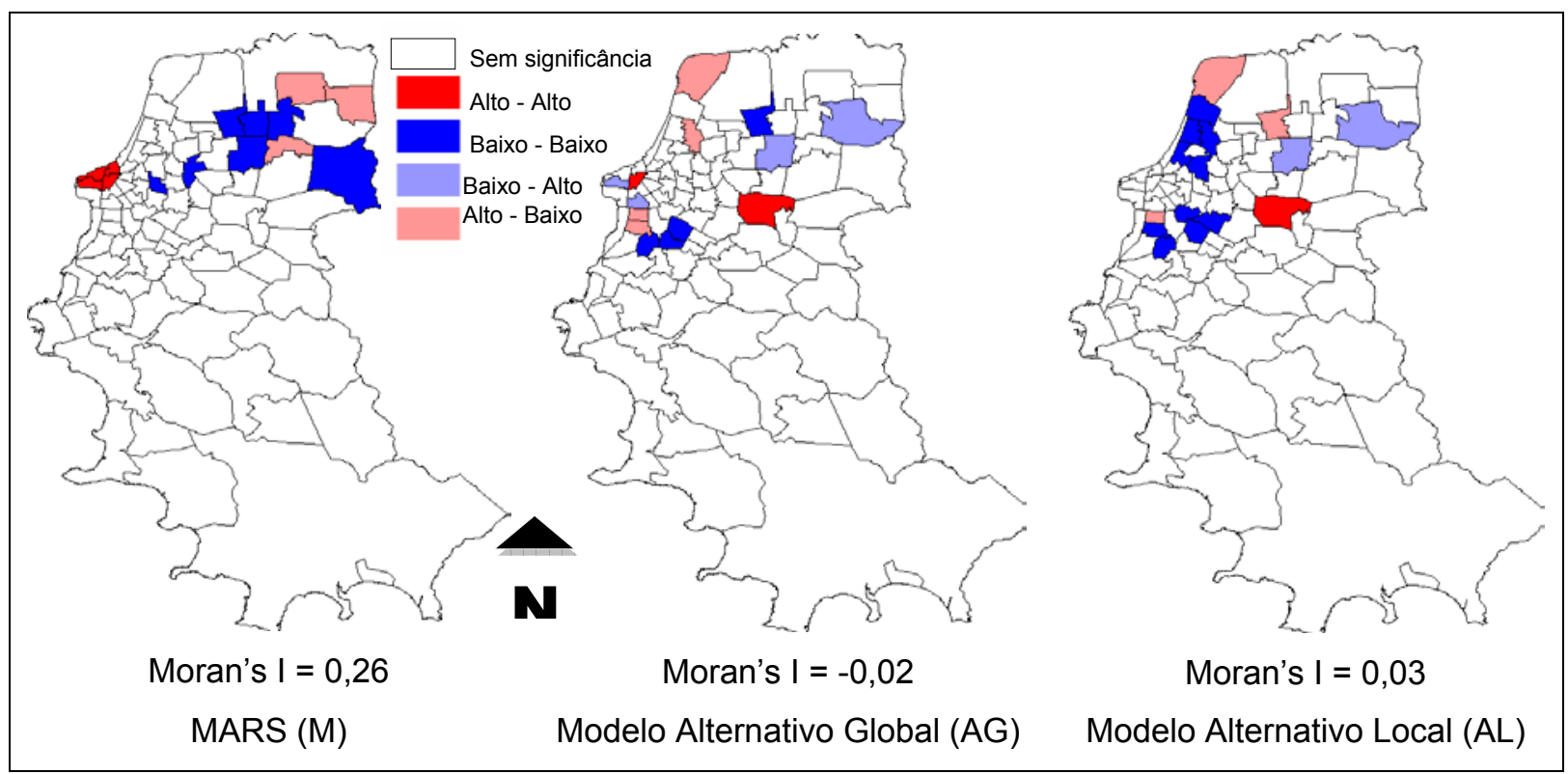

Figura 39 - Análise da distribuição espacial dos resíduos das estimativas de VACTTM com o modelo MARS e os modelos espaciais AG e AL.

O ERM das estimativas do modelo $A G$, que reduziu em $10 \%$ em relação ao submodelo do MARS (Tabela 19), e também, os resultados das análises apresentadas na Tabela 21 e no gráfico da Figura 40, confirmam, mais uma vez, a melhoria obtida através da inserção da variável espacial global no modelo de VACTTM. Na análise de regressão entre real e estimado, a inclinação da reta ficou em $45^{\circ}(\beta=1)$, ou seja, o valor ideal, enquanto os outros 
dois parâmetros ficaram muito próximos dos valores ideais $\left(R^{2}=0,999\right.$ e $\left.\alpha=7,66\right)$. Estes últimos resultados indicaram uma melhora significativa em relação aos resultados obtidos na etapa de calibração do MARS, onde os resultados do ajuste do modelo de atração de viagens haviam ficado piores do que os do modelo de produção de viagens, considerando o motivo trabalho (vide Tabela 21 e Figura 40).

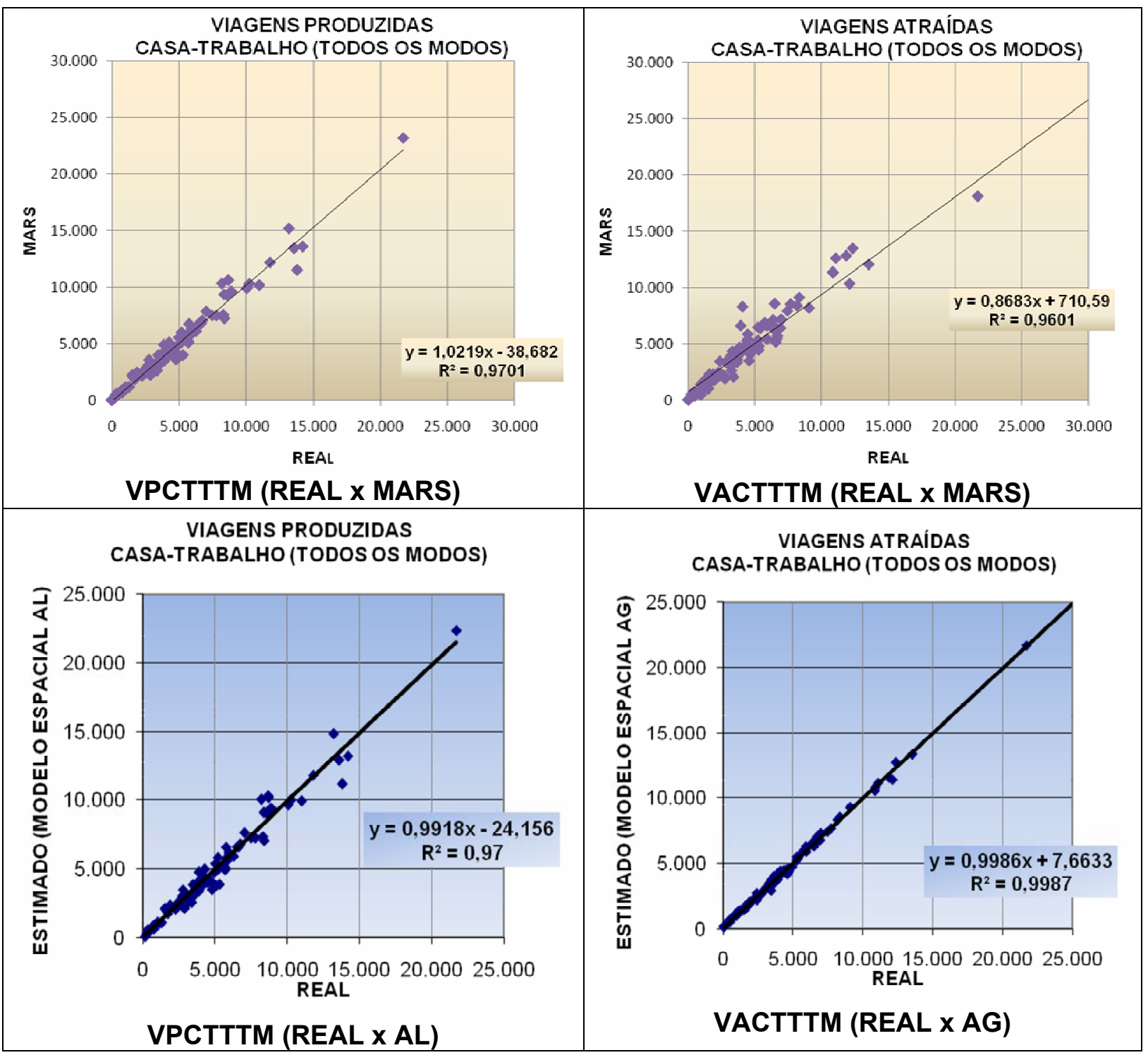

Figura 40 - Analise comparativa do ajuste dos submodelos do MARS e modelos espaciais, alternativo local (AL) e alternativo global (AG), para estimativas de VPCTTM e VACTTM, respectivamente.

\subsubsection{Considerações finais do Bloco 4}

Verificou-se, através dos resultados do modelo espacial AG para VACTTM, que a introdução de variáveis espaciais no MARS POA pode constituir melhoria para o modelo. No entanto, confirmando as análises apresentadas no item 6.2, mais uma vez foi verificado que a introdução destas variáveis requer uma análise criteriosa, dado que nem sempre resultam 
em melhor desempenho do modelo e melhores estimativas (vide resultados do modelo espacial AG para VPCTTM). Portanto, um estudo mais aprofundado de outras variáveis e submodelos e de como se devem considerar as variáveis espaciais no MARS se faz necessário. Por este motivo a sequência do estudo será através da aplicação do MARS POA, sem considerar os efeitos espaciais.

\subsection{Bloco 5 - Viabilidade de aplicação do MARS POA para avaliar políticas de mobilidade urbana sustentável}

A análise da viabilidade de aplicação do MARS POA se deu através da implementação e simulação de oito diferentes cenários, seguindo método aplicado em projeto financiado pela União Européia. Este projeto, intitulado "Cenários para o Sistema de Transportes e Oferta de Energia e seus Efeitos Potenciais" (STEPs - Scenarios for the Transport System and Energy Supply and their Potential Effects), teve por objetivo desenvolver, comparar e estabelecer possíveis cenários futuros, levando-se em conta o desenvolvimento econômico e tecnológico e as interações entre transporte e desenvolvimento espacial, avaliando os efeitos causados ao meio ambiente (FIORELLO et al., 2006).

No projeto STEPs, seis modelos integrados de desenvolvimento territorial existentes para a Europa como um todo e para cinco regiões urbanas européias (Edimburgo, Dortmund, Helsinque, Bruxelas e Tirol Sul) foram aplicados para a previsão de impactos econômicos, sociais e ambientais gerados em longo prazo por um conjunto comum de cenários focados no aumento de preço de combustível e políticas de infraestrutura, tecnologia e regulação de demanda.

Entre os seis modelos integrados analisados no projeto STEPs está o MARS, ajustado para a região urbana de Edimburgo, Escócia. A etapa de modelagem do projeto STEPs foi um exercício impar de modelagem colaborativa. A aplicação coordenada de vários modelos socioeconômicos complexos para uma tarefa comum representou uma oportunidade única de validação cruzada dos modelos, ou seja, para verificar sua validade pela comparação dos seus resultados, o que, por sua vez, forneceu uma ferramenta para a validação do modelo MARS POA, através da técnica de meta-análise.

Como os objetivos do projeto STEPs estão ajustados aos propósitos do modelo MARS e, consequentemente, aos do modelo MARS POA, foi possível integrar à meta-análise aplicada no projeto STEPs os resultados obtidos com o modelo de Porto Alegre. Obviamente, foi preciso seguir todos os critérios de definição de cenários e de indicadores estabelecidos pelos especialistas envolvidos no projeto, durante o período de seu 
desenvolvimento (STEPs, 2004-2006), tendo sempre o modelo MARS Edimburgo como principal referência para o ajuste do MARS POA.

É importante salientar que, embora tenham sido feitas adaptações dos cenários para adequá-los às características de Porto Alegre, as análises aqui apresentadas não têm a pretensão de estabelecer planos definitivos de mobilidade sustentável para a cidade. 0 intuito é apenas testar a capacidade da ferramenta de servir de apoio à decisão na análise de possíveis planos e políticas com este fim.

\subsubsection{Definição dos cenários a serem simulados no MARS POA}

Ao combinar políticas de demanda energética com a disponibilidade de energia, foi definida, pelos especialistas do Projeto STEPS, uma matriz com oito cenários que deveriam ser simulados para prever o futuro do transporte e do sistema energético até 2030. Os mesmos cenários foram adaptados para Porto Alegre para serem simulados pelo MARS POA 2003.

Do ponto de vista da disponibilidade energética, dois grupos de cenários foram identificados e denominados de cenários $A$ e $B$. Do ponto de vista da demanda energética, três grupos de cenários foram identificados e denominados como cenários 0,1 e 2 . Foram definidos, ainda, os cenários A-1 e B-1, como cenários de referência para as análises.

Os oito cenários simulados com cada modelo analisado são apresentados na Tabela 22 e as características básicas de cada um são apresentadas na sequência. Mais detalhes destes cenários para os demais modelos analisados são encontrados nos relatórios do Projeto STEPs (2004-2006).

Tabela 22 - Cenários simulados com cada modelo analisado no Projeto STEPs

\begin{tabular}{|c|c|c|c|c|c|}
\hline \multirow{2}{*}{ MATRIZ DE CENÁRIOS DO PROJETO } & \multicolumn{4}{|c|}{ DEMANDA ENERGÉTICA } \\
\cline { 3 - 6 } STEPs & $\begin{array}{c}\text { Sem } \\
\text { Políticas }\end{array}$ & $\begin{array}{c}\text { Atividades } \\
\text { Como de } \\
\text { Costume }\end{array}$ & $\begin{array}{c}\text { Investimento } \\
\text { Tecnológico }\end{array}$ & $\begin{array}{c}\text { Regulação } \\
\text { de } \\
\text { Demanda }\end{array}$ \\
\hline $\begin{array}{c}\text { OFERTA } \\
\text { ENERGÉTICA } \\
\text { (preço do } \\
\text { combustível) }\end{array}$ & $\begin{array}{c}\text { Previsões Usuais } \\
\text { (baixas taxas de aumento) }\end{array}$ & $\begin{array}{c}\text { A-1 } \\
\text { (altas taxas degativo }\end{array}$ & A0 & A1 & A2 \\
\hline
\end{tabular}




\section{Cenários com foco na demanda energética}

- Cenários 0 - Atividades Como de Costume ou BAU (Business As Usual)

- Para o pacote de políticas BAU, os planos políticos existentes são utilizados como ponto de partida. Para a perspectiva em 2030, os desenvolvimentos esperados das políticas, como estimado por especialistas (“opiniões de especialistas"), foram utilizados para estimar os valores das variáveis relativas aos cenários BAU.

- Cenários 1 - Investimentos Tecnológicos ou INVEST (Technological Investment)

- Para o pacote de políticas INVEST, foram assumidos investimentos diretos em infraestrutura, tecnologia e sistemas inovadores, com o foco no impacto causado no sistema energético e de transportes. A base do INVEST é o cenário BAU. Dentro desse pacote, algumas medidas explícitas relacionadas à tecnologia e à capacidade de investimento foram incluídas e descritas qualitativa e quantitativamente:

- Investimentos em infraestrutura;

- Investimentos em eficiência energética;

- Investimentos em competências, conhecimentos, capacidade de produção de combustíveis alternativos e material circulante.

- Cenários 2 - Regulação de Demanda ou DR (Demand Regulation)

- O foco do pacote de políticas DR está nos impactos gerados nos sistemas de transporte e de energia pela implantação de medidas de regulação de demandas. Da mesma forma que no INVEST, a base do cenário DR é o cenário BAU. Algumas medidas explicitamente relacionadas à regulação de demanda foram incluídas e descritas de forma quantitativa:

- Taxação do uso do carro;

- Taxação do combustível;

- Regulação do desenvolvimento urbano com ênfase no uso de transporte público.

Foram associados indicadores para cada uma das medidas descritas para os três cenários, as quais foram divididas em cinco diferentes sistemas:

i. Subsistema Socioeconômico e Cultural;

ii. Sistema Espacial; 
iii. Sistema de Transporte de Passageiros;

iv. Sistema de Transporte de Carga;

v. Sistema de Energia de Transportes.

Para possibilitar a configuração de cada cenário foram estimados, por um grupo de especialistas, valores para cada um dos indicadores, com base no estado da arte, nas tendências e em análise PEST (Fatores Políticos, Econômicos, Socioculturais e Tecnológicos). Essa análise levou à definição de taxas anuais de mudança, para cada um dos cenários (em percentagens, com exceção do sistema espacial, para o qual foi dada uma indicação qualitativa de mudança), que puderam ser utilizadas para alimentar os modelos.

\section{Cenários com foco na oferta energética}

- Cenários A - Previsões Usuais de Suprimento de Energia (baixas taxas de aumento)

- Com base em estimativas descritas pela Agência Internacional de Energia, IEA (International Energy Agency), e do Conselho Mundial da Energia, WEC (World Energy Council), para os cenários $A$ foi assumido um aumento baixo, de $1 \%$ a.a., resultando em um preço de combustível, para o consumidor final no posto de gasolina, de $€ 1,60$ por litro em 2030 (em valores de 2008), se outras políticas não forem implementadas.

- Cenários B - Quadro Negativo de Previsão de Energia (altas taxas de aumento)

- Com base em análise de vários cenários de energia disponibilizados pelo IEA e pelo Painel Intergovernamental sobre Mudança Climática, IPPC, (Intergovernmental Panel on Climate Change), os cenários B assumem uma taxa média de crescimento de $4 \%$ a.a., resultando em um preço ao consumidor de €3,33 por litro em 2030.

\section{Cenários de Referência}

- Cenários - 1 - Sem Políticas (no-policy scenarios)

- Para fins de modelagem, é importante que o efeito das alterações nos preços da energia possa ser isolado. Foi, então, definido um conjunto de cenários onde apenas o pressuposto relativo ao aumento do preço do petróleo é considerado, sem nenhuma política adicional. 


\subsubsection{Configuração, simulação e análise dos impactos dos cenários para Porto Alegre}

Para compreender melhor o processo de configuração de cenários, aplicação e avaliação dos resutados obtidos com o modelo MARS POA é apresentada, neste item, uma visão geral do modelo e algumas características relevantes da área modelada. A Tabela 23 apresenta de forma esquemática, a estrutura geral do modelo, com os principais dados de entrada e resultados fornecidos para avaliação de impactos nos transportes, uso do solo e meio ambiente para cada cenário simulado. As Figuras 41 e 42 apresentam as características gerais da área modelada em 2003 (início da análise) em termos de distribuição espacial da população e de configuração da rede viária e infraestrutura de transportes, respectivamente.

Tabela 23 - Visão Geral do Modelo MARS POA - Ano base 2003

\section{MARS POA 2003}

\begin{tabular}{|c|c|c|}
\hline \multicolumn{3}{|c|}{ Uso do Solo } \\
\hline & $\begin{array}{l}\text { PRINCIPAIS DADOS DE ENTRADA } \\
\text { (para o ano de 2003) }\end{array}$ & $\begin{array}{l}\text { PRINCIPAIS RESPOSTAS } \\
\text { (por ano, de } 2003 \text { a 2033) }\end{array}$ \\
\hline Transporte & $\begin{array}{l}\text { Custos, distâncias, frequências de } \\
\text { transporte público, pedágios, } \\
\text { impostos, custos de estacionamento, } \\
\text { taxa de viagens a trabalho, fatores de } \\
\text { ocupação. }\end{array}$ & $\begin{array}{l}\text { Desempenho do tráfego, divisão } \\
\text { modal, carregamento da rede, } \\
\text { velocidade média e níveis de } \\
\text { congestionamento. }\end{array}$ \\
\hline \multicolumn{3}{|c|}{$\begin{array}{l}\text { Renda média, população, posse de } \\
\text { veículo, postos de trabalho, emprego e } \\
\text { habilitação para dirigir. }\end{array}$} \\
\hline Uso do Solo & $\begin{array}{c}\text { Áreas para uso residencial; Áreas para } \\
\text { uso comercial; Áreas verdes (proteção } \\
\text { ambiental). }\end{array}$ & $\begin{array}{l}\text { Localização de residências e } \\
\text { localização de postos de trabalho. }\end{array}$ \\
\hline Meio Ambiente & $\begin{array}{l}\text { Funções de emissão de poluentes e } \\
\text { fatores de consumo de combustível }\end{array}$ & $\begin{array}{c}\text { Consumo de combustível, níveis de } \\
\text { emissões de poluentes, custos totais } \\
\text { de acidentes. }\end{array}$ \\
\hline
\end{tabular}


O modelo MARS assume que o uso da solo não é uma constante, mas é sim parte de um sistema dinâmico que é influenciado pela infraestrutura de transportes. Este processo de interação é modelado através de retroalimentação periódica, com lapsos de tempo, entre os submodelos de transporte e de uso do solo durante um período de 30 anos.

Sendo assim, os dados socioeconômicos e de transportes de Porto Alegre, conforme esquematizados na Tabela 23 e apresentados em mais detalhes no item 6.3 (Bloco 2), foram alimentados no modelo MARS POA com base nas informações de 2003 (ano-base) e em projeções de crescimento anual de população, empregos e frota de 2003 a 2033. Estes dados servem como variáveis iniciais e parâmetros comportamentais locais para os submodelos de transporte. A acessibilidade no ano "n" é, então, estimada pelos submodelos de transporte e utilizada como dado de entrada para os submodelos de localização no ano "n + 1". Os postos de trabalho e residências do ano "n", estimados para cada ZT pelos modelos de uso do solo, são variáveis explicativas de atração e produção de viagens para o modelo de transporte no ano $n+1$.

A região modelada no MARS abrange apenas o município de Porto Alegre, com aproximadamente $500 \mathrm{~km}^{2}$ de área. Tem o Lago Guaíba como limite oeste, excluindo a região das ilhas, conforme é apresentado nas Figuras 41 e 42. Esta definição foi baseada na abrangência da pesquisa O-D de 2003 (EDOM 2003). Segundo dados da mesma pesquisa, a população de quase 1,4 milhão de habitantes, distribuída nas 96 ZTs, conforme apresentado na Figura 41, gera em torno de 2 milhões de deslocamentos por dia.

O centro da cidade, a pequena área destacada em vermelho na Figura 42, com apenas $4 \%$ da área total da cidade, é responsável pela geração de $20 \%$ das viagens diárias. A rede viária principal de Porto Alegre esta estruturada por vias radiais (ver Figura 42), que se caracterizam por fluxos bem distintos conforme o horário de pico, com grandes carregamentos no sentido bairro-centro no pico da manhã, o que se inverte no pico da tarde. As vias perimetrais complementam a rede viária distribuindo o tráfego entre os bairros.

As características estruturais da cidade, somadas à distribuição espacial da população, mais concentrada na periferia, e das atividades, com grande parte concentrada na pequena área do centro, agravam a situação de congestionamentos e atrasos nos horários de pico. 


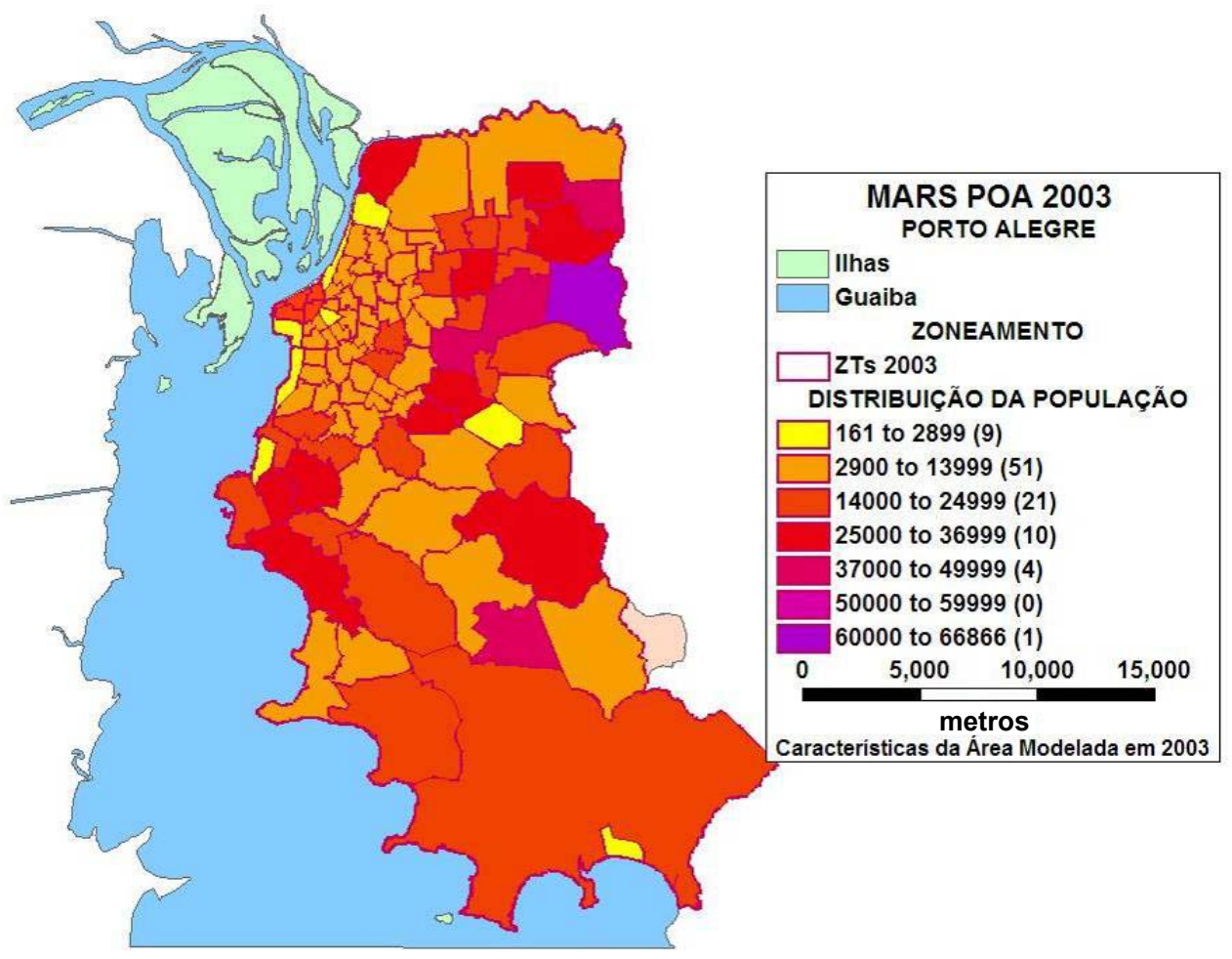

Figura 41 - Distribuição espacial da população de Porto Alegre em 2003

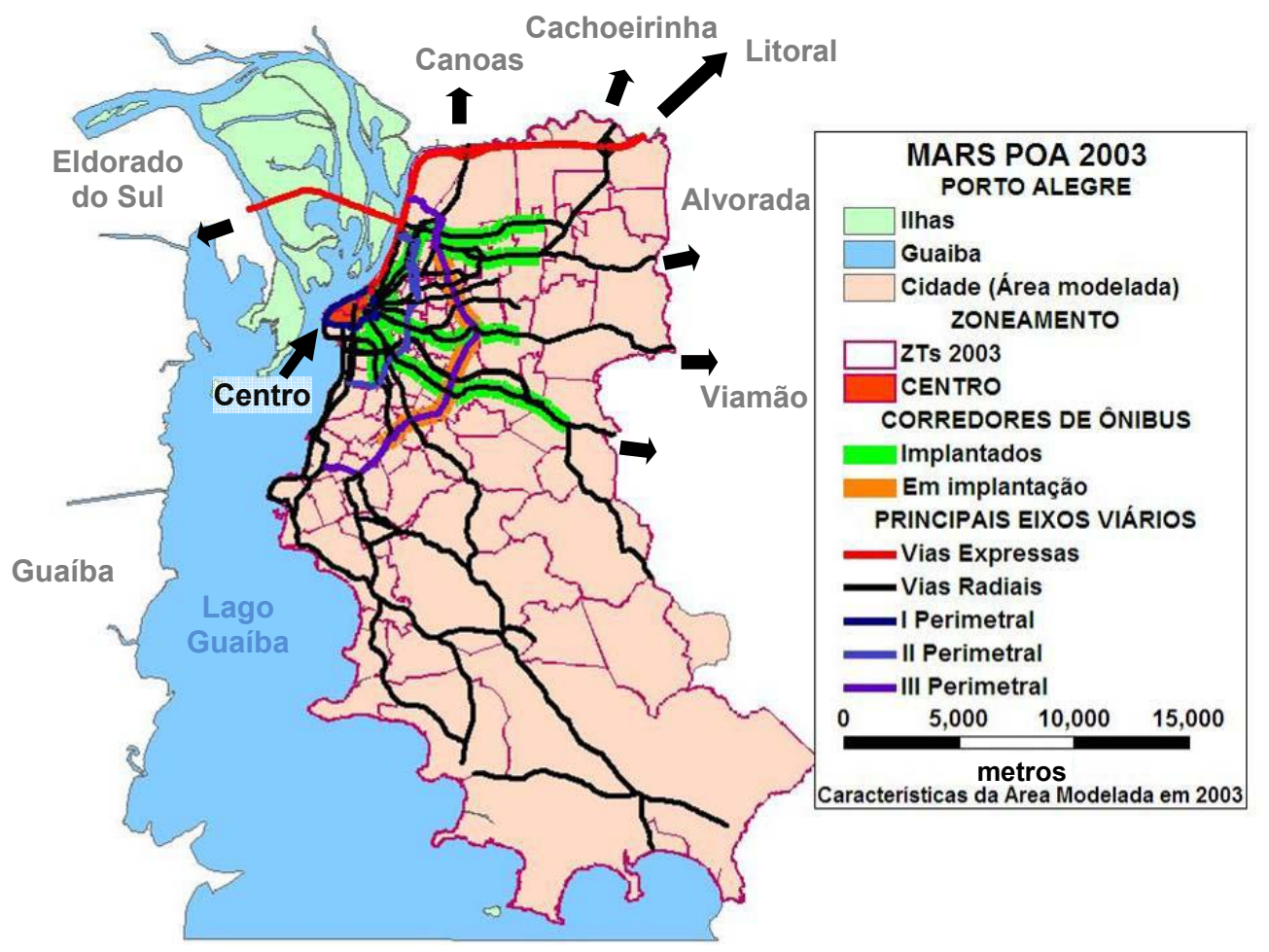

Figura 42 - Distribuição espacial da população de Porto Alegre em 2003 


\section{Cenário de referência para o modelo de Porto Alegre}

No cenário de referência $(A-1)$ do modelo MARS de Porto Alegre, estima-se que a população deva crescer $13 \%$ em trinta anos. A população inicial na área de estudo, de 1.348.288 habitantes em 2003, conforme dados da EDOM 2003, deve crescer $7 \%$ nos sete anos seguintes, conforme estimativas anuais de população do IBGE para Porto Alegre. As taxas anuais iniciais e tendências de crescimento populacional foram extrapoladas para o período posterior de avaliação, assumindo-se que, para cada ano a partir de 2010, a taxa de crescimento populacional é uma média das taxas anuais dos sete anos que o antecedem. Chega-se assim em 2033, fim do período de análise, com uma população de 1.528 .531 habitantes na área de estudo.

Quanto ao mercado de trabalho, a área de estudo apresenta 579.224 empregos no início do período de análise, sendo a maior parte no setor de comércio e serviços (97\%) e apenas $3 \%$ no setor de produção. Com base na transformação do mercado de trabalho verificado nos sete primeiros anos, quando houve um aumento de $17 \%$ na oferta de emprego, segundo dados do IBGE e MTE, estima-se que em 2033 o número de postos de trabalho deverá ser $56 \%$ maior que em 2003. Da mesma forma que foi feito para população, as taxas anuais e tendências de crescimento de empregos verificadas nos sete primeiros anos foram extrapoladas para o período posterior a 2010, até 2033.

A taxa média de propriedade de veículos é de 301 automóveis por 1000 habitantes em 2003, a qual se estima chegar a 659 automóveis por 1000 habitantes em 2033. Assume-se a mesma tendência verificada nos sete anos iniciais, quando houve em aumento de $30 \%$ da frota de veículos particulares em Porto Alegre, considerando os tipos auto, caminhonete e moto, conforme dados e classificação do DETRAN-RS. Este aumento da frota representou um aumento de $22 \%$ na taxa de veículos por 1000 habitantes em 2010, em relação a 2003.

\section{Adaptação dos Cenários do projeto STEPs para Porto Alegre}

A configuração dos cenários no MARS POA seguiu o mesmo critério do MARS Edimburgo, que está apresentada na Tabela 23, com algumas adaptações para a cidade de Porto Alegre. Para a política de controle do uso do solo dos Cenários A2 e B2 e para a subdivisão da cidade em área central (CBD - Central Business District), urbana e extra-urbana, para Porto Alegre estabeleceu-se os seguintes critérios (Figura 40 e 41):

- Área central (CBD) - foi considerada a área dentro dos limites do centro histórico de Porto Alegre, onde se concentra grande parte dos empregos e, consequentemente, responsável por parte considerável da geração de viagens. Foi estabelecido que na "área central" o espaço ainda disponível para ocupação fosse, exclusivamente, para uso 
residencial, atendendo uma política de criação de áreas de ocupação mista de interesse do desenvolvimento sustentável. O custo do terreno foi reduzido em $30 \%$;

- Área Urbana - foi considerada a área além dos limites da área central e com melhor infraestrutura de transporte público, com corredores de ônibus já implantados, projetados ou em estudo. Para a "área urbana" foi estabelecido que o espaço disponível para ocupação fosse 50\% para uso residencial e 50\% para fins econômicos e o custo do terreno foi reduzido em $50 \%$ em relação ao custo real;

- Área extra-urbana - foi considerada a área além dos limites da área urbana. Para esta área também se estabeleceu uma ocupação equilibrada de uso residencial e econômico (50\% para cada), no entanto quem for se estabelecer aí terá um custo maior, pois foi considerado um aumento de $100 \%$ no valor do terreno em relação ao existente.

Tabela 23 - Variáveis representativas dos cenários e das políticas para o MARS Edimburgo que foram adaptadas para o MARS POA 2003

\begin{tabular}{|c|c|c|c|}
\hline $\begin{array}{c}\text { Variável } \\
\text { Política/Cenário }\end{array}$ & $\begin{array}{l}\text { Atividade como de } \\
\text { Costume (A0 / B0) }\end{array}$ & $\begin{array}{l}\text { Investimentos em } \\
\text { Tecnologia (A1 / B1) }\end{array}$ & $\begin{array}{c}\text { Regulação da } \\
\text { Demanda (A2 / B2) }\end{array}$ \\
\hline Custo de & $\mathrm{A} 0+1 \%$ a.a. & $=\mathrm{A} 0$ & $=\mathrm{A} 0$ \\
\hline Combustível & $\mathrm{BO}+4 \%$ a.a. & $=\mathrm{B} 0$ & $=\mathrm{B} 0$ \\
\hline $\begin{array}{l}\text { Imposto no } \\
\text { Combustível }\end{array}$ & $\begin{array}{c}\text { Gasolina: }+0,7 \% \text { a.a. } \\
\text { Diesel: }+1,5 \% \text { a.a. }\end{array}$ & $=\mathrm{A} 0 / \mathrm{B} 0$ & $\begin{array}{l}\text { Gasolina: }+4,7 \% \text { a.a. } \\
\text { Diesel: }+4,7 \% \text { a.a. }\end{array}$ \\
\hline $\begin{array}{l}\text { Velocidade do } \\
\text { Transporte Público }\end{array}$ & $+0,3 \%$ a.a. & $\begin{aligned} & +1,1 \% \text { a.a. (pico) } \\
= & \text { A0/B0 (fora do pico) }\end{aligned}$ & $=\mathrm{A} 0 / \mathrm{B} 0$ \\
\hline $\begin{array}{l}\text { Taxas do Transporte } \\
\text { Público }\end{array}$ & $+0,8 \%$ a.a. & $=\mathrm{A} 0 / \mathrm{B} 0$ & $-1,7 \%$ a.a. \\
\hline $\begin{array}{l}\text { Tarifação } \\
\text { Rodoviária }\end{array}$ & - & - & $€ 2$ até $€ 5$ no ano 30 \\
\hline Teletrabalho & Sem Alteração & $=\mathrm{AO} / \mathrm{B} 0$ & $\begin{array}{c}+0,3 \% \text { a.a. de viagens } \\
\text { eliminadas }\end{array}$ \\
\hline $\begin{array}{l}\text { Controle do Uso do Solo } \\
\text { em Novos } \\
\text { Empreendimentos }\end{array}$ & Como no Plano Estrutural & $=\mathrm{A} 0 / \mathrm{B} 0$ & $\begin{array}{l}\text { Cidade Compacta: } \\
\text { subdivisão dos novos } \\
\text { empreendimentos } \\
30 / 70 / 0 \text { (i) }\end{array}$ \\
\hline $\begin{array}{l}\text { Distribuição da Frota (ii) } \\
\text { (POLES/ASTRA) }\end{array}$ & $\begin{array}{c}\text { A0: } 86,0 / 8,2 \text { / 0,6 / 0,1 / } \\
4,8 \\
\text { B0: } 74,0 / 13,5 / 0,3 / 0,3 / \\
11,6 \\
\end{array}$ & $\begin{array}{c}\text { A1: } 69,0 / 17 / 0,1 / 0,0 / \\
13,8 \\
\text { B1: } 51,0 / 20,0 / 0,10 / 0,0 / \\
28,6 \\
\end{array}$ & $\begin{array}{c}\text { A2: } 86,0 / 9,0 / 0,5 / 0,1 \\
/ 5,4 \\
\text { B2: } 76,0 / 13,4 / 0,4 / \\
0,2 / 10,2 \\
\end{array}$ \\
\hline $\begin{array}{l}\text { Taxa de Crescimento } \\
\text { Propriedade de Carro }\end{array}$ & $\begin{array}{l}\text { A0: } 1,20 \% \text { a.a. } \\
\text { B0: } 1,12 \% \text { a.a. }\end{array}$ & $\begin{array}{l}\text { A1: } 1,21 \% \text { a.a. } \\
\text { B1: } 1,15 \% \text { a.a. }\end{array}$ & $\begin{array}{l}\text { A0: } 1,02 \% \text { a.a. } \\
\text { B0: } 0,76 \% \text { a.a. }\end{array}$ \\
\hline $\begin{array}{l}\text { Uso de } \\
\text { Energia }\end{array}$ & $\begin{array}{c}\text { Gasolina: }-0,5 \% \text { a.a. } \\
\text { Diesel: }-1,0 \% \text { a.a. }\end{array}$ & $\begin{array}{c}\text { Gasolina: }-2,0 \% \text { a.a. } \\
\text { Diesel: }-3,0 \% \text { a.a. }\end{array}$ & $=\mathrm{A} 0 / \mathrm{B} 0$ \\
\hline $\begin{array}{l}\text { Fatores de Emissão de } \\
\text { Poluentes }\end{array}$ & $-8,1 \%$ a.a & $-16 \%$ a.a. & $=\mathrm{A} 0 / \mathrm{B} 0$ \\
\hline $\begin{array}{l}\text { i. } \\
\text { ii. }\end{array}$ & \multicolumn{3}{|c|}{$\begin{array}{l}\text { Área Central (CBD - Central Business District) / urbano / extra-urbano } \\
\text { Subdivisão em: convencional / híbrido / gás natural veicular / eletricidade / hidrogênio }\end{array}$} \\
\hline
\end{tabular}




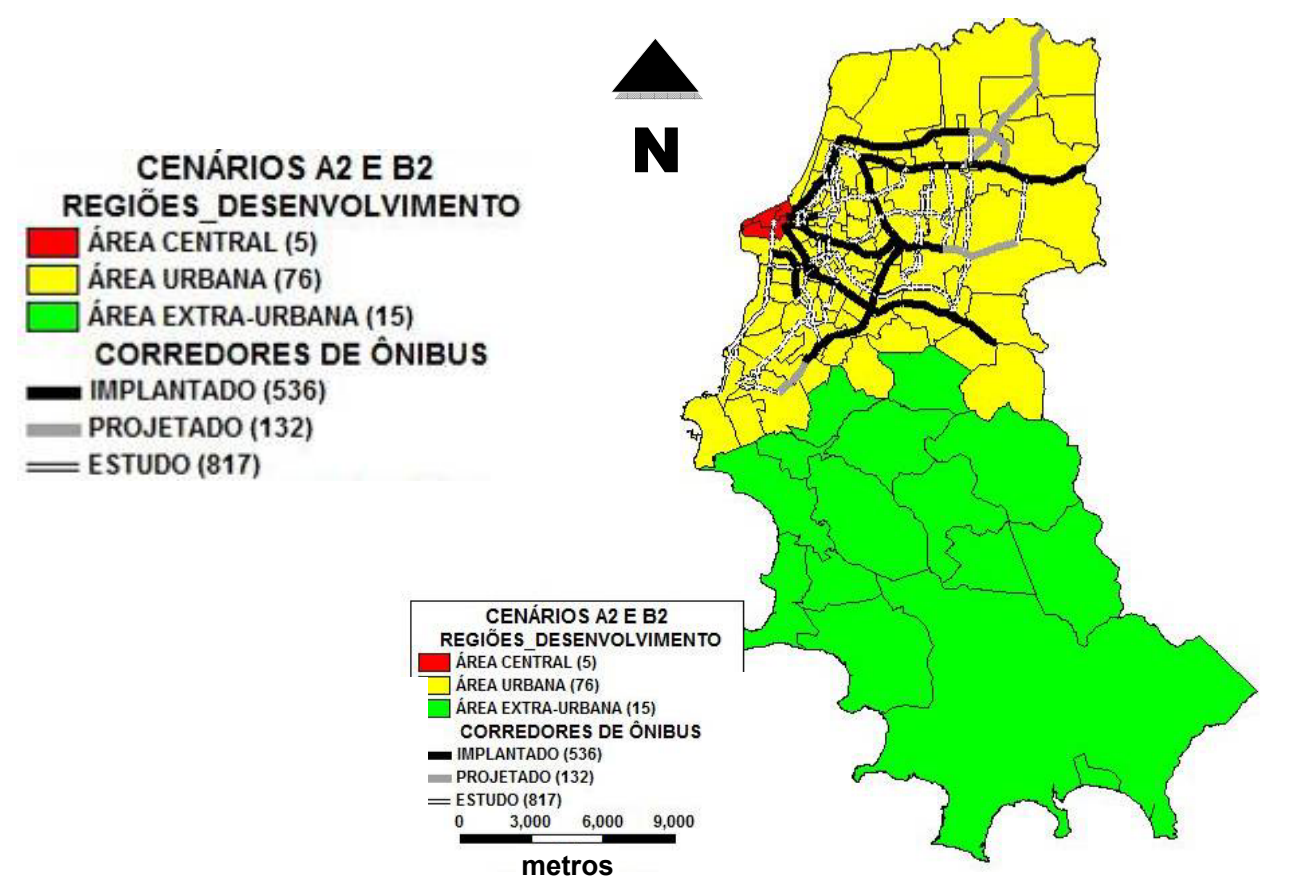

Figura 43 - Zoneamento de Porto Alegre com as subdivisões de desenvolvimento urbano adotadas para as políticas de controle de uso do solo dos Cenários A2 e B2.

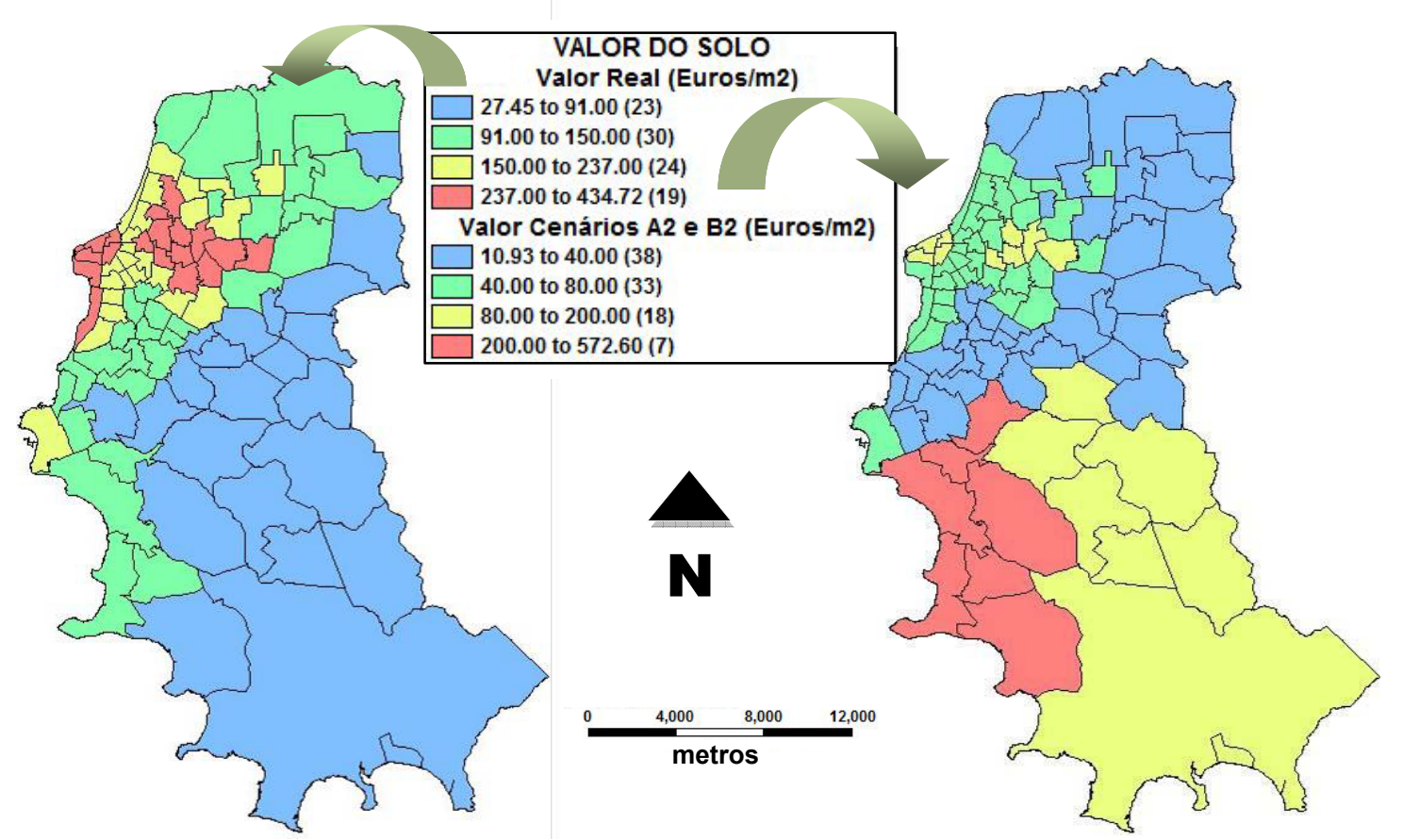

Figura 44 - Valores do solo em $€ / \mathrm{m}^{2}$ - real e adotado para os Cenários A2 e B2. 
Para a política de tarifação rodoviária (Tabela 23), foram consideradas para Porto Alegre duas linhas de cobrança de pedágio, onde uma é o limite da "área central", para as viagens de automóvel originadas na "área urbana" e a outra é o limite externo da "área urbana", para as viagens de automóvel originadas na "área extra-urbana" (Figura 43).

Para a definição da composição de frota e dos fatores de emissões, o modelo MARS de Edimburgo considerou os resultados dos modelos POLES/ASTRA, o que foi mantido no MARS POA. Estes resultados respondem às hipóteses de investimento tecnológico e, em menor grau, a outras políticas e variáveis dos cenários, como custo do combustível e posse de veículos particulares. Igualmente como no MARS Edimburgo, foi assumido que a composição de frota para os cenários A-1 e B-1 é igual à dos cenários $\mathrm{A} 0$ e $\mathrm{B} 0$.

\section{Simulação e análise dos impactos dos cenários propostos para Porto Alegre}

O modelo MARS produz como resultados da simulação, inúmeros indicadores que podem ser avaliados em gráficos que apresentam a sua evolução ao longo de 30 anos. Os indicadores podem ser agregados para toda a região de estudo ou desagregados por áreas de análise (ZTs), podendo, ainda, serem visualizados em mapas, através de um SIG dinâmico (Animap), que apresenta a evolução da distribuição espacial da população, empregos e divisão modal para os quatro modos considerados (a pé/bicicleta, transporte público por ônibus e por metrô e automóvel). O Animap permite, ainda, que as evoluções da distribuição espacial destas variáveis sejam comparadas para dois cenários simultaneamente, apresentando as diferenças desta evolução, para cada ZT, em um terceiro mapa. A título de exemplo e para avaliar o potencial da ferramenta para análises de políticas de mobilidade sustentável são apresentados, na sequência, os principais resultados do MARS POA 2003 para os oito cenários analisados.

\section{Principais resultados da aplicação do MARS POA 2003 para os oito cenários}

A Figura 45 apresenta a trajetória do indicador "passageiros de automóvel - km" ao longo dos 30 anos de análise, que reflete a demanda do uso do automóvel. Verifica-se um aumento em torno de $35 \%$ desta demanda para o cenário de referência A-1 em 2033. Para a maioria dos cenários o aumento fica entre $20 \%$ e $35 \%$, exceto sob a política de regulação de demanda (cenários A2 e B2). Para o cenário A2, o aumento da demanda para o uso do automóvel ficou abaixo de $3 \%$ em 2033 , enquanto que no cenário B2 foi verificada, inclusive, uma redução em torno de $2 \%$ do uso do automóvel neste período.

Como esperado, o impacto também é refletido na divisão modal, cujas trajetórias podem ser avaliadas nas Figuras 46, 47, e 48 para o modo automóvel, transporte público e a pé / bicicleta, respectivamente. Obviamente, os cenários de regulação de demanda A2 e B2, 
tiveram um maior impacto no uso do automóvel, devido ao aumento significativo nos custos para este modo, comparados aos outros cenários, em função da tarifação rodoviária. No entanto, o aumento do custo de combustível, somente, não gera grandes impactos na divisão modal, o que pode ser verificado pela pouca variação entre cenários do tipo $A$ e $B$.

Para o cenário de referência A-1, onde nenhuma política de mobilidade foi considerada e para o qual foram definidas baixas taxas anuais de aumento de combustível, verifica-se um aumento em torno de $23 \%$ na divisão modal para o modo automóvel e, uma consequente redução, em torno de $15 \%$ e $3 \%$, para os modos Transporte Público e A pé / bicicleta, respectivamente. Os cenários de investimento em tecnologia A1 e B1 não geram impactos na divisão modal, uma vez que uma frota de veículos mais eficiente encoraja mais viagens fora do horário de pico. A política de regulação de demanda é a que gera maiores impactos, revertendo o quadro de aumento do uso do automóvel, para o aumento, em torno de $10 \%$, da demanda para modos não motorizados. Uma redução, em torno de $5 \%$, do uso do Transporte Público é também observada para estes cenários.

O aumento da demanda para modos não motorizados pode ser explicado pela redução das distâncias médias de viagens (em torno de 4\%) verificadas nestes dois cenários, resultantes da política de cidade compacta e zonas mistas, a qual aproxima os residentes de seus empregos e demais atividades diárias. Como resultado dos impactos observados na divisão modal para os diferentes cenários, observa-se os efeitos transmitidos ao meio ambiente. A Figura 49 apresenta, como exemplo, a variação das emissões de $\mathrm{CO}_{2}$ para os diferentes cenários. Neste caso, as medidas adotadas pela política de regulação de demanda, somadas ao aumento de combustíveis (Cenário B2), apresentaram maior impacto na redução de emissões do que o investimento em novas tecnologias com este intuito (Cenários A1 e B1).

Outro benefício verificado ao adotar políticas de regulação de demanda foi a significativa diminuição nos índices de acidentes de trânsito. Enquanto que para a maioria dos cenários, ao final do período de análise, o índice ficou entre $95 \%$ e $97 \%$ do observado no ano base, para os Cenários A2 e B2, o mesmo índice fiou reduzido a, aproximadamente, 82\% (Figura 50). A redução do uso do automóvel e o aumento de deslocamento por modos não motorizados explicam os impactos positivos no meio ambiente e na segurança viária.

A Figura 51 apresenta, a título de exemplo de análise comparativa no SIG dinâmico Animap, o impacto nos deslocamentos por modos não motorizados para os Cenários A-1 e A2 ao final do período de análise. Os dois primeiros mapas da Figura 51 apresentam a diferença percentual para o modo A pé / bicicleta em relação ao ano base e o terceiro mapa apresenta as diferenças do cenário $\mathrm{A} 2$ em relação ao cenário de referência $\mathrm{A}-1$. 


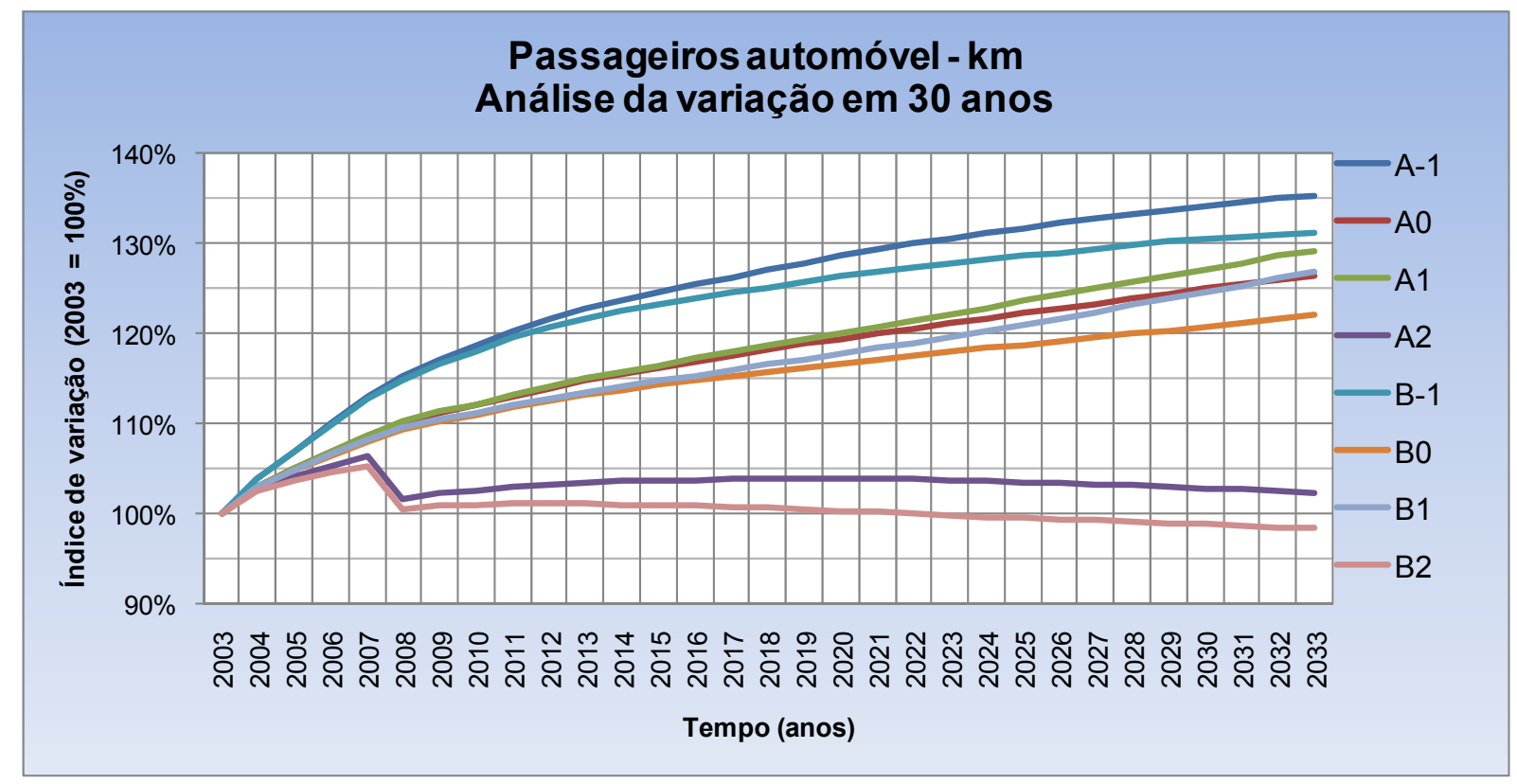

Figura 45 - Demanda do uso de automóvel - variação de "passageiros automóvel - km" em 30 anos para cada cenário

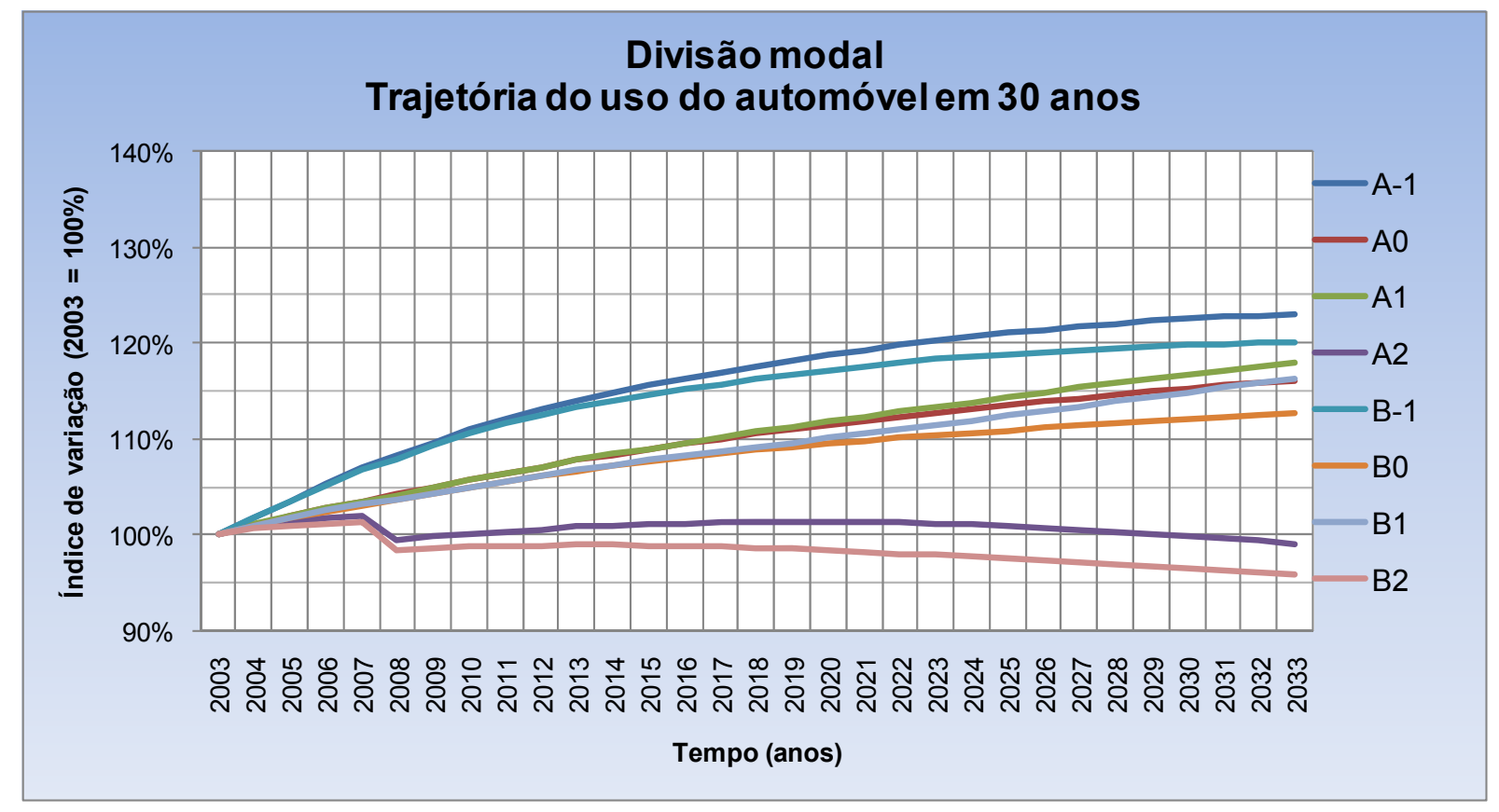

Figura 46 - Divisão modal (automóvel) - Trajetória do uso do automóvel nos 30 anos para cada cenário 


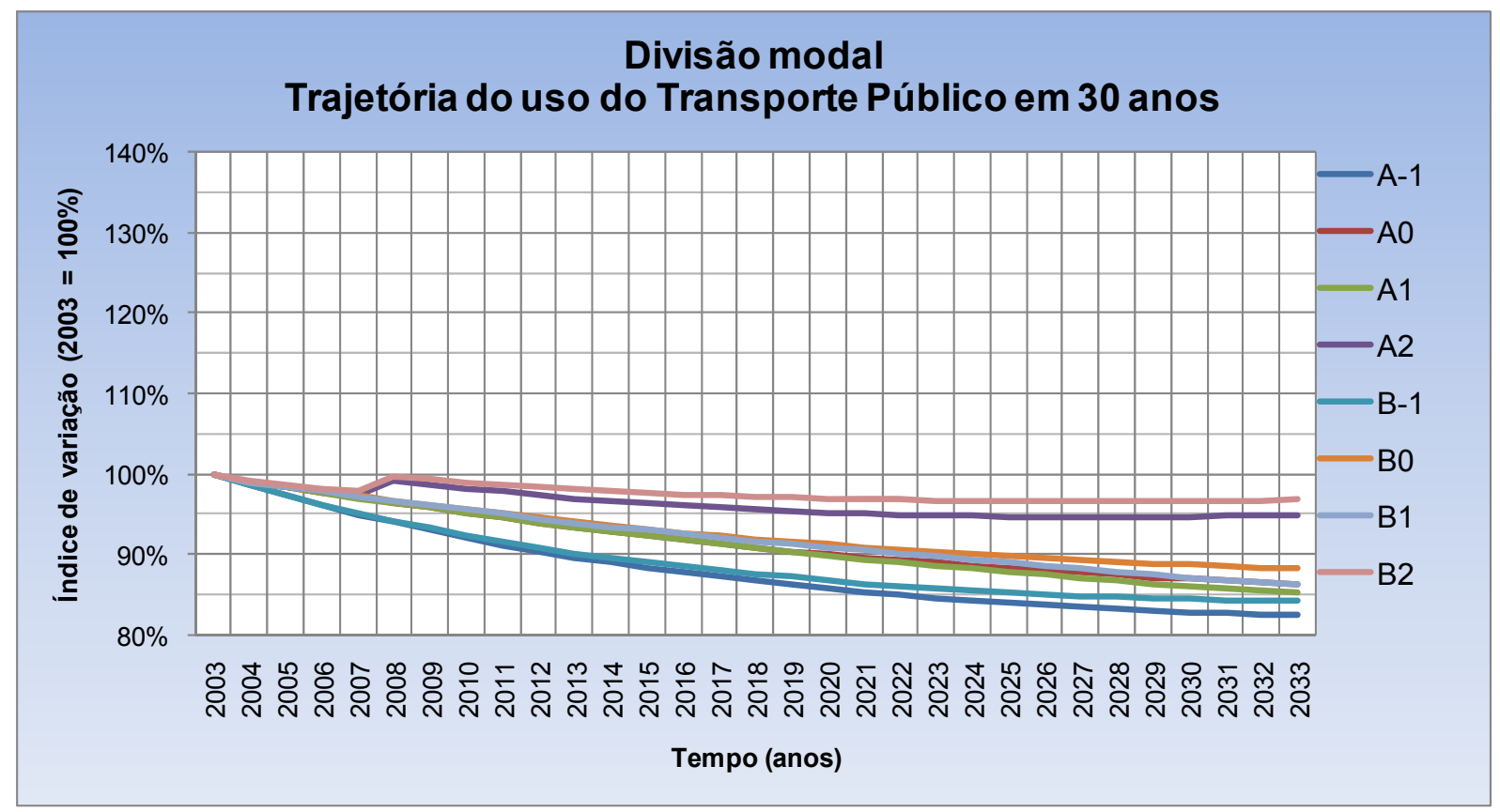

Figura 47 - Divisão modal (Transporte Público) - Trajetória do uso do Transporte púbico nos 30 anos para cada cenário

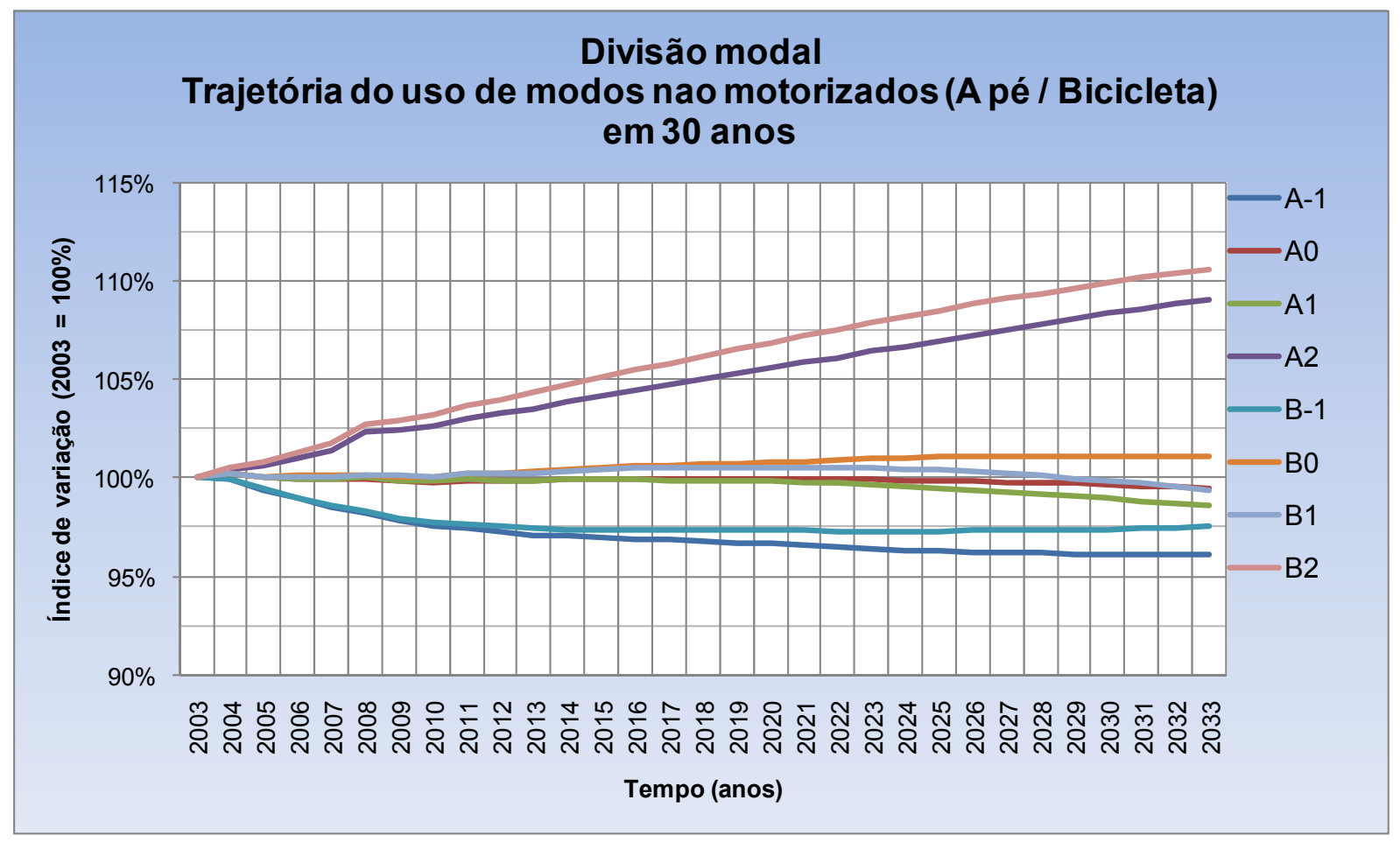

Figura 48 - Divisão modal (A pé / bicicleta) - Trajetória do uso dos modos não motorizados nos 30 anos para cada cenário 


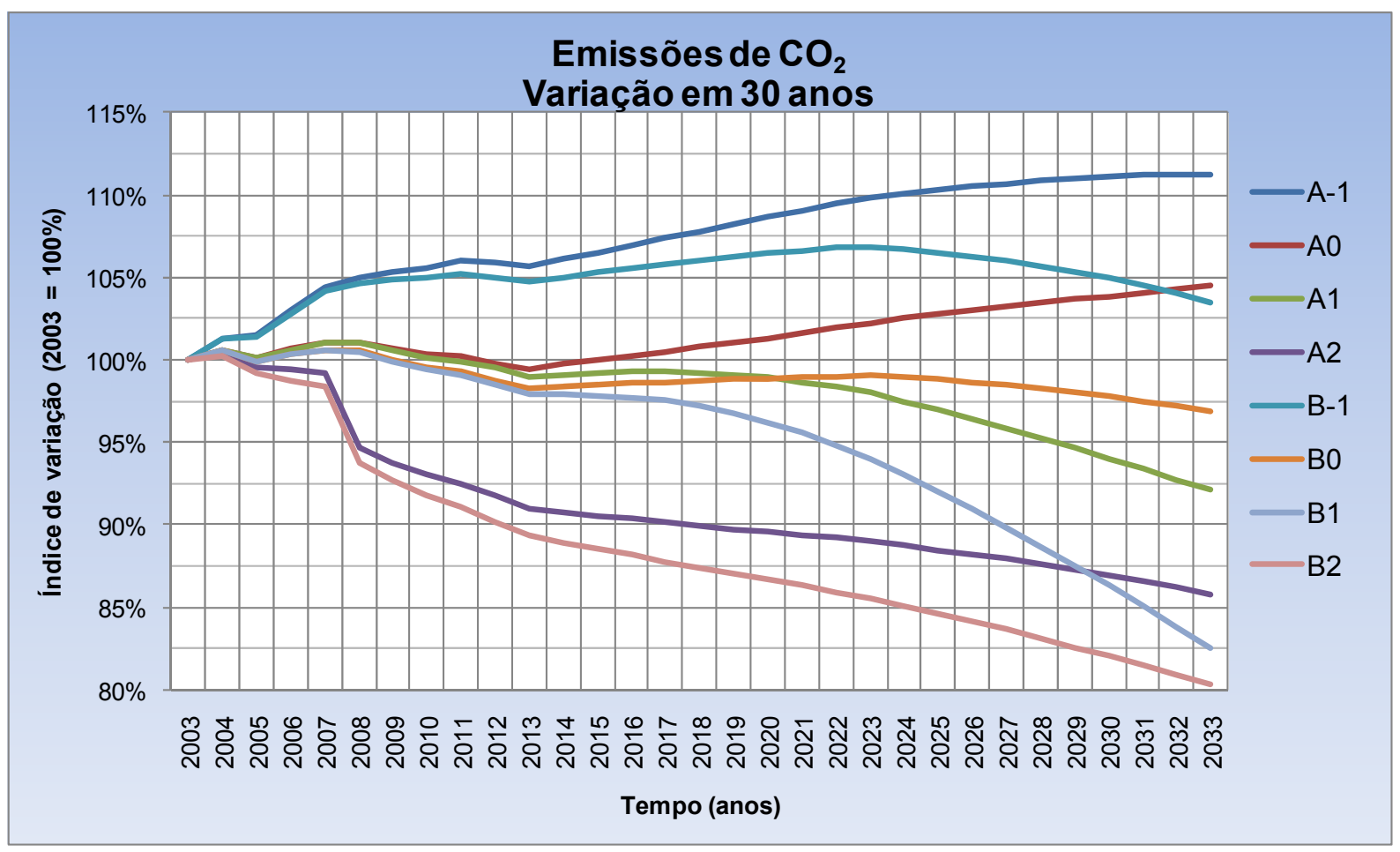

Figura 49 - Impactos no meio ambiente - Evolução das taxas de emissões de CO2 em 30 anos para cada cenário

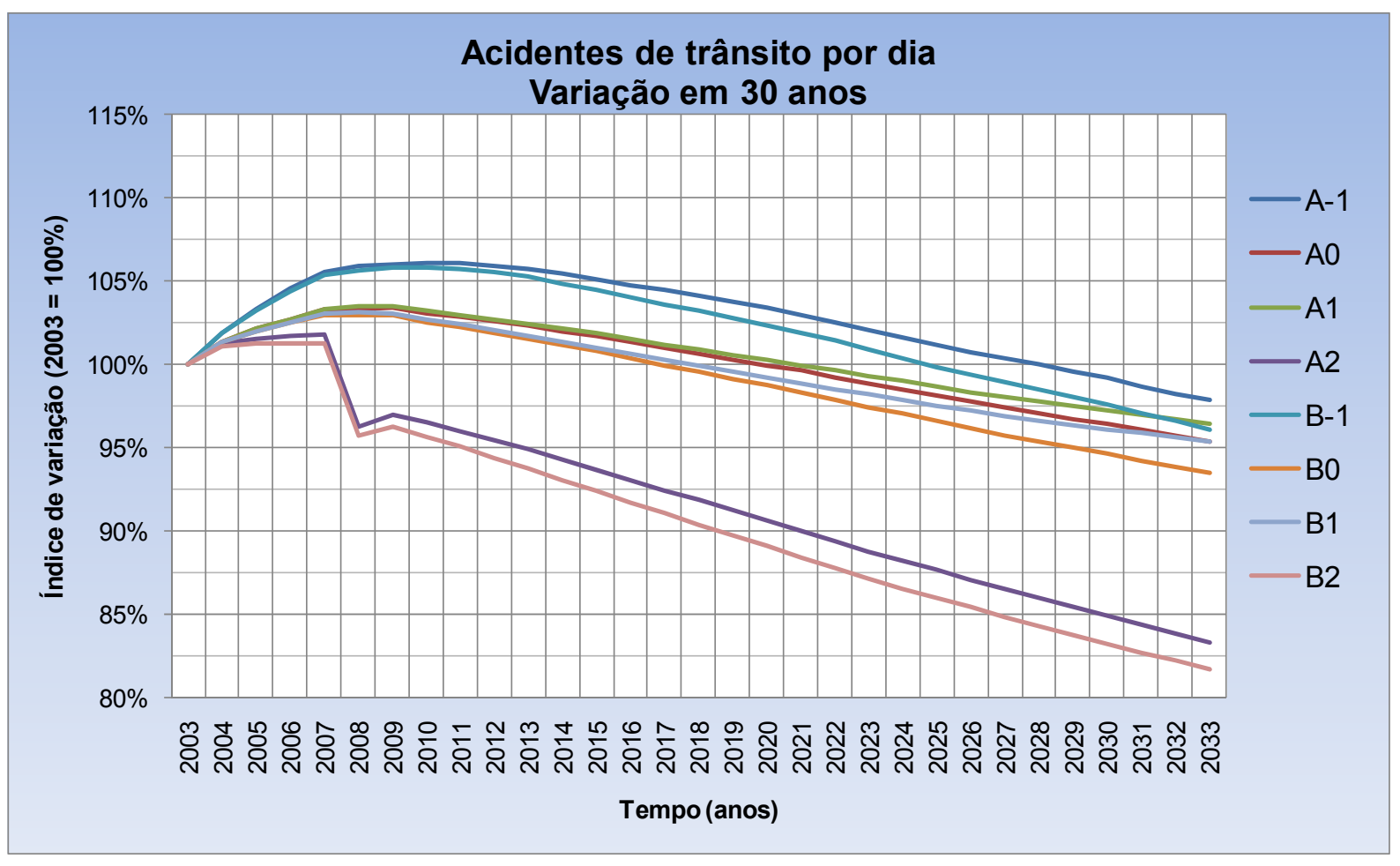

Figura 50 - Evolução dos níveis de acidente em 30 anos para cada cenário 


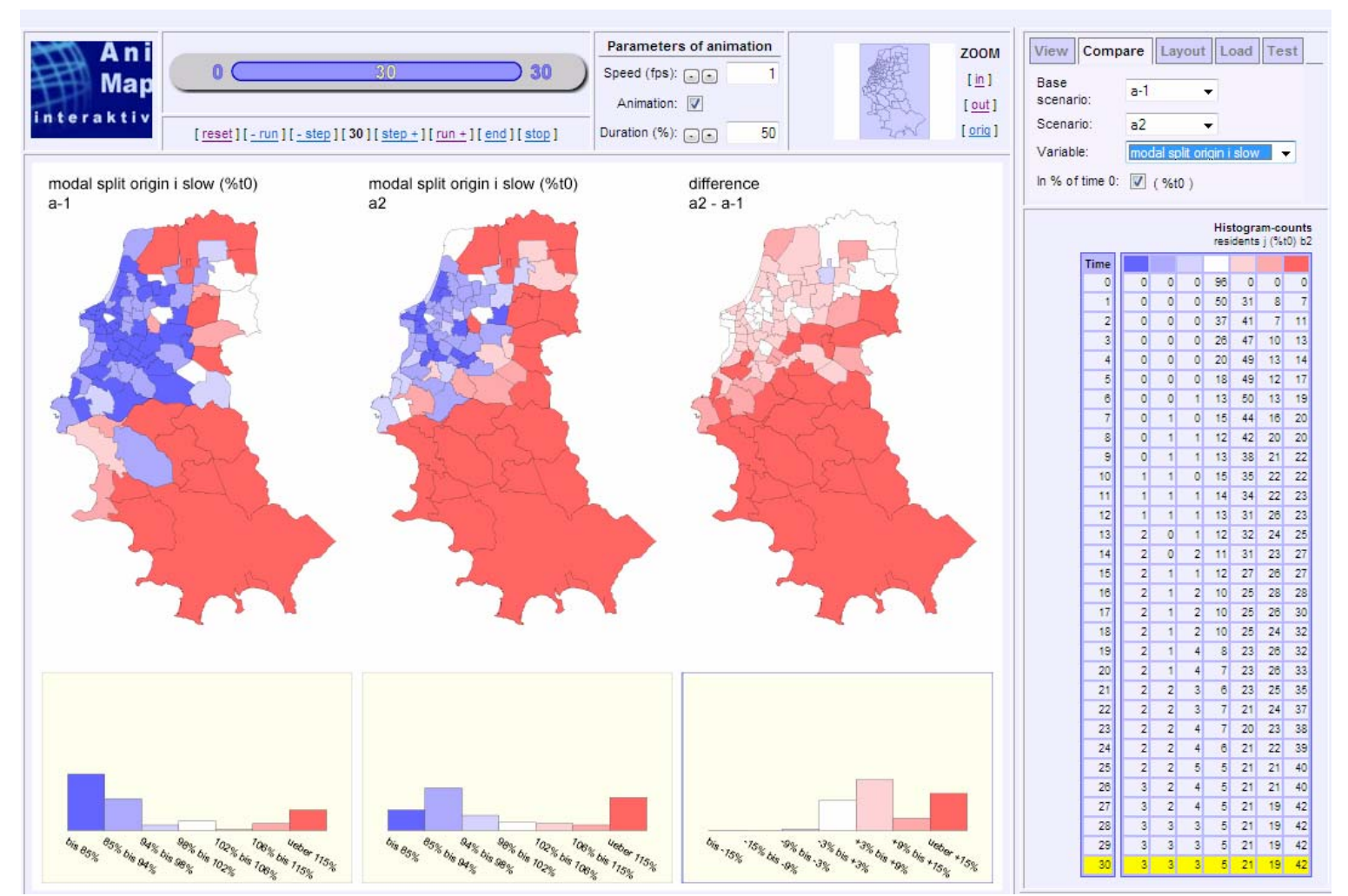

Figura 51 - Análise comparativa dos Cenários A-1 e A2 no SIG dinâmico AniMap - Divisão modal para o modo A pé / Bicicleta ao final da simulação - Percentual em relação ao ano base e diferenças entre os dois cenários.

\subsubsection{Análise da consistência das projeções - Meta-análise}

A meta-análise permite a validação cruzada de modelos, ou seja, por comparação sistemática dos resultados de modelos diferentes com hipóteses similares é possível avaliar a consistência das projeções. Por causa do tempo e esforço necessários para criar um modelo integrado de transporte e uso do solo, poucas são as situações em que mais de um modelo foi aplicado a uma dada região, situação que permitiria a validação cruzada. Constituem as exceções o Projeto ISGLUTI (International Study Group on Land Use Transport Interaction - Webster et al., 1988; Wegener et al., 1991) e o Projeto PROPOLIS (Planning and Research of Policies for Land Use and Transport for Increasing Urban Sustainability - Lautso et al., 2004), da União Européia.

Em uma meta-análise de validação cruzada ideal os modelos a serem comparados trabalham com hipóteses de trabalho rigorosamente idênticas. No entanto, em situações como as do Projeto STEPs, em que especificações de cenários rigorosamente comparáveis não foram possíveis, ainda assim é possível realizar uma meta-análise de validação cruzada 
mediante comparação de cenários com especificações similares, ainda que os nomes das variáveis consideradas não sejam os mesmos.

\section{Modelos analisados no projeto STEPs}

Apesar de existir um consenso significativo entre os modelos analisados com relação a suas tendências, opções de políticas e conclusões gerais a serem extraídas, existem, também, diferenças em seus detalhes, que são de interesse para a validade dos modelos e da transferência dos seus resultados. Os seis modelos aplicados no projeto STEPs e que tiveram seus resultados analisados através de meta-análise são apresentados na Tabela 24.

A meta-análise é desenvolvida através de análises estatísticas, geralmente regressão simples (ou univariada) ou regressão múltipla (ou multivariada), dos resultados dos modelos e dos dados de entrada. Trata-se de uma tentativa de identificar e isolar a contribuição específica de políticas ou tendências relevantes para as mudanças nas variáveis de saída dos modelos, da mesma forma que, na pesquisa empírica, procura-se explicar mudanças no fenômeno observado associando-as a potenciais fatores (causas). Em ambos os casos, somente pode-se concluir que há uma relação causal, ou seja, os indicadores de saída podem ser considerados os "efeitos" e as variáveis de entrada as "causas", com base nos valores das propriedades estatísticas (por exemplo, nível de confiança, coeficiente de determinação, sinal esperado etc.). 
Tabela 24 - Modelos integrados analisados no Projeto STEPs

\begin{tabular}{ll}
$\begin{array}{l}\text { MODELO } \\
\text { Local de } \\
\text { Aplicação }\end{array}$ & CARACTERÍsTICAS \\
\hline \hline & $\begin{array}{l}\text { Descreve as ligações entre o sistema de transportes, a economia e o meio } \\
\text { ambiente na Europa, considerando que a economia afeta a demanda por }\end{array}$ \\
transportes através da quantidade de bens produzidos e a maior mobilidade \\
Europa & $\begin{array}{l}\text { decorrente do aumento da taxa de emprego, enquanto que o efeito sobre o meio } \\
\text { ambiente depende do volume de tráfego e da tecnologia da frota de veículos. }\end{array}$
\end{tabular}

$\begin{array}{ll} & \text { É um modelo de desenvolvimento socioeconômico de } 1.330 \text { regiões européias, } \\ \text { SASI } & \text { condicionado por hipóteses exógenas a respeito da economia e do crescimento } \\ \text { demográfico na União Européia como um todo, e de investimentos em transportes, } \\ \text { Europa }\end{array}$

\begin{tabular}{ll}
\hline É um modelo que tem por objetivo definir uma estratégia global de \\
desenvolvimento através da análise da relação entre uso do solo, transportes, \\
desenvolvimento socioeconômico e impactos ambientais. Trata-se de um modelo \\
de transportes clássico ("quatro etapas"), com previsão do número de viagens \\
produzidas e atraídas por cada zona na hora de pico, divisão por modo de \\
transportes e alocação de tráfego.
\end{tabular}

\begin{tabular}{|c|c|}
\hline $\begin{array}{l}\text { DORTMUND } \\
\text { Dortmund }\end{array}$ & $\begin{array}{l}\text { Faz a previsão dos impactos de políticas de desenvolvimento econômico, } \\
\text { habitação, instalações públicas, uso do solo e transportes em termos de decisão } \\
\text { intra-regional sobre localização de empresas e residências e as consequências em } \\
\text { termos de migração e padrões de viagens, atividade do setor de construção civil, } \\
\text { desenvolvimento do uso do solo e qualidade ambiental. }\end{array}$ \\
\hline $\begin{array}{l}\text { MARS } \\
\text { Edimbugo } \\
\text { Porto Alegre }\end{array}$ & $\begin{array}{l}\text { Modelo estratégico de interação do uso do solo e transportes, em que indicadores } \\
\text { de acessibilidade são calculados a partir dos efeitos dos transportes sobre a } \\
\text { localização dos postos de trabalho e das residências, enquanto que o uso do solo } \\
\text { fornece as origens e destinos para os modelos de transportes. }\end{array}$ \\
\hline $\begin{array}{l}\text { MEPLAN } \\
\text { Helsinque } \\
\text { Tirol Sul }\end{array}$ & $\begin{array}{l}\text { Modelo de uso do solo e transportes em que a economia local é representada por } \\
\text { uma matriz insumo-produto, cujos fatores incluem setores da economia, grupos } \\
\text { populacionais e espaço territorial. Mudanças de localização são introduzidas por } \\
\text { variações nos custos de transportes ou novos serviços elou infraestruturas. Simula } \\
\text { as interações entre economia, população e território em termos das relações de } \\
\text { produção e consumo, com realimentação do sistema a partir dos resultados dos } \\
\text { modelos de uso do solo e de transportes. }\end{array}$ \\
\hline
\end{tabular}

Fontes: Wegener (2010) e STEPs (2004-2006).

Problemas como regiões com diferentes extensões, diferentes horizontes de previsão, crescimento ou declínio das regiões urbanas, diferentes suposições sobre tendências externas e diferentes suposições sobre as políticas podem ser contornados com a padronização dos indicadores, ou seja, a definição de resultados como diferenças em relação ao cenário de referência, e com a meta-análise dos resultados.

Na meta-análise realizada no Projeto STEPs, os resultados dos cenários simulados pelos seis modelos foram considerados como observações. Após testes preliminares, as equipes 
de modelagem foram requisitadas a fornecer, para cada um dos cenários modelados, dois conjuntos rigorosamente padronizados de indicadores de dados de entrada e de saída:

- Indicadores de entrada dos modelos ou possíveis "causas": são as variáveis independentes ou explicativas, definidas exogeneamente pelos usuários, como, por exemplo, evolução de fatores globais (alterações do preço de combustíveis, avanço tecnológico) ou medidas de política pública (taxas sobre os combustíveis, pedágios, limites de velocidade, controle do uso da terra);

- Indicadores de saída dos modelos ou possíveis "efeitos": nas análises de regressão, são as variáveis dependentes, constituídas por indicadores de interesse científico e político, sobre os quais é interessante saber por quais fatores são afetados nos modelos. Para tanto, a cadeia causal é seguida para trás até que seja possível identificar as variáveis de entrada (políticas ou hipóteses) que causaram as mudanças.

A Tabela 25 apresenta os indicadores de entrada e de saída definidos para a meta-análise do Projeto STEPs e que, similarmente, será desenvolvida neste trabalho com a inclusão do MARS POA. São 27 indicadores, 13 de entrada e 14 de saída, para os quais são apresentadas as siglas, associadas à definição em inglês, com apresentação também em português, e a unidade com que cada indicador é quantificado.

Os 27 indicadores, para todos os cenários analisados, são transformados em índices, expressos como porcentagem dos valores correspondentes obtidos com o Cenário de Referência A-1, no ano meta do modelo (2020 ou 2030). Os resultados da meta-análise são apresentados, neste trabalho, com base em regressões univariadas (ou simples).

\section{Regressões Univariadas}

As análises de regressão simples exploram a correlação entre dois atributos dos cenários, com base em uma hipótese sobre a relação de causa-efeito entre eles, que é quantificada pelo Coeficiente de Determinação $\left(R^{2}\right)$, ou seja, $R^{2}$ elevado significa que é forte a relação causal admitida pela hipótese. Os efeitos explorados podem ser classificados como diretos ou indiretos. 
Tabela 25 - Indicadores de Entrada e Saída para as Meta-análises.

\begin{tabular}{|c|c|c|c|c|}
\hline & & & Indicador & Unidade \\
\hline \multirow{13}{*}{ 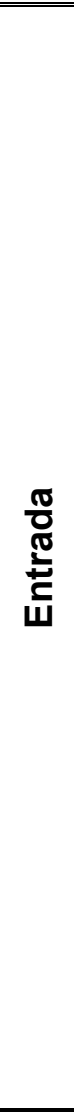 } & 1 & gdpc & $\begin{array}{l}\text { PIB per capita } \\
\text { (GDP per capita) }\end{array}$ & $€$ \\
\hline & 2 & fcpl & $\begin{array}{l}\text { custo de combustível de automóvel, incluindo impostos } \\
\text { (fuel cost per liter for car users including taxes) }\end{array}$ & $€ / I$ \\
\hline & 3 & twrk & $\begin{array}{l}\text { teletrabalho } \\
\text { (telework) }\end{array}$ & $\%$ \\
\hline & 4 & luc & $\begin{array}{l}\text { controle do uso do solo }(1=\text { nenhum, } 2=\text { fraco, } 3=\text { forte }) \\
\quad(\text { land use control: } 1=\text { none, } 2=\text { weak, } 3=\text { strong) }\end{array}$ & 1, 2 ou 3 \\
\hline & 5 & devl & $\begin{array}{l}\text { área urbanizada per capita } \\
\text { (developed land per capita) }\end{array}$ & $\mathrm{m}^{2}$ \\
\hline & 6 & apts & $\begin{array}{l}\text { velocidade média dos transportes públicos } \\
\text { (average public transport speed) }\end{array}$ & $\mathrm{km} / \mathrm{h}$ \\
\hline & 7 & acs & $\begin{array}{l}\text { velocidade média dos automóveis particulares } \\
\text { (average car speed) }\end{array}$ & $\mathrm{km} / \mathrm{h}$ \\
\hline & 8 & cptt & $\begin{array}{l}\text { custo de viagem por transporte público } \\
\text { (cost of a public transport trip) }\end{array}$ & $€$ \\
\hline & 9 & afcc & $\begin{array}{l}\text { consumo médio de combustível por automóvel } \\
\text { (average fuel consumption per car) }\end{array}$ & $\mathrm{l} / 100 \mathrm{~km}$ \\
\hline & 10 & palt & $\begin{array}{l}\text { porcentagem de veículos alternativos } \\
\text { (percentage of alternative vehicles) }\end{array}$ & $\%$ \\
\hline & 11 & $\mathrm{CC}$ & $\begin{array}{l}\text { custo da posse de automóvel } \\
\text { (cost of car ownership) }\end{array}$ & $€ /$ carro/mês \\
\hline & 12 & ctc & $\begin{array}{l}\text { custo de viagem de carro } \\
\text { (car travel cost) }\end{array}$ & $€ / \mathrm{km}$ \\
\hline & 13 & ctcp & $\begin{array}{l}\text { custo de viagem de carro mais tarifação rodoviária } \\
\text { (car travel cost including road pricing) }\end{array}$ & $€ / \mathrm{km}$ \\
\hline \multirow{14}{*}{$\frac{\frac{\pi}{0}}{\frac{0}{\pi}}$} & 14 & $\mathrm{tdpc}$ & $\begin{array}{c}\text { distância total viajada per capita por dia } \\
\text { (total distance traveled per capita per day) }\end{array}$ & $\mathrm{km}$ \\
\hline & 15 & $\mathrm{cdpc}$ & $\begin{array}{l}\text { distância percorrida por carro por habitante por dia } \\
\text { (car distance traveled per capita per day) }\end{array}$ & $\mathrm{km}$ \\
\hline & 16 & adt & $\begin{array}{l}\text { distância média por viagem } \\
\text { (average distance per trip) }\end{array}$ & $\mathrm{km}$ \\
\hline & 17 & adct & $\begin{array}{l}\text { distância média por viagem de carro } \\
\text { (average distance per car trip) }\end{array}$ & $\mathrm{km}$ \\
\hline & 18 & swct & $\begin{array}{c}\text { porcentagem de viagens por modo lento (a pé ou de bicicleta) } \\
\text { (share of walking and cycling trips) }\end{array}$ & $\%$ \\
\hline & 19 & sptt & $\begin{array}{l}\text { porcentagem de viagens por transporte público } \\
\text { (share of public transport trips) }\end{array}$ & $\%$ \\
\hline & 20 & sct & $\begin{array}{l}\text { porcentagem de viagens por automóvel } \\
\text { (share of car trips) }\end{array}$ & $\%$ \\
\hline & 21 & $\mathrm{fcpc}$ & $\begin{array}{c}\text { consumo de combustível de automóvel per capita por dia } \\
\text { (fuel consumption per car per capita per day) }\end{array}$ & I \\
\hline & 22 & $\operatorname{co} 2$ & $\begin{array}{c}\text { emissões de } \mathrm{CO}_{2} \text { pelos transportes per capita por dia } \\
\left(\mathrm{CO}_{2} \text { emissions by transport per capita per day }\right)\end{array}$ & $\mathrm{kg}$ \\
\hline & 23 & nox & $\begin{array}{l}\text { emissões de } \mathrm{NO}_{x} \text { pelos transportes per capita por dia } \\
\left(\mathrm{NO}_{x} \text { emissions by transport per capita per day) }\right.\end{array}$ & $g$ \\
\hline & 24 & $\mathrm{pm}$ & $\begin{array}{c}\text { emissões de material particulado pelos transportes per capita } \\
\text { (PM emissions by transport per capita per day) }\end{array}$ & $\mathrm{mg}$ \\
\hline & 25 & cown & $\begin{array}{l}\text { propriedade de carro por } 1.000 \text { habitantes } \\
\text { (car ownership per 1,000 population) }\end{array}$ & \# \\
\hline & 26 & tdpm & $\begin{array}{l}\text { mortes no trânsito por milhão de habitantes por ano } \\
\text { (traffic deaths per million population per year) }\end{array}$ & \# \\
\hline & 27 & acc & $\begin{array}{l}\text { acessibilidade } \\
\text { (accessibility) }\end{array}$ & índice \\
\hline
\end{tabular}




\section{Resultados da meta-análise do Projeto STEPs incluindo as simulações dos cenários com o MARS POA}

Alguns resultados da meta-análise, para os seis modelos avaliados no Projeto STEPs, são apresentados nas Figuras 52 a 55, incluindo o MARS POA. Quando comparadas com as projeções dos oito cenários similares dos seis modelos aplicados na Europa, os resultados do MARS POA apresentaram muita proximidade entre as principais respostas comportamentais e efeitos ambientais previstos pelos modelos considerados, a partir das políticas energéticas examinadas. Isto pode ser verificado pelas linhas de tendência e coeficientes de determinação $R^{2}$ das análises de regressão apresentadas nos gráficos. Para efeito de comparação estes resultados são apresentados de duas formas nas Figuras 52 a 55: linhas de tendência somente dos resultados dos modelos do projeto STEPs e incluindo os resultados do MARS POA.

\section{Efeitos diretos}

Os efeitos diretos das políticas energéticas são respostas comportamentais a mudanças nas opções de transporte devido, por exemplo, a alteração nos preços dos combustíveis, nos impostos sobre combustíveis, nas tarifas dos transportes públicos, nos pedágios, nas taxas de estacionamento, na tecnologia dos veículos, no consumo de combustível, na velocidade de deslocamento, nas leis de trânsito ou na regulamentação do uso da terra.

Um exemplo de resposta comportamental é a escolha da modalidade, em que as viagens por transporte público (Figura 52) ou automóvel (Figura 53) são apresentadas em função do custo de viagem de carro, incluindo a tarifação rodoviária, com os diagramas de dispersão mostrando as diferenças entre os modelos na definição dos cenários. No entanto, os diagramas de dispersão mostram, também, que os resultados das simulações dos seis modelos Europeus e do MARS POA, apesar de suas diferenças na especificação dos cenários, são mais semelhantes do que podem parecer à primeira vista.

Se a comparação não é de cenários com nomes idênticos, mas de cenários com pressupostos semelhantes sobre o aumento do custo de viagem de automóvel, pode-se observar que os sete modelos mostram uma concordância muito boa, todos eles apresentando uma redução consistente na participação de viagens de automóvel em resposta ao aumento do custo de viagem de automóvel. Conclusões semelhantes podem ser tiradas na análise das distâncias médias percorridas em função do custo de viagem de automóvel incluindo tarifação rodoviária (Figura 54). Há diferenças na especificação de cenários, mas também similaridade na reação dos usuários de automóveis ao aumento das despesas nas viagens de carro. 


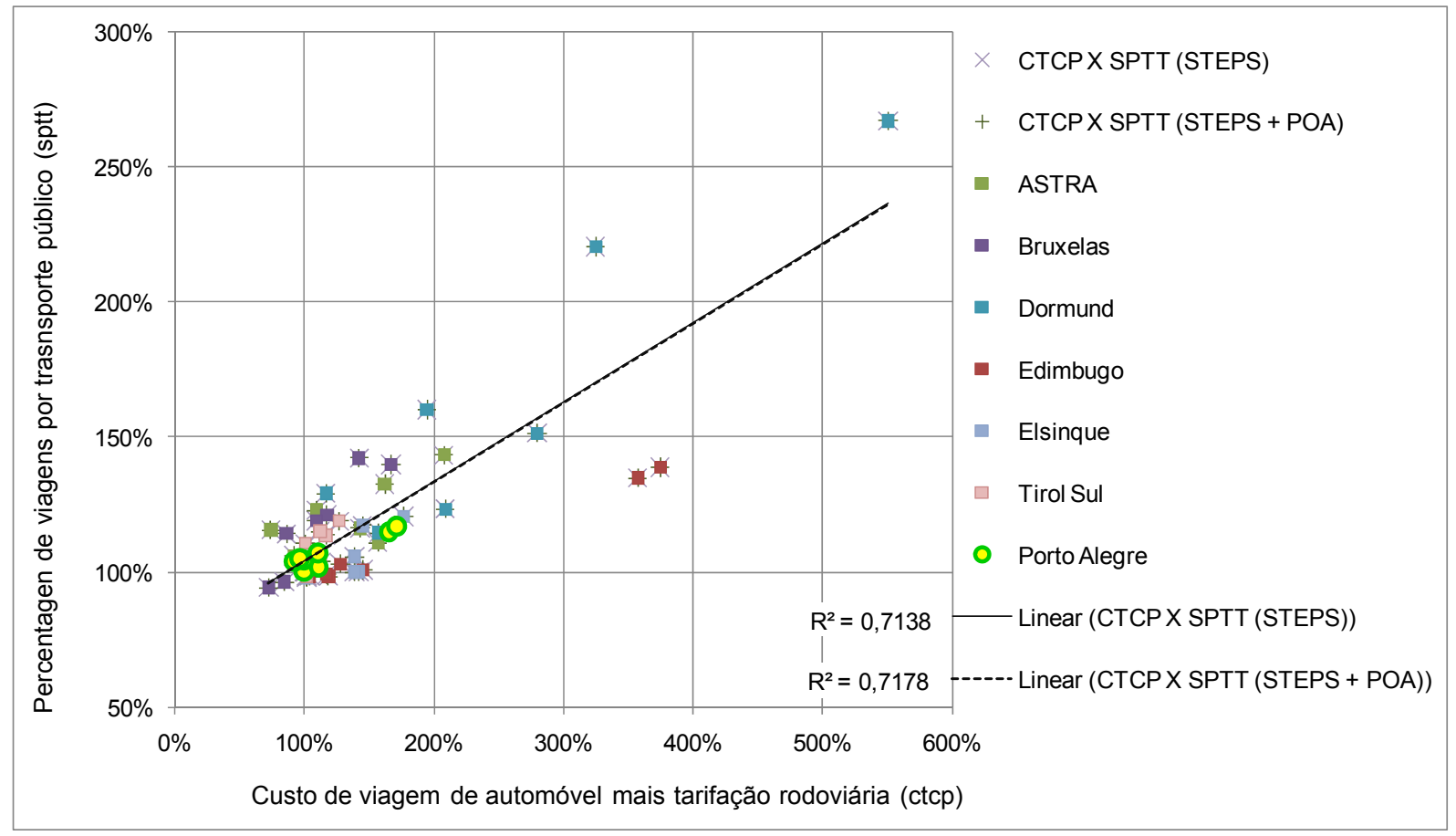

Figura 52 - Porcentagem de viagens por transporte público (sptt) em função do custo de viagem por automóvel, incluindo tarifação rodoviária (ctcp).

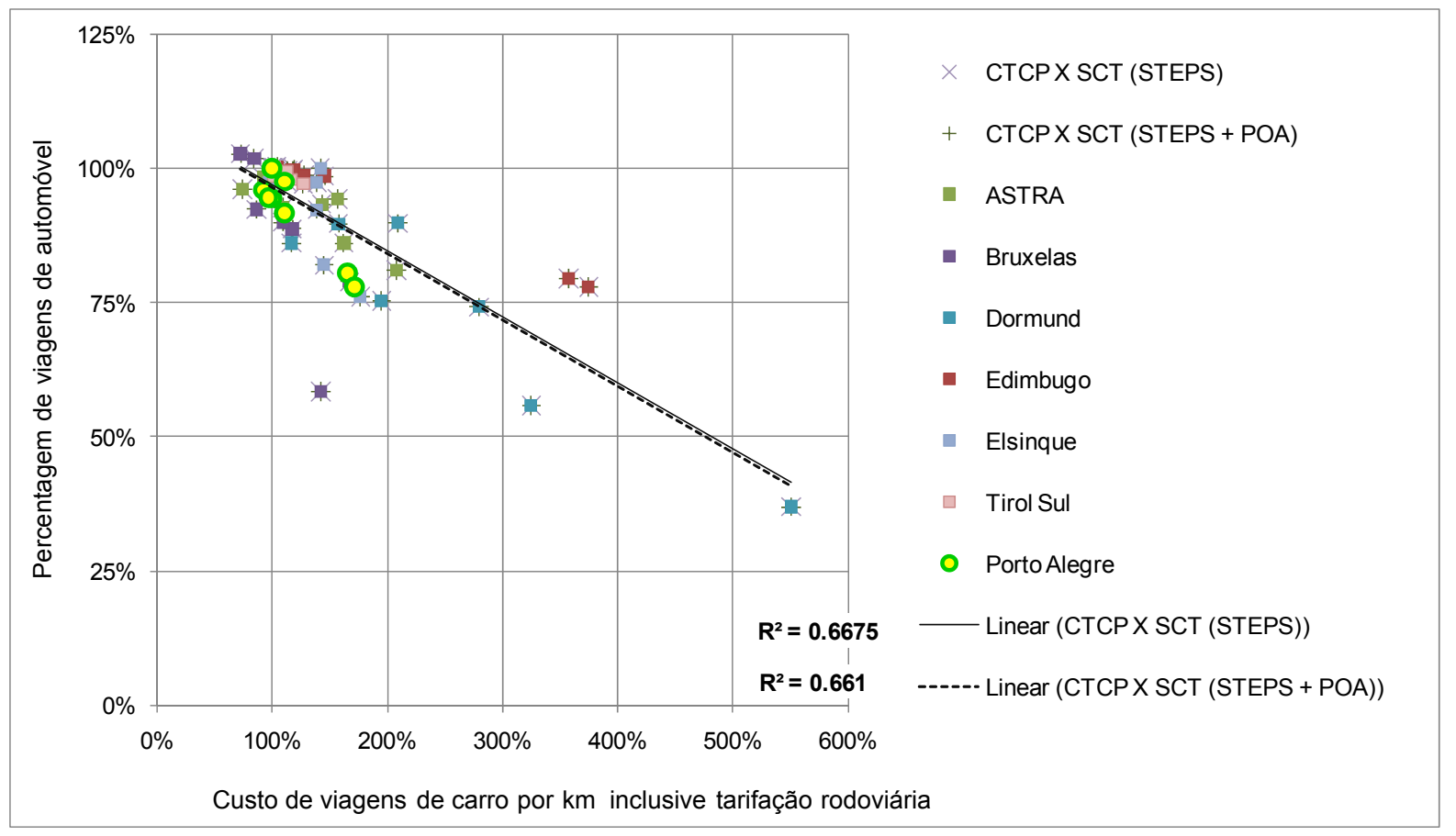

Figura 53 - Porcentagem de viagens por automóvel (sct) em função do custo de viagem por automóvel, incluindo tarifação rodoviária (ctcp). 


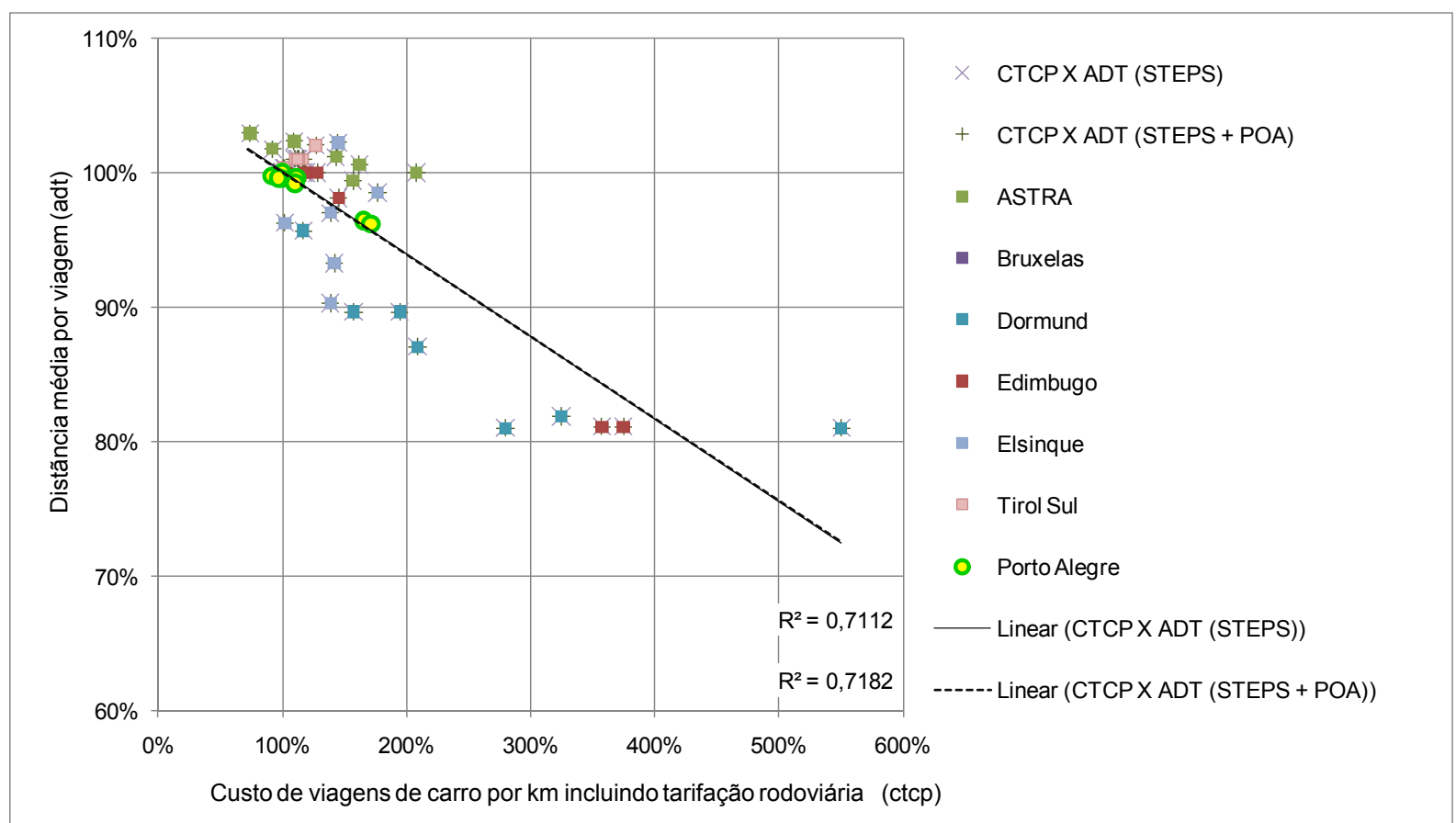

Figura 54 - Distância média por viagem (adt) em função do custo de viagem por automóvel, incluindo tarifação rodoviária (ctcp).

\section{Efeitos Indiretos}

Os efeitos indiretos das políticas energéticas são alterações em indicadores como as emissões de poluentes $\left(\mathrm{CO}_{2}, \mathrm{NO}_{\mathrm{x}}\right.$ e material particulado), mortes no trânsito, acidentes de trânsito e acessibilidade, em função, por exemplo, da distância percorrida de carro. Um exemplo de efeito indireto é apresentado na Figura 55, para a emissão de $\mathrm{CO}_{2}$ em função da distância percorrida por carro por habitante por dia. Nesse caso, os resultados dos modelos, incluindo o MARS POA, são ainda mais próximos, parecendo que os modeladores utilizaram funções de probabilidade de emissões iguais ou muito parecidas. 


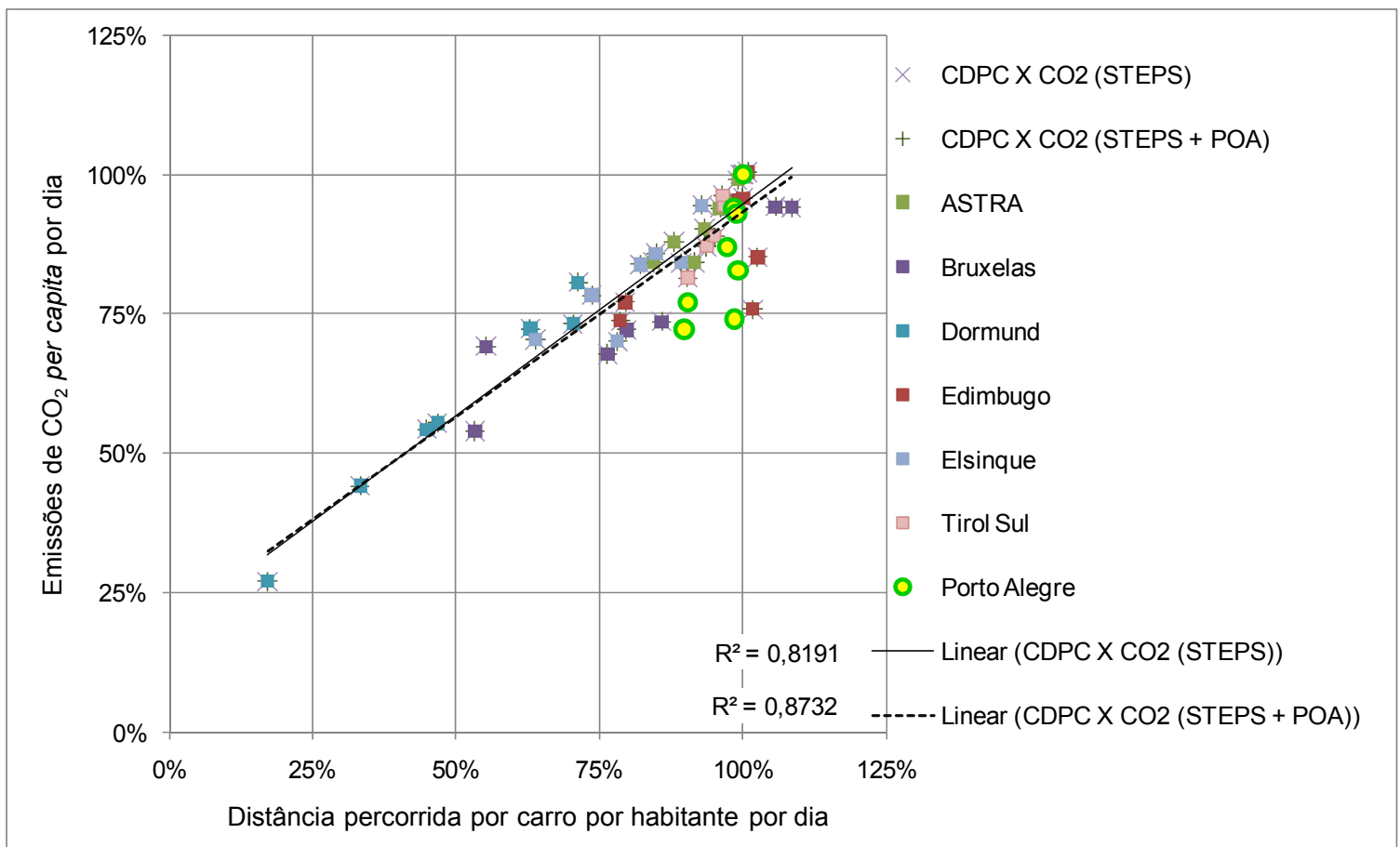

Figura 55 - Emissões de $\mathrm{CO}_{2}$ (co2) em função da distância percorrida por carro por habitante por dia (cdpc).

\subsubsection{Considerações finais do Bloco 5}

O objetivo das análises do Bloco 5 era o de avaliar a viabilidade de aplicação do Modelo MARS POA como um instrumento de apoio à decisão de políticas de mobilidade urbana sustentável, contemplando o quinto e último objetivo específico da pesquisa. Concluiu-se que o MARS POA é capaz de reproduzir e simular cenários de políticas de mobilidade realizando projeções em longo prazo. A própria estruturação do modelo MARS é voltada para este fim. O módulo de configuração de políticas facilita o processo de implementação dos cenários. Adicionalmente, foi verificada a viabilidade de gerar e analisar indicadores relacionados às questões de mobilidade. Os módulos de análise estruturados no MARS e a conexão com o mapa dinâmico Animap facilitam a geração e visualização de indicadores.

A meta-análise realizada pelo Projeto STEPs, e incluindo os resultados dos cenários do MARS POA, mostrou que há muita proximidade entre as principais respostas comportamentais e efeitos ambientais previstos pelos modelos considerados, a partir das políticas energéticas examinadas: o aumento de preço dos combustíveis terá um efeito significativo sobre as distâncias de viagem e sobre a escolha modal, reduções na utilização de automóvel reduzirão significativamente a poluição do ar, as emissões de gases do efeito estufa, os acidentes de trânsito e as mortes no trânsito, enquanto que a redução no uso do carro terá efeitos negativos sobre a acessibilidade, a menos que os transportes públicos sejam significativamente melhorados. 
Considerando-se que os cenários não diferem apenas em suas suposições sobre os preços dos combustíveis, mas também nas decisões em áreas de infraestrutura, tecnologia e regulação da demanda, os resultados da meta-análise do Projeto STEPs suportam a hipótese de que o custo de viagem de carro, ou, mais especificamente, o preço dos combustíveis, é a variável mais importante. Esta medida supera a importância de adoção de políticas a respeito de veículos alternativos, regulação do tráfego (da velocidade, em particular), em concordância com outros estudos de modelagem empírica desenvolvidos no âmbito da União Européia, como o projeto PROPOLIS (LAUTSO et al., 2004).

Há grande potencial para melhoria da validade e da possibilidade de transferência dos resultados de modelos, através da validação cruzada, podendo a meta-análise contribuir para o aumento da credibilidade dos modelos e de sua relevância para o estabelecimento de políticas. A meta-análise do Projeto STEPs também mostrou que existe uma demanda por pesquisas complementares, pois a previsão do aumento de preço da energia parece ser mais difícil do que a previsão de seus efeitos. 


\section{CONCLUSÕES E SUGESTÕES PARA TRABALHOS FUTUROS}

Este capítulo apresenta as principais conclusões do trabalho, desenvolvido com o objetivo de contribuir para o planejamento da mobilidade sustentável no Brasil. Discute-se o método aplicado para implementação e avaliação de uma ferramenta de apoio à decisão, que considera o uso do solo e transportes de forma dinâmica e integrada e também, de forma explícita, as características espaciais das cidades. Apresentam-se os principais resultados obtidos, assim como os problemas enfrentados e as soluções encontradas para viabilizar o ajuste e a aplicação dessa ferramenta a uma cidade brasileira de grande porte. Ao final, listam-se sugestões para trabalhos futuros na importante área de pesquisa acadêmica e tecnológica que é o planejamento de transportes, com todas as suas interfaces.

Dando continuidade à pesquisa de mestrado (LOPES, 2005), Porto Alegre, capital do estado do Rio Grande do Sul, foi escolhida como cidade brasileira de grande porte para o estudo de caso deste trabalho. Como uma das características da ferramenta que se pretendia desenvolver, decorrente da principal conclusão do trabalho anterior, era a consideração dos efeitos espaciais de forma explicita, iniciou-se a revisão bibliográfica com ênfase nos modelos e técnicas de estatística espacial aplicados à mobilidade, com o intuito de encontrar uma ferramenta que atendesse aos requisitos desta pesquisa e pudesse ser aplicada a Porto Alegre de forma a se atingir os objetivos complementares. 


\subsection{Conclusões}

A dependência espacial e seus efeitos em modelos de transporte, ainda que estejam entre as questões de análise espacial, não têm sido totalmente explorados em análises de mobilidade urbana. Tanto que, na revisão bibliográfica, foram encontrados, dentre vinte e seis estudos desenvolvidos nas últimas duas décadas, vinte e quatro trabalhos com foco em associação espacial (i.e., dependência espacial ou autocorrelação espacial), porém apenas oito foram aplicados em estudo de mobilidade, para análise de demanda.

\subsubsection{Conclusões do Bloco 1- Obtenção de modelos espaciais}

No estudo exploratório para verificação da contribuição de indicadores de dependência espacial em modelos de demanda por transportes, incluindo dados mais recentes, da Entrevista Domiciliar para Pesquisa de Origem e Destino realizada em 2003 (EDOM 2003), a variável dependente continuou sendo VPBD (Viagens Produzidas de Base Domiciliar), mas outras formas de consideração de efeitos espaciais foram investigadas.

Com o modelo tradicional de regressão múltipla, que incluía duas variáveis explicativas (População Total e Frota de Veículos Particulares), foram comparados os resultados de três tipos de modelos espaciais: o modelo espacial auto-regressivo misto (Spatial Auto Regressive = SAR ou Spatial Lag Model), o modelo do erro espacial (Conditional Auto Regressive = CAR ou Spatial Error Model) e o modelo com indicadores Locais e Globais de dependência espacial. Este último é resultante do método desenvolvido em Lopes (2005), tendo sido denominado de Modelo Alternativo. Foram obtidos resultados que permitiram as seguintes conclusões:

- A inclusão dos efeitos da dependência espacial nos modelos de regressão é importante, corroborando as conclusões anteriores, uma vez que os melhores resultados foram obtidos com modelos espaciais (regressão espacial ou aqueles que incluíram variáveis espaciais). Este fato foi observado nas etapas de diagnóstico e calibração, tanto para os dados de 1974 como para os dados de 2003;

- O Modelo Alternativo apresentou-se como uma técnica mais atraente do que os modelos de Regressão Espacial SAR e CAR, pois o modelo AGL74 (modelo alternativo com variáveis espaciais globais e locais) foi o que melhor se ajustou aos dados de 1974, assim como o modelo AG03 (modelo alternativo ajustado para 2003, utilizando as mesmas variáveis que o modelo alternativo ajustado para 1974) foi o que apresentou melhores resultados para os dados de 2003. 


\section{Escolha das variáveis espaciais com maior significância estatística}

O método proposto foi baseado em ferramentas de análises exploratória e confirmatória de dados espaciais, ESDA (Exploratory Spatial Data Analyses) e CSDA (Confirmatory Spatial Data Analyses), utilizadas não só para produzir indicadores de dependência espacial mas também para avaliar as estimativas dos modelos, em um ambiente SIG. Com dados de 2003, foi investigada a significância estatística para outras variáveis explicativas tradicionais e também outras variáveis espaciais, com os seguintes resultados:

- As variáveis taxas, ponderadas pela área, como as variáveis D_POP (densidade de população), D_DOM (densidade de domicílios) e D_FRO (densidade da frota), foram as que apresentaram índices de autocorrelação espacial significativos, tanto para os dados de 1974, como de 2003, provavelmente porque a ponderação reduz os efeitos de eventual ocorrência de MAUP, que pode camuflar a existência de autocorrelação espacial nas variáveis de contagens totais;

- No caso do modelo alternativo mais ajustado aos dados de 2003, o modelo AG03 (modelo alternativo somente com variável espacial global), verificou-se que a introdução da variável espacial não melhorou o poder preditivo do modelo e até piorou, quando comparado com o modelo tradicional mais ajustado para os dados de 2003.

Deve-se destacar que, mesmo havendo casos em que não seja necessária a consideração dos efeitos espaciais, o uso de ferramentas ESDA e CSDA constitui um avanço na análise de modelos de transportes, pois os diagnósticos tradicionais de regressão não levam em conta os efeitos espaciais e, consequentemente, as inferências de ajuste baseadas somente no coeficiente de determinação $\left(R^{2}\right)$ poderão ser incorretas.

\section{Validação do modelo espacial - inexistência de "estabilidade temporal"}

Uma conclusão complementar foi que, para estimativas futuras de demanda por transportes em longo prazo (de 1974 para 2003), apesar da obtenção de resultados ligeiramente melhores com o modelo alternativo AGL74, ainda se faz necessária a análise mais detalhada da dinâmica do desenvolvimento urbano.

Com a análise das alterações dos coeficientes das variáveis dos modelos ajustados para 2003 em relação aos ajustados para 1974, verificou-se a grande alteração ocorrida no período de quase 30 anos, com a população, variável explicativa de viagens produzidas de base domiciliar, tendo atualmente um peso bem maior do que em 1974. Verificou-se, também, grande alteração nos padrões espaciais das viagens. O processo de espalhamento urbano é uma explicação para estas alterações e para os índices mais baixos de 
autocorelação espacial verificados em 2003. Outra explicação, e decorrente disto, é a maior agregação das ZTs nas áreas periféricas, o que sugere um estudo mais detalhado dos efeitos da MAUP nas análises dos índices de autocorrelação espacial.

Os resultados sugerem, também, a necessidade de uma investigação mais detalhada da evolução dos padrões espaciais ao longo do tempo. Acredita-se que exista uma tendência de formação de subcentros urbanos na periferia, criando novos aglomerados espaciais e tendendo também a aumentar novamente os índices de autocorrelação espacial.

Com esses resultados são reforçadas as evidências de inexistência de estabilidade temporal e, portanto, de inadequação do uso de um modelo de quatro etapas na sua forma tradicional. Os resultados indicam, também, que apenas a inserção de variáveis espaciais não é suficiente, havendo necessidade de estudo aprofundado da dinâmica do desenvolvimento urbano, passo inicial na tentativa de se melhorar ainda mais os modelos espaciais apresentados. O primeiro objetivo específico, de obter modelos espaciais capazes de amenizar os efeitos de dependência espacial em modelos de geração de viagens, foi alcançado e os modelos Alternativos Globais e Locais deram prosseguimento à pesquisa.

\subsubsection{Conclusões do Bloco 2 - Ajuste de um Modelo LUTI Dinâmico para Porto Alegre}

A escolha do modelo MARS, dentre mais de vinte alternativas, mostrou-se adequada aos objetivos propostos. Adicionalmente, a flexibilidade do MARS em permitir alterações em sua estrutura, atendeu ao propósito de se testar a hipótese de que a inclusão de variáveis espaciais constitui melhoria para o modelo.

Deve-se destacar que o estágio de seis meses na Universidade Tecnológica de Viena, em contato direto com o criador da ferramenta, foi fundamental, não somente para adquirir familiaridade na aplicação do modelo, como para o estabelecimento de contatos importantes e trocas de experiências valiosas com os pesquisadores de outros centros de pesquisa que se destacam no cenário mundial, como por exemplo, o Professor Simon Shepherd, da Universidade de Leeds, particularmente interessado na conexão do MARS com o modelo de macrossimulação do tráfego SATURN.

A etapa de aprendizado sobre o MARS, para ajuste do modelo a Porto Alegre, foi fundamental para a verificação dos dados necessários e compreensão dos pressupostos do modelo, particularmente das interrelações entre as variáveis, podendo facilitar futuras pesquisas (por exemplo, introdução de variáveis espaciais e estudo da conexão MARSSATURN). 


\section{Obtenção de dados}

A obtenção dos dados para alimentar um modelo com a complexidade de interações dinâmicas entre uso do solo e transportes constitui, ainda hoje, um problema para qualquer cidade brasileira de grande porte, com Porto Alegre não fugindo à regra. No entanto o problema não está só no contexto nacional. $\mathrm{Na}$ análise de outras aplicações do MARS, inclusive em cidades de países desenvolvidos, verificou-se a necessidade de simplificação do processo de ajuste devido à falta de dados.

O MARS, dentre os modelos LUTI existentes, apesar da complexidade de suas análises, é considerado um modelo mais estratégico e de nível mais agregado, graças à preocupação dos seus criadores de evitar problemas relacionados com o excesso de detalhes, inclusive no que diz respeito à necessidade de dados. No entanto, a quantidade de variáveis necessárias para alimentar o MARS ainda é grande (90 ao todo), o que acabou inviabilizando o ajuste pensado inicialmente (MARS POA74) e, consequentemente, impossibilitando um processo completo de calibração e validação.

Com a impossibilidade de ajuste de um modelo para o ano base 1974, a saída foi ajustar um modelo para o ano base 2003, utilizando-se os dados da pesquisa OD disponível (EDOM 2003), uma vez que a pesquisa OD realizada em 1986 (EDOM 86) não contemplava a totalidade do município.

Para o ajuste do MARS POA2003, ainda que contando com a existência de banco de dados em SIG e muitos dados na forma digital, teve-se de enfrentar muitos problemas, como a incompatibilidade de formatos de algumas bases de dados, inexistência de informação, diferentes níveis de agregação e incongruência dos dados, que exigiram muito esforço e tempo com análises estatísticas e espaciais para a obtenção das variáveis. Um aspecto a se destacar é a desagregação da informação, pois quanto mais desagregado é o zoneamento, maior é a dificuldade para se estimar ou avaliar incongruências em dados vetoriais e matrizes. Este foi o caso do modelo MARS Porto Alegre, cidade que possui, aproximadamente, a mesma área total da cidade de Viena, porém o número de áreas de análise é quatro vezes maior (96 ZTs em Porto Alegre, enquanto que Viena tem 23 distritos).

Para auxiliar no processo de coleta, uma vez que eram muitas variáveis, de diferentes fontes de dados e com diferentes níveis de agregação, foi criado um "Guia de Coleta de Dados". O guia foi fundamental para acompanhar o andamento do processo de obtenção das variáveis e de alimentação do modelo, pois à medida que ia sendo avaliada e registrada a situação de cada variável, em relação à coleta, alimentação, problemas e possíveis soluções para tratamento, já se tinha idéia do quanto ainda faltava. Como Porto Alegre não 
é exceção e sim faz parte da regra geral brasileira, vislumbra-se grande utilidade para o "Guia de Coleta de Dados" quando do ajuste de modelos para outras cidades do Brasil.

\section{Processo de Calibração do modelo MARS-POA2003}

Tendo de usar dados tão recentes para o ano-base, e, desta forma, não existindo, ainda, dados posteriores, ficou inviabilizada a calibração dos submodelos de uso do solo do MARS para Porto Alegre. Isto ocorre porque esses submodelos devem ser calibrados para as mudanças ocorridas num período de, aproximadamente, 10 anos na população, no número de unidades habitacionais e nos postos de trabalho da área de estudo. No entanto, com os dados do Censo 2010, em poucos meses será viável a calibração de acordo com o procedimento tradicional.

Quanto aos submodelos de transportes, foi realizada a calibração transversal (crosssectional) para a divisão modal observada em 2003, com base nos dados da pesquisa de origem e destino (EDOM 2003). Apesar dos primeiros resultados deste processo terem sido desestimulantes, os resultados finais, após o ajuste de alguns problemas de incongruência encontrados entre as bases de dados, foram promissores.

O processo de calibração iniciou-se com a verificação da conformidade das estimativas de viagens geradas com base domiciliar, por motivo trabalho (Casa-Trabalho) e por outros motivos (Casa-Outros). Ao final da calibração, as estimativas do MARS apresentaram 99\% de conformidade com as viagens geradas Casa-Trabalho e $92 \%$ de conformidade com as viagens geradas Casa-Outros.

A divisão modal estimada pelo MARS ficou, igualmente, bem compatível com a dos dados da EDOM2003. Conforme os dados da pesquisa para viagens Casa-Trabalho, a repartição modal em 2003 era de 15\% para o modo lento (A pé/bicicleta), 50\% para o modo Transporte Público e $35 \%$ para o modo Automóvel. Conforme as estimativas do MARS, a repartição modal ficou em $15 \%, 49 \%$ e $36 \%$, para os mesmos modos, respectivamente.

Considerando-se as viagens Casa-Outros, conforme os dados da EDOM 2003, a repartição modal era de $34 \%$, 35\% e 31\%, para os modos lento (A pé / bicicleta), Transporte Público e Automóvel, respectivamente. Conforme as estimativas do MARS, a divisão modal ficou em $33 \%, 34 \%$ e $33 \%$, para os mesmos modos, respectivamente, o que representa um excelente resultado.

Quanto aos dados de viagens produzidas e atraídas por zona de tráfego (ZT), considerandose todos os modos, as estimativas do MARS apresentaram um ótimo ajuste. A análise comparativa foi realizada através de regressão entre dados reais e estimados pelo modelo. As estimativas de viagens produzidas por zona de tráfego, Casa-Trabalho, por todos os 
modos, apresentou um coeficiente de determinação $R^{2}$ de 0,97 , enquanto que $\circ R^{2}$ das mesmas viagens atraídas às ZTs foi de 0,96.

Na mesma análise, mas por modos de viagem, os resultados do ajuste não foram tão bons como os obtidos considerando-se todos os modos. O melhor ajuste foi verificado para o modo Transporte Público, com $R^{2}$ de 0,89 para viagens produzidas e 0,96 para viagens atraídas. O pior ajuste foi para as viagens pelo modo lento ( $A$ pé / bicicleta), com $R^{2}$ de 0,41 para viagens produzidas e de 0,22 para viagens atraídas. O ajuste do modo Automóvel apresentou $R^{2}$ de 0,75 , para produção de viagens, e melhor resultado para a atração das viagens às $Z T s$, com $R^{2}$ de 0,85 . Esses resultados refletem, também, a falta de alguns dados específicos para os modos, que tiveram de ser estimados, principalmente no que diz respeito ao automóvel.

A qualidade do ajuste é inversamente proporcional ao detalhamento da análise, como, por exemplo, na análise de distribuição de viagens entre pares $O D$, em que os ajustes das estimativas do MARS não ficaram bons quando comparados com os dados reais. O melhor ajuste foi verificado para o modo Transporte Público, com $R^{2}$ de 0,61 , e o pior para o modo lento, com $\mathrm{R}^{2}$ igual a 0,12 .

Verificou-se, uma vez mais, que o zoneamento adotado interferiu negativamente, por ser muito desagregado para a aplicação de um modelo estratégico como o MARS. Observouse, na matriz de viagens entre pares OD com zoneamento muito desagregado, que muitas células ficam vazias, principalmente nas viagens pelo modo lento, o que dificulta a alocação de viagens na zona correta quando existem várias zonas pequenas próximas, já que nem todas compartilham viagens.

Uma alternativa seria realizar uma análise mais detalhada dos motivos pelos quais essas zonas não compartilham viagens, entendendo-se que, de imediato, a solução mais razoável seria considerar zonas mais agregadas para análises com o Modelo MARS, tanto que essa hipótese foi confirmada ao se analisar a distribuição das viagens por zonas mais agregadas. Considerando-se o zoneamento das 18 macrozonas estabelecidas na EDOM 2003, o $\mathrm{R}^{2}$ das estimativas de distribuição de viagens Casa-Trabalho, pelos modos lentos, sobe para 0,64 , e pelo modo Transporte Público sobe para 0,82. Mesmo considerando-se os 47 Distritos de Tráfego, também definidos na EDOM 2003, as viagens Casa-Trabalho, pelo modo Transporte Público, continuaram apresentando um ajuste razoável $(0,78)$.

Os ajustes da distribuição de viagens Casa-Trabalho por pares OD, pelo modo Automóvel, fizeram o $\mathrm{R}^{2}$ variar de 0,58 , considerando-se a matriz com as 96 ZTs, a 0,79, considerandose a matriz das 18 macrozonas. 
Conclui-se, portanto, que os problemas causados por um zoneamento muito desagregado têm um efeito em cascata, dificultando desde a coleta de dados, causando distorções em estimativas de dados de entrada, muitas vezes inexistentes, complicando a calibração e distorcendo as estimativas do modelo. Por todas essas considerações, concluiu-se que, em geral, os resultados das estimativas do submodelo de transportes do MARS para Porto Alegre ficaram bem razoáveis, podendo melhorar significativamente através da consideração de um zoneamento mais agregado. O ajuste do modelo MARS POA 2003 cumpriu o objetivo do Bloco 2, permitindo dar prosseguimento à pesquisa.

\subsubsection{Conclusões do Bloco 3 - MARS POA Espacial}

As análises apresentadas no Bloco 3 confirmam que é possível atender ao terceiro objetivo especifico desta pesquisa de obter, através do MARS, um modelo que considere, além do uso do solo de forma dinâmica e integrada, também a distribuição espacial das atividades urbanas de forma explicita. Através do modelo MARS a primeira característica já é contemplada e, graças a sua flexibilidade, mostrou-se que é viável introduzir as características espaciais, inclusive de forma dinâmica e obter o MARS POA Espacial.

Dentre as duas alternativas apresentadas para considerar as variáveis espaciais, ou seja, de forma exógena ou de forma endógena, a segunda opção é a mais indicada, pelas evidências de que os padrões espaciais não são estáticos. No entanto, esta alternativa requer um estudo mais detalhado e criterioso. Conforme visto nas análises do Bloco 1, nem sempre as variáveis espaciais constituem melhorias para o modelo. Neste caso, seria preciso considerar uma forma de geração de Índices de autocorrelação espacial e, também, de avaliação destes índices dentro da estrutura do MARS, para definir se os indicadores deveriam ou não ser considerados.

\subsubsection{Conclusões do Bloco 4 - Avaliação do Modelo LUTI Dinâmico e espacial}

Conclui-se que a introdução de variáveis espaciais pode constituir melhoria para o modelo MARS, no entanto, as análises do Bloco 4 confirmaram o que já havia sido concluído no Bloco 1. A introdução destas variáveis requer uma análise criteriosa, uma vez que, nem sempre resultam em melhor desempenho do modelo e melhores estimativas. Portanto, acredita-se que muitos benefícios podem ser obtidos através da introdução de características espaciais no MARS, especialmente no que diz respeito à introdução de uma matriz de vizinhança como dado de entrada do modelo. No entanto, um estudo mais aprofundado de outras variáveis e submodelos e de como se devem considerar as variáveis espaciais no MARS se faz necessário. 


\subsubsection{Conclusões do Bloco 5 - Viabilidade de aplicação do MARS POA para avaliar políticas de mobilidade sustentável}

O quinto e último objetivo desta pesquisa foi contemplado através das análises do Bloco 5 . O Modelo MARS POA foi avaliado como um instrumento de apoio à decisão de políticas de mobilidade urbana sustentável através da configuração, simulação e análise de oito cenários de planejamento urbano, considerando diferentes políticas energéticas.

Concluiu-se que o MARS é uma ferramenta capaz de reproduzir e simular cenários de políticas de mobilidade realizando projeções em longo prazo. A própria estruturação do modelo é voltada para este fim. O módulo de configuração de políticas facilita o processo de implementação dos cenários. Adicionalmente, foi verificada a viabilidade de gerar e analisar indicadores relacionados às questões de mobilidade. Os módulos de análise estruturados no MARS e a conexão com o mapa dinâmico Animap facilitam a geração e visualização de indicadores.

Os resultados do MARS POA, quando comparados com as projeções de cenários similares de seis modelos aplicados na Europa, confirmaram a viabilidade de aplicação e a consistência das previsões para a cidade brasileira. A meta-análise realizada pelo Projeto STEPs e, neste trabalho, com a inclusão do MARS POA, mostraram que há muita proximidade entre as principais respostas comportamentais e efeitos ambientais previstos pelos modelos considerados, a partir das políticas energéticas examinadas.

Considerando-se que os cenários não diferem apenas em suas suposições sobre os preços dos combustíveis, mas também nas decisões em áreas de infraestrutura, tecnologia e regulação da demanda, pode-se concluir que há grande potencial para melhoria do processo de validação, com a meta-análise podendo contribuir para o aumento da credibilidade dos modelos e de sua relevância para o estabelecimento de políticas.

A partir das políticas energéticas examinadas concluiu-se que o aumento de preço dos combustíveis terá um efeito significativo sobre as distâncias de viagem e sobre a escolha modal, reduções na utilização de automóvel reduzirão significativamente a poluição do ar, as emissões de gases do efeito estufa, os acidentes de trânsito e as mortes no trânsito. Os cenários de regulação de demanda e de uso do solo incentivando a formação de cidades mais compactas e com zonas mistas tiveram impactos mais significativos na redução do uso do automóvel e consequente redução de acidentes e impactos ambientais. 


\section{Conclusões Gerais}

O "Guia de Coleta de Dados" desenvolvido para este projeto poderá servir de base para a elaboração de termos de referência para novas pesquisas O-D, adequada a um planejamento da mobilidade que considere de forma integrada o uso do solo e transportes.

A organização dos dados coletados, para alimentar o Modelo MARS, com suas 90 variáveis, constitui um banco de dados sistematizado e georreferenciado para Porto Alegre. Constitui o embrião de um arquivo histórico de informações, indispensável para a calibração e validação de modelos, ou seja, útil para quaisquer atividades de planejamento.

As etapas de simulação, calibração e validação permitiram uma melhor compreensão das relações entre as variáveis e do grau de sensibilidade em relação à adoção de políticas e dos impactos gerados.

A transferência do Modelo MARS para cidades brasileiras poderá apresentar resultados ainda melhores se forem consideradas, de forma independente, as viagens escolares (casaescola), que são caracterizadas pelo uso intensivo do automóvel no horário de pico, até mais do que as viagens a trabalho características das cidades européias. Mais detalhes sobre esta análise podem ser verificados em Lopes, Silva e Pfaffenbichler (2010).

\subsection{Sugestões para Trabalhos Futuros}

Os resultados obtidos e as conclusões deste trabalho não esgotam o assunto investigado. Ao contrário disso, representam apenas uma etapa da investigação, cuja maior contribuição reside em ter destacado o potencial do Modelo MARS como ferramenta de análise estratégica que pode considerar os efeitos espaciais de forma explícita, e que é capaz de integrar os modelos de transportes e de uso do solo, de forma dinâmica, em busca da mobilidade urbana sustentável.

Apesar do esforço dedicado ao estudo, limitações decorrentes da quantidade e qualidade das informações disponíveis, das ferramentas de análise e do tempo disponível para elaboração do trabalho após a obtenção dos dados, muito ainda há para se fazer, em continuidade a esta pesquisa, destacando-se:

i. Possibilidade de calibração dos submodelos de uso do solo do MARS POA com os dados do Censo 2010, que em breve estarão disponíveis;

ii. Possibilidade de validação dos submodelos de transportes mediante realização de nova pesquisa O-D;

iii. Ajuste do modelo MARS-POA tendo por base um zoneamento com maior agregação de informação, por exemplo, trabalhando-se com macrozonas; 
iv. Conexão do Modelo MARS POA com o SATURN POA.

Integrar o MARS com um modelo de alocação de tráfego já era uma proposta antiga do seu criador, conforme sugerido em Pfaffenbishler (2003), que acredita que os efeitos das relações fluxo-velocidade embutidas no MARS podem se beneficiar de um estágio de alocação de tráfego. Atualmente estes efeitos são considerados pela relação fluxo-velocidade dos pares O-D. Os primeiros estudos a este respeito iniciaram em 2004. Estudos através da aplicação do MARS Madrid, usando o modelo de alocação de tráfego VISUM, e através da aplicação do MARS Edimburgo, usando o modelo de alocação de tráfego o SATURN, não tiveram sequência. Com a aplicação do MARS POA surgiu uma nova expectativa de dar continuidade ao estudo (Pfaffenbishler, 2008), uma vez que o SATURN já era utilizado pela EPTC desde 2000. No entanto, vários problemas operacionais do SATURN POA, como tamanho, desatualização e calibração não concluída da rede modelada para toda a cidade, inviabilizaram o estudo ainda no âmbito desta pesquisa. Recentemente, estudos sobre a forma de se efetuar essa conexão foram desenvolvidos em parceria pelas Universidades de Leeds e Tecnológica de Viena, no âmbito do projeto MARS DISTILATTE (SHEPHERD et al., 2010, KOH; SHEPHERD, 2009). A aplicação em Porto Alegre, análoga à que foi feita para a cidade de Leeds, poderá constituir mais um estudo para o aprimoramento do uso das duas ferramentas através da análise integrada MARS-SATURN;

v. Desenvolvimento e ampliação do Modelo MARS POA para análises espaciais, mediante conexão direta com uma ferramenta de estatística espacial, para obtenção e consideração de variáveis espaciais de forma dinâmica e integrada nos submodelos de transporte e de uso do solo. Foi verificado, neste estudo, que a flexibilidade do MARS permite, até certo ponto, inclusive que características espaciais sejam integradas e que algumas variáveis espaciais sejam geradas na própria estrutura do modelo, porém estudos mais detalhados devem ser desenvolvidos neste sentido;

vi. Efetuar os ajustes necessários no Modelo MARS para melhor considerar a influência das viagens escolares (casa-escola), associadas ao uso do carro de forma intensa nos horários de pico, até mais do que as viagens a trabalho, dando continuidade ao estudo apresentado por Lopes, Silva e Pfaffenbichler (2010);

vii. Desenvolvimento de aplicação análoga à do Modelo MARS Porto Alegre para uma cidade de médio porte, onde os impactos da falta de planejamento não chegaram a níveis tão elevados, que seriam beneficiadas pelo planejamento "preventivo" em lugar do planejamento "corretivo". 


\section{REFERÊNCIAS BIBLIOGRÁFICAS}

ALMEIDA, C. M. Modelagem da dinâmica espacial como uma ferramenta auxiliar ao planejamento: simulação de mudanças de uso da terra em áreas urbanas para as cidades de Bauru e Piracicaba (SP), Brasil. 2003. 321 p. (INPE-10567-TDI/942/A). Tese (Doutorado em Sensoriamento Remoto) - Instituto Nacional de Pesquisas Espaciais, São José dos Campos. 2003. Disponível em: <http://urlib.net/sid.inpe.br/jeferson/2003/12.18.07.29>. Acesso em: 27 out. 2010.

ANSELIN, L. GeoDa 0.9 User's Guide. 2003. Disponível em: <http://sal.agecon.uiuc.edu> Acesso em: abr. 2005.

ANSELIN, L. GeoDa 0.9.5-i Relese Notes. 2004. Disponível em: <http://sal.agecon.uiuc.edu Acesso em: abr. 2005.

ANSELIN, L. Local Indicators of Spatial Association - LISA. Geographical Analysis n. 27, 1995, p. 93-115,.

ANSELIN, L. Under the hood: Issues in the specification and interpretation of spatial regressions models. Agricultural Economics, 2002. Disponível em: <http://agec221.agecon.uiuc.edu/users/anselinqpapers/hood.pdf>. Acesso em: 3 mar. 2004.

ARRUDA, F.S. Aplicação de um Modelo Baseado em Atividade para Análise da Relação Uso do Solo e Transportes no Contexto Brasileiro. 2005. Tese (Doutorado em Engenharia de Transportes) - Escola de Engenharia de São Carlos - Universidade de São Paulo, São Carlos: EESC, 2005.

BATTY, M. Urban modelling: algorithms, calibrations, predictions. Cambridge: Cambridge University Press, 1976.

BENDER, B.; HWANG, H. Hedonic housing price indices and secondary employment centers. Journal of Urban Economics n. 17. 1985, p. 90-107.

BHAT C.; ZHAO H. M. The spatial analysis of activity stop generation. Transportation Research B n. 36. 2002, p. 557-575.

BOLDUC, D.; DAGENAIS, M. G.; GAUDRY, M. J. I. Spatially autocorrelated errors in origindestination models: A new specification applied to aggregate mode choice. Transportation Research B n. 23: 1989, p. 361-372. 
BOLDUC, D.; LAFERRIERE, R.; SANTAROSSA, G. Spatial autoregressive errorcomponents in travel flow models. Regional Science and Urban Economics n. 22: 1992, p. 371-385.

BOLDUC, D.; LAFERRIERE, R.; SANTAROSSA, G. Spatial autoregressive error components in travel flow models: an application to aggregate mode choice. In Anselin, L. and Florax, R. J. G. M. (eds), New Directions in Spatial Econometrics, pp. 96-108. Berlin: Springer - Verlag, 1995.

BRASIL. Ministério das Cidades. Gestão Integrada da Mobilidade Urbana: Mobilidade e desenvolvimento urbano. Brasília, DF: MCidades, SeMob. 2006, 164p.

BRASIL. Ministério das Cidades. Secretaria Nacional de Transporte e Mobilidade Urbana. Política Nacional de Mobilidade Urbana Sustentável: Princípios e Diretrizes da PNMUS. Brasília: SEMOB, 2004.

BRASIL. Ministério das Cidades. Secretaria Nacional de Transporte e Mobilidade Urbana. Projeto de Lei da Mobilidade Urbana - PL 1687/2007 http://www.cidades.gov.br/secretariasnacionais/transporte-e-mobilidade/projeto-de-lei-da-mobilidade-urbana/PL\%2018672007\%20Mobilidade.pdf/view. Brasília: SeMob, 2007.

BRICEÑO, L.; COMINETTI, R.; CORTÉS, C. E.; MARTINEZ, F. Modelo Integrado de Transporte y Uso de Suelo: Un Enfoque de Optimización en Redes. In: XIV CONGRESO PANAMERICANO DE INGENIERÍA DE TRÁNSITO Y TRANSPORTE, 2006, Las Palmas de Gran Canaria. Anais... Las Palmas de Gran Canaria: XIV PANAM, 2006.

CÂMARA, G.; CARVALHO, M.S.; CRUZ, O.G.; CORREA, V. Análise Espacial de Áreas, In: Análise Espacial de Dados Geográficos, eds. Fuks, S.D.; Carvalho, M.S.; Câmara, G.; Monteiro, A.M.V. - São José dos Campos: Divisão de Processamento de Imagens - Instituto Nacional de Pesquisas Espaciais, INPE, 2002. - Disponível em: http://www.dpi.inpe.br/ gilberto/livro/analise/. Acesso em: 23 mar. 2004.

CASA Centre for Advanced Spatial Analysis. Michael Batty e Paul Longley. Londres: University College London. Disponível em: http://www.casa.ucl.ac.uk/research/index.htm. Acesso em: jul. 2006.

CETESB - Transporte Sustentável - Companhia de Tecnologia e Saneamento Ambiental Secretaria de Estado do Meio Ambiente - Governo do Estado de São Paulo - Disponível em: http://www.cetesb.sp.gov.br/Ar/emissoes/sustentavel.asp. Acesso em: jul. 2006. 
CHALERMPONG, S. Rail Transit and Residential Land Use in Developing Countries: Hedonic Study of Residential Property Prices in Bangkok, Thailand. Transportation Research Record: Journal of the Transportation Research Board, n. 2038, Washington, D.C.: Transportation Research Board, 2007, p. 111 - 119.

CHANG, J.S. Models of the relationship between transport and land-use: a review, Transport Review, V. 26, n. 3, 2006, p. 325 - 350 Disponível em: http://www.informaworld.com/smpp/ content?content $=10.1080 / 01441640500468432$ Acesso em: out. 2007.

CIRCELLA, G. Integrated Land Use and Transportation Modeling for Sustainable Transport Solutions (Doctoral Dissertation), 2008, Bari: Politecnico di Bari, 2008.

CITYMOBIL. Towards Advanced Roads Transport for the Urban Environment. Sixth Framework Programme. Disponível em: http://www.citymobil-project.eu/. Acesso em: jul. 2007.

CZADO, C.; PROKOPENKO, S. Modelling transport mode decisions using hierarchical logistic regression models with spatial and cluster effects. Statistical Modeling, v. 8, n. 4, 2008, p. 315-345.

DSC / ME \& P. Review of land-use/transport interaction models. Relatório para: SACTRA - Standing Advisory Committee on Trunk Road Assessment. David Simmonds Consultancy e Marcial Echenique and Partners, Londres: Department of the Environment, Transport and the Regions, 1999.

ECHENIQUE, M. El concepto de sistemas, modelos y teorias em los estúdios urbanos. In: Echenique, M. (org.) Modelos matemáticos de la Estructura Espacial Urbana: Aplicaciones em América Latina. Buenos Aires: Ediciones SIAP, 1975, p. 13-45.

ECHENIQUE, M. H.; FLOWERDEW, A. D. J.; HUNT, J. D.; MAYO, T. R.; SKIDMORE, I. J.; SIMMONDS, D. C. The MEPLAN models of Bilbao, Leeds and Dortmund. Transport Reviews, V. 10, 1990, p. 309 - 322.

EMBERGER, G.; MAYERTHALLER, A.; HALLER, R. National Scale Land-Use Transport Policy Modelling. In: $12^{\text {th }}$ WORLD CONFERENCE ON TRANSPORTATION RESEARCH, 2010, Lisboa. Anais... Lisboa: $12^{\text {th }}$ WCTR, 2010.

EMBERGER, G.; PFAFFENBICHLER, P. C.; JAENSIRISAK, S. Application of the European Landuse Transport Interaction Model Mars to Asian Cities. In: $9^{\text {th }}$ INTERNATIONAL CONFERENCE ON COMPUTERS IN URBAN PLANNING AND URBAN MANAGEMENT, 2005, Londres. Anais... Londres: CUPUM-2005, 2005. 
EMBERGER, G.; RIEDL, L. MARS meets ANIMAP In: DIE KOPPELUNG DER MODELSUITE MARS MIT DYNAMISCHER INTERNET-KARTOGRAPHIE; REAL CORP, 2007, Viena. Anais...Viena: To Plan Is Not Enough, Tech Gate Vienna, 2007.

EOM, J. K.; PARK, M. S.; HEO, T.; HUNTSINGER, L. F. Improving the Prediction of Annual Average Daily Traffic for Nonfreeway Facilities by Applying a Spatial Statistical Method. Transportation Research Record: Journal of the Transportation Research Board, N. 1968, Transportation Research Board of the National Academies, Washington, D.C., 2006, p. 20-29.

EPE - Estudo de Planejamento Estratégico de Integração do Transporte Público Coletivo da Região Metropolitana de Porto Alegre. Relatório Final, 2006. Disponível em: http://www.trensurb.com.br/php/estudos projetos/planejamento estrategico.php?PHPSESSI

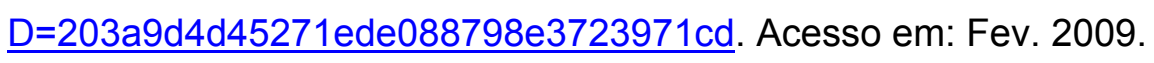

FIORELLO, D.; HUISMANS, G.; LÓPEZ, E.; MARQUES, C.; STEENBERGHEN, T.; WEGENER, M.; ZOGRAFOS, G. Transport Strategies under the Scarcity of Energy Supply. Final Report of the EU project STEPs. Den Haag. Ed. A. Monzon e A. Nuijten. Buck Consultants. 2006. Disponível em http://www.steps-eu.com/reports.htm. Acesso em: ago. 2010.

FOTHERINGHAM, A. S.; BRUNSDON, C.; CHARLTON, M. Quantitative Geography: Perspectives on Spatial Data Analysis. Londres: Ed. Sage, 2000.

GEODA CENTER. GeoDa. Disponível em: http://geodacenter.asu.edu/. Acesso em: set. 2010.

GRIFFITH D. A.; LAYNE L. J. A Casebook for Spatial Statistical Data Analysis: A Compilation of Analyses of Different Thematic Data Sets. Nova lorque: Oxford University Press. 1999.

GRIFFITH, D. A. Advanced Spatial Statistics: Special Topics in the Exploration of Quantitative Spatial Data Series. Dordrecht: Kluwer. 1988.

GUNDOGDU, I. B.; SARI, F.; ESEN, O. A New Approach for Geographical Information System-Supported Mapping of Traffic Accident Data. TS 1B - GIS. In: URBAN PLANNING AND MANAGEMENT, 2008, Estocolmo. Integrating Generations FIG Working Week 2008. Estocolmo, 2008. 
GUO, F.; WANG, X.; ABDEL-ATY, M. A. Corridor Level Signalized Intersection Safety Analysis Using Bayesian Spatial Models. In. $88^{\text {th }}$ ANNUAL MEETING OF THETRANSPORTATION RESEARCH BOARD, Washington, D.C. Janeiro, 2009. TRB 2009 Annual Meeting. Washington, D.C: TRB, 2009. CD-ROM.

GUZMÁN-GARCIA, L. A.; HOZ, D.; PFAFFENBICHLER, P.; SHEPHERD, S. Impacts of fuel consumption taxes on mobility patterns and $\mathrm{CO}_{2}$ emissions using a system dynamic approach. In: $10^{\text {th }}$ INTERNATIONAL CONFERENCE ON APPLICATION OF ADVANCED TECHNOLOGIES IN TRANSPORTATION, 2008, Atenas. Proceedings Atenas: 2008. Disponível em: http://oa.upm.es/1866/1/GUZMAN PON 2008 04.pdf. Acesso em: jul. 2010. HACKNEY, J.; BERNARD, M.; BINDRA, S.; AXHAUSEN, K. W. Explaining Road Speeds with Spatial Lag and Spatial Error Regression Models. In: TRANSPORTATION RESEARCH BOARD $86^{\text {th }}$ ANNUAL MEETING, 2007, Washington DC. Anais... Washington DC: Transportation Research Board, n. 07-1605, 2007a.

HACKNEY, J.; BERNARD, M.; BINDRA, S.; AXHAUSEN, K. W. Predicting road system speeds using spatial structure variables and network characteristics. Journal of Geographical Systems, Springer Berlin / Heidelberg 007, v. 9, n. 4, pp. 397-417, 2007b.

HAIDER, M.; MILLER, E. J. Effects of transportation infrastructure and location on residential real estate values: application of spatial autoregressive techniques. Transportation Research Record. Washington, D.C.: Transportation Research Board,1722: 1-8, 2000.

HAINING, R. Spatial Data Analysis in the Social and Environmental Sciences. Cambridge: Cambridge University Press, 2000.

HAKEN, H. Advanced Synergetics - Instability Hierarchies of Self-Organizing Systems and Devices, Springer-Verlag, 1983.

HARDY, M. H. Modeling Interdependent Transportation and Land Use Policies within the Metropolitan Planning Process. Ph.D. Dissertation Proposal - School of Public Policy George Mason University - Washington, D.C. 2009

HORNER, M. W.; MURRAY, A. T. Excess commuting and the modifiable areal unit problem. Urban Studies, 39: 131-139. 2002. Disponível em: http://usj.sagepub.com/content/ 39/1/131.full.pdf+html. Acesso em: jul. 2009.

IACONO, M.; LEVINSON, D.; EL-GENEIDY, A. Models of Transportation and Land Use Change: A Guide to the Territory. Journal of Planning Literature, v. 22, n. 4, 2008. 
INSTITUTE FOR TRANSPORT PLANNING AND TRAFFIC ENGINEERING - VIENNA UNIVERSITY OF TECNOLOGY. International Projects. IVV - TUWIEN. Disponível em: http://www.ivv.tuwien.ac.at/forschung Acesso em Julho de 2007.

INSTITUTO BRASILEIRO DE GEOGRAFIA E ESTATÍSTICA. Censo Demográfico - Rio Grande do Sul - VIII Recenseamento Geral - 1970. Rio de Janeiro: IBGE, 1973. Disponível em: $\quad$ http://biblioteca.ibge.gov.br/visualizacao/monografias/GEBIS\%20-\%20RJ/CD1970/ CD_1970_RS.pdf. Acesso em: 8 jul. 2008.

INSTITUTO BRASILEIRO DE GEOGRAFIA E ESTATÍSTICA. Censo Demográfico - Rio Grande do Sul - VIII Recenseamento Geral - 1980. Rio de Janeiro: IBGE, 1982. Disponível em: http://biblioteca.ibge.gov.br/visualizacao/monografias/GEBIS\%20-\%20RJ/CD1980/ CD_1980_RS.pdf. Acesso em: 8 jul. 2008.

INSTITUTO BRASILEIRO DE GEOGRAFIA E ESTATÍSTICA. Censo Demográfico 1991: Mão-de-Obra - Resultados da Amostra - Rio Grande do Sul. Rio de Janeiro: IBGE, 1991. p. 1 - 306, 1991. Disponível em: http://biblioteca.ibge.gov.br/visualizacao/monografias/ GEBIS\%20- \%20RJ/CD1991/CD_1991_mao_de_obra_RS.pdf. Acesso em: 28 jul. 2008.

INSTITUTO BRASILEIRO DE GEOGRAFIA E ESTATÍSTICA. Censo Demográfico 1991: Resultados do universo relativos às características da população e dos domicílios - Rio Grande do Sul. Rio de Janeiro: IBGE p. 1 - 688, 1991. Disponível em: http://biblioteca.ibge.gov.br/visualizacao/monografias/GEBIS\%20-\%20RJ/CD1991/ CD_1991_caracteristicas_populacao_domicilios_RS.pdf. Acesso em: 28 jul. 2008. INSTITUTO BRASILEIRO DE GEOGRAFIA E ESTATÍSTICA. Censo Demográfico 2000 Agregados por Setores Censitários dos Resultados do Universo - Rio Grande do Sul. Rio de Janeiro: IBGE, 2003. Disponível em: ftp://ftp.ibge.gov.br/Censos/Censo_Demografico_2000/ Dados_do_Universo/Agregado_por_Setores_Censitarios. Acesso em: 28 jul. 2008.

INSTITUTO BRASILEIRO DE GEOGRAFIA E ESTATíSTICA. Contagem da População 1996 - Resultados Definitivos da Contagem 96. Rio Grande do Sul. Rio de Janeiro: IBGE, 1996. Disponível em: http://www.ibge.gov.br/home/estatistica/populacao/contagem/ default.shtm. Acesso em: 28 jul. 2008.

INSTITUTO BRASILEIRO DE GEOGRAFIA E ESTATÍSTICA. Contagem da População 2007 - Resultados Definitivos da Contagem 2007. Rio Grande do Sul. Rio de Janeiro: IBGE, 2007. Disponível em: ftp://ftp.ibge.gov.br/Contagem_da_Populacao_2007/ Agregado_por_Setores_Censitarios_2007. Acesso em 20 jan. 2008 
INSTITUTO BRASILEIRO DE GEOGRAFIA E ESTATÍSTICA. Indicadores: População, Economia, Geociências, Canais, Download e Pesquisas. Disponível em: http://www.ibge.gov.br/home/ Acesso em: jul. 2008.

INSTITUTO BRASILEIRO DE GEOGRAFIA E ESTATÍSTICA. VIII Recenseamento Geral do Brasil - 1980 - Censo Demográfico - Dados Distritais - Rio Grande do Sul., Rio de Janeiro: IBGE, 1982. Disponível em: http://biblioteca.ibge.gov.br/visualizacao/monografias/ GEBIS\%20-\%20RJ/CD1980/CD_1980_Dados_Distritais_RS.pdf. Acesso em: 28 jul. 2008.

KAWAMURA, K; MAHAJAN, S. Hedonic Analysis of Impacts of Traffic Volumes on Property Values. Transportation Research Record: Journal of the Transportation Research Board, n. 1924, Washington, D.C.: Transportation Research Board of the National Academies, p. 69-75, 2005.

KHAN, G.; SANTIAGO-CHAPARRO, K. R.; QIN, X.; NOYCE, D. A. Application and Integration of Lattice Data Analysis, Network K-functions, and GIS to Study Ice-related Crashes. $88^{\text {th }}$ ANNUAL MEETING OF THE TRANSPORTATION RESEARCH BOARD. 2009,Washington, D.C. Anais... Washington, D.C.: Transportation Research Board, n. 093674, p. 67-76, 2009.

$\mathrm{KOH}, \mathrm{A}$; SHEPHERD, S. MARS-SATURN link. 2009. MARS DISTILLATE, Report to DfT on Task 3, V 3.2, Leeds: ITS, 2009. Disponível em: http://www.its.leeds.ac.uk/ projects/mars distillate/ Acesso em: jul. de 2010.

KRAFTA, R. Configuração e Apropriação do Espaço Urbano. In: SEMINÁRIO INTERDISCIPLINAR SOBRE CIDADE E PRODUÇÃO DO COTIDIANO, 1995, Recife. Anais... Recife: Cidade e Produção do cotidiano, v. 1. p. 83-94, 1995.

KRIEGER, M. H. Segmentation and filtering into neighborhoods as processes of percolation and diffusion: stochastic-processes (randomness) as the null hypothesis. Environment and Planning A, 23: 1609-1626. 1991.

KWAN, M. P. Interactive geovisualization of activity-travel patterns using three-dimensional geographical information systems: a methodological exploration with a large data set. Transportation Research C, 8: 185-203, 2000.

LANDIS, J.; ZHANG, M. Using GIS to improve urban activity and forecasting models: three examples. In: Fotheringham, A. S. e Wegener, M. (eds), Spatial Models and GIS: New Potential and New Models. Londres: Taylor and Francis, 2000. p. 63-81. 
LAU, K. H.; KAM, B. H. A cellular automata model for urban land-use simulation. Environment and Planning B: Planning and Design, v. 32, n. 2, 2005. p. 247-263. Disponível em: http://econpapers.repec.org/RePEc:pio:envirb:v:32:y:2005:i:2:p:247-263. Acesso em: jul. 2009.

LAUTSO, K.; SPIEKERMANN, K.; WEGENER, M.; SHEPPARD, I., STEADMAN, P.; MARTINO, A.; DOMINGO, R., GAYDA, S. PROPOLIS: Planning and Research of Policies for Land Use and Transport for Increasing Urban Sustainability. Final Report. Helsinki: LT Consultants, 2004.

LI, L.; ZHANG, Y. A GIS-based bayesian approach for identifying hazardous roadway segments for traffic crashes. In: TRANSPORTATION RESEARCH BOARD ANNUAL MEETING, 2007, Washington, D.C. Anais... Washington, D.C.: Transportation Research Board, CD-ROM, 2007.

LOPES, D. Viabilidade de Uso de Modelos Sintéticos Integrados de Uso do Solo e Transportes. Dissertação (Mestrado) - Escola Politécnica, Universidade de São Paulo, São Paulo, 2003.

LOPES, S. B. Efeitos da Dependência Espacial em Modelos de Previsão de Demanda por Transporte. Dissertação (Mestrado em Engenharia de Transportes), Universidade de São Paulo, São Carlos, 2005.

LOPES, S. B.; BRONDINO, N. C. M.; SILVA, A. N. R. Um Estudo da Dependência Espacial em Modelos de Previsão de Demanda por Transportes no Caso de Porto Alegre In: Planejamento Urbano, Regional, Integrado e Sustentável - Desenvolvimentos recentes no Brasil e em Portugal, São Carlos: EESC/USP, 2005, p. 173-190.

LOPES, S. B.; BRONDINO, N. C. M.; SILVA, A. N. R. Análise do Desempenho de Modelos de Regressão Espacial na Previsão de Demanda por Transportes In: XIV CONGRESO PANAMERICANO DE INGENIERÍA DE TRÁNSITO Y TRANSPORTE, 2006, Las Palmas de Gran Canaria. Anais...Las Palmas de Gran Canaria: XIV PANAM, 2006.

LOPES, S. B.; BRONDINO, N. C. M.; SILVA, A. N. R. Exploratory and Confirmatory Spatial Data Analysis Tools in Transport Demand Modeling. In: $10^{\text {th }}$ INTERNATIONAL CONFERENCE ON COMPUTERS IN URBAN PLANNING AND URBAN MANAGEMENT, 11-13 Julho 2007, Foz de Iguacu. Anais... São Carlos: EESC, 2007.

LOPES, S. B.; SILVA, A. N. R. An Assessment Study of The Spatial Dependence In Transportation Demand Models In: XIII PAN-AMERICAN CONFERENCE OF TRAFFIC AND TRANSPORTATION ENGINEERING, 2004, Albany, Anais...Albany: XIII PANAM, 2004. 
LOPES, S. B.; SILVA, A. N. R. Modelos de Previsão de Demanda por Transportes Empregando Análise de Dependência Espacial In: XIX CONGRESSO DE PESQUISA E ENSINO EM TRANSPORTES, 2005, Recife. Anais... Rio de Janeiro: ANPET, 2005.

LOPES, S. B.; SILVA, A. N. R.; PFAFFENBICHLER, P. Uma Aplicação do Modelo de Uso do Solo e Transportes MARS no Brasil. In: $4^{\circ}$ CONGRESSO LUSO-BRASILEIRO PARA O PLANEAMENTO URBANO, REGIONAL E INTEGRADO, SUSTENTÁVEL, 2010, Faro. Anais... Braga: PLURIS 2010 - The Challenges of Planning in a Web Wide World, 2010.

LOPES, S. B.; SILVA, A. N. R.; PFAFFENBICHLER, P. Uma Aplicação do Modelo de Uso do Solo e Transportes MARS no Brasil. Selecionado para publicação, 2010, Engenharia Civil, Universidade do Minho, Guimarães, Portugal.

LOWRY, I. S. A model of metropolis, Rand Corp, 1964.

MARTINEZ, C.; JAVIER, F.; DONOSO, P.P. MUSSA II: A Land Use Equilibrium Model Based on Constrained Idiosyncratic Behavior of All Agents in an Auction Market. In: TRANSPORTATION RESEARCH BOARD ANNUAL MEETING, 2007, Washington, D.C. Anais... Washington, D.C.: Transportation Research Board, 2007, p. 07-1661.

MARTINEZ, F.; HENRÍQUEZ, R. A random bidding and supply land use equilibrium model Transportation Research Part B n. 41, 2007, p. 632-651.

MARTÍNEZ, F. J. MUSSA: A land use model for Santiago City. Transportation Research Record 1552: Transportation Planning and Land Use at State, Regional and Local Levels, 1996, p. 126-134.

MARTÍNEZ, F. J.; DONOSO, P. MUSSA: Un Modelo de Equilibrio del Uso del Suelo con Externalidades de Localización, Planos Reguladores y Políticas de Precios Optimos. In: CONGRESO CHILENO DE INGENIERÍA DE TRANSPORTE, 2001, Concepción. Anais... Concepción: Congreso Chileno de Ingeniería de Transporte, 2001.

MAYERTHALER, A., HALLER, R.; EMBERGER, G. A Land-Use/Transport interaction model for Austria. In: $27^{\text {th }}$ INTERNATIONAL CONFERENCE OF THE SYSTEM DYNAMICS SOCIETY, 2009, Albuquerque. Anais... Albuquerque: 2009a.

MAYERTHALER, A., HALLER, R.; EMBERGER, G. Modelling land-use and transport at a national scale - the MARS Austria model. In: $49^{\text {th }}$ EUROPEAN CONGRESS OF THE REGIONAL SCIENCE ASSOSIATION INTERNATIONAL, 2009, Lodz. Anais... Lodz: Territorial Cohesion of Europe and Integrative Planning, 2009b. 
MILLER, E. J.; KRIGER, D. S.; HUNT, J. D.; BADOE, D. A. Integrated Urban Models for Simulation of Transit and Land-Use Policies. Final Report, TCRP Project H-12. Toronto: Joint Program of Transportation, University of Toronto, 1998.

MILLER, H. J. Potential contribution of spatial analysis to Geographic Information Systems for Transportation (GIS-T). Geographical Analysis, v. 31, 1999, p. 373-399.

NOVAK, D. C.; HODGDON, C.; GUO, F.; AULTMAN-HALL, L. Nationwide Freight Generation Models: A Spatial Regression Approach. Networks and Spatial Economics, Springer Netherlands, 2008. Disponível em: http://www.springerlink.com/content/ an2mx454g47u8155. Acesso em: ago. 2009.

ORTÚZAR, J. D.; WILLUMSEN, L. G. Modelling transport. 3.ed. Chichester: John Wiley, 2001.

PÁEZ, A.; SCOTT D. M. Spatial statistics for urban analysis: A review of techniques with examples. GeoJournal n. 61, 2004. Kluwer Academic Publishers. Springer Netherlands, 2004, p. 53-67.

PERRATON, J.; BAXTER, R. Models, evaluations \& information systems for planners. Lancaster: MTP Construction, 1974. 305 p.

PFAFFENBICHLER, P. MARS - Metropolitan Activity Relocation Simulator. A System Dynamics based Land Use and Transport Interaction Model. Saarbrücken: VDM Verlad Dr. Müller, 2008.

PFAFFENBICHLER, P. The Strategic, Dynamic and Integrated Urban Land Use Transport Model MARS - (Metropolitan Activity Relocation Simulator) - Development, testing and application. 2003. 274 p. Ph. D. Thesis (Transport Planning and Traffic Engineering). Institute for Transport Planning and Traffic Engineering - Vienna University of Tecnology, Viena. 2003. Disponível em: http://www.ivv.tuwien.ac.at/fileadmin/ mediapoolverkehrsplanung/Diverse/Forschung/MARS/ Dokumente/Thesis\%20MARS.pdf Acesso em: jul. 2007.

PFAFFENBICHLER, P.; EMBERGER, G. Are European cities becoming similar? In: CORP2003 COMPUTER AIDED SPATIAL PLANNING, Anais... 8th Symposion on Information Technology In Urban and Spatial Planning, 25 de Fevereiro - 10 de Março de 2003, Technische Universität Wien / Vienna University of Technology, Viena: Ed. Manfred Schrenk, 2003. Disponível em: http://www.corp.at/archive/CORP2003_Pfaffenbichler.pdf Acesso em: Agosto 2007. 
PFAFFENBICHLER, P.; EMBERGER, G.; SHEPHERD, S. P. The Integrated Dynamic Land Use and Transport Model Mars. Networks and Spatial Economics. V. 8, 2008, p. 183-200 PFAFFENBICHLER, P.; EMBERGER, G.; SHEPHERD, S. P. A system dynamics approach to land use transport interaction modelling: the strategic model MARS and its application. System Dynamics Review,v. 26, n. 3, 2010, p. 262-282.

PIETRANTONIO, H.; STRAMBI, O.; GUALDA, N. D. F. Integração entre Políticas de Uso de Solo e de Transportes: Dificuldades e Necessidades. 1996. Disponível em: http://www.poli.usp.br/p/hugo.pietrantonio/ trabalhos.html. Acesso em: 30 de jul. 2006.

PITMUrb. Plano Integrado de Transporte e Mobilidade Urbana da RMPA. 2009. Disponível em: http://www.trensurb.gov.br/php/estudos projetos/ plano transporte.php?PHPSESSID=504f282715eaed2aabf1eacf60807786. Acesso em: fev. 2007.

PITOMBO, C. Estudo de Relações entre Variáveis Socioeconômicas, de Uso do Solo, Participação em Atividades e Padrões de Viagens Encadeadas Urbanas. Tese (Doutorado em Engenharia de Transportes) 2007. Universidade de São Paulo, São Carlos: EESC, 2007.

PORTO ALEGRE. Empresa Pública de Transportes e Circulação. Entrevista Domiciliar: Pesquisa de Origem e Destino para Porto Alegre. Porto Alegre: EPTC, 2004.

PORTO ALEGRE. Prefeitura Municipal de Porto Alegre. Plano Diretor Cicloviário Integrado. Projeto de lei complementar, 2009. Disponível em: http://200.169.19.94:4000/sisprotweb/processo detalhe/96727?pagina atual=1\# Acesso em: set. 2010.

PORTO ALEGRE. Prefeitura Municipal de Porto Alegre. Portais da Cidade: Sistema de Transporte Integrado. Disponível em: http://lproweb.procempa.com.br/pmpa/prefpoa/ ppp/default.php?p secao=59. Acesso em: jul. 2008.

PORTO ALEGRE. Prefeitura Municipal de Porto Alegre. Secretaria do Planejamento Municipal. Transportes Urbanos. Porto Alegre: PMPA-SPM, 1978.

PORTO ALEGRE. Prefeitura Municipal de Porto Alegre. Secretaria do Planejamento Municipal. $1^{\circ}$ PDDU - Plano Diretor de Desenvolvimento Urbano. Lei Complementar 43/79. Porto Alegre: PMPA-SPM, 1979.

PORTO ALEGRE. Prefeitura Municipal de Porto Alegre. Secretaria do Planejamento Municipal. Vazios Urbanos: Análises Propostas. Porto Alegre: PMPA-SPM, 1989. 
PORTO ALEGRE. Prefeitura Municipal de Porto Alegre. Secretaria do Planejamento Municipal. Lei Complementar $n^{\circ} 434$ - Plano Diretor de Desenvolvimento Urbano e Ambiental - PDDUA. Porto Alegre: PMPA-SPM, 1999. Disponível em: http://www2.portoalegre.rs.gov.br/ spm/default.php?p_secao=191. Acesso em: 15 set. 2008. PROSPECTS Project Consortium. PROSPECTS: Procedures for Recommending Optimal Sustainable Planning of European City Transport Systems, 2003. Leeds: Project Co-ordinator, ITS, University of Leeds, 2003. Disponível em: http://www.ivv.tuwien.ac.at/forschung/projekte/international-projects/prospects-2000.html. Acesso em: jul. 2007.

RAIA JR., A. A. Acessibilidade e Mobilidade na Estimativa de um Índice de Potencial de Viagens Utilizando Redes Neurais Artificiais. 2000. Tese (Doutorado em Engenharia de Transportes), Universidade de São Paulo, São Carlos: EESC, 2000.

RAMOS, R. A. R.; SILVA, A. N. R. Oportunidades e desafios de técnicas emergentes para o planeamento urbano: O caso dos modelos de Cellular Automata. In: VII ENCONTRO DE UTILIZADORES DE INFORMAÇÃO GEOGRÁFICA, 2002, Lisboa, Portugal. Anais... Lisboa: ESIG, 2002.

RIBEIRO, A.; ANTUNES, A. P. Accessibility and the development in Portuguese off-cost regions - A spatial regression analysis. In: $3^{\text {rd }}$ WORLD CONFERENCE OF THE SPATIAL ECONOMETRICS ASSOCIATION, 2009, Barcelona. Anais...Barcelona: sea2009, 2009. Disponível em: www.ub.edu/sea2009.com/Papers/126.pdf. Accesso em: Nov. 2009.

RIO GRANDE DO SUL. Departamento de Trânsito. DETRAN-RS. Estatísticas. Disponível em: http://www.detran.rs.gov.br/ index.php?action=estatistica. Acesso em: 18 jul. 2008.

RIO GRANDE DO SUL. Fundação Estadual de Planejamento Metropolitano e Regional Metroplan. Documentação da Pesquisa Domiciliarl EDOM 1986. Porto Alegre: METROPLAN, 1989.

RIO GRANDE DO SUL. Fundação Estadual de Planejamento Metropolitano e Regional Metroplan. Plano Diretor de Transportes Metropolitanos/PLAMET 1976. Porto Alegre: METROPLAN,1976a.

RIO GRANDE DO SUL. Fundação Estadual de Planejamento Metropolitano e Regional Metroplan: Pesquisas domiciliar: EDOM 1974. Porto Alegre: METROPLAN,1976b.

RIO GRANDE DO SUL. Fundação Estadual de Planejamento Metropolitano e Regional Metroplan: Pesquisas domiciliar: EDOM 1997. Porto Alegre: METROPLAN,1997. 
SALVINI, P.; MILLER, E. J. ILUTE: An operational prototype of a comprehensive microsimulation model of urban systems. Networks and Spatial Economics, V.5, (2) 217 34. 2005.

SARAIVA, M. A Cidade e o Tráfego: Uma Abordagem Estratégica. Recife: Editora Universitária - UFPE, 2000.

SCATTER. Sprawling Cities and Transport: from Evaluation to Recommendations. Research Project, European Commission DG Research, 5th Framework Programme. 2005. Disponível em: http://www.casa.ucl.ac.uk/scatterl. Acesso em: Jul. 2006.

SHEPHERD S. P.; PFAFFENBICHLER, P.; MARTINO, A.; FIORELLO, D.; CHRISTIDIS, P. The Effect of Oil Prices on Transport Policies in Europe. International Journal of Sustainable Transportation, v.2 n.1, S., 2008, p. 19 - 40.

SHEPHERD, S. P., KOH, A., BALIJEPALLI, N. C., PFAFFENBICHLER, P. Use of modelling tools to deliver a sustainable transport system. In: 12TH WORLD CONFERENCE ON TRANSPORT RESEARCH, 2010, Lisboa. Anais... Lisboa:WCTR, 2010.

SIMMONDS, D. C. The design of the DELTA land-use modelling package. Environment and Planning B, Planning Design 26. 1999, P. 665-684.

SIMMONDS, D. C. The objectives and design of a new land use modelling package: DELTA. Clark G. P., Madden M. (eds), Regional science in business. Berlin: Springer, 2001.

SPARKLE. Viena: IVV, TUWIEN, 2006 Disponível em: http://www.ivv.tuwien.ac.at/ forschung/projekte/international-projects/sparkle-2004.html. Acesso em: jul. 2007.

SPRAWLSIM. 2000-2004. TORRENS, P. M. UK Economic and Social Research Council Disponível em: http://www.geosimulation.org/simulating-sprawl/ Acesso em: jul. 2006.

STEENBERGHEN T.; DUFAYS T.; THOMAS I.; FLAHAUT, B.Intra-urban location and clustering of road accidents using GIS: a Belgian example. International Journal of Geographical Information Science v.18, n. 2. 2004, p.169-181.

STEPs. Transport Strategies under the scarcity of energy supply - STEPs Final Report. 2006. Disponível em http://www.steps-eu.com/. Acesso em: ago. 2010.

STERMAN, J. A Skeptic's Guide to Computer Models. In: Barney, G. O. et al. (eds.), Managing a Nation: The Microcomputer Software Catalog. Boulder, CO: Westview Press, 1991, p. 209-229.

STERMAN, J. Business dynamics: systems thinking and modeling for a complex world, Boston: Irwin/McGraw-Hill, 2000. 
TMIP. Travel Model Improvement Program. Disponível em:http://tmip.fhwa.dot.gov/ Acesso em: ago. 2010.

TOBLER, W. A computer movie simulating urban growth in the Detroit region. Economic Geography, v. 26, 1970, p. 234-240.

TORRENS, P. M. How Cellular Models of Urban Systems Work. WP-28. Centre for Advanced Spatial Analysis (CASA). Londres: University College London, 2000.

VAN VLIET, D. SATURN - Simulation and Assignment of Traffic in Urban Road Network. SATURN Manual v10.9, Junho de 2010, Leeds: Atkins, ITS-University of Leeds, 2010.

VASCONCELOS, E. A. Transporte Urbano nos Países em Desenvolvimento: Reflexões e

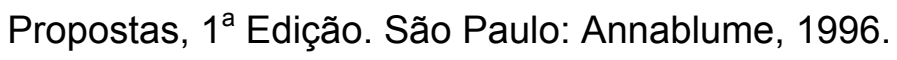

VICHIENSAN, V.; PÁEZ, A.; KAWAI, K.; MIYAMOTO, K. Non stationary Spatial Interpolation Method for Urban Model Development. Transportation Research Record: Journal of the Transportation Research Board, n. 1977, Washington, D.C.: Transportation Research Board of the National Academies, 2006, p. 103-111.

VICTORIA, I. C.; PROZZI J., WALTON, C. M.; PROZZI, J. Environmental Justice Concentration Zones for Assessing Transportation Project Impacts. Transportation Research Record: Journal of the Transportation Research Board, n. 1983, Washington, D.C.: Transportation Research Board of the National Academies, 2006, pp. 75-80.

WADDELL, P. UrbanSim: Modeling urban development for land use, transportation and environmental planning. Journal of the American Planning Association, v. 68, n. 3, 2002, p. 297-314.

WALKER, W. T.; GAO, S.; JOHNSTON, R. A. UPlan: A GIS Integrated Land Use Planning Model. Transportation Research Record: Journal of the Transportation Research Board, n. 1994. Washington, D.C.: Transportation Research Board, 2007, p. 117-127.

WANG, F. H. Explaining intraurban variations of commuting by job proximity and workers' characteristics. Environment and Planning B n. 28, 2001, p.169-182.

WANG, X.; KOCKELMAN, K. M. Forecasting network data: spatial interpolation of traffic counts using Texas data. $88^{\text {th }}$ ANNUAL MEETING OF THE TRANSPORTATION RESEARCH BOARD, 2009, Washington, D.C. Anais... Washington, D.C.: TRB 2009 Annual Meeting CD-ROM, 2009.

WEBSTER, F. V.; BLY, P. H.; PAULLEY, N. J. Urban Land-Use and Transport Interaction. Policies and Models. Report of the International Study Group on Land-Use/Transport Interaction (ISGLUTI). Aldershot: Avebury, 1988. 
WEGENER, M. Meta Analysis of Scenario Results. Technical Note S\&W STEPs 03. Dortmund: Spiekermann \& Wegener Urban and Regional Research, 2010. Disponível em: http://www.spiekermann-wegener.de/pro/pdf/SuW_STEPs_03.pdf. Acesso em: ago. 2010.

WEGENER, M. Overview of land-use and transport models. In: CUPUM03 - THE $8^{\text {th }}$ INTERNATIONAL CONFERENCE ON COMPUTERS IN URBAN PLANNING AND URBAN MANAGEMENT, 2003, Sendai. Anais...Center for Northeast Asian Studies, Tohoku University, 2003.

WEGENER, M. The IRPUD Model: Overview. Michael Wegener, IRPUD, 1998. Disponível em: http://www.raumplanung.uni-dortmund.de/irpud/pro/mod $/ \mathrm{mod} . h t m$. Acesso em: set. 2007.

WEGENER, M.; FÜRST, F. Land-Use Transport Interaction: State of the Art. Dortmund: Berichteaus dem Institut für Raumplanung 46. Institut für Raumplanung, Universität Dortmund, 1999. Disponível em: http://www.inro.tno.nl/transland/Deliverable\%202a.pdf. Acesso em: out. 2007.

WEGENER, M.; MACKETT, R. L.; SIMMONDS, D. C. One city, three models: comparison of landuse/ transport policy simulation models for Dortmund. Transport Reviews n.11, 1999, p. 107-129.

WEINER, E.; DUCCA, F. Upgrading Travel-Demand Forecasting Capabilities. ITE Journal, v. 69 n.7. Washington, D.C.: 1999, p. 28-34.

WISE, S.; HAINING, R.; MA, J. S. Providing spatial statistical data analysis functionality for the GIS user: the SAGE project. International Journal of Geographical Information Science, n. 15, 2001, p. 239-254.

ZHOU, B.; KOCKELMAN, K. M. Microsimulation of residential land development and household location choices: bidding for land in Austin, Texas. $87^{\text {th }}$ ANNUAL MEETING OF THE TRANSPORTATION RESEARCH BOARD, 2008, Washington, D.C. Anais... Washington, D.C.: TRB 2008 Annual Meeting CD-ROM, 2008.

ZONDAG, B.; PIETERS, M. Influence of accessibility on residential location choice $-\ln : 84^{\text {th }}$ ANNUAL MEETING OF THE TRANSPORTATION RESEARCH BOARD, 2005, Washington, D.C. Anais... Washington, D.C: TRB, National Research Council, CD-ROM, 2005. 